\title{
DOEl125-79--T/ (001.1)
}

MASTEP COPY Research Report No. 77/5-62

CAMEPA-READY

FLEXIBLE ROOF DPILL FOR LOW COAL

Volume 1, Phase I and Phase II

by

Norman H. Shoup and

L. Alden Kendall

August 1977

U.S.B.M. Contract Report HO242027

$$
\text { AC OI- } 7+\text { ET } 12579
$$

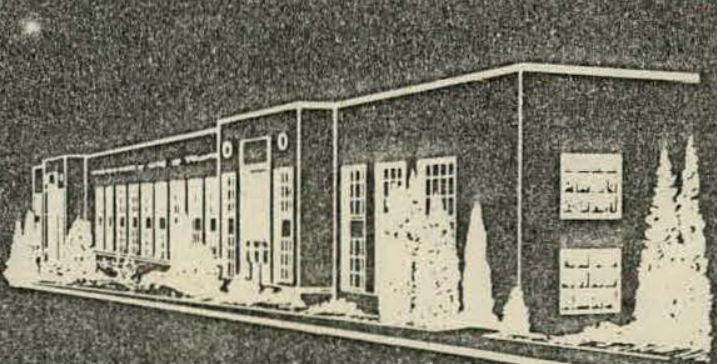

WASHINGION STATE UNIVERSIIY COLLESE OF ENGINEERING RESEARCH DIVISION 


\section{DISCLAIMER}

This report was prepared as an account of work sponsored by an agency of the United States Government. Neither the United States Government nor any agency Thereof, nor any of their employees, makes any warranty, express or implied, or assumes any legal liability or responsibility for the accuracy, completeness, or usefulness of any information, apparatus, product, or process disclosed, or represents that its use would not infringe privately owned rights. Reference herein to any specific commercial product, process, or service by trade name, trademark, manufacturer, or otherwise does not necessarily constitute or imply its endorsement, recommendation, or favoring by the United States Government or any agency thereof. The views and opinions of authors expressed herein do not necessarily state or reflect those of the United States Government or any agency thereof. 


\section{DISCLAIMER}

Portions of this document may be illegible in electronic image products. Images are produced from the best available original document. 
FLEXIBLE ROOF DRILL FOR LOW COAL

Vol. 1, Phase I and Phase II
DOE/ET/12579--Tl Vol I

DE8I 014789 by

NORMAN H. SHOUP and

L. ALDEN KENDALL

United States

Department of the Interior

Bureau of Mines

USBM Contract Report H0242027

August 30,1977

$$
\text { (1) }
$$

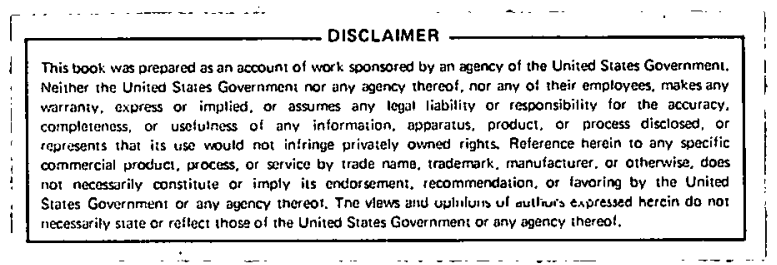




\section{DISCLAIMER NOTICE}

The views and conclusions contained in this document are those of the authors and should not be interpreted as necessarily representing the official policies or recommendations of the Interior Department's Bureau of Mines or of the U.S. Government.

FOREWORD

This report was prepared by Washington State University, Department of Mechanical Engineering, Pullman, Washington, under USBM Contract Number H0242027. The contract was initiated under the Coal Mine Health and Safety Program. It was administered under the technical direction of SMRC with Mr. Robert Burnham and later $\mathrm{Mr}$. John Bevan acting as the Technical Project Officer. Mr. R. J. Simonich was the contract administrator for the Bureau of Mines.

This report is a summary of the work recently completed as part of this contract during the period June 15, 1974 to October 7, 1977. This report was submitted by the authors on September 8, 1977, and consists of two volumes. Volume 1 includes Phase I and Phase II project work done under the direction of Principal Investigator Dr. L. Alden Kendall. Volume 2 covers Phase III and Phase IV during which time Professor Norman $H$. Shoup was serving as principal investigator following Dr. Kendall's transfer to another University in August 1975. Phase V, Mine test of the Flexible Drill System, was deleted from the contract under terms agreed on in Modification No. 5 effective, April 1, 1977.

The authors wish to acknowledge the cooperation and generous assistance rendered by the United States Steel Corporation. At a most nominal cost, they have made their mine operations, equipment, and test facilities available during project field test studies and have provided valuable technical assistance throughout the design development phases. Particular thanks are due Mr. R. C. Miles, Associate Research Consultant at the U.S. Steel Research Laboratory, 
for his diligent efforts in coordinating the field work and various conferences held with U.S. Steel personnel. Also, we wish to extend our thanks to Mr. Harley G. Pyles, Division Vice President, Engineering, of FMC Corporation, Mining Equipment Division, for his cooperation and technical assistance in the procurement of the Galis Roof drill Components purchased for use in this project.

A project of this type and long duration involved the services of many members of the Mechanical Engineering faculty working as a team. The authors gratefully acknowledge the extensive and valued contributions made by Dr. Gary L. Sheldon, Dr. Arthur L. Jones, Dr. John A. Seevers, Professor Jack T. Kimbrell and Professor James S. England. Graduate research assistants participated extensively throughout the project. We are indebted particularly to Mr. William A. McI1vanie whose graduate thesis work, supported by the Bureau of Mines, provided the basis for the initial project proposal on development of the segmented shaft drill. Other graduate research assistants making important contributions to the project and design work were Sash Eirich, Gordon H. Beeman, Allan G. Olson, Anwar U. H. Mirza, John L. Stevens, Lowel1 R. McDaniels, Tony Chung, Rodger Cox, Arun K. Das, and Ray L: Davis. The construction of the prototype model and preparation of all plans and working drawings would not have been possible without the able assistance of our drafting technician Mrs. Karla Kalasz and all of the effort put in by Instrument Makers Marion L. Johnson, Jon B. Grimes, and others of the Engineering shops most capably superizised by Mr. Tommy Hellesto. Our appreciation is also extended to the W.S.U. Engineering Extension Service for assistance in the preparation of this report and more specifically to Mr.Vernon L. Barr for his services in editing Volume I. 
DISCLAIMER NOTICE . . . . . . . . . . . . . . . . . . $\frac{\text { Page }}{\text { ii }}$

FOREWORD . . . . . . . . . . . . . . . . . . . . . . . ii

Table of Contents . . . . . . . . . . . . . . . . . . . iv

List of Tables:... . . . . . . . . . . . . . . . . . . . vii

List of Figures . . . . . . . . . . . . . . . . . . . . . . viii

1.0.0 SUMMARY . . . . . . . . . . . . . . . . . . . . . . . . xiii

2.0.0 TASK DESCRIPTION AND OPERATIONAL SPECIFICATION . . . . . . . . . . 1

2.1.0 Coal Mine Environment . . . . . . . . . . . . . . . . . 1

2.2.0 Operating Cycle..................... 3

2.3.0 Power and Control Requirements . . . . . . . . . . . 6

2.3.1 Torque and Thrust Requirements--

Straight Holes................. 10

2.3.2 Torque and Thrust Requirements--

Curved Hole . . . . . . . . . . . . . . . . . . . 11

2.3.3. Drilling Control and Duty Cycle . . . . . . . . 11

$\begin{array}{ll}2.3 .4 & \text { Flexible Drill-Bolt Bender/ } \\ & \text { Inserter System . . . . . . . . . . . . . . } 14\end{array}$

3.0.0 DESIGN DEVELOPMENT . . . . . . . . . . . . . . . . . . 17

4.0.0 DRIVEHEAD LOCATION . . . . . . . . . . . . . . . . . . . 21

4.1.0 Evaluation Criteria . . . . . . . . . . . . . . 21

4.2.0 In-Hole Location . . . . . . . . . . . . . . . . . . . . 21

4.3.0 Location in Vehicle. . . . . . . . . . . . . . . . . 23

4.4.0 Location on Mine Roof . . . . . . . . . . . . . . 24

5.0.0 EVALUATION OF FLEXIBLE SHAFTS . . . . . . . . . . . . . . . . . 26

5.1.0 Characterization of Segmental Flexible-

Shaft Systems..................... . 28

5.2.0 Tubular Segment Variations . . . . . . . . . . . . 28

5.3.0 Interfacial Restraint Options . . . . . . . . . . . . . . . 32

5.3.1 Snap-Ring Concept . . . . . . . . . . . . . . 37

5.3.2 Cylindrical Clip Concept . . . . . . . . . . . . 37

5.3.3 Elastomeric Connector Concept . . . . . . . . . . 37

5.3.4 Tensile Wire Concept . . . . . . . . . . . . . . . . 38

5.3.5 Curvature Relationships for

Segmental Shafts.............. . 39

5.5.0 Comparative Cost Estimate--Segmented

Flexible Shaft vs. Traditional Drill Steel . . . . . . . 41

5.6.0 Function and Strength Comparisons of

Segmental Shaft Options .. . . . . . . . . . . . 43

6.0 .0 DRIVEHEAD ANALYSIS . . . . . . . . . . . . . . . . . 4 47 
Table of Contents (Cont.)

Page

6.1.0 Continuous Drives.................... 50

6.1.1 Gear Drive Systems . . . . . . . . . . . . . 50

6.1 .2 Chain Drive .. . . . . . . . . . . . . 54

6.2.0 Reciprocating Drives . . . . . . . . . . . . . . 57

6.2.1 Reciprocating Hydraulic Drive . . . . . . . . 58

6.2.2 Reciprocating Friction Drive . . . . . . . . . . 59

6.2.3 Reciprocating Cam-Operated Drivehead . . . . . . 60

6.3.0 Drivehead Summary .. . . . . . . . . . . . . 61

7.0 .0 CHIP RETURN SYSTEM . . . . . . . . . . . . . . . . 62

8.0.0 STOWAGE SYSTEM FOR FLEXIBLE SHAFT DRILL. . . . . . . . . . . . . 64

9.0 .0 BIBLIOGRAPHY . . . . . . . . . . . . . . . . . . 66

\section{PHASE II}

Summary . . . . . . . . . . . . . . . . . . . . 68

Introduction . . . . . . . . . . . . . . . . . . . . 69

Discussion . . . . . . . . . . . . . . . . . . . . . . . 74

Design Refinement and Analysis . . . . . . . . . . . . . . . 74

Performance Testing . . . . . . . . . . . . . . . . . . 76

\section{APPENDICES}

Appendix

A Drill Hole Starter Section and Curvature

of Bolt Hole . . . . . . . . . . . . . . . . . . A-1

B Thrust Force Transmiśsion.:Due to Hole Curvature... . . . . . . B-1

C . Restraint Forces on Flexible Shaft Curvature . . . . . . C-1

D Selecting the Coupled Segment Interface . . . . . . . . . . D-1

E Snap-Ring Segmental Shaft Design . . . . . . . . . . . . E-1

F Cylindrica1 Clip Concept . . . . . . . . . . . . . F-1

G Segmental Shaft with Wire Connection

H Bonded Interface . . . . . . . . . . . . . . . . H-1

..I Pawl-and-Ratchet Drivehead . . . . . . . . . . . . . . . I-1 
Table of Contents (Cont.)

Appendix

$\mathrm{J}$

Ring Performance on the Frictional Drivehead Concept . . . . J-1

K Reference Drawings ...................... K-1

"L Drill Stress Analysis..................... . L-1

M Curvature Tests .................... $\mathrm{M}-1$

$\mathrm{N}$ Field Test ...................... . . . . . . . .

o Destructive Tests .................... . . . . .

p Chip Return Tests . . . . . . . . . . . . . . . . P-1 


\section{List of Tables}

Table

Typical Drilling and Bolting Data . . . . . . . . . . . 7

2 Functional Comparison of Segmental Shaft Concepts . . . . . . . 44

3 Strength Comparison of Segmental Shaft Concepts . . . . . . . . 45

4 Function Comparison of Driveheads . . . . . . . . . . . . . 48

Appendix D

D-1 Stress Comparison of Interface Types . . . . . . . . . . . D-2

Appendix L

L-1 Drill Tooth Stress Summary . . . . . . . . . . . . . . L-9

L-2 Summary of Fatigue Analysis . . . . . . . . . . . . . . L-15

Appendix M

M-1 Curvature Specifications for Dynamic Testing . . . . . . . . . M-3

M-2 Dynamic Testing Speeds and Times . . . . . . . . . . . M-6

Appendix $\mathrm{N}$

N-1 Field Test Data - November 4, 1974. . . . . . . . . . . N-10

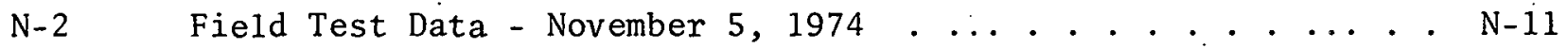

Appendix 0

0-1 Segment Torsion Tests ................. . . 0-3

0-2 Retainer Ring Connector Pull Test Results . . . . . . . . 0-7 


\section{List of Figures}

Figure

$\underline{\text { Page }}$

1 Typical Development of Coal Seam Room . . . . . . . . . . . . . 2

2 Bolter Vehicle with Stabilizer Bar Down and

Thrust Arm Fully Extended . . . . . . . . . . ..... 4

3 Front View of Bolter Vehicle . . . . . . . . . . . . . . . . 4

$4 \quad$ Drill Steel, Chucks and Drilling Bits Used

To Drill Roof Bolt Holes . . . . . . . . . . . . . . . . . 5

Distribution of Activities per Bolt Cycle . . . . . . . . . . . 8

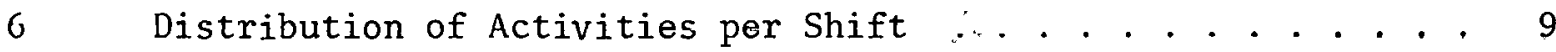

7 Starter Section Length vs. Clearance Distance

for Höle Deviation at $10^{\circ}$. . . . . . . . . . . . . . . 12

8 Information Flow for Drilling System Development . . . . . . 18

9 Basic Configurations . . . . . . . . . . . . . . . . 19

10 Alternate Basic Configurations . . . . . . . . . . . . 20

11 Selection of Drive Head Location . . . . . . . . . . . . . 21

12 In-Hole High-Speed Air Turbine Drive with

Nutation Gear Reduction to Cutting Speed . . . . . . . . . . 22

13 Flexible Shaft Alternatives . . . . . . . . . . . . . 26

14 Volute Spring Type Flexible Shaft . . . . . . . . . . . . . 27

15 Helically Wound Type Flexible Shaft . . . . . . . . . . . 27

16 Curvature Development Mechanism for

Segmental Drill Stem . . . . . . . . . . . . . . . 29

17 Vertebrae Drill Shaft and Guide Section . . . . . . . . . . 30

18 Characteristics of Segmental Shaft Systems . . . . . . . . . 31

19 Segments with Retainer Ring Interfacial Restraint . . . . . . . 33

20 Segment Detail for Retainer Ring Interfacial Restraint . . . . 34

21 Scgments with Cylindrical C1ip Interfacial Restraint . . . . . 35

22 Segment Detail for Cylindrical Clip

Interfacial Rcstraint . . . . . . . . . . . . . . . 36

23 Geometric Relationship for Segments on a Curve . . . . . . . 40

24 Drive Pinion Engagement of the Drill Shaft . . . . . . . . . 51

25 Rack Pinion Engagement . . . . . . . . . . . . . . . . 52

26 Two Ways to Bridge the Coupling Interface . . . . . . . . . 53

27 Schematic of Chain Drive . . . . . . . . . . . . . 55

28 Differential Sprocket Drive . . . . . . . . . . . . . . 56

29 Drill Cuttings from Fine Gray-Black Shale . . . . . . . . . 63

30 Available Space in the Fletcher LDTO for Flexible

Shaft Drill Head and Flexible Shaft Stowage . . . . . . . 65 
List of Figures (Cont.)

Figure

31 Proposed Segmental Flexible Shaft Drilling System . . . . . . 70

32 Drive Method for Segmental Flexible Shaft Drill . . . . . . . 71

33 Proposed $13 / 8$-in. Diameter Flexible Shaft . . . . . . . 78

34 Proposed 1-in. Diameter Flexible Shaft . . . . . . . . . . 79

35 Proposed Starter Section for Flexible Shaft Drill . . . . . . 80

36 Tooth Surface Wear Pattern . . . . . . . . . . . . . 82

37 Tooth Surface Wear Pattern . . . . . . . . . . . . 83

38 Tooth Surface Wear Pattern . . . . . . . . . . . . . . 84

39 Wear Test Box with Drilling Chips . . . . . . . . . . . . 86

40 Wear Test Box as Used During Test . . . . . . . . . . . . . 87

41 Shaft Broken by Mishandling . . . . . . . . . . . . . . 88 
List of Figures (Cont.)

Figure

Appendix A

$\underline{\text { Page }}$

A-1 Rigid Starter Section and Bolt Hole Curvature

Based on Starter Section Length . . . . . . . . . . . . . A-2

Appendix B

B-1 Thrust Force Transmission in Curved Hole . . . . . . . . . . B-2

Appendix D

D-1 Flexible Interconnectors . . . . . . . . . . . . D-3

D-2 Square Tooth Coupling . . . . . . . . . . . . . . . D-4

D-3 Ellipsoidal Facoe Toroidal Tooth Coupling . . . . . . . . . D-6

D-4 Spiral Tooth Loading . . . . . . . . . . . . . . D-7

Appendix E

E-1 Relative Geometry of Shaft Segments . . . . . . . . . . . E-2

E-2 Stress Analysis for Shaft Section . . . . . . . . . . . . . E-2

E-3 Force Couple Resulted from Torsion . . . . . . . . . . . . E-4

E-4 Load Pattern on Shaft Tooth . . . . . . . . . . . . . . . . E-4

E-5 Approximate Section Modulus for Shaft Tooth . . . . . . . . E-4

E-6 Goodman Diagram for Snap-Ring Segment Loading . . . . . . . . . E-8

E-7 Fatigue Strength Diagram for Snap-Ring Segments . . . . . . . . E-8

E-8 Ref. Dwg. No. 1331-74-07-2: Hexagon Bar Segment . . . . . . E-9

Appendix F

F-1 Cylindrical Clip Concept . . . . . . . . . . . . . F-2

Appendix G

G-1 Segmental Shaft with Wire Connection

for Torque Transmission . . . . . . . . . . . . . . G-2

Appendix $\mathrm{H}$

H-1 Elastomer Connector for Segments - Type I . . . . . . . . . . . H-2

H-3 Elastomer Connector for Segments - Type II . . . . . . . . . . H-3

Appendix I

I-1 Schematic of Drive Unit . . . . . . . . . . . . . . . . . . I-2

I-2 Upper End Cap Assembly ... . . . . . . . . . . . . .... I-3

I-3 Rod Head Assembly . . . . . . . . . . . . . . . . . . I-3

I-4 Exploded View of Paw1 Control Mechanism . . . . . . . . . . . . I-4 
List of Figures (Cont.)

Figure

$\underline{\text { Page }}$

I-5 Hydraulic and Electricäl Schematics . . . . . . . . . . I-5

I-6 Exploded View of Drive Unit . . . . . . . . . . . . . . . I-6

I-7 Assembly Drawing of Drive Unit . . . . . . . . . . . . . I-7

Appendix J

J-1 Driving Ring for Frictional Drive Concept . . . . . . . . . . . J-2

J-2 Load Pattern on the Driving Ring . . . . . . . . . . . . . J-2

J-3 Bending of a Curved Bar with a Symmetric Cross Section . . . . J-3

J-4 Load Condition of Rings . . . . . . . . . . . . . . . . J-6

J-5 Estimation of Fatigue Life . . . . . . . . . . . . . . . J-6

\section{Appendix K}

K-1 Drivehead Friction Force Drive Mechanism with Eccentric Lift . . . . . . . . . . . . . . . . K-2

K-2 Drivehead Friction Force with Chain Drive and Load Ring ...... . . . . . . . . . . . . . . . K-3

K-3 Drivehead Cam-Operated Lift Mechanism and Cam-Actuated Pawls . . . . . . . . . . . . . . . K-4

K-4 Section C-C Reciprocating Hydraulic Drivehead . . . . . . . . . K-5

K-5 Section A-A Reciprocating Hydraulic Drivehead . . . . . . . . . K-6

K-6 Section B-B Reciprocating Hydraulic Drivehead . . . . . . . . . K-7

K-7 Mine Vehićle in 30-in. Coal . . . . . . . . . . . . . K-8

Appendix L

L-1 Drill Segments Force Acting on Two Teeth . . . . . . . . . . L-2

L-2 Force Balance . . . . . . . . . . . . . . . . . . . . L-3

L-3 Drill Segment, Top View . . . . . . . . . . . . . . . . L-3

L-4 Force Distribution . . . . . . . . . . . . . . . . L-6.

L-5 Misaligned Case ... . . . . . . . . . . . . . . L-6

L-6 Twisting Moment . . . . . . . . . . . . . . . . L-11

L-7 Tooth Configurations .. . . . . . . . . . . . . . . . L-11

L-8 Goodman Diagram . . . . . . . . . . . . . . . . . L-14

Appendix M

M-1 Curvature Test Configuration . . . . . . . . . . . . . . . M-2

M-2 Unshielded Flexible Shaft Drill During Curvature Tests . . . . M-4

M-3 Shielded Flexible Shaft Drill During Curvature Tests . . . . M-5 
List of Figures (Cont.)

Figure

$\underline{\text { Page }}$

M-4 Orientation of Flexible Segments and

Retainer Ring During Misalignment . . . . . . . . . . . . . . M-8

M-5 Radius Geometry for Flexible Shaft Dril1 . . . . . . . . . . M-9:;

M-6 Retainer Ring Groove Geometry . . . . . . . . . . . . . . . M-10

M-7. Bent Retainer Ring Caused by Too Small

a Radius of Curvature . . . . . . . . . . . . . . M-12

M-8 .1 3/8-in. Drill Segment Detail . . . . . . . . . . . . M-14

Appendix $\mathrm{N}$

N-1 Flexible Shaft Sections for Field Test . . . . . . . . . . N-2

$\mathrm{N}-2$. Drilling Sequence for Field Tests . . . . . . . . . . . . . N-3

N-3 Starter Section, Bit Holder and Drilling Bit .......... . N-4

N-4 Drilling System for $13 / 8$-in. Flexible Shaft . . . . . . . N-6

N-5 Drilling System for 1-in. Flexible Shaft Drill . . . . . . . N-7

N-6 Coupled Field Test System Ready for Testing .......... . N-8

N-7 Drill Used for Field Tests . . . . . . . . . . . . . . N-9

N-8 Location of Separation on the $13 / 8$-in. Diameter Drill

That Failed During Field Testing . . . . . . . . . . . N-13

N-9 Plugging of Chip-Return Passages--1 3/8-in. Diameter Dril1 . . N-14

N-10 Plugging of Chip-Return Passages--1-in. Diameter Dril1 . . . N-15

Appendix 0

0-1 Torsion Test Compression Fixture . . . . . . . . . . . . . 0-2

0-2 Tooth Failure by Shear Across Teeth--1-in. Diameter Shaft . . 0-4

0-3 Segment Failure Through Hexagonal Web........... . 0-5

0-4 Retainer Ring Failures . . . . . . . . . . . . . . . . 0-9

0-5 Segmental Shaft $13 / 8$-in. Drill Segment

Retainer Ring Design . . . . . . . . . . . . . . 0-10

0-6 Segmental Shaft 1-in. Drill Segment Detail

Retàiner Ring Design . . . . . . . . . . . . . . 0-11

0-7 $13 / 8$-in. Drill Segments Adapted for Torsion

Test Evaluation (2- and 3-tooth style) . . . . . . . . . 0-12

0-8 1-in. Dril1 Segments Adapted for Torsion Test

Evaluation $(2-$ and 3 -tooth style)............. . -13 


\subsubsection{SUMMARY}

The Phase I report serves two purposes. It documents the effort expended by the Washington State University (WSU) research team towards meeting the terms of the contract and provides a working document to be referred to by the rescarch team during the later phases of this research project.

The flexible shaft drill concepts for low coal were investigated under U.S. Bureau of Mines contract HO242027 based upon operational specifications prepared by the WSU research team after consultation with the Coal Mine Productivity Tașk Force of the U.S. Steel Corporation, and visiting some of their Gary District coal mines in West Virginia. These operational specifications are presented in section 2.0 .0 of this report. However, some of the pertinent design specifications for the project will be repeated here.

Investigations disclosed that a flexible shaft drill should be designed to withstand a torque load of $3,000 \mathrm{in.}-1 \mathrm{~b}$, a thrust load of $6,000 \mathrm{lb}$, a mean feed rate of $3 \mathrm{ft} / \mathrm{min}$ (feed rate range should be 1 to $6 \mathrm{ft} / \mathrm{min}$ ), withdrawal rate of $40 \mathrm{ft} / \mathrm{min}$, and have the ability to drill an 8 - ft deep hole within $\pm 10^{\circ}$ of the vertical centerline. In order to maintain this alignment, a straight starter section would be used at the drill bit end of the drill. Figure 7 shows how the length of this starter section varies with hole tolerance. Drill hole measurements in soft, semi-consolidated shale indicate a maximum gap of $0.030 \mathrm{in.,}$ which implies a minimum starter section length of about 9 in.

Visits to the coal mines showed that the mining environment was hostile to machinery, making it desirable to design the equipment to take considerable abuse from normal and abnormal operating practices. A visit to the Fletcher Company to discuss possible modifications of their drilling machine to accommodate the flexible shaft drill revealed that space restrictions would not be as severe as had been anticipated. One restriction imposed during the concept development: the drill head should be within $16 \mathrm{in}$. of the roof of the mine. This would provide adequate room for a 12-in. flexible shaft radius in $30-i n$. coal. The flexible shaft drill should be able to drill a 1 -in. or $13 / 8$-in. 
diameter hole. The stress analysis for strength was based upon the $13 / 8$-in. size hole.

After considering a number of alternative types of flexible shafts, it was concluded that the flexible shaft should be made up of short rigid segments interlocked at their interfaces with intermeshed teeth. This study of flexible shaft concepts concentrated on variations of this segmental shaft idea. From this study, it was concluded that such a segmented shaft should have the following characteristics:

1. Three interlocking clutch teeth at the interface. To increase the number of clutch teeth would increase the stress in each tooth to a prohibitively high level. The symmetry of three clutch teeth makes it easier to machine the teeth in a segment. For the same reason, it would be preferable that the clutch teeth were square. (There is some concern that segments interlocked using square teeth will not run smoothly. Some curvature of the teeth may be necessary. This report suggests a number of alternatives.)

2. Segments should have some restraining devices at the connecting interfaces preventing the segments from separating. This interfacial restraint should allow the segments to transmit tension loads across the interface. This is desirable so that the drill string can be withdrawn from the hole by applying tensile force to the segments. Interfacial restraints proposed are:
a. Internal snap rings.
b. Elastomeric connectors.
c. Internal cylindrical clips.

3. Of the above interfacial restraint methods, the elastomeric connector would be the easiest to replace if a segment failed. The other types of connectors would require the disassembly of the entire segmental shaft to replace a failed segment.

4. Another way of providing positive interlocking of clutch teeth at the interface is by use of a wire tensioning device. This provides a wire running through the center of the shaft connecting the starter section near the drill bit with the other end of the drill string. The wire in tension provides a compressive load between the shaft segments. 
5. A hexagonal outer geometry will be more compatible with the hex collar torque drives utilized in most of the drive head designs under consideration. For a friction type drive, the hex cross section would exist throughout the length of the segment. For drives using yoke thrusters, the center portion of the segment would have to be machined, creating a "dumbbel1" profile. This alteration would provide a thrust collar on the segment.

6. In all of the segment concepts except one, a inner chip return line must be used. The exception is the elastomeric connector which is designed to provide a seal at the interface between segments.

7. A cost analysis of the segmental shaft versus the traditional drill steel showed the segmental shaft would cost about 22 cents more per hole. This estimate does not account for any additional time saving possible from use of a more automated system of drilling and inserting bolts. Mining companies, like U.S. Steel, anticipate using a flexible shaft drill in conjunction with a continuous miner. Use of a flexible shaft drill would eliminate movement of machinery in and out of the working space as the cycle of mining coal and bolting the roof are repeated. The savings in time should make a flexible shaft drill more attractive from a cost standpoint.

8. The technical staff at U.S. Steel hopes to implement a water flushing method to remove drill chips. Removal water could come through the center of a segmented drill string, flushing the chips from the drill bit and out the annular space around the drill. The reason this has not been used in the past is that water would run down onto the miner working beneath the drill hole. A remotely operated flexible shaft drill eliminates this problem, making water chip removal a much more attractive process. With a water chip removal system, the inner hole could be a maximum of $1 / 4$ in. in diameter. Such a small hole would increase the wall thickness of the flexible shaft segments, making a felxible shaft easier to design.

Investigation of possible locations for the drivehead led to the conclusion that the best place was the roof of the mine. This permits application of torque and thrust loads to the drill shaft above the drive hole, allowing the portion of the shaft that curves from the drill head back to the vehicle to idle in an unloaded state. Investigation identified five basic types of driveheads: 
1. Pawl and ratchet driveheads

2. Reciprocating hydraulic driveheads

3. Reciprocating cam driveheads

4. Reciprocating friction driveheads

5. Continuous friction driveheads

The simplest of these five driveheads would be the friction drivehead. A friction drive would not require drill segments with the dumbbell profile. Technical consultants at U.S. Steel expressed concern whether a friction drivehead could provide the necessary thrust. Contamination of a drill string with dirt, water, and oil could reduce the friction coefficient to an unacceptable leve1. Further tests will verify this concept.

Drivehead concepts 3,4, and 5 utilize a differential drivehead system. This type of drivehead has the advantage of not requiring rotating fluid seals. Drivehead number 1 requires a rotating hydraulic seal and number 2 requires a rotating pneumatic seal (100 psi air).

The technical consultants at U.S. Steel favored a reciprocating hydraulic drivehead because of its positive acting yoke thruster, fewer moving parts, and the facility to control thrust pressure and speed. The five drivehead concepts developed suggest a number of combinations which could provide a more optimal approach.

Continuous friction driveheads have the advantage of being reversible to remove the drill string from the hole. The other driveheads have provisions for retracting the thrust mechanism requiring that the drill string be withdrawn from the hole by a force applied to the drill segments or an inner wire.

Questions concerning the integration of the flexible shaft drill with the Bendix bolt bender/inserter were answered during a visit to the Fletcher Company. Examination of the types of mining machines used showed there was adequate space to stow a flexible shaft drill and maneuver the drivehead during drilling and bolting cycles as well as when tramming the vehicle to a new work location.

The proposed program for Phase II will be directed toward investigating the following areas of interest:

1. The static testing program should concentrate on permissible torsion loads for the clutch teeth and the tension load characteristics of various interfacial restraints. These static tests will be supported by further stress calculations and possible use of photoelastic models to clarify stress distribution. 
2. If an elastomeric connector appears favorable, studies of various elastomers will be made. There are a number of possibilities for increasing the tension load restraint capabilities of the elastomeric connector as well as maintaining its flexibility. In order to satisfactorily carry out these studies, we would utilize services of the College of Engineering polymer research section.

3. Dynamic behavior of the shaft will be investigated by rotating it through different curvatures without any applied loads. This study will provide an indication of the type of restraining tube that should be used to guide a flexible shaft drill from the drivehead to the vehicle and its stowage position. These studies will also determine how smoothly the segments rotate when meshed together.

4. The drilling chip return system would be studied to establish what the minimum inside diameter should be and the difficulties that might occur when conveying chips around the radius back to the vehicle. Chip samples could be obtained from U.S. Steel mines for use during this study.

5. From these preliminary tests, field tests would be designed. These tests would be carried out at the U.S. Steel Test Facility at their Contour Mine near Gary, West Virginia. This facility has the capability of positioning a large block of shale so a standard drilling machine can be used beneath it. A 4- to 5-ft thick block of shale should provide a realistic evaluation of the flexible shafts under consideration. 


\subsubsection{TASK DESCRIPTION AND OPERATIONAL SPECIFICATION}

The Washington State University proposal responding to RFP HO242027 stated that an operational specification would be prepared during Phase I. This specification would be based upon the statement of work given in contract $\mathrm{H} 0242027$, consultations with the coal-mine productivity task force at U.S. Steel, and observations during a field trip to the Gary District mines in West Virginia. The objective of the operational specification was to state as completely as possible all aspects of coal mine drilling and roof-bolting which would be considered in the design of a flexible-shaft drill for low coal.

\subsubsection{Coal Mine Environment}

Bolting has become the standard method of supporting coal mine roofs. The room-and-pillar coal mining method makes extensive use of roof bolts. As coal is removed from the seam, large rooms are developed and separated from each other by pillars of coal. The only support of the roof in these rooms is from rock bolts inserted into holes drilled into the ceiling. Figure 1 is a plan view of a typical development heading in a coal mine. The figure shows a typical spacing of roof bolts and the location of temporary support jacks ahead of the roof bolt line. Temporary roof-support jacks are used to support the roof until bolts have been inserted. The maximum depth of unsupported roof ranges from 12 to $20 \mathrm{ft}$ depending on the depth of cut made by the mining machine. Once the coal has been extracted and temporary support jacks have been put into place, an orderly process of advancing the roof bolt line toward the face is started. The flexible-shaft roof drill to be developed under this contract will be used to drill holes into the mine roof. The use of such a flexible-shaft roof drill will avoid the present dangerous process requiring the miner to work under a temporarily supported roof.

The length of roof bolts required in a particular coal mine depends upon the stability of the roof. Roof bolts as long as $8 \mathrm{ft}$ may be required. Coal seams as narrow as $30 \mathrm{in.} \mathrm{can} \mathrm{be} \mathrm{profitably} \mathrm{mined,} \mathrm{and} \mathrm{drilling} 8$-ft vertical holes can present a problem. In a narrow coal seam, the miner uses short segments of solid drill shaft to drill a deep hole in the roof. The miner drills the hole as deep as possible with one segment. He then couples a new segment to the drill-string and continues drilling. This system requires the 


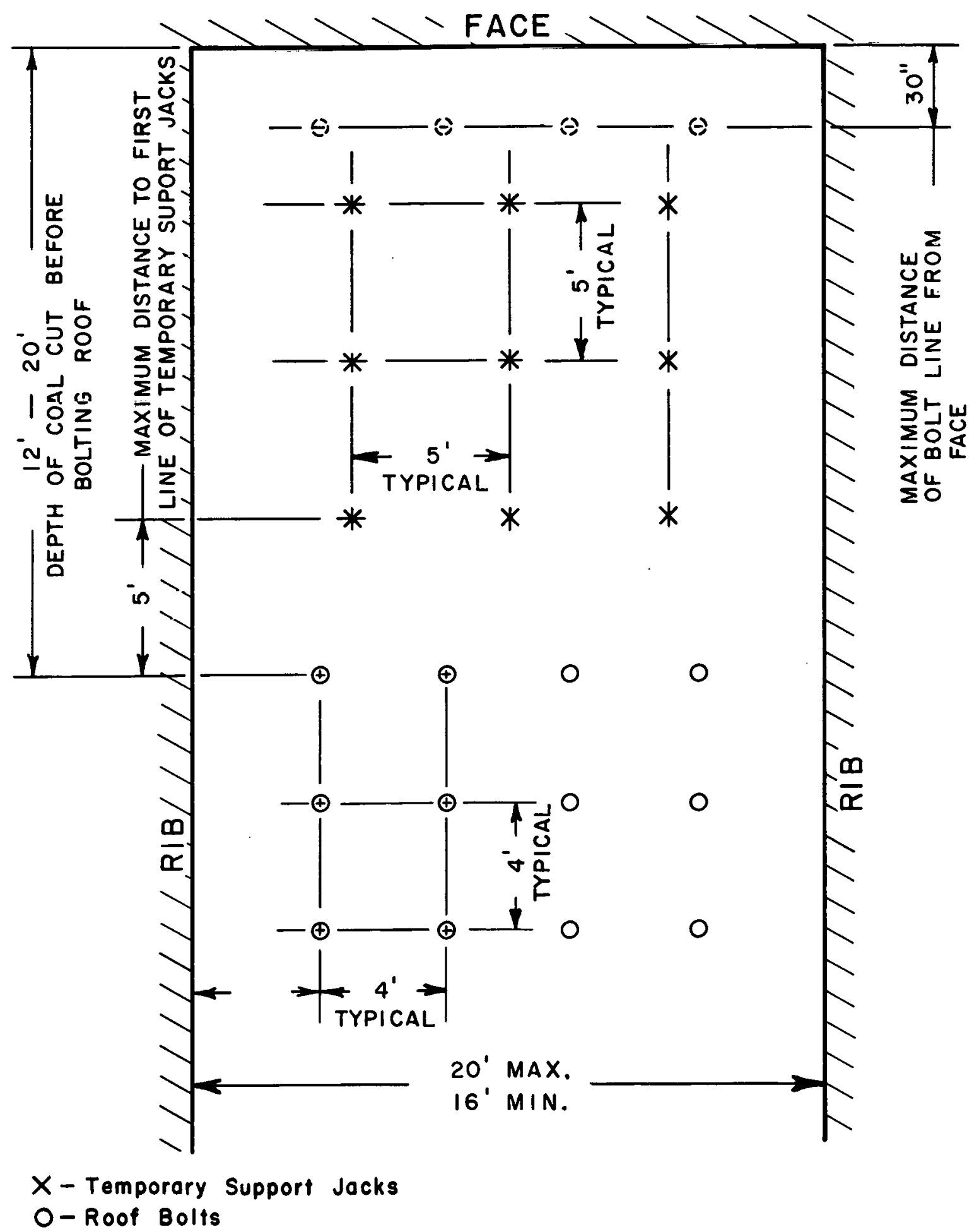

FIGURE I. TYPICAL DEVELOPMENT OF COAL SEAM ROOM 
miner to work near the hole being drilled and beneath temporarily supported roof. The operator of a flexible-shaft drill could stay behind the bolt line, while drilling holes for roof bolts being placed to support newly mined-out areas.

A typical roof-bolter vehicle that can be operated by one man is shown in Figures 2 and 3 . The drill head is moved up and down by a boom that extends in front of the vehicle. The typical coal mine will have a roof that is uneven and a floor that is irregular. A floor covered with chunks and chips of coal can create unstable footing for a mine vehicle. Mine vehicles must have a stabilizer bar to provide stability during the drilling and bolting cycle. Figures 2 and 3 show a Fletcher drill with a stabilizing bar extended against the ground for support. The unstable, uneven roof, the irregular floor, the restricted space, and the required manual effort result in a working environment that needs improvements via a better drilling and bolting system.

\subsubsection{Operating Cycle}

Some mines use two-headed machines with a worker at each head drilling and inserting bolts. Description of the present drilling and bolting cycle will be referenced to a one-headed machine as shown in Figures 2 and 3 . A drilling cycle is started by maneuvering the vehicle to the location that has been premarked for the bolt. The stabilizer bar is lowered to support the vehicle. Starting a new hole can present problems to the miner. If the roof is too irregular and/or the drill feed axis is not perpendicular to the mine roof, the drill bit tends to climb away from the intended hole location until the rock surface is penetrated and cutting action is established. The miner uses a starter segment to provide a good pilot hole for feeding successive extension segments to deepen the hole. The starter segment for a 1-3/8-in. diameter hole has a 1-1/2-in. drilling bit that enlarges the first 18 in. of the hole, providing more clearance for other drill-steel segments that follow. Drill-steel extensions are successively added during the drilling operation until the required depth for the hole is obtained. Figure 4 shows a typical extension length of drill steel, coupler, drill bit, and chuck.

A seven-hour shift of a miner engaged in inserting roof bolts consists of the following activities: 


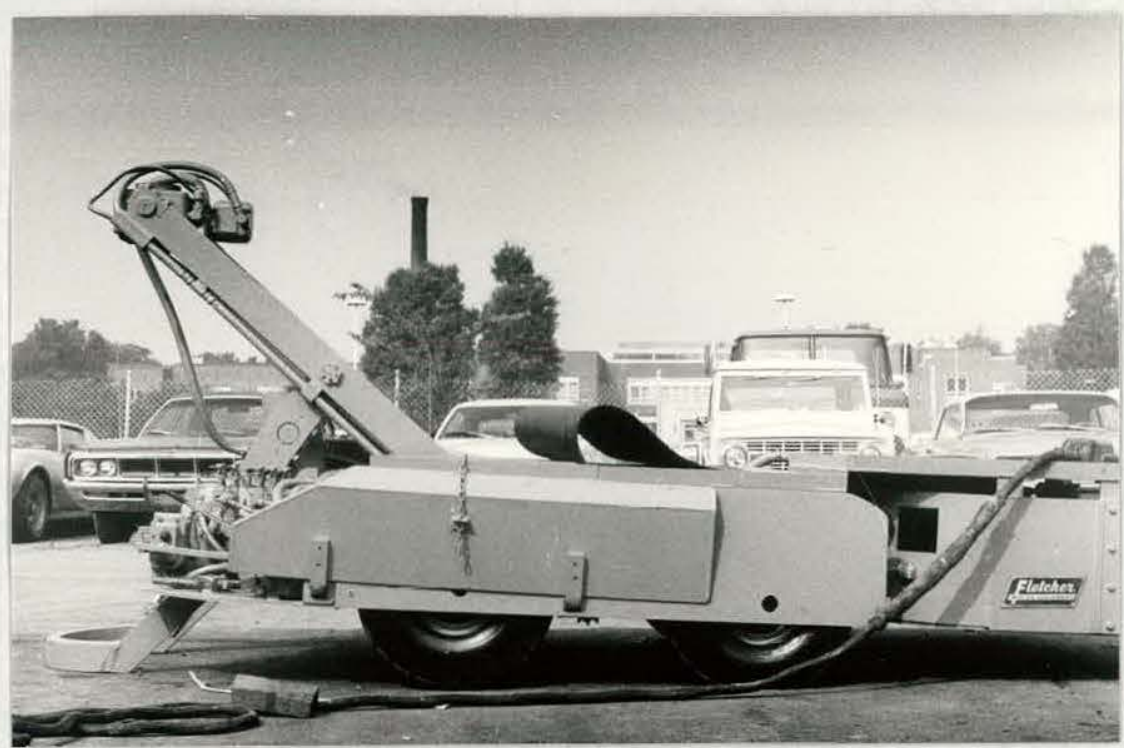

Figure 2. Bolter Vehicle with Stabilizer Bar Down and Thrust Arm Fully Extended.

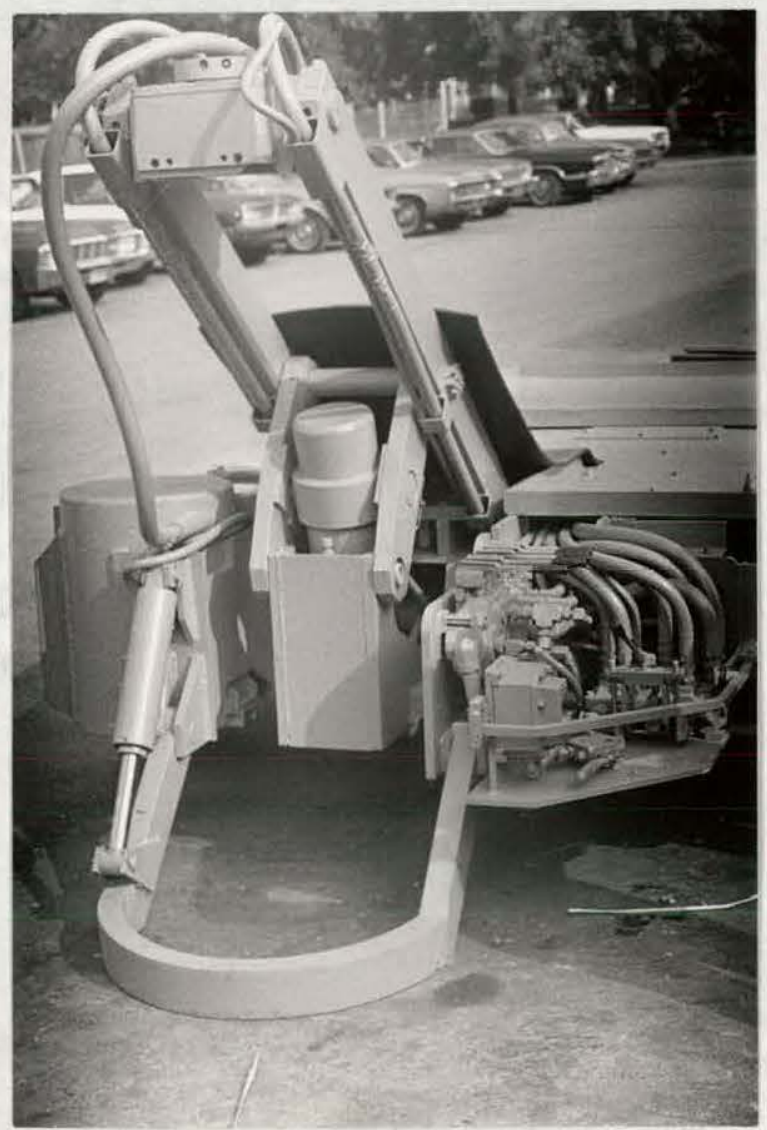

Figure 3. Front View of Bolter Vehicle. 


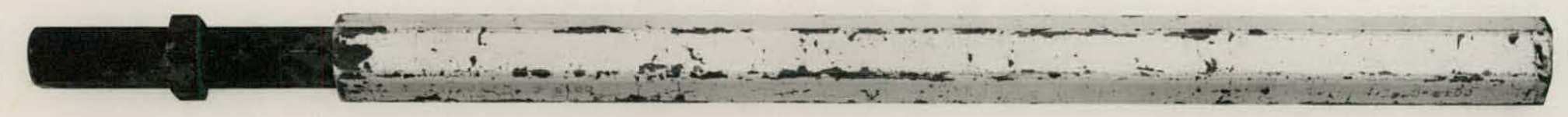

COUPLER

DRILL STEEL

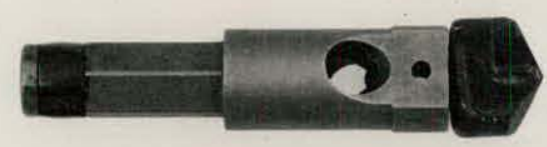

DRILL CHUCK WITH I-3/8" BIT

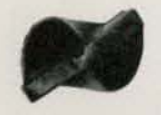

END VIEW

OF DRILL BIT

FIGURE 4. DRILL STEEL, CHUCKS AND DRILLING BITS USED TO DRILL ROOF BOLT HOLES 
1. Activities related to the drilling cycle:

a. drilling

b. changing drill steel

c. inserting and tightening the roof bolt

d. maneuvering the drill head

e. maneuvering the machine.

2. Other activities:

a. setting and advancing the temporary support jacks

b. miscellaneous activities such as

--man trip in and out of the mine

--marking off the top for placement of roof bolts

--emptying dust boxes

--adjusting the ventilation curtain

--rock dusting

--changing dull bits

--freeing a stuck drill

--waiting on a partner if he is working at a double-headed drill machine

--waiting because space is unavailable for insertion of a bolt.

U.S. Steel provided time study information obtained from three of their Gary District mines. The time study data are presented in Table 1. Mine number 9 has a roof condition that could require long bolts to stabilize the rock strata. A considerable thickness of semi-consolidated shale must be penetrated before suitable anchorage is found in an overlying strata of fine gray-black shale. Mine number 10 does not have as much semi-consolidated shale; therefore, the bolt holes need not be as deep. Mine 50 has no semiconsolidated shale. The existence of the fine gray-black shale in Mine 50 provides a good roof but requires more extensive drilling. The three mines do not typify all coal mines but do provide a spectrum of mining conditions providing data useful for this project. The data in Table 1 for all three mines have been averaged for use in Figures 5 and 6 . These figures show how activities during each shift and bolt-insertion cycle are distributed.

\subsubsection{Power and Control Requirements}

Thousands of bolt holes are drilled every day in coal mines, but very few data are available concerning the torque and thrust requirements for drilling. One difficulty in accumulating such data is that characteristics of shale vary considerably. The information that follows is based on consultation with U.S. Steel coal mining personnel, the J. H. Fletcher Company, and investigation of the literature available on the subject. 
TABLE 1

Typical Drilling and Bolting Data

(Source: U.S. Steel Corporation, Gary District, West Virginia)

\begin{tabular}{|c|c|c|c|c|c|c|c|}
\hline Mine & $\begin{array}{l}\text { Roof } \\
\text { Characteristics }\end{array}$ & Activity & $\begin{array}{l}\text { Average Seam } \\
\text { Height, in. }\end{array}$ & $\begin{array}{l}\text { Average Bolt } \\
\text { Length, ft. }\end{array}$ & $\begin{array}{l}\text { Production } \\
\text { Time/Hole } \\
\text { in weeks }\end{array}$ & $\begin{array}{l}\text { Bolts/ } \\
\text { Shaft }\end{array}$ & $\begin{array}{l}\text { Average } \\
\text { Drill Rate, } \\
\mathrm{ft} / \mathrm{min}\end{array}$ \\
\hline \# 9 & $\begin{array}{l}3^{\prime}-8^{\prime} \text { semi-con- } \\
\text { solidated shale } \\
\text { beneath fine } \\
\text { gray-black shale }\end{array}$ & $\begin{array}{l}\text { pillar and } \\
\text { develop- } \\
\text { ment }\end{array}$ & 56 & 7 & 4.3 & 54 & 3.69 \\
\hline$\# 10$ & $\begin{array}{l}15^{\prime \prime}-3^{\prime} \text { semi- } \\
\text { consolidated } \\
\text { shale beneath } \\
\text { fine gray-black } \\
\text { shale }\end{array}$ & pillar & 57 & 5 & 4.2 & 57 & 3.72 \\
\hline \multirow[t]{3}{*}{$\# 50$} & $\begin{array}{l}\text { fine gray-black } \\
\text { shale }\end{array}$ & $\begin{array}{l}\text { develop- } \\
\text { ment }\end{array}$ & 55 & 5 & 3.5 & 94 & 2.37 \\
\hline & \multicolumn{7}{|c|}{ Activity Times, Minutes/Shift } \\
\hline & Drilling & $\begin{array}{l}\text { Steel } \\
\text { Change }\end{array}$ & $\begin{array}{l}\text { Insert and } \\
\text { Tighten Bolt }\end{array}$ & $\begin{array}{l}\text { Maneuver } \\
\text { Head }\end{array}$ & $\begin{array}{l}\text { Maneuver } \\
\text { Machine }\end{array}$ & $\begin{array}{l}\text { Set and } \\
\text { Advance } \\
\text { Jacks }\end{array}$ & $\begin{array}{l}\text { No. of } \\
\text { Time } \\
\text { Studies }\end{array}$ \\
\hline \# 9 & 102 & 27 & 49 & 28 & 26 & 11 & 6 \\
\hline$\# 10$ & 107 & 20 & 41 & 37 & 34 & 49 & 11 \\
\hline$\# 50$ & 188 & 27 & 52 & 36 & 26 & 27 & 15 \\
\hline
\end{tabular}




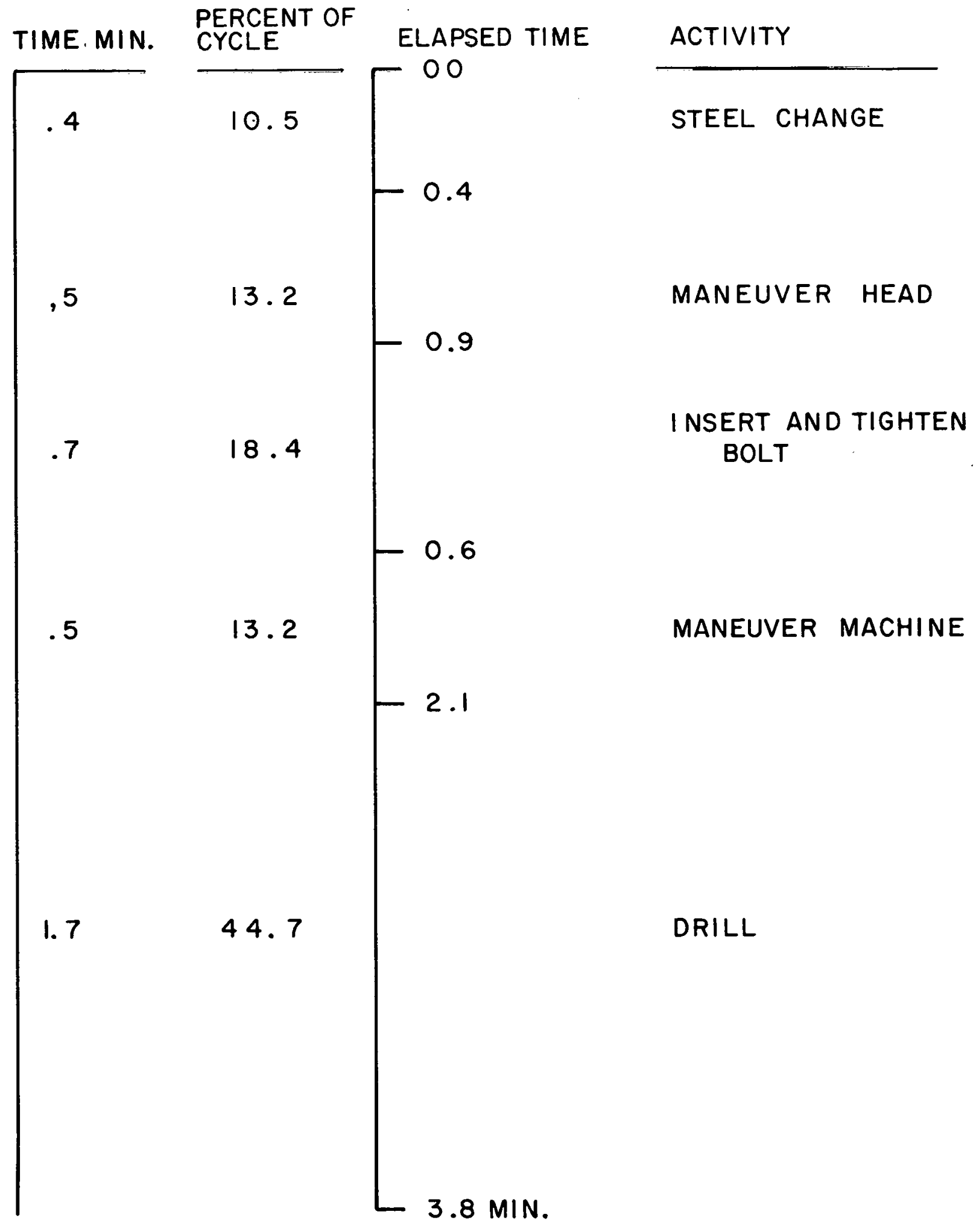

FIGURE 5. DISTRIBUTION OF ACTIVITIES PER BOLT CYCLE 


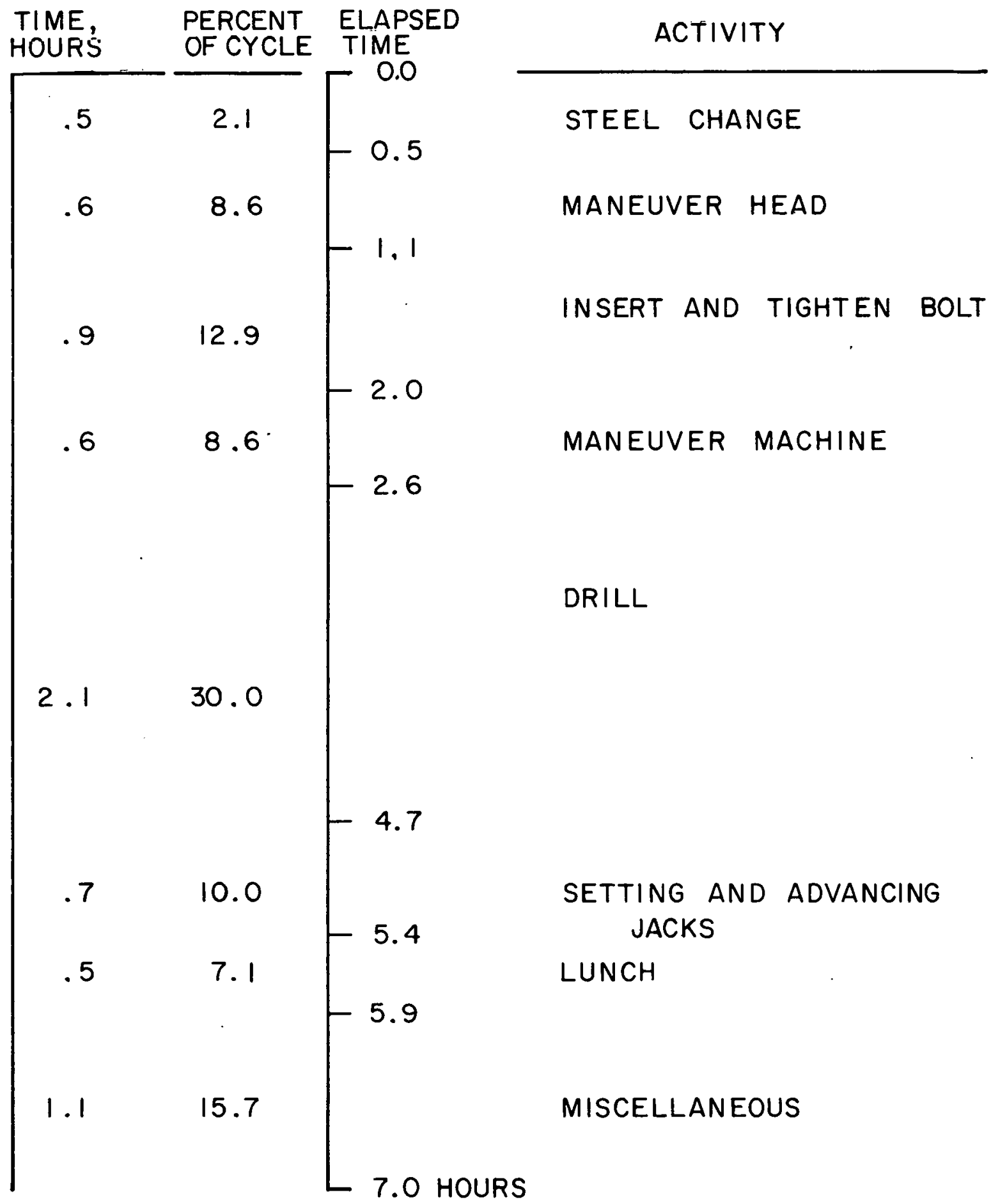

FIGURE 6. DISTRIBUTION OF ACTIVITIES PER SHIFT 
2.3.1. Torque and Thrust Requirements--Straight Holes

If a roof hole is drilled perfectly straight, very little of the required thrust and torque is wasted as friction due to the rubbing of the drill steel against the sides of the hole. In this ideal situation, the torque and thrust delivered by the drill head will be effectively transferred to the drill bit to fracture the rock at the bottom of the hole. The energy available at the drill bit for fragmenting the rock can be classified as thrust energy and/or rotation energy. Thrust energy is proportional to the product of thrust force and drill feed rate. Similarly, drill torque multiplied by rotational speed is proportional to rotation energy. Specific energy, which is the sum of these two terms divided by the volume of material removed per unit time, is often used to characterize the difficulty in drilling particular materials. ${ }^{1}$ Some studies of specific energy, torque, and thrust requirements have been made by the National Coal Board in the United Kingdom; $2,3,4,5$ however, the drilling conditions did not represent those found in typical United States coal mines. These studies were based on wet drilling using a scroll-type drill bit. Such drill bits generally have a high torque and low thrust component. A National Coal Board study indicated that when drilling three feet per minute at $200 \mathrm{rpm}, 3,600 \mathrm{in.}-1 \mathrm{~b}$ of torque are required to drill Chislet shell (a mud stone from Chislet Colliery, Kent). The Fletcher Company designs its drilling equipment for a maximum of 3,600 in.-1b of torque. They indicated their equipment has never failed due to an excessive torsion load. This is a fair indication that normal drilling torque in U.S. coal mines under dry conditions and with the bits shown in Figure 4 must be less than 3,600 in.-1b. The hexagonal drill steel used in U.S. Steel coal mines is a low-carbon (approximately 45,000 psi ultimate tensile strength) material that should transmit 2,000 in.-1b of cyclical torque based on the material's endurance strength. Normal drill steel fails at the coupling due to localized yielding in the joint. This type of failure appears to be due to excessive bearing pressure associated with the contact surfaces of loose joints.

Preliminary studies at U.S. Steel indicate a good design figure would be a torque of 3,000 in. $-1 \mathrm{~b}$ and an effective thrust force of 5,000 to 6,000 $1 \mathrm{~b}$.

It seems a flexible-shaft drill designed for 5,000 $1 \mathrm{~b}$ of thrust and 3,000 in. $-1 \mathrm{~b}$ of torque would be adequate. These criteria would represent an extremely difficult drilling condition not consistently encountered. 
2.3.2. Torque and Thrust Requirements--Curved Hole

A number of conditions can cause a drill hole to deviate from a straight vertical path. Appendix A discusses these conditions and presents a method of estimating the deviation of the hole from the vertical when the hole is guided by a straight starter section. The effectiveness of a starter section in maintaining a minimum deviation from the vertical path depends upon its length and the clearance between the ID of the starter section and the OD of the drilled hole. Based on the analysis presented in Appendix A, the deviation of a hole at a depth of $8 \mathrm{ft}$ will be within 10 degrees of vertical if the starter section length is sized in accordance with the results shown in Figure 7 . Figure 7 relates the expected clearance distance to the required starter section length.

Appendix $B$ shows how required torque and thrust at the drive head varies with increase in the curvature of the hole. This is due to the component of side thrust on the shaft that becomes greater as the curvaturc increases. For a required longitudinal thrust force of $5,000 \mathrm{lb}$ at a drill bit located at a vertical depth of $8 \mathrm{ft}$, the estimated thrust force at the drive head based on Eq. B-4 would be 5,276 lb. Equation B-5 estimates the side force exerted by the starter section against the side of the hole. Under the same thrust conditions, this side force is $1,700 \mathrm{lb}$.

\subsubsection{Drilling Control and Duty Cycle}

A variety of opinion exists among coal miners and supervisors concerning the best methods of controlling the drilling rate. Mines generally control the thrust force and rotation speed. The Fletcher LTDO vehicle uses an on-off control method for preset thrust and rotation speed. Other drilling vehicles use a "feathering" control for the operator to vary the rotation speed and thrust around a preset value. These types of drills depend on the operator's experience to optimize his drilling rate without using an excessive number of drill bits. The Fletcher LTDO, as an example, has a proprietary "black box" control which senses abnormal drilling conditions and compensates by automatically adjusting thrust and speed.

U.S. Steel began conducting drilling tests to explore drilling conditions in their coal mines. Their preliminary conclusions indicate better drill rates and cutting conditions result when high thrust loads and low speeds are used. They have not proceeded with testing far enough to establish what optimum ranges should be used for these speeds and thrusts. The latest 


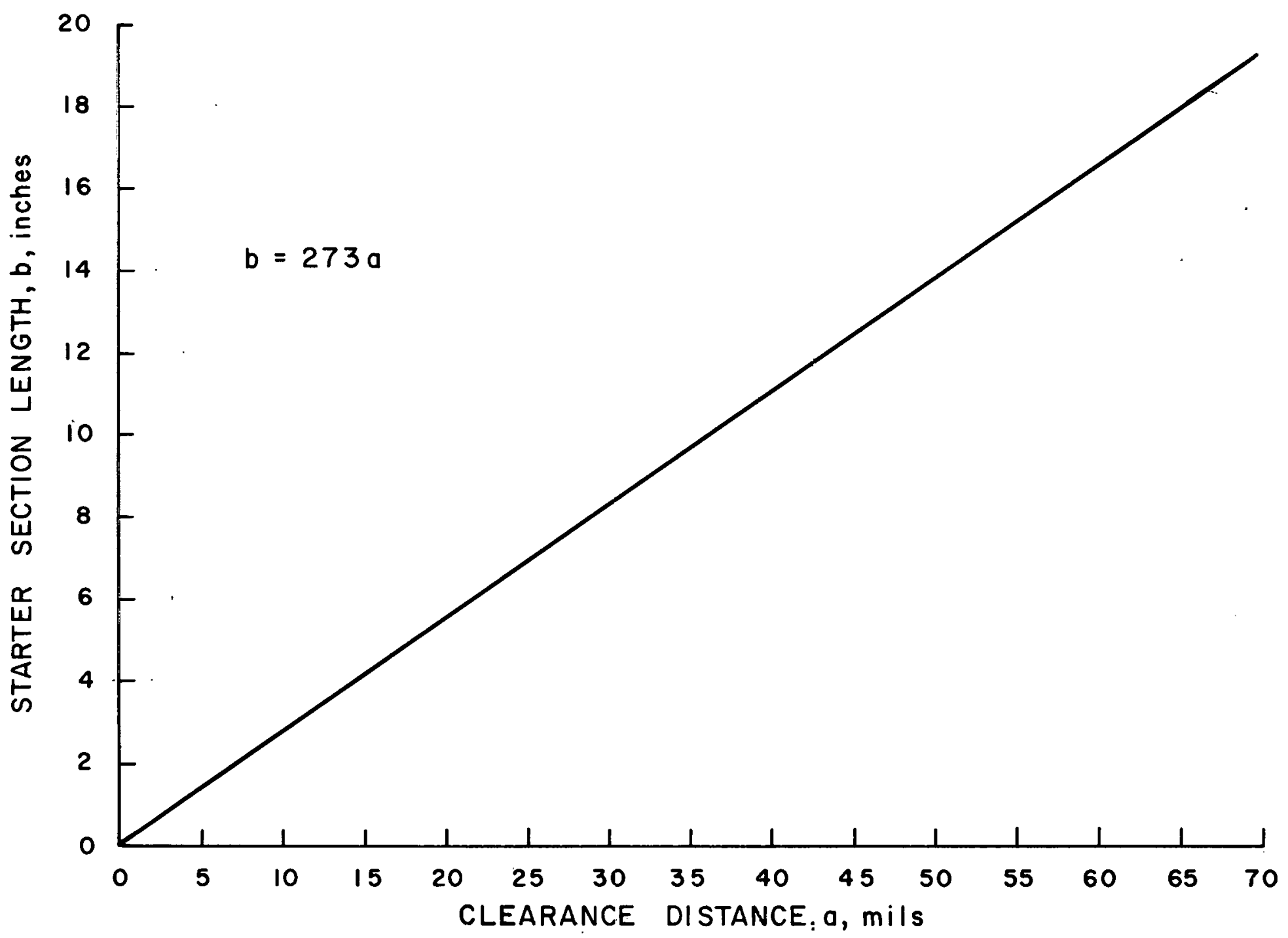

FIGURE 7. STARTER SECTION LENGTH vs. CLEARANCE DISTANCE FOR HOLE DEVIATION AT $10^{\circ}$

n 
information obtained showed that rotation speeds were in the range of 100 to $200 \mathrm{rpm}$ and thrusts were approaching 5,000 to 6,000 $1 \mathrm{~b}$. Lower rotation speeds and higher thrusts result in larger cutting chips. Larger cutting chips are associated with more efficient drilling conditions, representing a desirable goal in drilling studies.

Characteristics of the cutting chips produced by a drilling process can limit the capabilities of the drilling system. Drill cuttings can be extremely fine, representative of drilling fine, gray-black shale, or coarse and flaky, when drilling in less consolidated shale. In each case, wet conditions could produce chips which can easily plug the chip-extraction passage in the drill or set up like cement, freezing the drill bit. Figure 29 shows cutting chips that typically result when dry-drilling fine, gray-black shale like that found in Mine 50. Consultations with the J. H. Fletcher Co. indicated their chip-extraction system is designed to plug up at a drilling feed rate between 7 and $8 \mathrm{ft} / \mathrm{min}$, which represents a maximum feed rate. Time study data obtained from U.S. Steel mines indicated a mean feed rate of $3.08 \mathrm{ft} / \mathrm{min}$ for the three mines studied. Data for this mean feed rate indicated a standard deviation of $2.94 \mathrm{ft} / \mathrm{min}$. Based on this information, it seems reasonable that a drill system should be designed for a range of 1 to $6 \mathrm{ft} / \mathrm{min}$.

The rotation speed required to drill varies and is not firmly established by the industry. The Fletcher LTDO vehicle has a range of 0 to $560 \mathrm{rpm}$. It is doubtful that the upper limits of this speed range are ever used. A more reasonable design range should be 100 to $400 \mathrm{rpm}$. This speed range, combined with the torque requirements, provides a horsepower rating for design of the drill system components. The industry standard is to use hydraulic gear motors with a working pressure of $2,000 \mathrm{lb} / \mathrm{sq}$ in. to provide the needed drilling power. Some mine operating personnel would prefer piston motors; this, however, is a controversial idea and does not represent a consensus of all operating people and manufacturers.

A typical production cycle for bolting crews is $7 \mathrm{hr}$ per shift, 2 shifts per day, 22 working days each month. These data, combined with the amount of drilling time per shift as specified in Figure 6 , provides a duty cycle to be used in estimating the life of most drilling components.

The operating and supervisory personnel contacted at U.S. Steel indicated that underground mining equipment is subjected to severe use. A vehicle must remain underground for 2 or 3 years before it is brought to the surface for a major overhaul. All maintenance, except on subassemblies that can be detached, 
must be performed underground using relatively basic hand tools. Hydraulic fluid leakage is one of the major problems on mining equipment. Not only is it costly, but it further contaminates an already messy environment. Another complaint by operators and supervisors is that present mining vehicles have hoses and valve blocks that are too smal1. This results in excessive oil heating because of flow rates in the 60 - to $80-\mathrm{ft} / \mathrm{sec}$ range. A more desirable flow rate would be $20 \mathrm{ft} / \mathrm{sec}$. (The Fletcher Company disagreed with this.)

The above data indicate the control philosophy incorporated into the WSU design should provide independent control of both rotation speed and thrust. A $3-\mathrm{ft} / \mathrm{min}$ feed rate appeared to be a good mean value. Equipment should be easily maintained underground and ruggedly constructed to withstand abuse by the miner.

Withdrawal of a drill string from the hole was specified in RP HO242027 as $40 \mathrm{ft} / \mathrm{min}$. The drill steel normally drops from the hole due to gravity forces or requires a minor effort by the miner to pull it out of the hole. There are times when a drill bit will stick in the hole. This is caused by a drill bit's breaking through hard'strata into a soft strata and becoming frozen in soft material due to the instantaneously high feed rate. A bit may stick when a crack is encountered during drilling, or it can be caused by the drill hole's curving from vertical to a point where straight drill steel binds in the hole. In some cases, the drill steel cannot be pulled out and is left in the hole. A flexible-shaft drill would run the risk of sticking due to the first two reasons. Being flexible, the last problem could possibly be avoided. It should be expected that the drilling conditions could create a situation where a flexible-shaft drill would stick and have to be abandoned.

\subsubsection{Flexible Dri11-Bolt Bender/Inserter System}

The work description of this contract specifies that the flexible-shaft drill developed must be used in conjunction with the bender/inserter system being developed by the Bendix Corporation. This requirement states that the bender/inserter must be cycled into position after the hole is drilled for insertion of the roof bolt. After the bolt has been inserted, the design must provide a mechanism for moving a torquing head into position to grasp the head of the bolt, which remains extended 12 to 15 in. below the mine roof. Each roof bolt is then pushed the final distance into the hole and torqued to a specified value. A 5/8-in.-diameter roof bolt is commonly torqued to 150 to 
$250 \mathrm{ft}-1 \mathrm{~b}$. Design criteria for this situation must await field tests by Bendix. The tolerance a bolt head will have with respect to the centerline of the drilled hole after it has been inserted and released by the bender/inserter is not available at this time. It is possible that with an excessively curved hole the springback in the bolt will move the center of the bolt head off the centerline of the drilled hole. This condition would make it difficult to find and grasp the bolt head for final insertion and torquing. 
THIS PAGE

\section{WAS INTENTIONALLY LEFT BLANK}




\subsubsection{DESIGN DEVELOPMENT}

Identification of the concepts and their evaluation can be represented by an information-flow system with feedback. Figure 8 is a flow graph depicting a design situation encountered when evaluating such a problem. The operational specification suggested a number of flexible-shaft concepts. For each flexible-shaft drill concept, a method of applying torque and thrust, a means for stowing the shaft in the vehicle, and a cutting chip evacuation system must be developed. It was not possible to conceptualize a flexible-shaft drill without considering other aspects of the system upon which the success of the drilling concept depends. Figure 8 shows how decisions concerning the drive head, storage system, and chip-evacuation system influence each other and the feasibility of the initial flexible-shaft concept.

To institute this design and evaluation approach required consideration of the type of vehicle to be modified for a flexible-shaft drilling system. The WSU research team assumed that the Fletcher LTDO vehicle would be selected and that similar problems would be encountered in modifying a different vehicle. This seemed a fair assumption since these vehicles fulfill the same mining function.

The WSU proposal presented in general terms various possible types of flexible shafts that had possibilities. Figures 9 and 10 show each of the proposed systems. First, the proposed systems were evaluated. Critical areas were examined and each configuration eliminated if the identified problems appeared insurmountable. The elimination process accomplished two things. It reduced considerably the spectrum of design possibilities, and the process provided the team with ideas concerning variations and improvements which were later pursued, producing feasible concepts. The remainder of this report documents this process of evaluation, elimination, and concept development. 


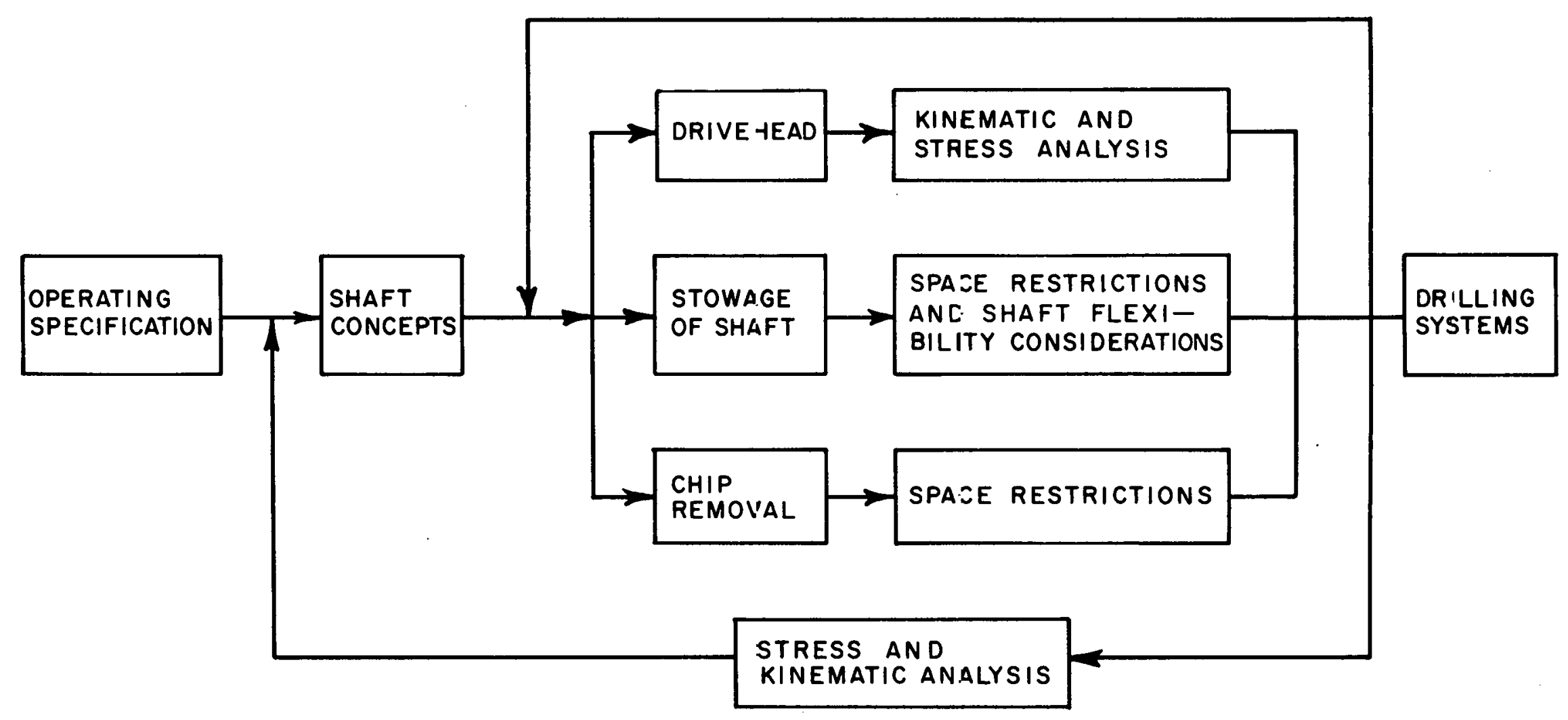

FIGURE 8. INFORMATION FLOW FOR DRILLING SYSTEM DEVELOPMENT 


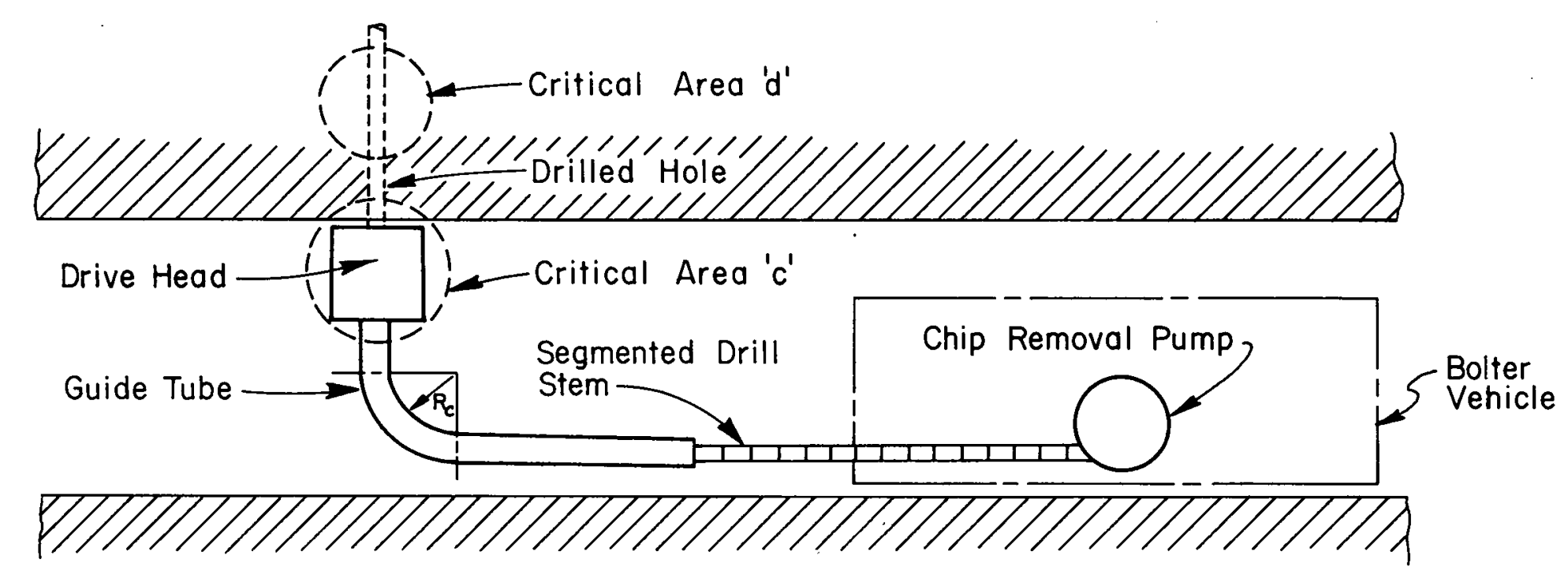

CONFIGURATION A - SEGMENTAL DRILL SHAFT

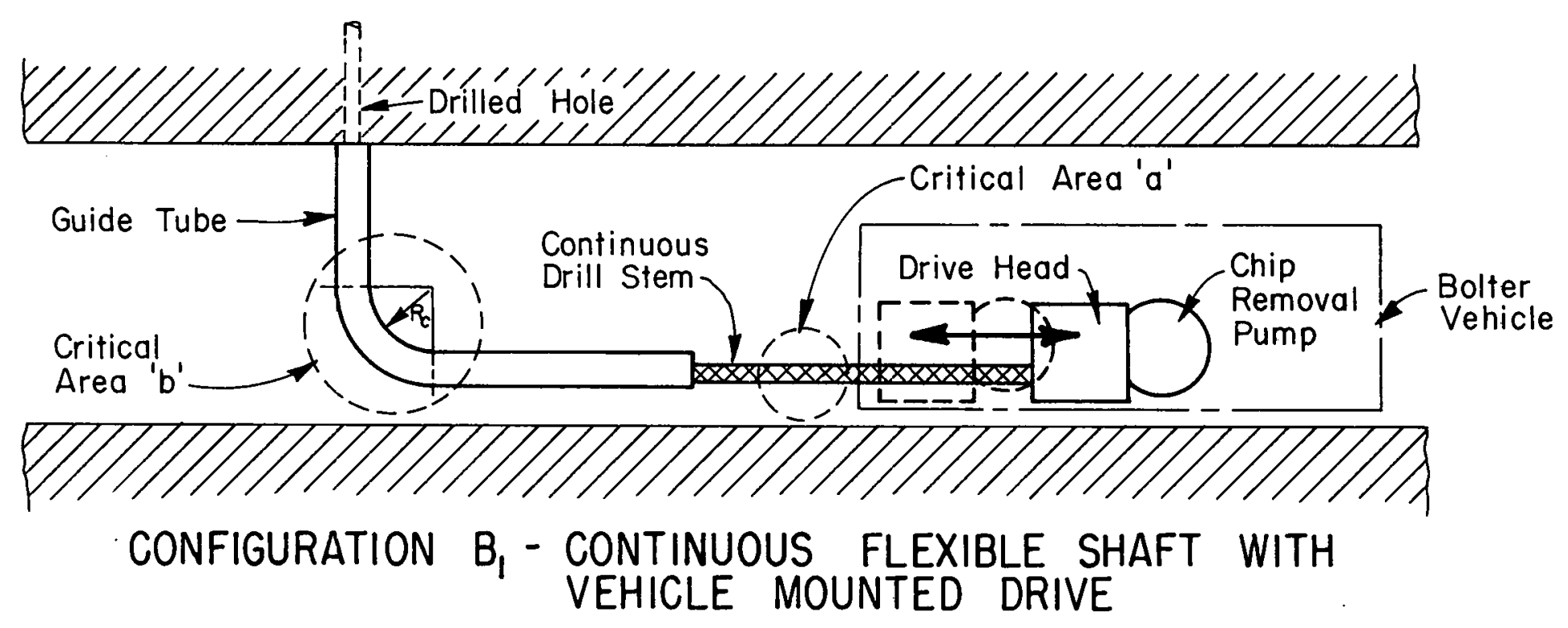

FIGURE 9 - BASIC CONFIGURATIONS 
Drill Point, Guide and Internal Gear

Speed Reduction

Unit

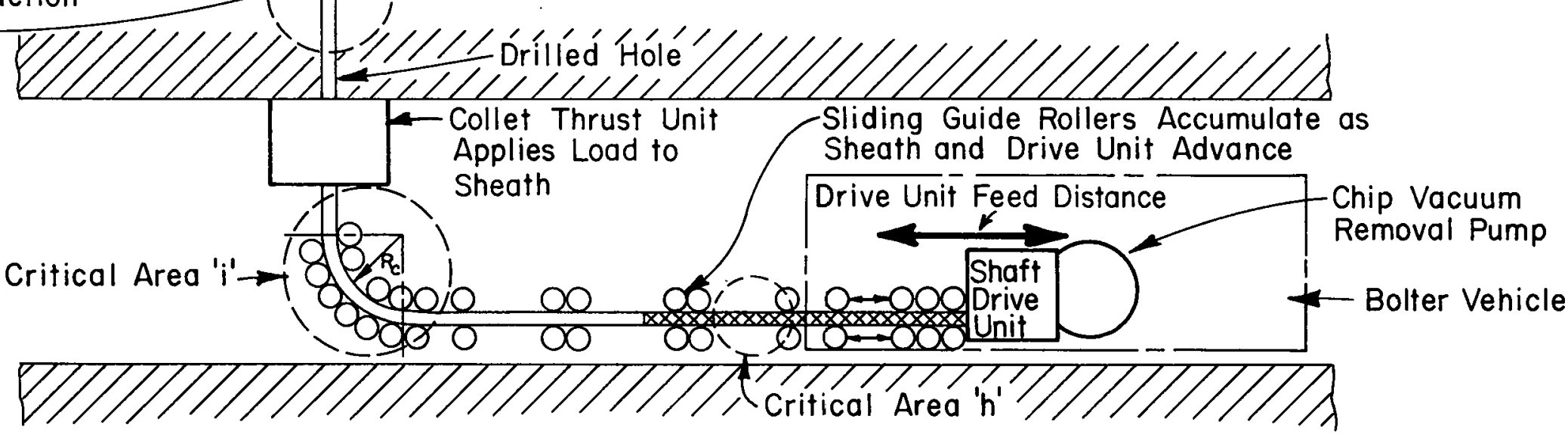

\section{CONFIGURATION $\mathrm{B}_{2}-$ ROTATING HOLLOW FLEXIBLE SHAFT INSIDE NON-ROTATING REINFORCED FLEXIBLE SHEATH}

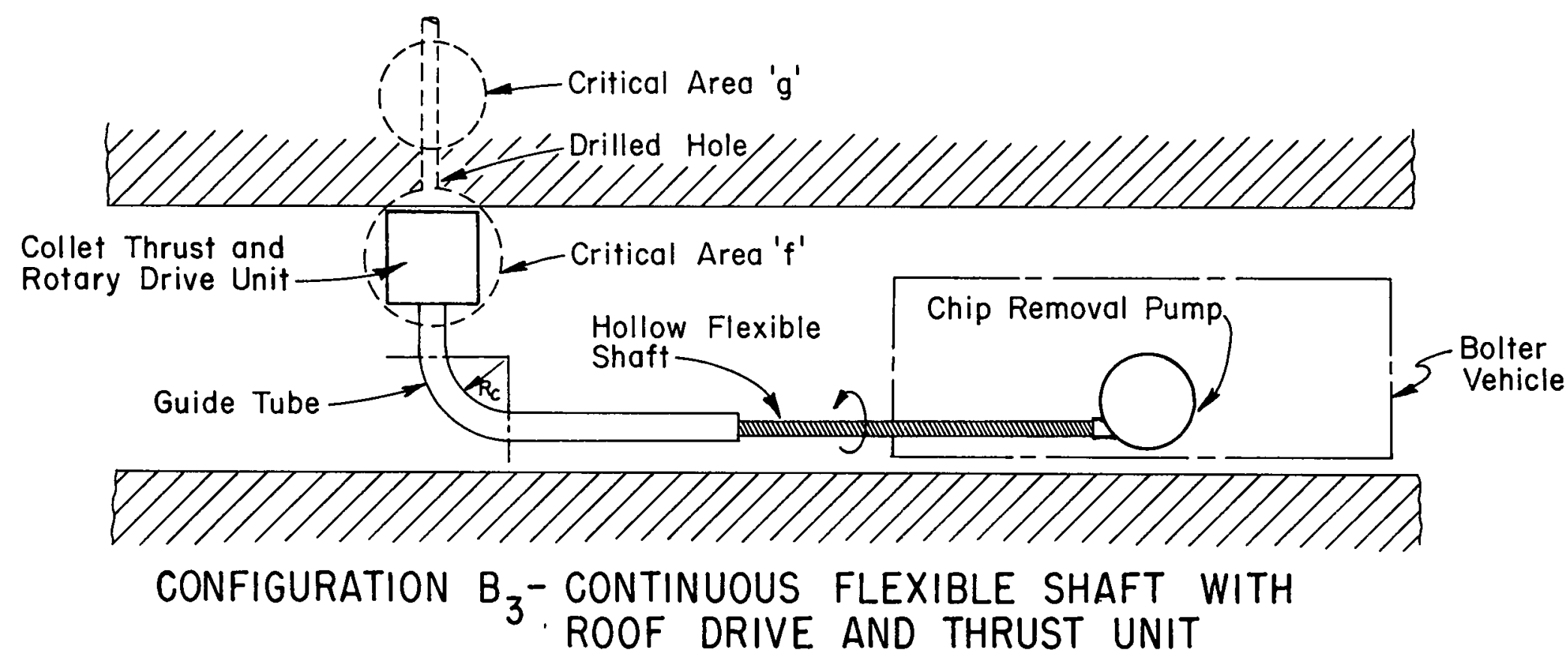

FIGURE IO- ALTERNATE BASIC CONFIGURATIONS 


\subsubsection{DRIVE HEAD LOCATION}

\subsubsection{Evaluation Criteria}

Location of the drive head for introducing torque and thrust has considerable influence on the nature of the flexible shaft used. The first task was to evaluate the possible locations shown in Figures 9 and 10, then select the best.

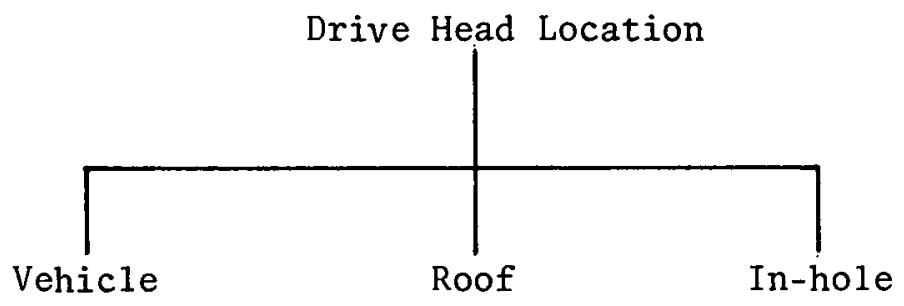

Figure 11. Selection of Drive Head Location

Figure 11 shows the location choices available. Evaluation of each location was based on the following criteria:

1. Ease of introducing torque and thrust to the shaft and its ability to transmit the necessary power.

2. The minimum bend radius imposed upon the shaft.

3. Problems associated with stowage of the flexible shaft when fully withdrawn and during tramming of the vehicle.

4. Space restrictions associated with drive head locations and feasibility of meeting these restrictions.

\subsubsection{In-Hole Location}

This concept is identified as configuration $B_{2}$ in Figure 10 . Figure 12 provides more detail concerning a method of applying torque and thrust to the drill bit. The concept depends upon utilizing a high-speed air-turbine drive followed by a compact nutating gear-reduction system. In Figure 12, the rotating portion of the drill would contain a gear-reduction system. The air turbine drive would be located beneath this rotating portion with its outer casing stationary. Air for the turbine drive would be transmitted through the inner diameter of the shaft, driving the turbine at 10,000 to 20,000 rpm. Exhaust air from the turbine could be used as a carrier for chip removal. The nutating gear-reduction system would need a reduction ratio of approximately 


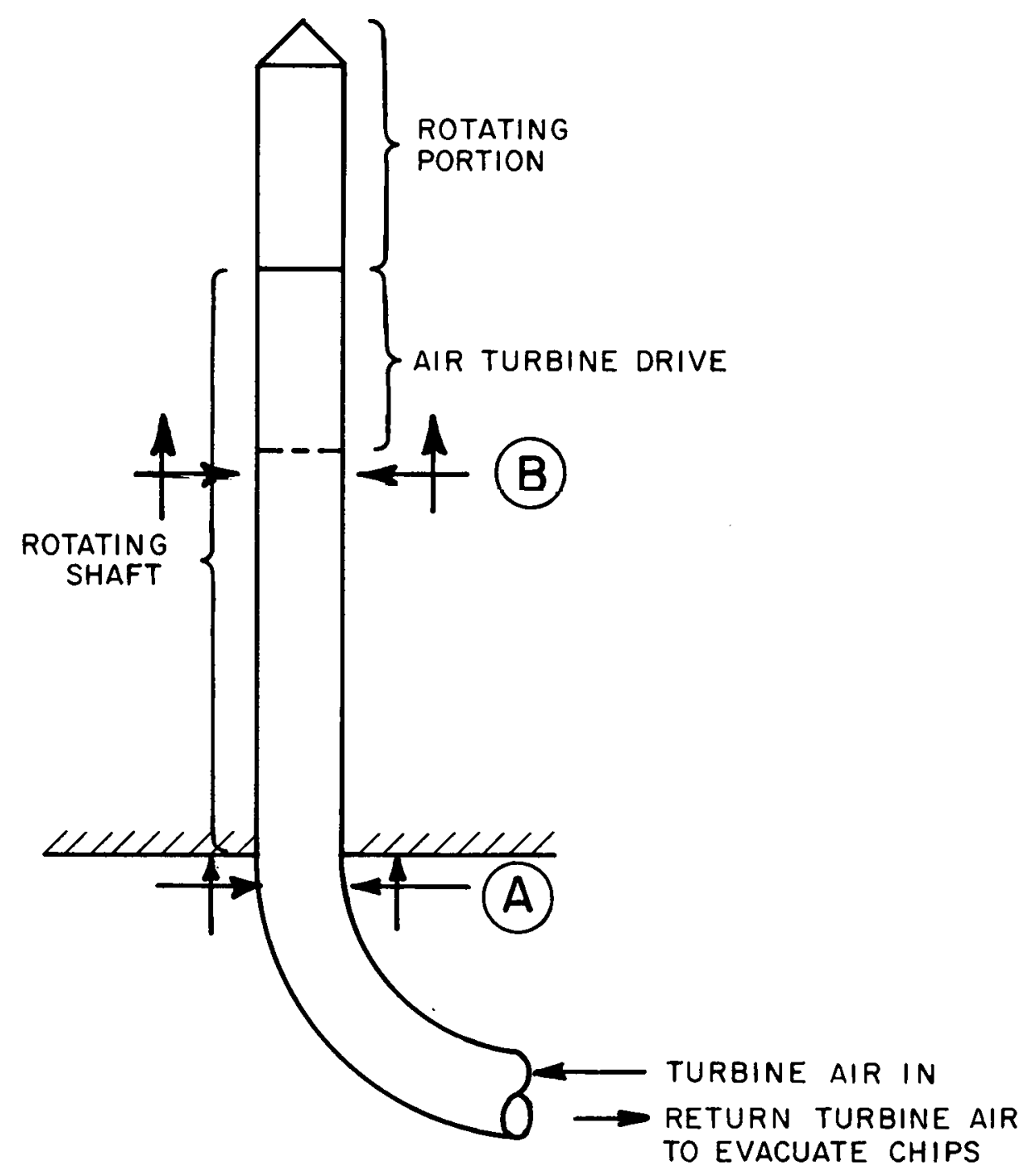

FIGURE 12. IN-HOLE HIGH SPEED AIR TURBINE DRIVE WITH NUTATION GEAR REDUCTION TO CUTTING SPEED 
100:1. Such a gear reducer would have very small teeth with extremely high tooth loads to provide the necessary torque. The flexible gear portion of the nutating gear system could be made long to reduce the high torque tooth loads. However, this configuration would be very difficult to manufacture. The compact requirements for the gear reducer, the high tooth loads, and the manufacturing difficulties are extremely restrictive with this concept.

If these difficulties were overcome, it does not appear that there is any great gain in using this system over others to be discussed. This evaluation is based on the fact that the air turbine drive housing must provide restraining torque and apply thrust equivalent to a specified requirement. This restraint can be provided at two places, identified as A and B in Figure 12 . Providing such a restraint and applying thrust at location $B$ would require an expansion sleeve or similar device which could be anchored in the bore hole. This expansion sleeve must be capable of sustaining the full thrusting force introduced hydraulically within the shaft. A mechanism suitable for this purpose is not readily available. This concept has introduced many complexities, making its feasibility doubtful. If a hydraulic mechanism that could clamp the shaft and introduce an inching upward thrust motion were available, the inner diameter of the shaft would need to be large enough to carry a compressed-air line and two hydraulic lines for the thrusting mechanism. There would not be sufficient space within a 1-3/8-in.-diameter hole to achieve these purposes.

Restraint for torque and application of thrust could be placed at location $A$, as shown in Figure 12. No advantage is gained over alternate systems since a non-rotating shaft between the roof of the mine and the air turbine needs to be strong enough to transmit drilling torque and thrust. If a shaft could be made which can sustain these torque and thrust loads over this portion, it does not appear practical to develop or find a turbine drive-nutating gear system for in-hole application of the required rotation speed for drilling.

\subsubsection{Location in Vehicle}

Location of the drive head in the mine vehicle is shown as configuration $B_{1}$ in Figure 9. It would be a conventional-type drill head providing rotational speed and torque via a hydraulic motor. The drive head could be moved horizontally along the vehicle to provide the thrust and feed motion. The development of such a drive head should present very few problems. 
A critical consideration for this drive head location is the loading of the shaft between the drive head and the mine roof. Between these two points, substantial torque and thrust must be transmitted by the shaft around the radius of curvature, $R_{c}$. In order to transmit this thrust, a rigid retainer tube is needed to restrain the shaft, and guide rollers are needed to reduce friction losses within the tube. Appendix $C$ develops a relationship for the required restraint forces. These restraint forces, coupled with the required transmission of torque and thrust through this radius, would create severe stress problems. Restraint forces would create circumferential pressures causing wear on a flexible shaft or its restraint rollers. To minimize shaft wear, extensive lubrication would be required.

In summary, the drive head located at the vehicle would be of conventional design, but would require an extensive mounting system. To drill an 8ft-deep hole, the drive head would need to travel at least $8 \mathrm{ft}$ during its feed stroke. This could present stowage problems in adapting this drill to an existing vehicle. This configuration appears undesirable in view of design difficulties in the drill bend area and stowage problems within the vehicle.

\subsubsection{Location on Mine Roof}

Configurations $\mathrm{A}$ and $\mathrm{B}_{3}$ shown in Figures 9 and 10, respectively, indicate variations of this roof location. The roof location has the advantage of loading only the portion of the drill shaft within the hole. However, this advantage is offset by the requirement that torque and thrust must be introduced to a shaft passing through the drive head. A drive head having a stationary housing must be able to introduce the rotation and feed motion in a limited space near the mine roof. This problem was given much attention during Phase I.

Space restrictions associated with this drive head location were not as severe as the in-hole configuration; however, early analysis of the situation showed that the vertical height of the drive head could not be too large. This restriction is more precisely shown in Drawing 1331-74-06-1 (App. K-8). Here the Fletcher LTDO is shown in a 30-in. coal seam. Approximate height allowed for the drive head is shown for a 14-in. maximum bend radius on the flexible shaft. The result is a height restriction of $16 \mathrm{in}$. The starter section should not be longer than the height of the drive head. Therefore, the maximum starter length is 16 in. 
This roof location is more favorable than other locations for three of the four specified location criteria. The vehicle location provides an easier way of introducing torque and thrust but lacks ability to transmit it through the radius of curvature. The conclusion was to concentrate future effort on the roof location configuration. 
Figure 13 shows the two basic choices considered for flexible shafts.

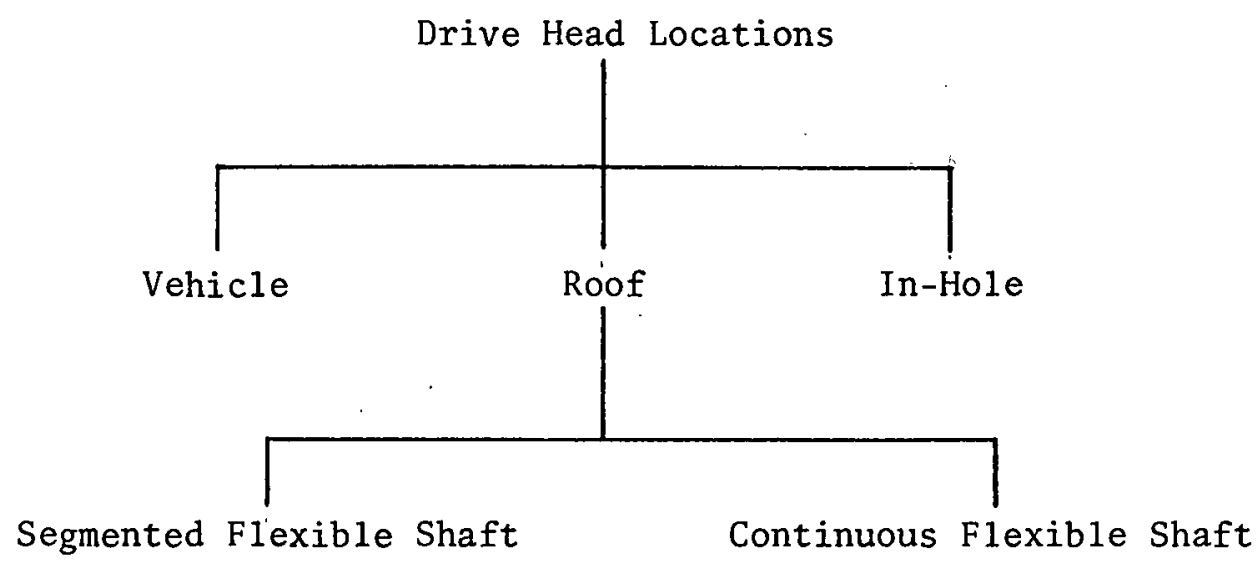

Figure 13. F1exible Shaft Alternatives

The distinction between these two basic types of flexible shafts is illustrated by the following two definitions:

a. A segmental flexible shaft consists of short, rigid sections strung like beads over an inner chip-return line and linked together by appropriate interfacial restraints. The interface between segments has a locking geometry such that the required amount of torque can be transmitted from segment to segment.

b. A continuous flexible shaft is fabricated from materials woven or braided together. This term could also apply to shafts made from a continuous strip of material which is coiled in a manner resulting in a rigid coupling under certain types of torsion loading.

A general discussion of these types of flexible shafts has been presented by McIlvanie. ${ }^{1}$ Woven or braided construction of a continuous flexible shaft is characteristic of commercial stranded-wire types widely used for mechanical power transmission and control purposes. A solid one-in.-diameter shaft operating at $600 \mathrm{rpm}$ in a straight line has a maximum dynamic torque capacity of 700 in.-lb. This is much less than required torque capacity, and such a shaft has no provision for the return of cutting chips through a center orifice. It would appear difficult to design a shaft utilizing this basic form of construction that would be able to transmit the necessary torque and thrust loads.

Continuous shafts called "coiled spring shafts" are shown in Figures 14 and 15. The shaft shown in Figure 14 winds up on itself when torque is 


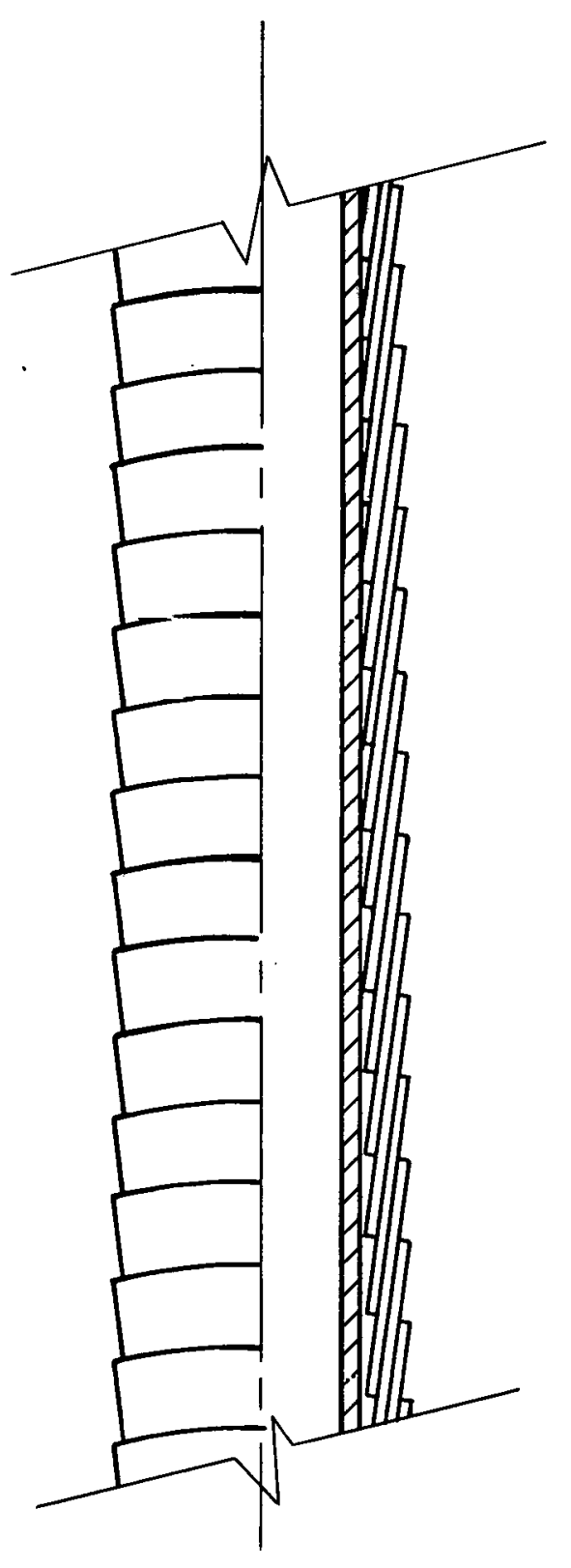

FIG. 14 - VOLUTE SPRING TYPE FLEXIBLE SHAFT

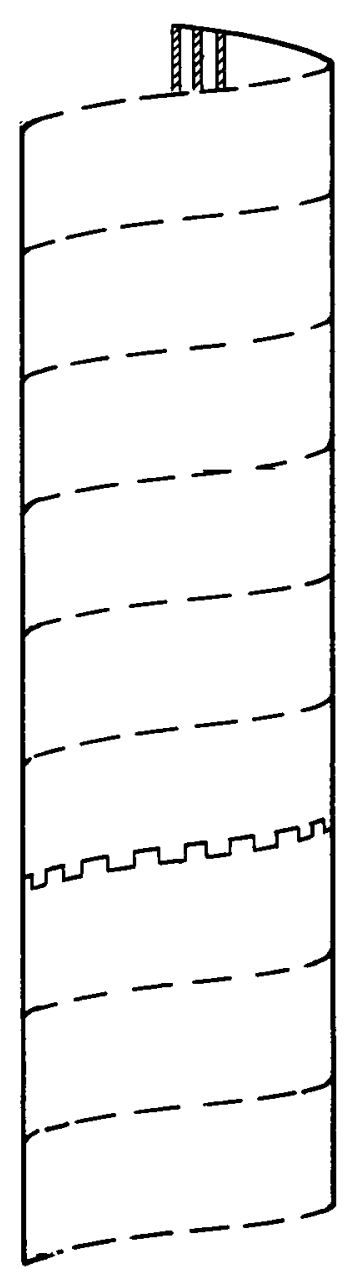

FIG. 15-HELICALLY WOUND TYPE FLEXIBLE SHAFT 
applied, causing it to be partially rigid and capable of transmitting a column thrust load into the drill hole. The second type, shown in Figure 15, consists of several helically wound strip-steel springs using serrated edges for torque transmission.

Both shaft types would be difficult to grasp at the drive head to apply the required torque and thrust. A more severe problem is the high maintenance cost for a shaft of this type. If the shaft were broken due to overload or mishandling, the entire shaft would have to be scrapped. It is doubtful that satisfactory repair of material such as this could be made, whereas a segmental shaft has the advantage that a broken segment can be removed and replaced. McIlvanie's findings, combined with a re-evaluation of the differences between segmental and continuous shafts, resulted in the conclusions that a segmental shaft is the most feasible.

\subsubsection{Characterization of Segmental Flexible-Shaft Systems}

Basic characteristics of a segmental flexible-shaft system are shown in Figures 16 and 17 . Figure 16 shows a drive head located at the mine roof with the segmental flexible shaft running through it and curving from vertical to horizontal in an arc beneath the drive head. This segmented flexible shaft consists of short tubular segments strung over a chip-return line. The shaft would extend back to the mine vehicle and be stowed within a retainer tube. The flexible-shaft system can be characterized as shown in Figure 18 in terms of (1) tubular segments; (2) drive head configuration, (3) chip-return system, and (4) stowage characteristics. The following sections of this report will develop each of these characteristics more thoroughly.

\subsubsection{Tubular Segment Variations}

One of the primary characteristics of tubular segments is the way they provide interfacial restraint. If restraint of tension loads exists, in which case the segment transmits tension across the interface, or, if no restraint of longitudinal tensile loads exists, the segments are capable of transmitting only torsional and compressive loads. Need for this distinction is necessary when considering some requirements of a flexible shaft. The shaft must be withdrawn from the hole at a rate of $40 \mathrm{ft} / \mathrm{min}$. This withdrawal motion could be obtained by pulling on the end of the shaft attached to the vehicle. If the shaft can withstand tension loading, the withdrawal force could be applied 


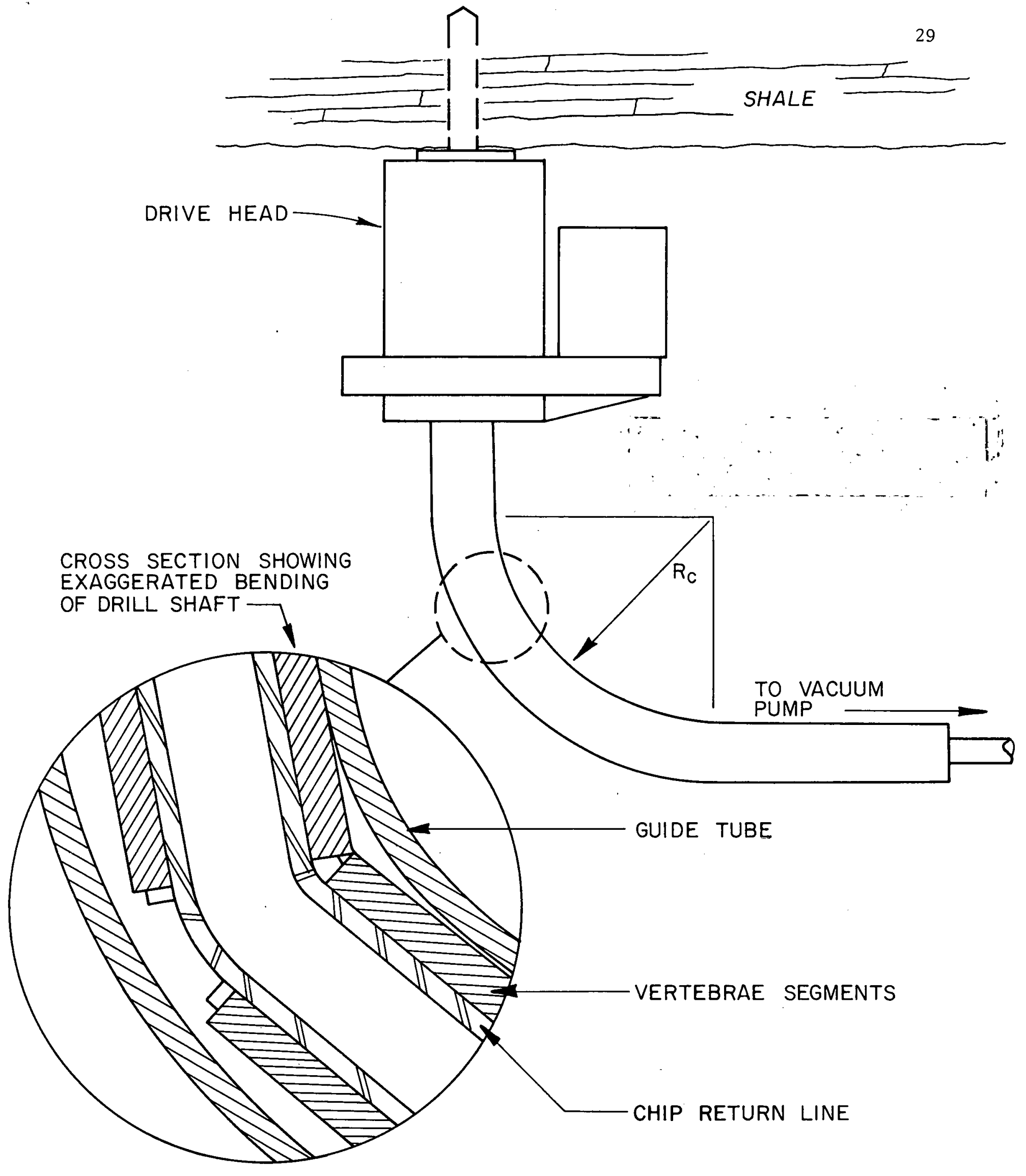

FIGURE 16 - CURVATURE DEVELOPMENT MECHANISM FOR SEGMENTAL DRILL STEM 


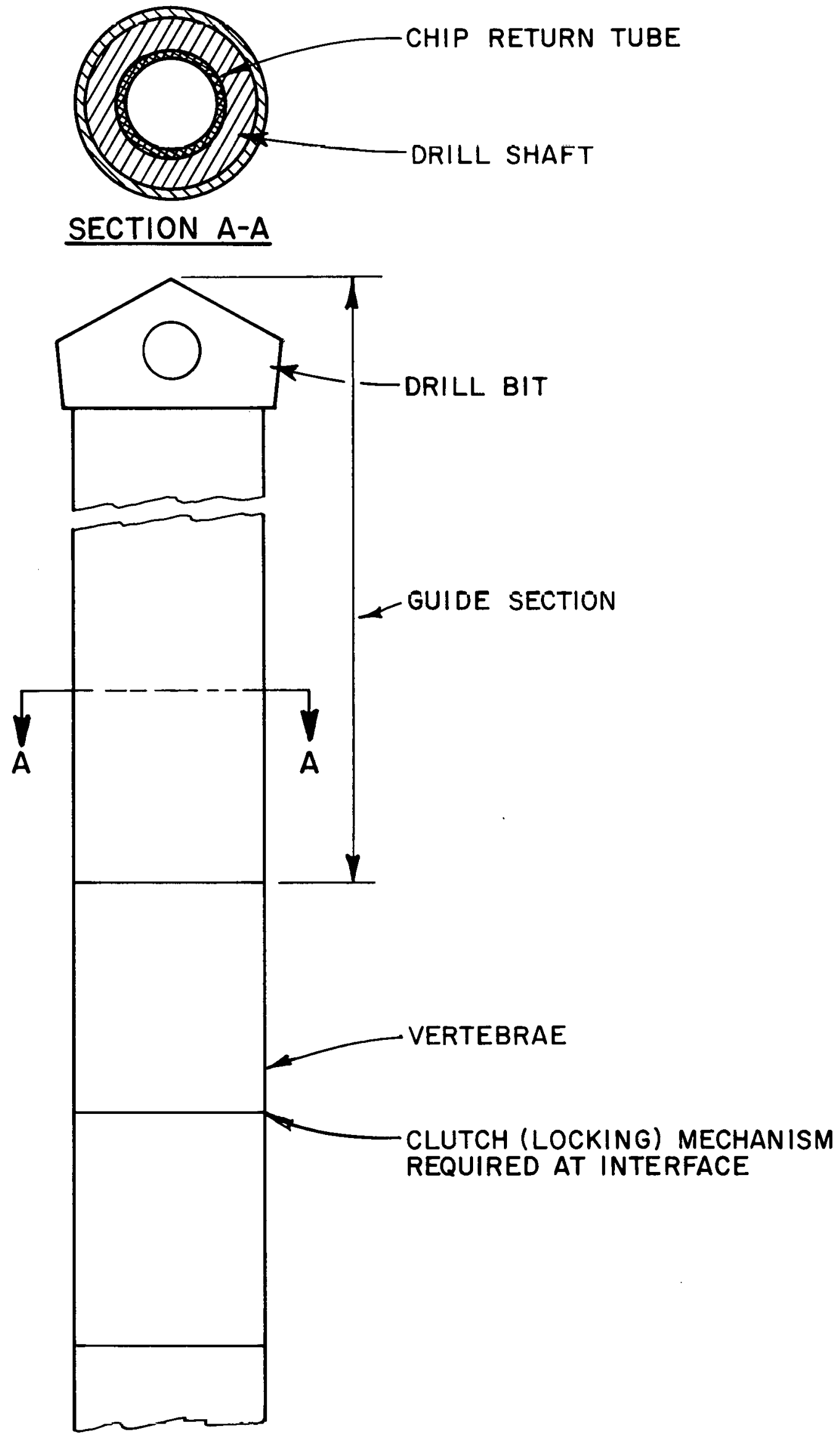

FIGURE I7-VERTEBRAE DRILL SHAFT AND GUIDE SECTION 
Drive Head Locations

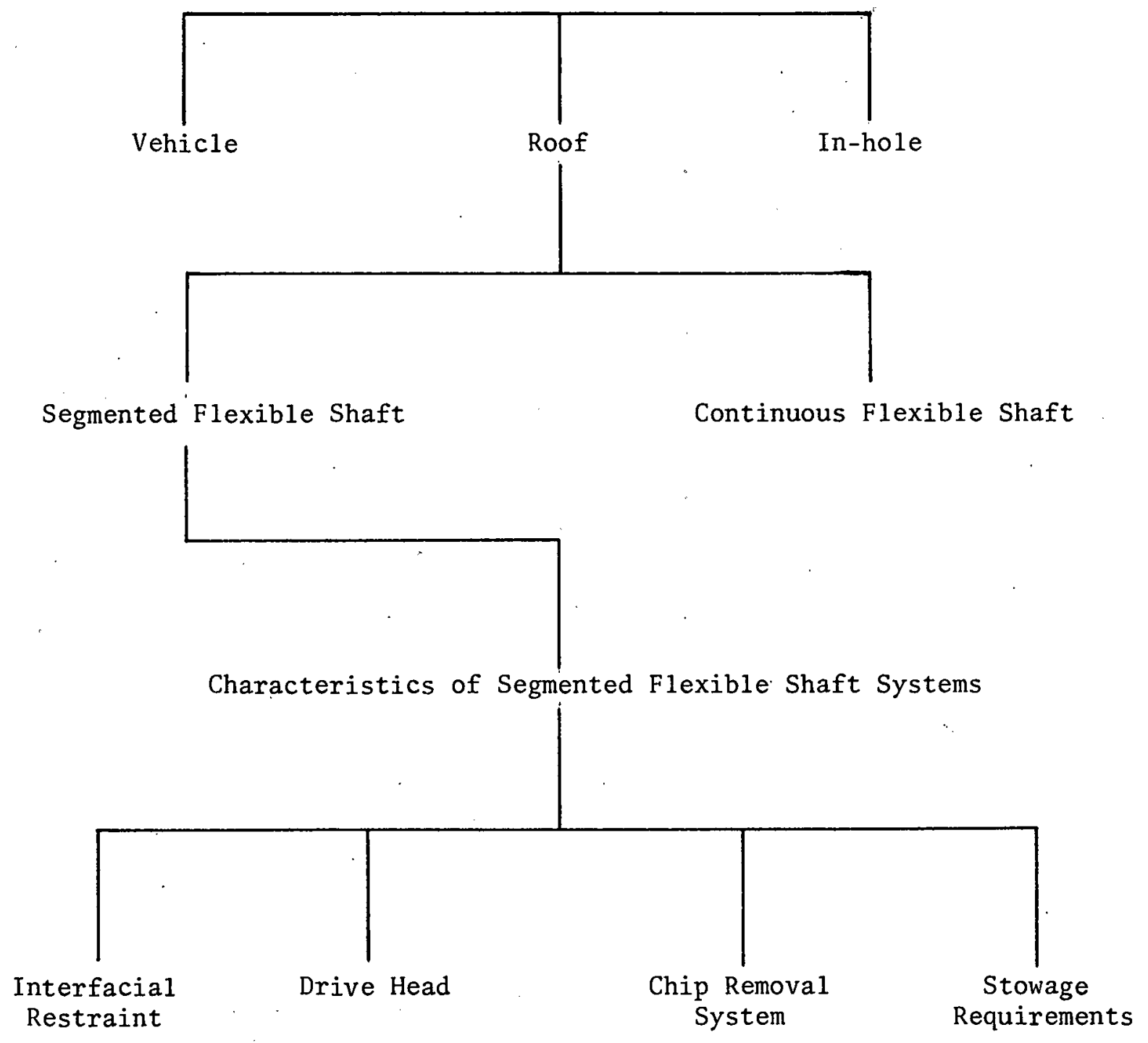

Figure 18. Characteristics of Segmental Shaft Systems. 
to the segments. With no tension restraint, another means of withdrawing the segments must be provided. One option is to pull on the inner chip-return line, which would be securely fastened at the other end to the starter section. The effect would be the same as pulling on the string of a long section of beads.

The type of interfacial restraint also affects the minimum radius of curvature possible for a particular flexible shaft. Most restraint devices limit the flexibility of the shaft. However, this problem was not as restrictive as previously thought, and restraint methods were developed which did result in acceptable curvatures.

Another criterion to consider when evaluating types of interfacial restraint is the shaft's ability to be withdrawn when the bit sticks. One method of accomplishing this is to reverse the torque on the drill and pull hard to remove the drill string. If the removal method consists of pulling on the chip-return line, the maximum withdrawal force would be limited by the strength of the chip-return tubing. It will be demonstrated later that space restrictions limit the robustness of this tube and reduce its strength in tension. Positive interfacial restraints generally sustain a greater withdrawal force. McIlvanie investigated a design in which there was no interfacial restraint for tension loads. Appendix D presents some of the results of this work.

At the beginning of the research it was recognized that an interfacial restraint method would be advantageous. The search for a better flexible shaft segment was directed toward concepts utilizing some sort of interfacial restraint.

\subsubsection{Interfacial Restraint Options}

McIlvanie's studies showed that clutch teeth at the interface could effectively transmit the required torque. He investigated interface conditions involving eight interlocking teeth. Having more teeth allows the shaft to rotate more smoothly; however, it also reduces tooth size and increases the stresses on each tooth. McIlvanie tried to reduce the stress roading by profiling the teeth so as to distribute the load to a greater number of teeth during a misaligned condition. In some cases, these profiled teeth could not transmit a reverse torque. His work did not involve segmental teeth which could be linked together to transmit tension loads. A summary of his analysis is presented in Appendix D. 


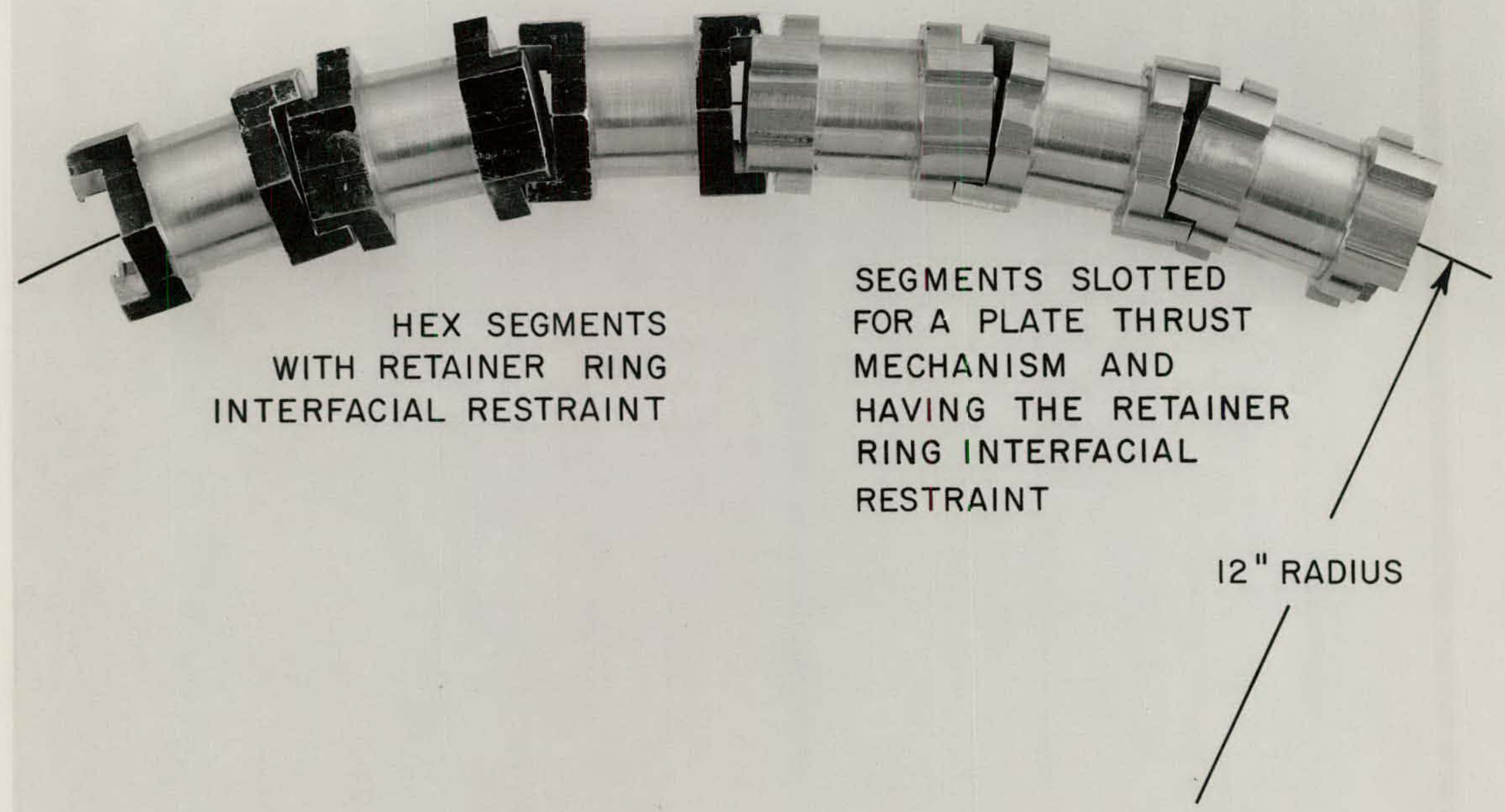

FIGURE 19. SEGMENTS WITH RETAINER RING INTERFACIAL RESTRAINT 
END VIEW
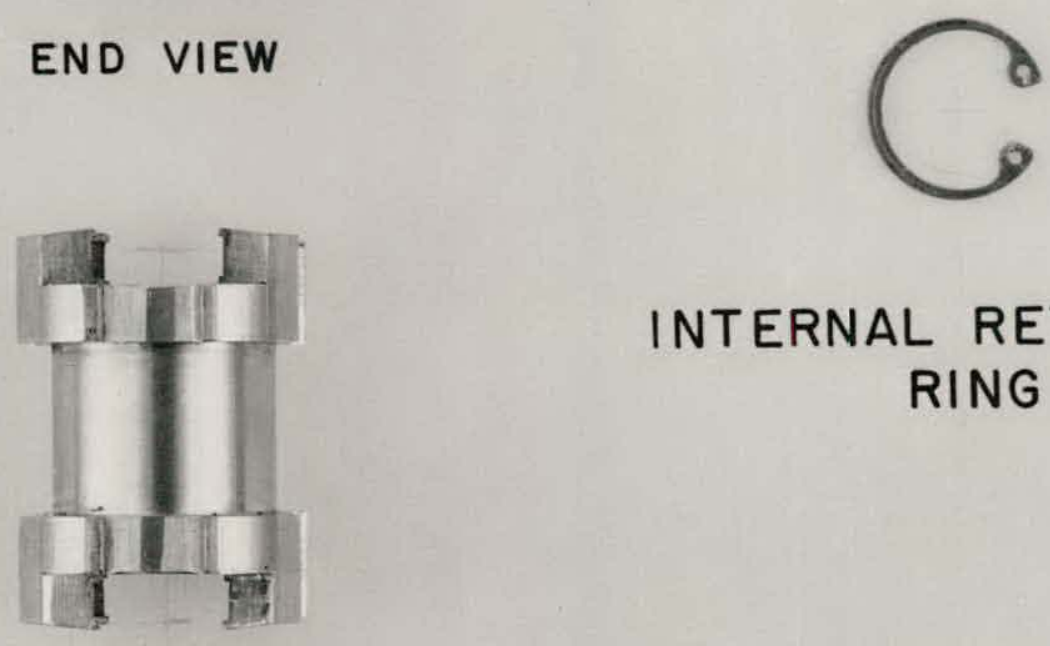

INTERNAL RETAINER

RING

SIDE VIEW

FIGURE 20. SEGMENT DETAIL FOR RETAINER RING INTERFACIAL RESTRAINT 


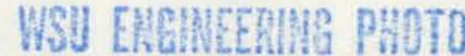

Na. $74194-5 A$ 


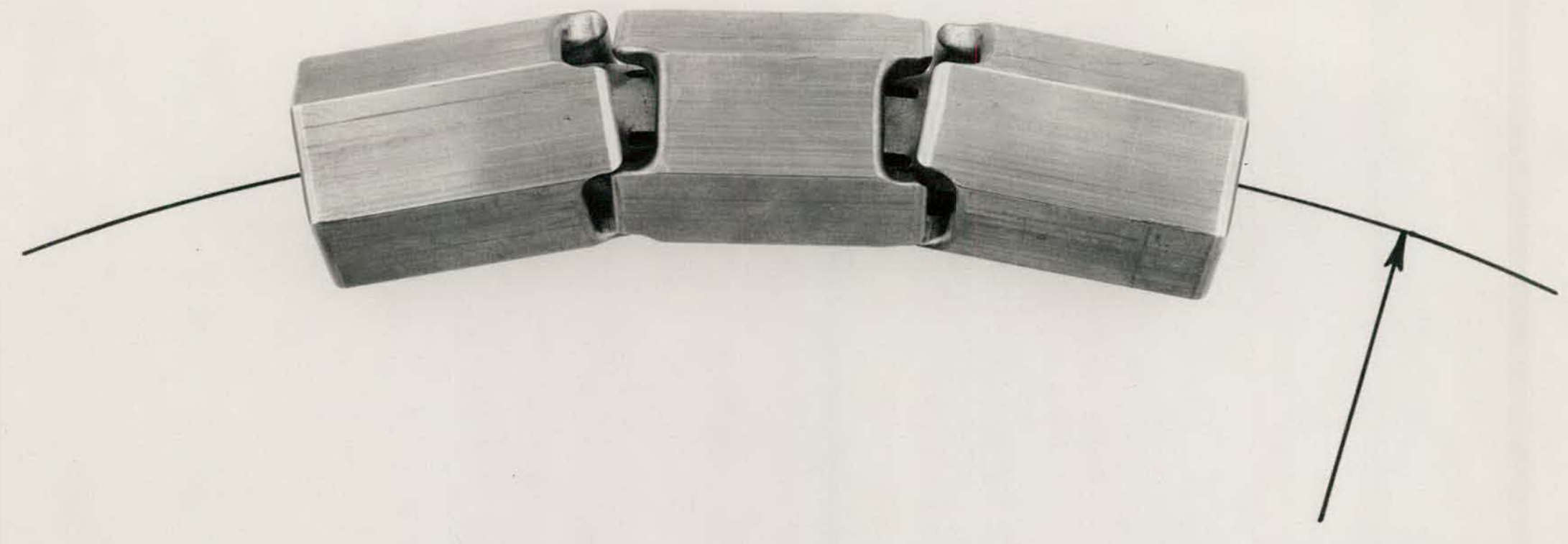

12" RADIUS

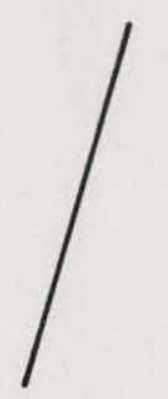

FIGURE 2I. SEGMENTS WITH CYLINDRICAL CLIP INTERFACIAL RESTRAINT 
PHOTO BY

WSU ENGWEEPING PHOTO

n日. $74194-2 A$ 


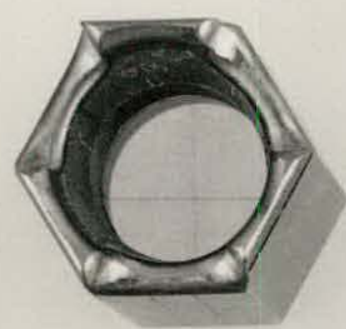

END VIEW

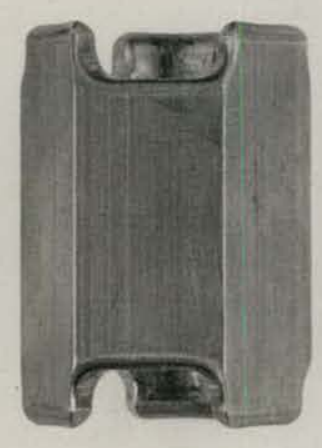

SIDE VIEW SEGMENT

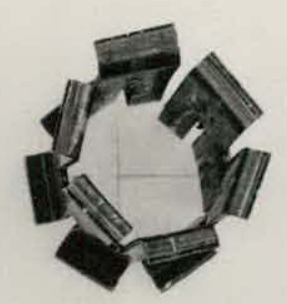

END VIEW

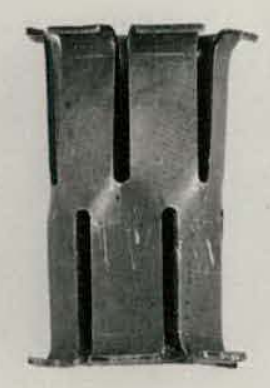

SIDE VIEW INTERNAL CLIP

FIGURE 22. SEGMENT DETAIL FOR CYLINDRICAL CLIP INTERFACIAL RESTRAINT 

The initial approach in investigating the new segmental shaft concepts was to go to the other extreme using a simple prototype made of an interface geometry with two interlocking teeth. This initial prototype used external snap rings to join two segments together. This concept became known as the snap-ring concept and was later developed more completely.

\subsubsection{Snap-Ring Concept}

A snap-ring concept is shown in Figures 19 and 20. The original prototype used external snap rings to link segments together. The prototype shown in Figures 19 and 20 uses an internal snap ring. Details concerning this segmental shaft can be found in Ref. Drawing 1331-74-07-2, Appendix E. The segment could be either circular or hexagonal in cross section and could have a straight or dumbbell profile, as shown in Figures 19 and 20. The type of drivehead used will influence which configuration is required.

The snap ring can withstand adequate tension loading, but a larger bending moment causes the snap ring to pop out of its retaining groove causing the shaft to separate. This separation was experienced with the prototype. Later studies may show that a snap ring could be designed and incorporated which will sustain greater bending loads. Appendix F contains the stress analysis for this concept.

\subsubsection{Cylindrical Clip Concept}

Figures 21,22 , and F-1 show the cylindrical clip developed to provide a greater transmission of tension loads and increased resistance to bending loads. Use of a cylindrical clip requires the tapering of the segment's inner surface, allowing it to curve in the required manner. Tapering of this inner surface had the effect of weakening the connecting clutch teeth, decreasing the wall thickness toward the center of the segment, and requiring a greater amount of machining to achieve segment geometry. Appendix F contains the stress analysis for this segment.

\subsubsection{Elastomeric Connector Concept}

The utilization of a bonded interface to connect drill segments is discussed in Appendix. $\mathrm{H}$. Figure $\mathrm{H}-1$ and $\mathrm{H}-2$ show an elastomer concept that on initial investigation appears to be promising. 
An attractive feature of this concept is that it eliminates the use of an inner chip return line. A properly designed interface connector using a suitable elastomer will seal the interface, preventing leakage in the vacuum return line that passes through the individual segments orifice. Elimination of the chip return line makes it possible to increase wall thickness toward the center of the segment.

Using an elastomer that requires a retaining groove on the segment's inner diameter allows for placing this retaining groove $3 / 8$ in. or more from the top of the interlocking teeth, removing it from the highly loaded teeth. This effectively provides stronger teeth for transmitting torque from segment to segment.

Use of elastomeric connectors could result in a flexible shaft which rotates around the curvature in a smoother fashion. The elastomer may provide restraint on the segments as they separate while bending. Such restraint will prevent some clatter at the segment interface, providing smoother operation. The elastomer connector tends to hold the drill segments together and should aid in attaining a vertically straight hole.

A 12-in. radius of curvature would require a 30 percent elongation of the elastomer. There are a vast number of elastomers with at least a 30 percent elongation factor which could suit the purposes of this concept. Desirable characteristics of the elastomer are that it should have a high durometer rating, be resistant to abrasion and oil, and be non-reactant with any metal used. The high durometer rating is necessary to prevent excessive stretching when a withdrawal force is applied to the drill string segments. Too much flexibility would result in the drill string having rubber-band characteristics. An elastomer connector capable of being inserted into a retaining groove by hand would be desirable. This would allow mine maintenance personnel to replace worn-out or broken drill string segments more easily. An adhesive bonding between the elastomer and the metal segment may be necessary.

\subsubsection{Tensile Wire Concept}

Use of tensile wire as a connector was developed to eliminate the complications associated with manufacturing snap rings and cylindrical clips. This type of segment would use no special connective device at its interface. It sould be patterned after the segments developed by McIlvanie using fewer teeth increasing the torque transmission capabilities of each segment. A long wire 
(piano or braided) has been added which runs through the center of the chip return line. This wire is connected to the straight starter section at the cutting end of the drill string and to a retaining cap at the vehicle, providing a spring load to the segments. Spring loading provides a positive compressive load along the length of the drill string, inhibiting the separation of the segments as they bend. The wire provides a positive method of applying withdrawal force through the center of the chip return line to the starter section. A wire running through the center of the drill string could help scour the chip return line, preventing it from clogging during drilling. The presence of such a wire may cause some abrasion, but the cleaning advantages probably outweigh any increased wear problems.

\subsubsection{Curvature Relationships for Segmental Shafts}

A11 the segmented shafts proposed in this phase of the project have the capability of meeting the necessary curvature requirements. Figure 23 shows the geometric relationships governing curvature. These curvature relationships are based on geometric formulas that apply to a regular polygon circumscribed about a circle. The diameter of the segment, $D$, the length of the segment, $L$, and the tooth height, $t$, are the important dimensions in determining the curvature radius of a drill string. The radius of the curvature can be calculated by solving the equations:

$$
R=\frac{L}{2 \tan \alpha}+\frac{D}{2} \quad \text { and } \quad \sin \alpha=\frac{t}{2 D}
$$

These formulas do not include parameters related to the method of interlocking the segment interface. When a snap ring is used, the radius of curvature is also determined by the snap ring thickness, the width of its retainer groove, in addition to dimensions $\mathrm{L}$ and $\mathrm{D}$ (see Appendix E). A theoretical radius of approximately 9 in. is possible for a segment $11 / 2$ in. long, $13 / 8$ in. diameter, with a tooth height of $1 / 4$ in. The actual design concepts are based on a centerline radius of $12 \mathrm{in.}$ to prevent excessive strain on the drill segments. 


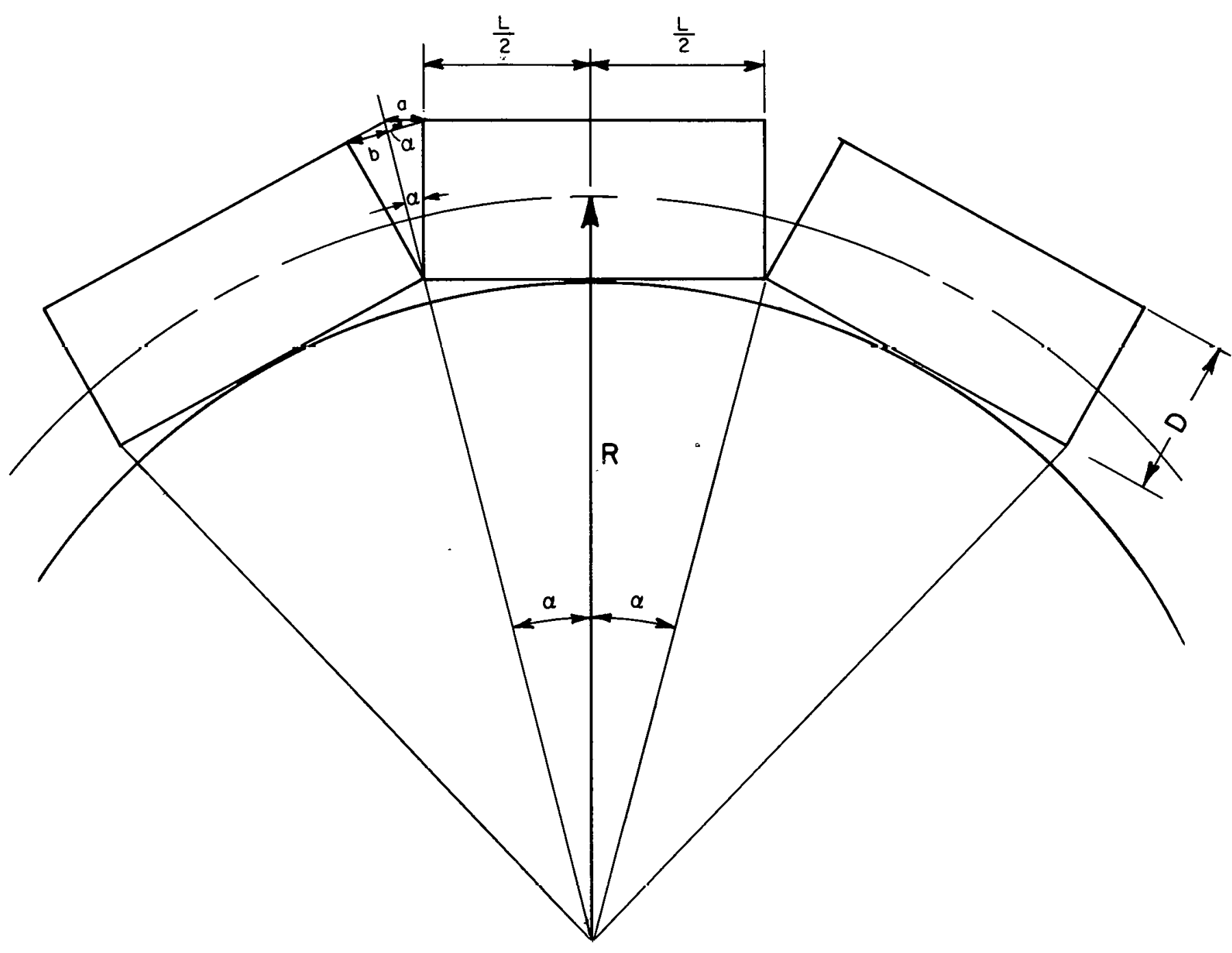

FIGURE 23. GEOMETRIC RELATIONSHIP FOR SEGMENTS ON A CURVE 
5.5.0 Comparative Cost Estimate--Segmented Flexible

Shaft vs. Traditional Drill Steel

The snap-ring-connected shaft segment is used in this comparative cost study. As shown in Fig. E-2, this shaft segment uses the dumbbe11 configuration discussed earlier in this phase of the research. Basing this cost comparison on the snap ring design will provide a conservative estimate, though some of the other concepts in phase I would be easier to manufacture.

This estimate is based on machining the segments from annealed 1 1/4-in. AISI 4340 bar stock. After machining, the segments will be oil-quenched from $1500^{\circ} \mathrm{F}$ and tempered at $1000^{\circ} \mathrm{F}$.

The estimate assumes the segments will be machined using:

-A turret lathe at a minimum charge of $\$ 15 / \mathrm{hr}$ ( $\$ 6$ for 1 abor, $11 \%$ for benefits and $150 \%$ overhead).

- A vertical end mill with indexing feature at the same charge rate.

A turret lathe could drill the center hole, turn the shoulder diameter, machine the snap ring groove, bevel the ends of the segment, break the corners of the hex to final diameter, and cut off the part. The vertical mill could cut the square teeth using three cuts per end, resulting in a segment having three interlocking teeth. All operations were estimated at reasonable cutting feeds and speeds for a total machine time per piece of $0.25 \mathrm{hr}$. Total cost per segment is as follows:

\begin{tabular}{lr} 
Machine cost, $0.25 \times \$ 15 / \mathrm{hr}$ & $\$ 3.75$ \\
Materiał cost (including heat treatment) & .25 \\
Assembly cost (with tubing) & .25 \\
\hline Total cost per segment & $\$ 4.25$
\end{tabular}

Using traditional drill steel with a 4-ft starter section and two 2 -ft extensions to drill an 8-ft hole would cost $\$ 41$. Estimated work life of such drill steel is 250 holes.

A snap-ring-interconnected shaft drill would contain 111 of the 1-1/2-in.long segments, costing $\$ 472.00 .(111 \times 4.25=\$ 472.00)$. Such a dril1 string manufactured of AISI 4340 steel has an estimated work life of greater than $10^{6}$ cycles. It will be assumed that the flexible shaft will be replaced every $10^{6}$ cycles. An average of $1.7 \mathrm{~min}$ at $250 \mathrm{rpm}$ is required to drill each hole. This would be the equivalent of 425 cycles per hole or 2300 holes in $10^{6}$ cycles.

Assuming some segments will wear out or fail--it could be anticipated that as many as 25 percent of the drill string segments may be replaced before 
2300 holes are drilled. Based on this replacement rate, the cost at $\$ 5.00$ per segment would be $\$ 139.00$ (111 x $0.25 \times \$ 5.00=\$ 139.00)$.

A cost credit for the flexible shaft drill is represented by the time normally required to change the traditional drill steel. Time study data gathered for this report indicate the average time required to change drill steel is 0.4 min per hole. Per-hour operating costs for the bolter of $\$ 12.50$ include labor, benefits, and overhead costs. For a 4-min drilling period this amounts to $\$ 192.00(0.4 / 60 \times 2300 \times \$ 12.50=\$ 192.00)$.

\footnotetext{
Cost

4340 Steel Segmented Drill

Initial cost

Segment replacement costs

$\$ 472.00$

SUBTOTAL $\$ \frac{139.00}{\$ 611.00}$

Cost credit for time savings

SUBTOTAL $\quad \frac{-192.00}{\$ 419.00}$

Cost of standby flexible drill

$\$ 472.00$

TOTAL cost for 2300 holes

$\$ 891.00$

Traditiona1 Drill Steel
Equivalent cost for 2300 holes $(2300 / 250 \times \$ 41)$
$\$ 377.00$
Total cost differential for 2300 holes
$\$ 514.00$

A segmented shaft drill would cost $\$ 514.00$ more to operate than using a traditional steel drill over a 2300-hole drilling life. This equals a $\$ 0.22-$ per-hole increase in cost with the segmented shaft. An additional time saving of $1.06 \mathrm{~min}(0.22 / 12 ; 50 \times 60=1.06 \mathrm{~min})$ must be realized to make the segmented shaft.cost-equivalent with the traditional system.

Use of the flexible shaft drill with the bolt bender/inserter could achieve such a time savings. If it were possible to insert and tighten the roof bolt while drilling;, a time saving of $0.7 \mathrm{~min}$ per hole could be realized. The more automated system would be less likely to experience delays because of human involvement, thus creating additional time savings.
} 


\subsubsection{Function and Strength Comparisons of Segmental Shaft Options}

Functional characteristics of each segmental shaft option have been discussed. Table 2 has been prepared to summarize this discussion. This table compares each concept with regard to its ability both to transmit reverse torque and tension loading from segment to segment, and to fulfill the requirements of each segment regarding a chip return line. Each segment must have the ability to transmit reverse torque in order to dislodge the shaft when it becomes stuck. Segment concepts not requiring an inner chip return tube would allow increased wall thickness and be capable of transmitting greater loads. The elastomeric connector as presented in Table 2 has the best characteristics, but a number of its unknown characteristics should be investigated.

Snap-ring, cylindrical-clip and tension-wire connectors all compare favorably with the elastomeric type. Of these, the cylindrical clip would be the most difficult to manufacture. The fact that the tensile-wire concept provides no means to transmit a tensionload from segment to segment is not serious since the inner wire itself provides withdrawal force for removing the drill string from the hole. McIlvanie's concepts except for one (Type 2a) cannot transmit reverse torque. All of his concepts have more teeth; which assures the shaft will run more smoothly; however, later investigations show that this does sacrifice strength.

Table 3 compares the strength of the spiral, cylindrical-clip, involute, rounded, and snap-ring concepts. The spiral-tooth concept is McIlvanie's Type 2e.. The involute and rounded connectors are variations of the snap ring and cylindrical clip connectors with teeth changed to involute and circular tooth profiles. Note that the stress analysis for the elastomeric and tension wire connectors is not included. Because neither of these connectors has a retaining ring groove machined on the inner diameter of their clutch teeth, they would have strengths equal to or greater than the snap-ring concept. This make the tooth stronger by eliminating stress concentration in the teeth.

According to stresses calculated, SAE 4340 material should be used to obtain a satisfactory fatigue life. Results in Table 3 must be evaluated in terms of loading conditions assumed for analysis and the probability that such conditions could exist for extended time periods during drilling. It is assumed that the segments would always be misaligned. Except for the spiral shaft, a single tooth then must carry the entire torque and thrust loads. The teeth are thus cyclically loaded to peak value because the shaft is rotating in a loaded condition. 
TABLE 2

Functional Comparison of Segmental Shaft Concepts

\begin{tabular}{lccc}
\hline Type & $\begin{array}{c}\text { Transmits } \\
\text { Reverse Torque }\end{array}$ & $\begin{array}{c}\text { Segment-to-Segment } \\
\text { Tension Loading }\end{array}$ & $\begin{array}{c}\text { Chip Return } \\
\text { Tube Required }\end{array}$ \\
\hline McIlvanie & & & \\
Type 2a & Yes & No & Yes \\
Type 2b & No & No & Yes \\
Type 2c & No & No & Yes \\
Snap Ring & Yes & Yes & Yes \\
Cylindrical C1ip & Yes & Yes & Yes \\
Elastomeric & Yes & Yes & No \\
Tension Wire & Yes & Yes & Yes \\
\hline
\end{tabular}


TABLE 3

Strength Comparison of Segmental Shaft Concepts

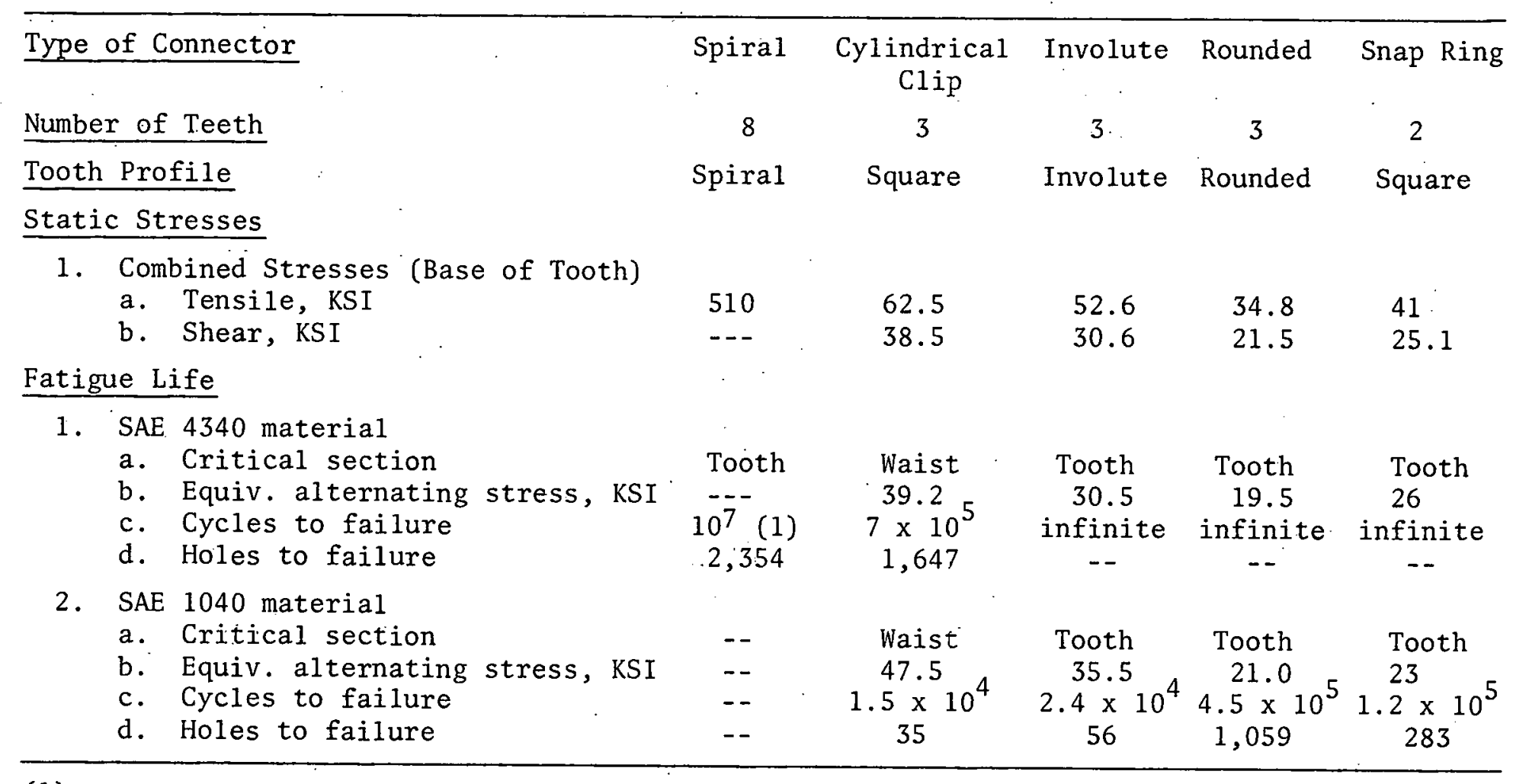

(1) Requires 3 of the 8 teeth to be carrying the load. 
The thrust and torque levels used for this design are perhaps high for most drilling conditions. The severe load conditions assumed in this fatigue analysis probably would not be experienced on a continuous basis.

Table 3 shows the involute, rounded, and snap-ring concepts have favorable fatigue lives. The spiral tooth and cylindrical clip connector would also be satisfactory; however, both these concepts require more intricate manufacturing techniques. The involute and rounded profiles are more easily manufactured. If the square tooth profile can be used without excessive noise, wear, or erratic dynamic behavior, it is the simplest profile to manufacture and it has satisfactory stress characteristics. 


\subsubsection{DRIVE HEAD ANALYSIS}

The direction of the team's drive head analysis was dependent on the type of segmental shaft selected. Fortunately, all of the segmental shaft concepts could be used with minor modifications for the types of driveheads investigated. Módifications necessary for adaptation to particular driveheads were related to the exterior geometry of the segment. Any alteration required was dependent on how the torque and thrust were to be applied to the shaft segment. To guide the design process, the following four considerations were given primary importance:

1. Avoid rotating hydraulic seals.

2. Provide a method for applying torque and thrust loads so that the feed motion is continuous.

3. Do not let the drivehead extend more than 16 in. below the mine roof.

4. Design the drivehead to minimize dirt contamination.

Table 4 is a functional comparison of the drivehead types that were investigated. Before discussing each of these in detail, some definitions of terms used in the table will be given. These definitions may also clarify some of the above-listed design considerations.

1. A reciprocating drive introduces the drive motion via a thrust mechanism that moves upward to apply the thrust force and then retracts back to a starting location. If the drive motion is continuous, two thrusters must alternate so that there is no appreciabłe time span in which the upward motion ceases.

2. A friction drive must have a mechanism to apply a normal load to the sides of the shaft segments. This normal load should be high enough to generate the required thrust force through friction forces.

3. The pawl-and-ratchet drive developed by McIlvanie is redescribed in detail in Appendix I.

4. A hex-collar torque mechanism is used to rotate the segmental shaft. The segments must be hexagonal so the hex collar will grasp them : $:$. like a box-head wrench.

5. The pin-in-slot drive mechanism used in McIlvanie's design would be an acceptable way of driving circular shaft segments. It consists of a pin:inserted in a slot through the side of the segment which transmits torque and thrust to the segment. 
TABLE 4

Function Comparison of Driveheads

\begin{tabular}{|c|c|c|c|c|c|c|}
\hline \multirow[b]{2}{*}{ Type } & \multicolumn{2}{|c|}{ Drive Mechanism } & \multirow{2}{*}{$\begin{array}{l}\text { Actuation of } \\
\text { Thrust Motion }\end{array}$} & \multirow{2}{*}{$\begin{array}{l}\text { Rotating } \\
\text { Seals }\end{array}$} & \multirow{2}{*}{$\begin{array}{l}\text { Source for } \\
\text { Thrust Force }\end{array}$} & \multirow{2}{*}{$\begin{array}{l}\text { Thrust Sequence } \\
\text { Control }\end{array}$} \\
\hline & Torque & Thrust & & & & \\
\hline $\begin{array}{l}\text { 1. Reciprocating } \\
\text { Hydraulic }\end{array}$ & Hex collar & Hyd. cylinder & Yoke thrusters & $\begin{array}{l}\text { Pneumatic for } \\
\text { yoke actuating } \\
\text { cylinders }\end{array}$ & Hyd. pressure & $\begin{array}{l}\text { Programmed snap- } \\
\text { acting penumatic } \\
\text { pilot valves }\end{array}$ \\
\hline $\begin{array}{l}\text { 2. Reciprocating } \\
\text { Cam Action }\end{array}$ & Hex collar & Cam surface & Yoke thrusters & None & $\begin{array}{l}\text { Differential } \\
\text { drive }\end{array}$ & Cam surface \\
\hline $\begin{array}{l}\text { 3. Reciprocating } \\
\text { Friction }\end{array}$ & Hex collar & Eccentric & Friction pads & None & $\begin{array}{l}\text { Differential } \\
\text { drive }\end{array}$ & Flip-up latch \\
\hline $\begin{array}{l}\text { 4. Continuous } \\
\text { Friction }\end{array}$ & Hex collar & Chain & Friction pads & None & $\begin{array}{l}\text { Differential } \\
\text { drive }\end{array}$ & Not applicable \\
\hline $\begin{array}{l}\text { 5. Pawl-and - } \\
\text { Ratchet }\end{array}$ & Pin in slot & Hyd. cylinder & Pin in slot & $\begin{array}{l}\text { Hydraulic to } \\
\text { thrust cyl- } \\
\text { inder }\end{array}$ & Hyd. pressure & $\begin{array}{l}\text { Mechanical link- } \\
\text { ages for inter- } \\
\text { mittent applica- } \\
\text { tion of thrust }\end{array}$ \\
\hline
\end{tabular}


6. A hydraulic cylinder mechanism is a double-acting hydraulic cylinder that provides thrust motion by cyclic extension and retraction.

7. A cam surface drive mechanism provides upward thrust through a cam roller moving up and down on the cam surface.

8. An eccentric drive mechanism provides upward thrust motion through the action of a rotating cam shaft with the required throw to give a feed motion.

9. A chain drive mechanism consists of standard chain and sprockets with the chain carrying the thrust-actuating device upward in a continuous manner.

10. Yoke thrusters are actuating devices that move into and around the waist of shaft segments. Yoke thrusters require segments with a "dumbbe11" profile that provides a shoulder for the yoke to push against to transmit thrust force to the shaft segment.

11. Friction-pad actuating devices are flat pads forced against the sides of the shaft segments by a large normal force. This normal force introduces thrust via friction forces at the interface between the pad and the segment.

12. A differential drive method of introducing thrust avoids the use of a rotating seal. Thrust motion is developed by the difference in the rotation speed of the segmental shaft and a differential gear. Upward thrust motion is proportional to the difference in rotation speed between the segmental shaft and the differential gear.

13. Thrust sequerice control via snap-actuating pneumatic pilot valves requires the upward stroke of the thrust cylinder to actuate the pilot valves in a prescribed sequence. These pilot valves then actuate the appropriate hydraulic and pneumatic valves in the motion sequence required to thrust the segmental shaft.

14. Thrust sequence control by a cam surface is obtained from a cam roller linked to a yoke thruster or pin. The yoke thruster or pin is moved in and out by a roller following the cam surface.

15. Thrust sequence control with a flip-up latch requires a latch mechanism to be available to support a sizeable thrust force when moving in one direction; however, at a predetermined point in its upward stroke or at the top when it reverses its direction of travel, the latch flips freely upward and away from the shaft segment, preventing interference during its return stroke to the starting position for the next cycle. 
Four of the driveheads presented in Table 4 use hex collars to apply torque to the shaft. Though this appears to be the most convenient method of applying torque; it does introduce an additional thrust load to be accounted for in the drive design. This load results from friction forces generated as the hex segments are pushed up through the hex collar. Torque for the rotation motion is being applied as the hex segments move through the collar, generating normal forces with resultant friction forces. Preliminary lab tests showed this friction force to be less than $1,000 \mathrm{lb}$ : when 3,000 in.-1b of torque is applied to a hex-shaped bar.

To provide realistic guidelines, it was assumed the vehicle used with this flexible-shaft drill would have pump capacities similar to the Fletcher LTDO. This vehicle has a three-section gear pump with 9,12 , and 14 gpm capacities and delivers a working pressure of 2,000 psi.

\subsubsection{Continuous Drives}

Continuous thrust motion can be obtained from chain drives and gear systems. Both methods would use a differential drive to obtain the thrust motion. Mechanically, a continuous drive is less complicated, runs smoother, and presents fewer problems in regard to timing and sequencing.

\subsubsection{Gear Drive Systems}

McIlvanie first investigated two types of gear systems that might be used to drive a segmental flexible shaft drill. The types investigated were the rack-and-pinion drive and pin-gear drive. Figures 24, 25, and 26 illustrate some of the engagement variations for a rack-and-pinion system. This gear drive used gear teeth as pins to engage slots in the side of the shaft segment. In effect, the flexible shaft becomes a gear rack driven by rotating pinions. McIlvanie's analysis showed the radial engagement of the pinion resulted in a contact ratio of less than one, making the design unacceptable. The tangential engagement method resulted in an acceptable contact ratio; however, the surface stresses on the pinion teeth and rack surfaces exceeded allowable limits. His analysis of a pin gear presented no contact ratio problems, but high stresses in the pin bushings were a cause for concern. Bushing pressure, combined with the hostile mine environment, could result in lubrication problems. His analysis did not eliminate the possibility of using pin: gears, but preliminary investigation was not encouraging enough to stimulate further investigation. 

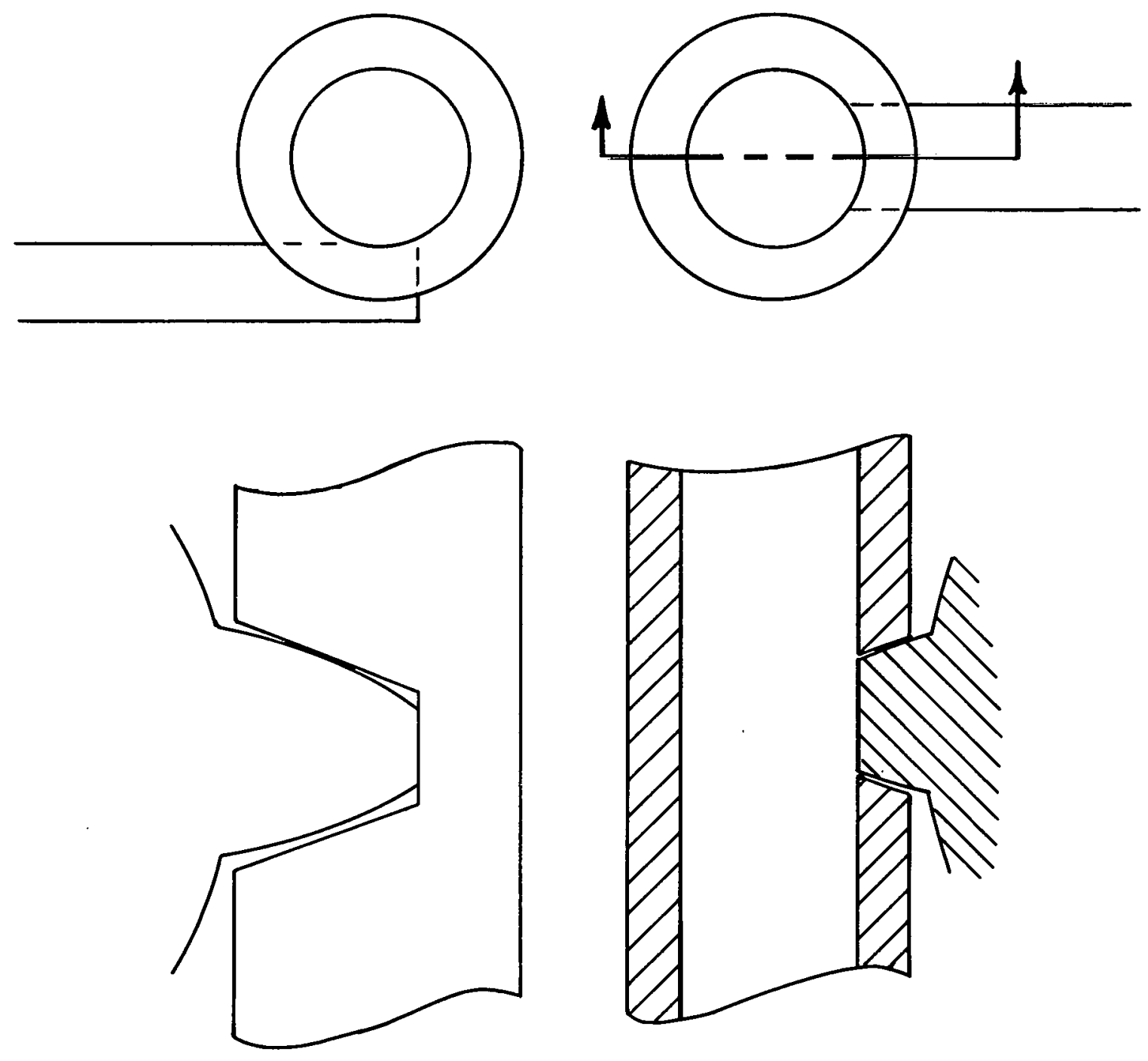

TANGENTIAL ENGAGEMENT

RADIAL ENGAGEMENT

FIG. 24. DRIVE PINION ENGAGEMENT OF THE DRILL SHAFT 


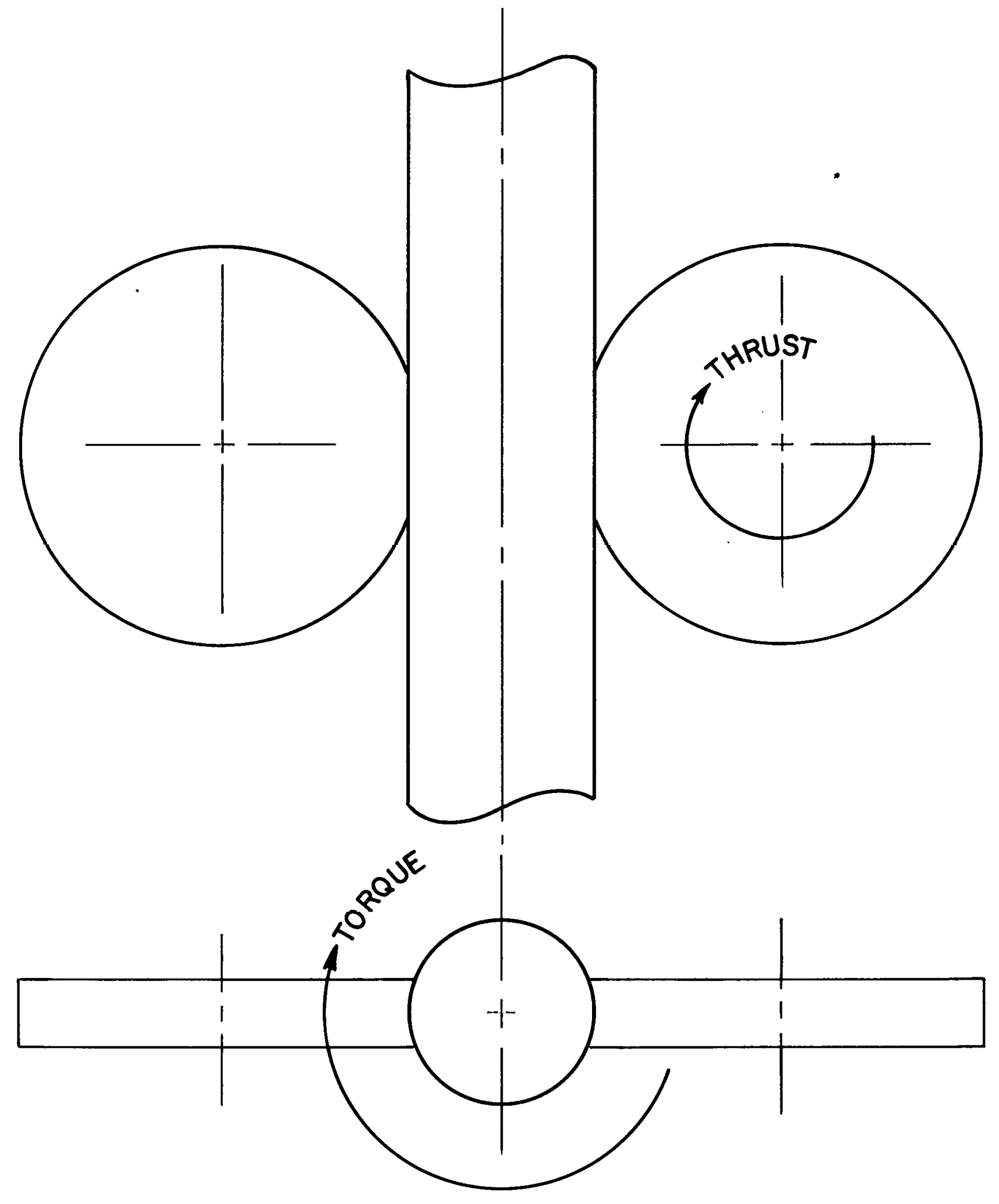

FIG. 25 RACK PINION ENGAGEMENT 

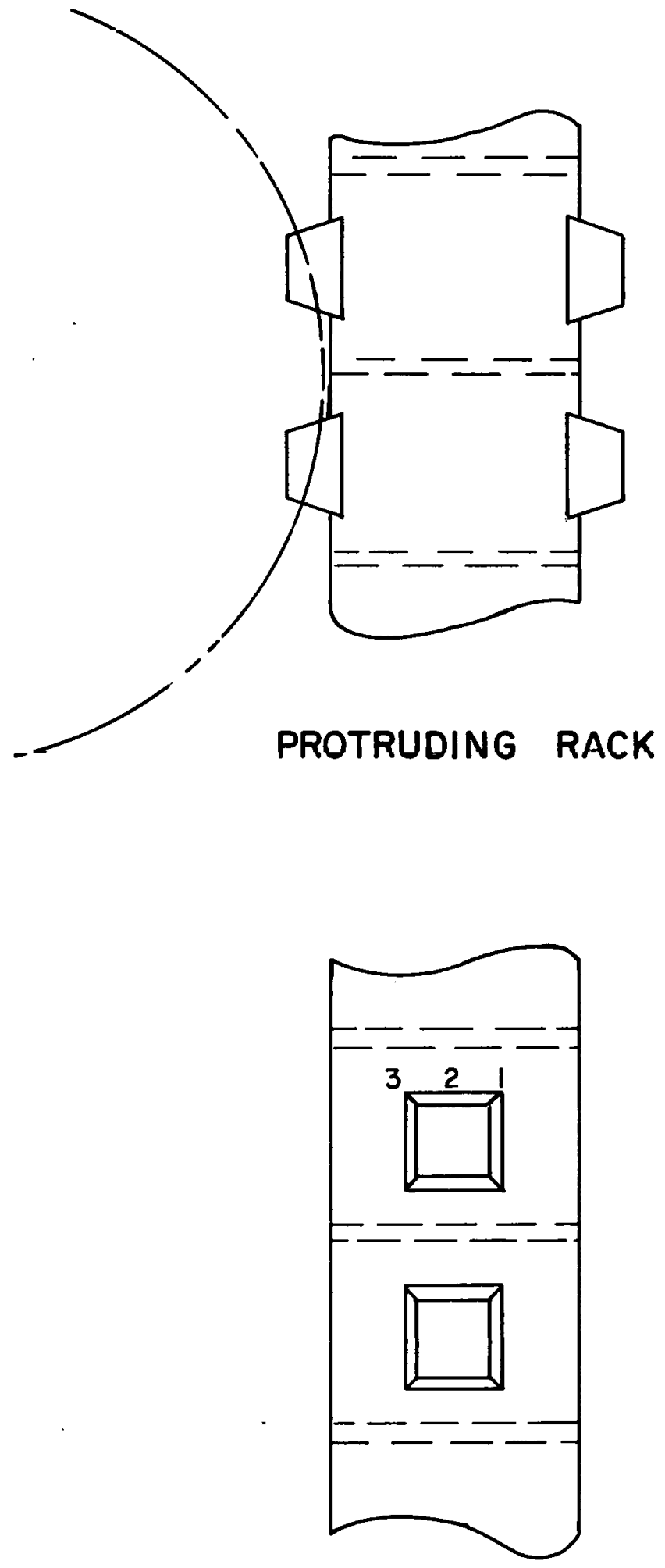

SLOTTED RACK

FIG. 26. TWO WAYS TO BRIDGE THE COUPLING INTERFACE 
There are possible combinations of the several drive concepts that could provide a drivehead with optimal features.

\subsubsection{Chain Drive}

The chain drive suggested by McIlvanie was not given developmental effort. It showed promise and may provide an acceptable way of driving a flexible shaft. Figure 27 shows the general structure of a chain drive using involute teeth that engage slots in the shaft's segments. The chain drive distributes the thrust load over a number of teeth and provides a good contact ratio with the segmental shaft. Figure 28 shows a differential sprocket drive that could be used to provide thrust motion. Figure 28 functionally illustrates the differential drive method used in other drivehead designs to obtain thrust motion.

Flexible shaft segments would be easier to manufacture and structurally stronger without slots machined in the sides as described above. The dumbbell profile also weakens the waist section of segments. A friction drive would avoid these problems. There are no established guidelines concerning the appropriate friction coefficient to use in the design of such a drive system. A friction coefficient of 0.25 was selected as a first approximation for this design. Phase II of the contract should explore the friction coefficient more thoroughly. Using a value of 0.25 , the required $6,000 \mathrm{lb}$ of thrust force would require $24,000 \mathrm{lb}$ of normal force or $12,000 \mathrm{lb}$ of normal force on each side of the segmental shaft.

The method of applying normal force utilized a circular ring elastically deflected a prescribed amount, providing a reactive normal force of $12,0001 \mathrm{~b}$. Figure K-2, Appendix K, shows how this concept was incorporated into a continuous friction drive using the chain-and-sprocket mechanism. Friction pads are carried on the chain and drawn up through a gap $0.05 \mathrm{in}$. too small. As these pads move through this gap, the normal force, $P$, is developed by an elastic deflection of the loading ring. Calculations concerning the normal load developed are shown. in Appendix $\mathrm{J}$.

The rotation speed of the segmental drill shaft identified as $N_{R}$ on this drawing is also the rotation speed of the chain-and-sprocket assembly around the centerline of the drill shaft. Rotation speed of the differential gear is identified as $\mathrm{N}_{\mathrm{D}}$ on this drawing. The differences between these rotational speeds $\left(N_{D}-N_{R}\right)$ adjusted by the gear ratio gives the rotational speed of the chain sprockets. This rotational speed varies independently of shaft rotation speed by varying the output rotation of the differential drive motor. 


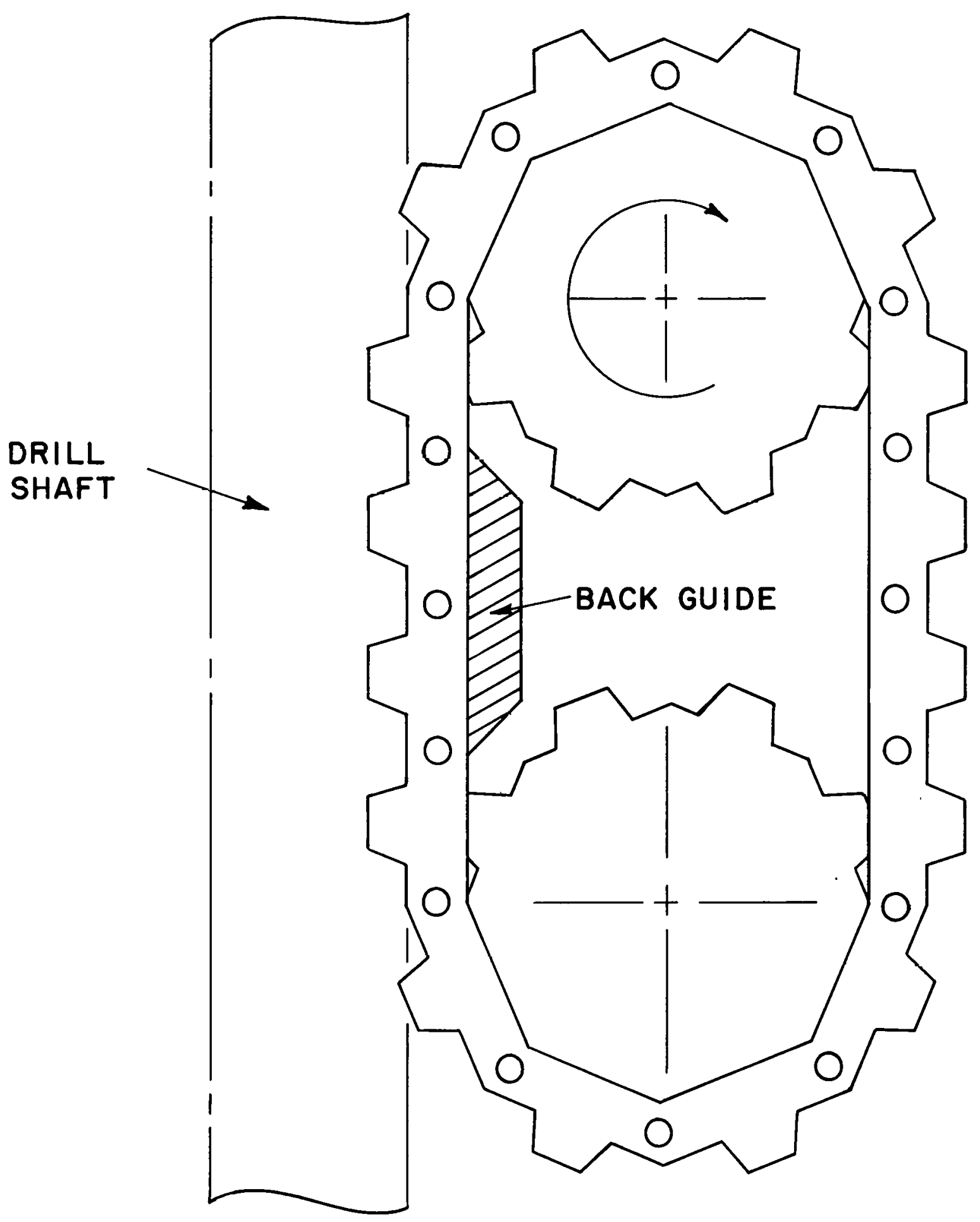

FIG. 27. SCHEMATIC OF CHAIN DRIVE 


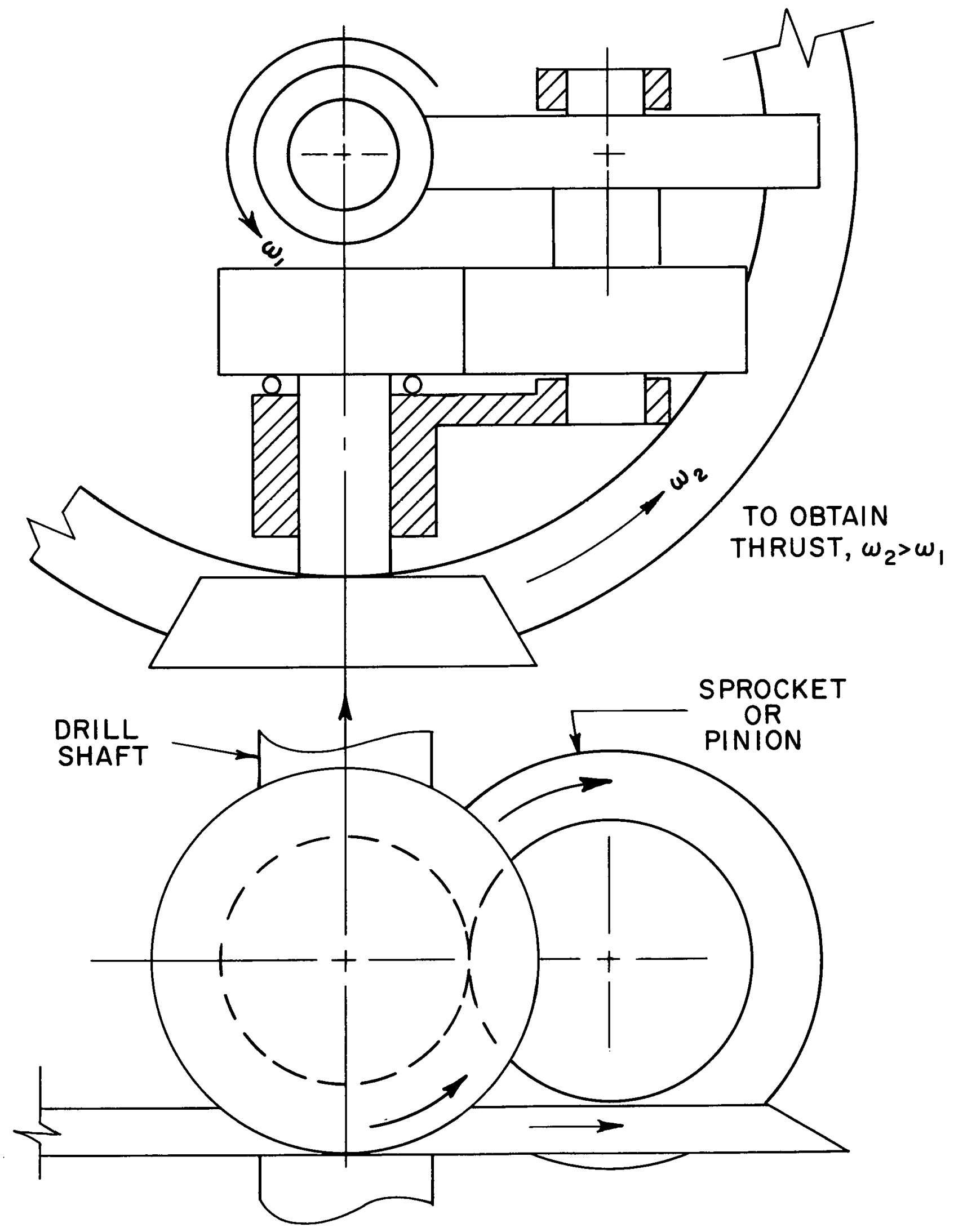

FIG. 28. DIFFERENTIAL SPROCKET DRIVE 
Will the normal force of this drive system provide adequate friction forces? If the friction pad surfaces shown in this drawing do not adequately generate the required friction forces, it may be necssary to modify the pads by serrating their surfaces or incorporating small involute-shaped teeth that would engage slots in the shaft, providing a more positive transfer of thrust force. Such a method would be a modified version of the one originally suggested by McIlvanie. The difference is that large normal forces would still be used to generate much of the thrust force and the involute teeth would provide a positive interlock when drilling forces become high or the friction coefficient becomes smaller due to contamination of the drill shaft surface.

Appendix $\mathrm{J}$ shows calculations to determine the size of the normal loading ring. These calculations include a fatigue analysis for the ring used with this friction drive; however, the analysis is not necessary since the cyclic loading of the ring would be minimal. The normal loading ring would be elas-: tically deflected as the drill string is inserted into the drivehead and unloaded as the drill string is removed. This cycle would occur infrequently and does not justify a great amount of concern for fatigue failure.

\subsubsection{Reciprocating Drives}

The idea of a reciprocating drive was introduced by McIlvanie, and he developed what was called a pawl-and-ratchet drivehead that reciprocated up and down and applied an intermittent thrust motion. The drive would advance the drill string upward, then release it to be held by a detention device while the thrust pawl returned to the slart and repeated the cycle. Appendix I describes the features of this paw1 and ratchet system.

Reciprocating motion appeared to be an attractive way of applying thrust motion to a drill string, and an effort was made to extend this idea to a system that could provide continuous upward thrust. Such a system would require two reciprocating mechanisms that would alternate by apply thrust. During the upward thrust motion of one mechanism, the other would be retracting to the start position in preparation for the next thrust cycle. Before describing three driveheads based on this principle of operation, a number of reciprocating drive concepts given some consideration at the start of Phase $I$ are listed as follows:

1. The use of various types of chucks or collets that could grasp shaft segments were considered. It was anticipated that large 
forces would be required to provide the necessary clamping pressure on the collets or chucks. Also it was apparent that rotating hydraulic seals would be required and such seals were considered undesirable.

2. Mechanisms similar to the one used to advance film in a movie projector were studied. Such a mechanism has the proper motion and could be driven by a differential drive system. One problem was the large forces that would have to be transmitted by the linkages. Additionally, the relatively large travel per stroke required linkages of considerable size. Mechanically, this was as complex as some of the other systems and involved more structural problems. It was not further developed.

\subsubsection{Reciprocating Hydraulic Drive}

This drivehead uses two cylinders which alternately apply thrust force to the shaft. This reciprocating hydraulic drivehead is shown in detail in Appendix K, Figures K-4, K-5, and K-6. McIlvanie's hydraulic drive required rotating hydraulic seals. The team consensus was that the rotating seal was a liability and should be eliminated. This was accomplished by mounting the thruster yokes on a plate isolated from the nonrotating hydraulic thrust cylinders by a thrust bearing. This arrangement is shown in Figures $\mathrm{K}-5$ and $\mathrm{K}-6$ of Appendix $K$. The upper and lower thrust yokes are rotating with the flexible shaft which is driven by a hex collar. Thrust cylinders apply load to the thruster yokes through isolating bearings as shown on thesc drawings. Inserting and withdrawing the thruster yokes when required proved to be the most difficult problem with this particular drive system. It was solved by using double-acting pneumatic cylinders to actuate the yokes. These cylinders operate with an air pressure of $100 \mathrm{psi}$, thus requiring a rotating pneumatic air seal as shown in Figures $\mathrm{K}-5$ and K-6 of the drivehead drawings. This low air pressure air system would appear to present minimal seal and leakage problems.

The hydraulic motor driving the ring gear is mounted to the plate supporting the thrust bearing. This plate is driven up and down in a reciprocating motion by two hydraulic cylinders. Vertical guide beams around the periphery of the support plate provide a counter-reaction to torque and keep the plate at a $90^{\circ}$ angle to the shaft. 
To conserve space and provide continuous thrusting action, a pair of hydraulic cylinders work in opposition to each other and are space $90^{\circ}$ apart. This orientation can be seen in Figure $\mathrm{K}-4$ and is developed in sectional views $A-A$ and $B-B$. When the drivehead is in operation, the hydraulic motor would be torquing the drill shaft at an rpm set by the operator... Top thrusting yokes would thrust through a distance of approximately $1.75 \mathrm{in}$. At the end of the stroke, a series of snap-acting pneumatic pilot valves would perform the following functions:

1. Bottom yokes engage the shaft.

2. Bottom cylinders begin thrust.

3. Top yokes retract.

4. Top cylinders return to begin another stroke and await actuation.

Bottom cylinders pull upward thrusting the drill shaft. Near the end of the 1.75-in. stroke the following pneumatic pilot valves are actuated:

5. Top yokes engage the shaft.

6. Top cylinders begin thrust.

7. Bottom yokes retract.

8. Bottom cylinders extend to begin another stroke and await actuation.

When the drill hole has been completed, the operator can withdraw both thrusting yokes simultaneously by overriding the sequenced pneumatic control system. This releases vertical support, permitting the shaft to be pulled from the hole via a retraction mechanism located at the drill vehicle.

\subsubsection{Reciprocating Friction Drive}

The reciprocating friction drivehead incorporates many of the features of the continuous friction drivehead. Figure K-1 shows the details of this drive. Friction pads have a normal load applied to them by the eleastic deflection of a load ring. The required deflection for a normal load of $12,0001 \mathrm{~b}$ is calculated in Appendix $\mathrm{J}$. This deflection is mechanically achieved by the movement of a latch mechanism through a gap between the friction pads and roller connected to the load ring. This gap is 0.05 in. too small and the elastic deflection of the load ring results in the required normal load. The upward motion of the latch mechanism is obtained by an eccentric shaft being rotated by a gear connected to the differential drive system. This shaft has a throw of 0.4 in. Because the thrust motion is a reciprocating motion, it requires 
two sets of friction pads, each set $90^{\circ}$ from the other. Both sets of pads are loaded by the same load ring. This means the load ring is elastically deflected twice during each revolution. This cyclic loading makes is necessary to consider the fatigue characteristics of the load ring. Details of this calculation are presented in Appendix $J$ and a ring made of SAE 6145 steel should provide satisfactory fatigue life for this application.

The differential drive mechanism used eliminates rotating hydraulic seals. The load rings and friction pads are rotating at the same speed as the drill shaft, and upward thrust motion results from the differential thrust gear rotating at a slightly faster rotation speed. The rate of upward motion is a function of the difference between $N_{D}-N_{R}$ modified by the gear ratio.

\subsubsection{Reciprocating Cam-Operated Drivehead}

Details for this drivehead are shown in Figure K-3. It uses a differential gear approach to provide the upward thrust of the segmental shaft. The upward thrust is obtained via a cam roller following an undulated cam surface. The above-mentioned drawing shows the profile for this cam surface. The drive has an upper cam surface and a lower cam surface which alternately thrust the shaft upward. The differential gear rotates the cam rollers at a relative speed equal to the difference between the differential gear rotation and the rotating gear rotation. During one rotation of the differential gear, the upper cam roller will twice have thrust the segmental shaft upward through a distance of $3 / 4$ in. During the same period, the lower cam similarly will have provided two upward thrusts. Thus, the total upward. thrust for one rotation of the differential gear will be 3 in. The differential gear rotation speed must exceed the rotating speed gear by $12 \mathrm{rpm}$ to obtain a $36-\mathrm{in} . / \mathrm{min}$ feed rate.

The yoke thrusters are inserted into the segmental shaft through a second cam surface. The profile for this cam surface is shown in Figure K-3. This cam surface causes the yoke to move radially with respect to the shaft, four times in 360 degrees. During each cyclic motion, the cam pushes the yoke thruster into egagement with the flexible shaft. The flexible shaft used with this drivehead concept must have segments with the dumbbell profile, providing a lifting shoulder for the yoke thrusters. These segments differ slightly from the other types in that the lower shoulder is not square, but has a $45^{\circ}$ taper. This taper matches the slope on the lower side of the yoke thrusters. The spacing between segments may not be precisely the same at all times. A 
variation in the spacing may cause the yoke thruster to be inserted too early or withdrawn too late. Thus, the tapered lower shoulder would help compensate by wedging the yoke thruster back into its slider cavity without causing dam-. age. If the yoke thruster is pushed toward the segment before the upper shoulder is clear to receive it, the interference compensation spring on the yoke thruster will absorb the thrust force and prevent damage to the system. This drivehead is compact, having a total height of $14 \mathrm{in.,}$ and the yoke thrusters provide a positive-acting thrust force when used in conjunction with the differential drive. They also provide independent control of the rotation speed and upward thrust motion.

\subsubsection{Drivehead Summary}

At this stage of the research program, it is difficult to recommend a specific drivehead concept. Each has attractive features that may be combined in some way to obtain a final drivehead design. The eccentric lifting mechanism used in the reciprocating friction drive could be combined with the reciprocating cam drive. Such a combination could use the eccentric mechanism to obtain the thrust motion for the yoke thrusters and retain the cam method for insertion and removal of the yoke thrusters. The research team feels this investigation has assured that a segmental flexible shaft can be driven by a drivehead located at the roof of the mine. Some additional tests during Phase II should clarify this area such that a specific type can be designed during Phase III. 


\section{0 .0 . CHIP RETURN SYSTEM}

A factor of primary importance in the design of a flexible shaft system is the capability to extract drill chips at a reasonable rate. This capacity would be a principal function of the inner diameter of the chip return tubing. Inner diameter of this tubing depends upon the concentric wall thickness of the segments and the wall thickness necessary to prevent collapse of the tubing under applied vacuum pressure.

The cutting chips that result from bolt-hole drilling vary depending on the material being drilled. Fine grey-black shale found predominantly in U.S. Steel mine \#50, produces cutting chips that resemble those shown in Figure 29. These chips are primarily a fine powder but have some large, thin laminar chips which are shown in Figure 29. When this fine material becomes wet, it can set up lke cement in a chip return line. Where the mine roof is semiconsolidated material, the chips would be larger. Present drill steel has circular starter sections with a 1/2-in. inner diameter, and the couplers that interconnect the hexagonal lengths together have a reduced orifice approximately $1 / 2$ in. in diameter.

Present dust extraction systems are capable of a maximum of 62 CFM of air volume at a vacuum of 8 to 12 in. of water. A C-9 nonreinforced nylon hose marketed by Imperial Eastman would be strong enough to resist collapsing under the operating vacuum. Sizes selected are:

1. For the 1-in. diameter drill hole, a hose ID of $3 / 8$ in. and an $0 . D$. of 0.5 in. would be acceptable.

2. For the $13 / 8$-in. drill hole, a hose I.D. of $1 / 2$ in. and an O.D. of 0.65 in. would be acceptable.

During Phase II, it would be desirable to test these two hose sizes to assure that extraction of the drill chips would be possible. Although it is not anticipated that these nylon tubes would be used for pulling the segments from the hole, it is possible that during Phase. II they could be shown to be acceptable for this use. 


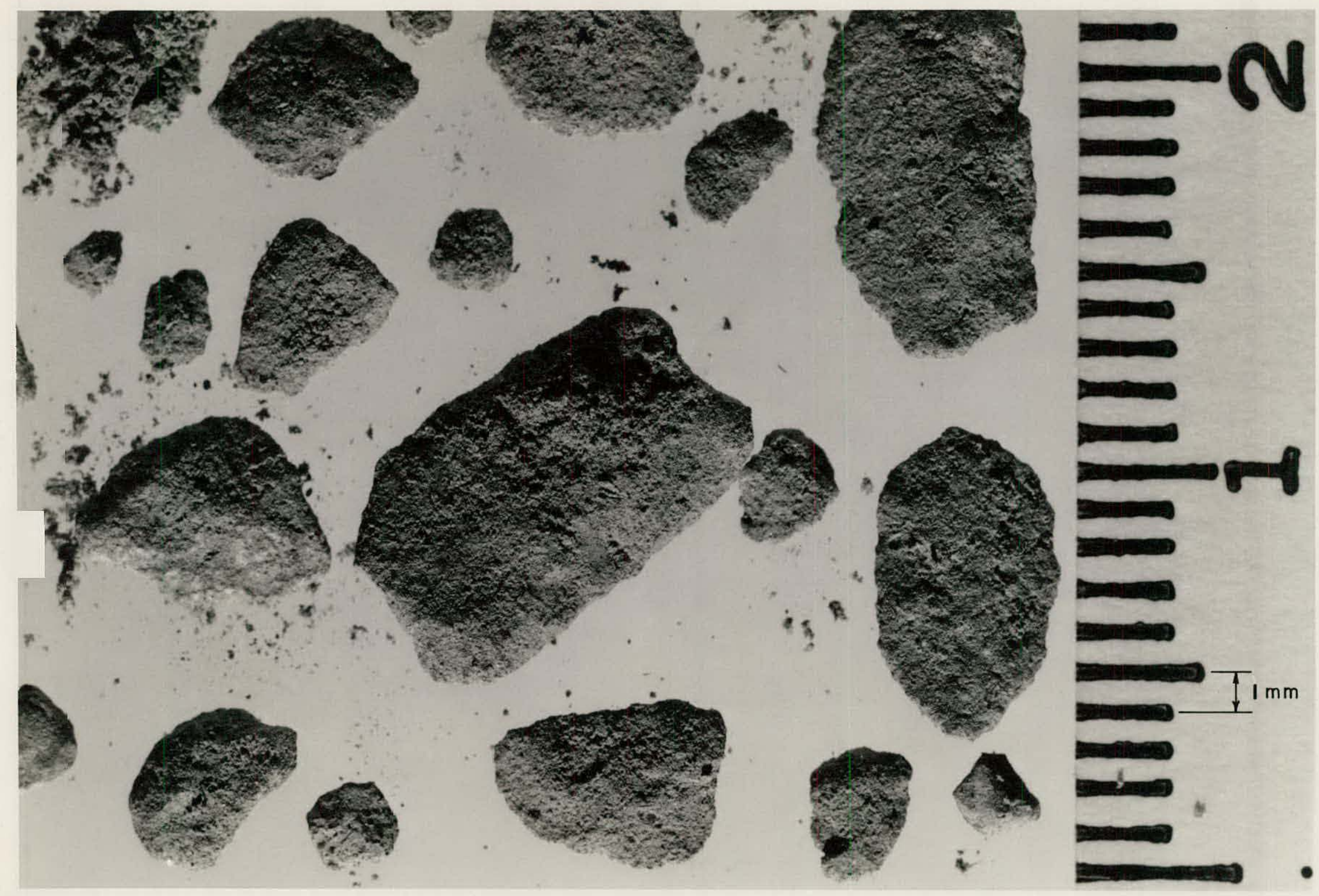

FIGURE 29. DRILL CUTTINGS FROM FINE GRAY BLACK SHALE 


\subsubsection{STOWAGE SYSTEM FOR FLEXIBLE SHAFT DRILL}

During tramming and drilling, there must be space in the bolter vehicle to stow the flexible shaft drill. This stowage facility would include a system for applying withdrawal force necessary to remove the drill bit from a completed hole. Figure K-7 shows two alternative locations for this stowage system.

One possible location for stowage is beneath the bolter vehicle close to the wheels on the left-hand side. This side of the Fletcher LTDO bolter has a chain-drive sprocket extending about $31 / 2 \mathrm{in}$. beneath the bottom of the vehicle. If the stowage passage extends no lower than the sprocket level, it should be high enough to avoid damage by scraping on the floor of the mine.

Another way of stowing the flexible shaft is to bend it more than $90^{\circ}$ and bring it back through the vehicle. This alternative path is shown in Figure $\mathrm{K}-7$. This is feasible since the area occupied by the present thrust arm is available for extensive modification to accommodate such a stowage system. Present thinking is that the thruster arm that carries the present drilling head as shown in Figure 2 would be removed. Once removed, the front end of the vehicle has space available for storage and support of the new flexible shaft drivehead as shown in Figure 30.

The retraction system must be able to withdraw the flexible shaft at a rate of $40 \mathrm{ft} / \mathrm{min}$ with a force estimated to be $500 \mathrm{lb}$ max. A retraction system having $1 \mathrm{hp}$ should be adequate for the above requirements.

Two withdrawal system options were investigated during Phase $I$. The first was a chain drive system. There would be no difficulty in developing a system that would be workable; however, the use of a chain and sprocket beneath the vehcile would require more space than is available. Lubrication of the chain ahd keeping it clean presents other problems. The second and more favored method of withdrawing the shaft and stowing it is using a cable connected to the end of the flexible shaft extending back to the rear of the vehicle. Such a cable would be wrapped on a drum, which could be rotated using a hydraulic drive motor. A 1/2-in. diameter cable would provide adequate strength and, when used with a 16-in. drum would prevent cable fatigue. The flexible shaft could be contained in a casing to protect it from damage and control its movement into the stowage position. The specific location for the stowage system will have to wait for the vehicle selected by the U.S. Bureau of Mines. It is anticipated that certain problems will be associated with location of a stowage system regardless of the vehicle selected. 


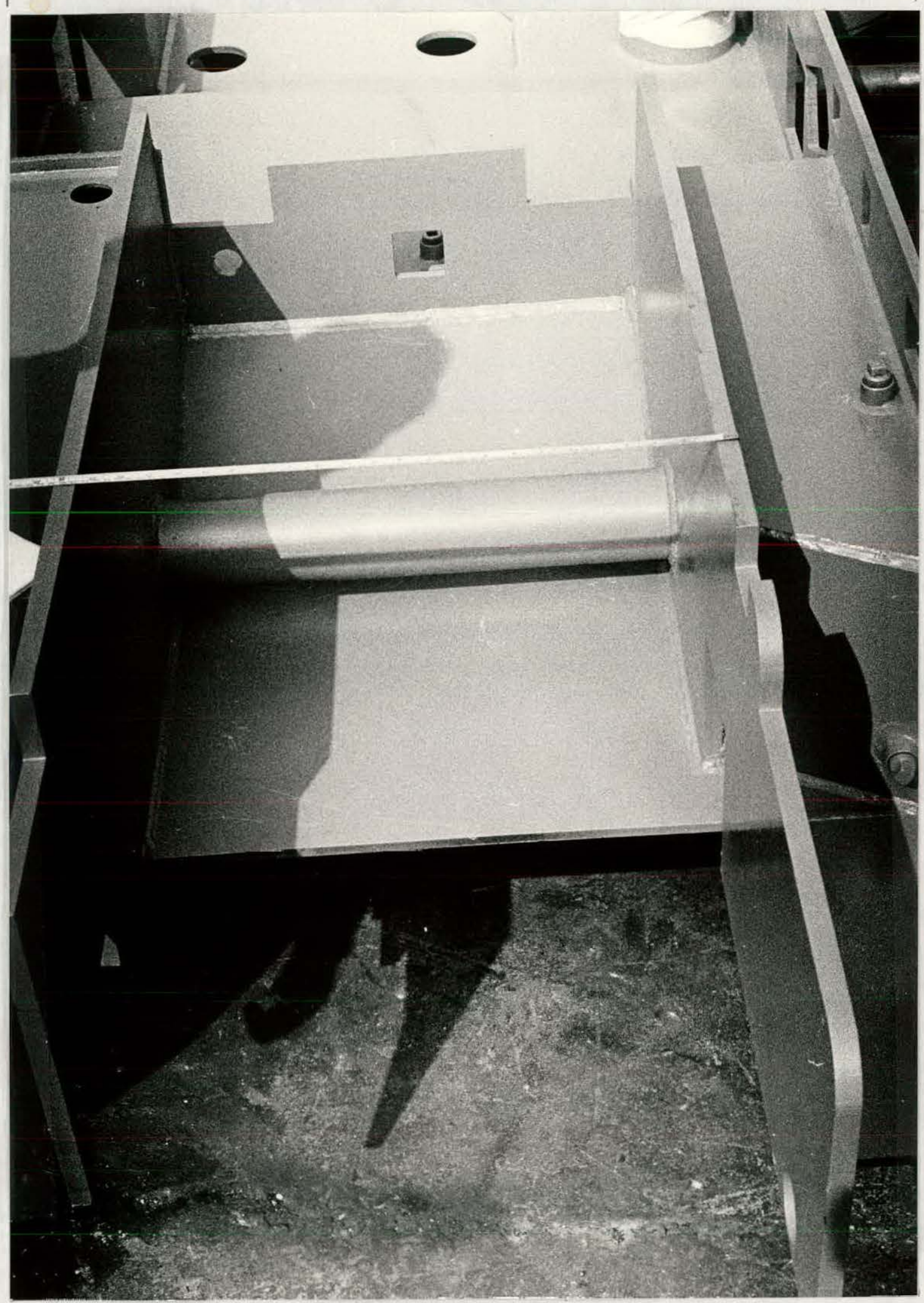

Figure 30. Available Space in the Fletcher LDTO for Flexible Shaft Drill Head and Flexible Shaft Stowage. 


\subsubsection{BIBLIOGRAPHY}

1. McIlvanie, W. A., "The Design of a Flexible Shaft Drill for Low Coal," Masters Thesis, Washington State University, 1974.

2. Teals, R., "The Concept of Specific Energy in Rock Drilling," Rock Mechanics Mining Science, Vo1. 2, pp. 57-73, 1965.

3. Fish, B. C. and Barker, J. S., "The Design of Rotary Drilling Tools, Part One," Colliery Engineering, November 1957.

4. Fish, B. C. and Barker, J. S., "The Design of Rotary Drilling Tools, Part. Two," Collièry Engineering, December 1957.

5. Fish, B. C. and Barker, J. S., "The Design of Rotary Drilling Tools, Part Three," Colliery Engineering, February 1958. 
USBM HO242027

FLEXIBLE ROOF DRILL FOR LOW COAL

Phase II 


\section{Summary}

Phase I completed the following studies:

1. Detailed stress analysis on two- and three-tooth flexible shaft segment geometries.

2. Curvature tests on the $13 / 8$-in.-diameter shaft for two- and three-tooth geometries.

3. Field tests with 1 -in.- and $13 / 8$-in.-diameter sectional flexible shaft drills.

4. Destructive tests to establish tooth and retainer ring strength.

5. Minimal wear studies.

The tests and calculations show the segmental flexible shaft drill concept is workable. The $13 / 8$-in.-diameter shaft successfully drilled to $7 \mathrm{ft}$, 7 in. in fine gray-black shale at a rate of $3.17 \mathrm{ft} / \mathrm{min}$. The drilling rates for the 1-in.-diameter drilit were slower, but the difference was caused by a correctable chip-evacuator problem. These tests suggest some design changes for the retainer ring interfacial restraint and the starter section.

Curvature tests showed the three-tooth geometry to result in a smoothrunning flexible shaft that can curve through simple and compound radii, : thereby allowing the flexibility of using a number of vehicile shaft stowage locations. The minimum design radius proposed will allow for a drivehead that extends 16 in. down from the roof of the mine. This is the design limitation suggested during the Phase I study.

Phase II firmed up the configuration of the flexible segments. This provides a shaft specification that can be used for final drivehead design during Phase III. Test facilities developed during Phase II will be available during the later phases to aid in validating final designs.

Cooperative effort with U.S. Steel has provided excerrent guidance concerning coal mining technology. Their continuing help during the coming phases will aid design efforts. The U.S. Bureau of Mines is urged to accept this design concept and continue this contract with Washington State University for Phases III, IV, and V. 
Introduction

The Phase I report recommended the flexible shaft drilling system be incorporated into a mining vehicle as shown in. Figure 31 . This figure shows the drivehead for the flexible shaft drill would be located at the roof of the mine. The flexible shaft drill would extend down from the drivehead through a radius into a horizontal position and then back into the vehicle for stowage purposes. The flexible shaft that extends down from the drivehead would rotate in an unloaded condition (transmitting no torque or thrust). The flexible shaft drill being driven upward into the hole by the drivehead would maintain its alignment by a straight starter section at the head of the drill. Note that the Phase I report established the criteria for this starter section.

All of the drivehead methods recommended in Phase I required the flexible shaft to have a hexagonal outer geometry. The flexible shaft that was recommended consisted of short, rigid segments coneected via an interfacial retention device. The general characteristics of these drive systems are shown in Figure 32. In all cases, rotation torque was applied by a torque collar that fit around the hexagonal segments. Upward thrust forces were applied by thruster yokes which engaged each segment at its circular waist. The reduced diameter at the waist resulted in a shoulder upon which the yoke thrusters could apply thrust force. Drive systems recommended in the Phase I report were:

1. Pawl-and-ratchet drivehead

2. Reciprocating hydraulic drivehead

3. Reciprocating cam drivehead

4. Reciprocating friction drivehead

5. Continuous friction drivehead.

It was concluded that none of the driveheads could be directly adapted to a flexible shaft drilling system until the specific geometry of the flexible shaft had been established. It was also felt that various features of all these drive systems could be combined to produce the best drive system for a flexible shaft.

The flexible shaft studies during Phase I could be categorized according to the types of interfacial restraint used. The purpose of the interfacial restraint was to link rigid segments together and permit the shaft to transmit a tension force. Such a tension force would be required when the flexible shaft was withdrawn from the hole. The interfacial restraints proposed were: 


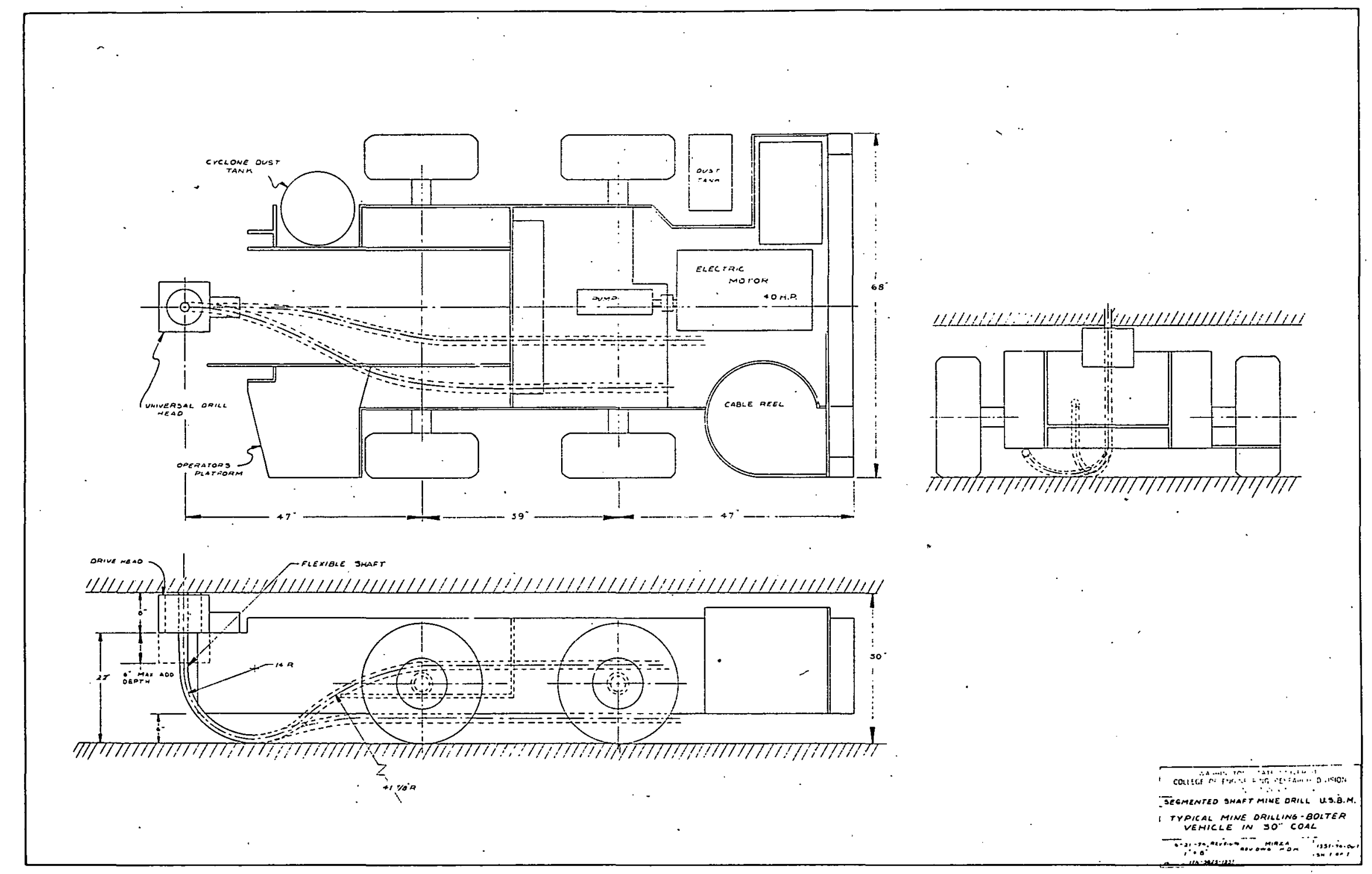

Figure 31. Proposed Segmental Flexible Shaft Drilling System. 


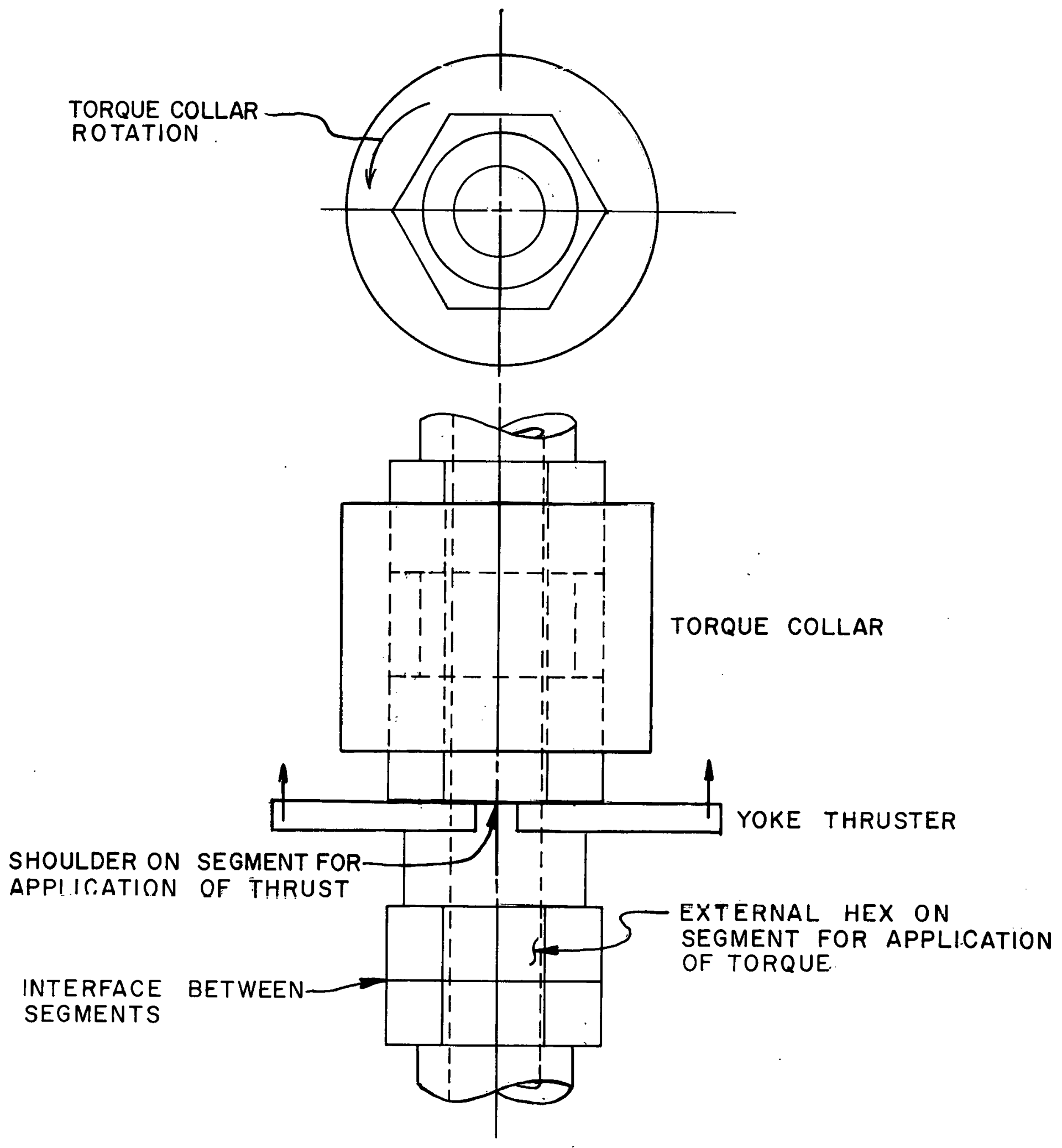

Fïgure 32. Drive Method for Segmental Flexible Shaft Drill. 


\section{Internal snap ring (retainer ring) \\ 2. Elastomeric connector \\ 3. Internal cylindrical clip.}

The discussion during the oral presentation of the Phase I report indicated that the retainer ring appeared to be the best and that the research should proceed to investigate its capabilities more fully. The flexible shaft segments could also be categorized according to the number of teeth at the interface. It was concluded in Phase I that the best. approach would be to have not more than three teeth. The more teeth at the interface, the smoother the flexible shaft should rotate; however, increasing the number of teeth could result in high stresses in each tooth. The Phase II approach was to investigate the two- and three-tooth configurations. Another consideration that had to be kept in mind was the profile of the teeth. The simplest tooth profile to fabricate is a rectangular tooth. Perfectly rectangular teeth would be undesirable due to stress concentrations as well as wear on the corners during rotation around a tight radius. The approach during Phase II was to design segments that had reasonable radii at stress concentration points and pivot points. Such configurations would be tested; if they prove to be satisfactory, no attempt would be made to design and test more exotic tooth profiles.

The summary section of the Phase I report provides greater detail concerning the nature of the Phase I study and its conclusions. These reported results, discussions, with USBM project personnel, and conclusions in the above paragraphs suggested that the following analysis and tests would be desirable during Phase II of this program:

1. A more detailed stress analysis on the two- and three-tooth geometries needed to be conducted. This stress analysis would have to be for the $13 / 8$-in. and 1-in. diameter flexible shafts. The stress analysis must consider the types of radii at the stress risers and bearing points at the interface. It was also felt that it would be advantageous to put this stress analysis into computer code so that design modifications could be quickly and more economically checked. A discussion of this stress analysis is presented in Appendix L.

2. The dynamic characteristics of the flexible shaft as it rotates through the required radii should be investigated. These tests would be conducted through simple and compound curves using an unloaded flexible shaft to simulate actual operating conditions that 
would eventually be encountered. Both the two- and three-tooth geometries would be tested; however, only the $13 / 8$-in. diameter shaft needed investigation. As will be shown, the $13 / 8$-in. diameter shaft is limiting, and any radius about which this shaft can bend, the 1-in. shaft should also bend. Appendix M discusses these tests.

3. Field test flexible shaft drills in the 1-in. and $13 / 8$-in. diameter sizes will be developed. These drills will be taken to a U.S. Steel coal mine in West Virginia for testing. The purpose of these tests is to verify how well the flexible shaft can drill, with the criteria being straightness of hole and drilling rate. Such field tests will also provide an opportunity to measure the torque and thrust required for drilling and thereby introduce greater precision into the calculations and redesign. These field tests are discussed in Appendix $\mathrm{N}$.

4. Destructive tests are planned to verify the load limits of the flexible shaft drill components; in̈.particular, to verify what loading is required to fracture the shaft elements. The second destructive test relates to the tension transmission characteristics of the retainer ring used to connect the segments. Both of these destructive tests were carried out for the 1 -in. and $13 / 8$-in. diameter flexible shaft. The destructive torsion tests were conducted on both the two- and three-tooth configurations. These destructive tests are discussed in Appendix 0.

5. Some evaluation of the chip-removal capabilities of the flexible shaft is needed. Appendix $P$ discusses this phase of the testing program. 


\section{Discussion}

The philosophy of the Phase II study is to provide specific data so the proposed flexible shaft concept could be refined and subjected to preliminary performance tests.

Design Refinement and Analysis

The exterior geometry of the segments developed in Phase I was to remain unchanged. The primary concern in refining the design was to investigate the interfacial geometry and interfacial restraint methods. The stress analysis presented in Appendix L provides details concerning the evaluation of the twoand three-tooth geometries for the 1 -in. and $13 / 8$-in. diameter shafts.

The three-tooth geometry was selected as being the best tooth configuration. There was only marginal difference in stress between the three- and twotooth configurations. The three-tooth configuration was expected to have better rotation characteristics through a curve. Dynamic tests later verified this premise.

The three-tooth configuration could have been oriented in two distinct ways. Figure L-3 shows the two choices available. The stress analysis did not show a great deal of difference between the two orientations; however, configuration I had the operational advantage of the edge of the tooth being on the flat. This location provided clearance between this edge and the hole surface, preventing the tooth edge from cutting into the hole.

The compressive load due to thrust and the tooth bending load due to torque were the design loads considered. For the $13 / 8$-in. diameter shaft, the thrust and torque used were $6,0001 \mathrm{~b}$ and 3,000 in. $-1 \mathrm{~b}$, respectively. For the 1-in. diameter shaft, the thrust and torque used were 3,174 $1 \mathrm{~b}$ and 1,587 in.-1b, respectively. These loads distributed themselves differently depending on whether the shaft was aligned or misaligned. The torsional load was distributed equally to all teeth when segments were either aligned or misaligned. The thrust load, however, was distributed equally on the three teeth when the segments were in alignment but was concentrated on a single tooth when the segments were misaligned.

The torsion load was converted to an equivalent load concentrated at the centroid of force and directed perpendicular to the tooth surface. This equivalent force and its location were based on assumption of a linear distribution of force from the inner diameter to the outer diameter of the tooth. 
The stresses calculated were:

1. Stress at the root of the tooth due to bending moment produced by the equivalent force.

2. Compression load on teeth or tooth.

3. Direct shear stress on tooth from equivalent force.

4. Twisting shear stress caused by the twisting moment due to the equivalent force having a line of action not intersecting the tooth centroid.

The magnitudes of these stresses either singly or as combined stresses were calculated at points A, B, C, D, E, and F shown in Figure L-3. The critical values occurred for the misaligned case. The magnitude of the principal stress at the base of the tooth for the critical points is noted below.

\begin{tabular}{ccc}
\hline & \multicolumn{2}{c}{ Stress Magnitude } \\
\cline { 2 - 3 } Critical Point & $1-$ in. & $13 / 8$ in. \\
\hline B & $-99,950$ & $-66,890$ \\
E & 97,740 & 47,420 \\
D & 67,240 & 35,730 \\
\hline
\end{tabular}

Based on using an AISI 4140 steel, heat-treated to a Rockwell hardness of Rc 43-45, the ultimate tensile strength would be 150,000 to 180,000 psi and the yield strength would be 135,000 to 162,000 psi. The margin of safety between calculated stresses and material strength was adequate; however, it was felt that the destructive tests that are later discussed would better substantiate thèse findings.

A cyclic load results when the teeth are misaligned. This produces a varying stress at the root of the tooth that could produce fatigue: failure. This stress variation is due to the compressive load being applied and released in combination with the varying bending moment resulting from the movement of the center of force associated with the equivalent torsion force. This force moves through a minimum to a maximum distance from the base of the tooth, thereby varying the bending stress at the root of the tooth. Based on a reliability factor of $90 \%$, the fatigue analysis predicted infinite life for the 1 3/8-in. and 1-in. diameter flexible shaft segments. As discussed in the Phase I report, the fatigue analysis assumed that the segments are always operating in the most extreme state of misalignment. 
Destructive tests using the torsion specimens are discussed in Appendix 0 and show that the three-tooth geometry could sustain a larger torsion load than the two-tooth geometry. These results, plus the fact that a three-tooth configuration should be easier to fabricate, helped narrow the decision to recommend the three-tooth geometry in the final design. It should also be noted that this tooth geometry is simple, having nominal radii in the area of stress concentration and at the tooth bearing points.

Stress analysis and other design calculations served as a guide in the design of the test specimens for performance testing. Performance tests suggested additional improvements and changes that should be incorporated into the final dèsign.

\section{Performance Testing}

The bending capabilities of the flexible shaft while rotating in the unloaded state were of primary concern. This testing program, discussed in Appendix M, provided the necessary information to recommend a final geometry for the segments. The flexibility tests were concerned with the following:

1. What minimum radius could the flexible shaft bend around without separating?

2. Can the flexible shaft bend around a compound as well as a simple radius?

3. Will the flexible shaft be robust enough to sustain abnormal as well as normal handling within the mine?

Appendix B reports that for the $13 / 8$-in, diameter, two-tooth geometry flexible shaft, a minimum curvature radius of 12 in. was successfully tested. The three-tooth, $13 / 8$-in. diameter flexible shaft was successfully tested at. a curvature radius of $16 \mathrm{in.} \mathrm{At} \mathrm{this} \mathrm{16-in.} \mathrm{radius} \mathrm{of} \mathrm{curvature,} \mathrm{partial}$ separation of the flexible shaft segments was noticed. On checking the design, it was found that the construction specifications did not provide enough allowance for machining tolerances. If normal machining tolerances were introduced into $\mathrm{Eq}$. (M-5), the variation of the midline radius of curvature, $\mathrm{R}$, would be 13 to $155 / 16 \mathrm{in}$, with a mean value of $14 \mathrm{in.}$. As reported in Appendix $M$, tests made at a radius of curvature of $14 \mathrm{in}$. resulted in shaft separation at the interface. The variation of $R$ due to the machining tolerances explains this failure.

To provide adequate allowances, the flexible.sshaft used should be designed for a minimum inner radius ( $r$ ) of $10 \mathrm{in.}$ The proposed drilling system 
shown in Figure 31 is designed for a flexible shaft with a midline radius of 14 in. Designing for an inner radius of 10 in. allows for ample tolerance and decrease in the likelihood of straining the retention rings connecting the segments. The 10-in. radius of curvature resulted in the new segment designs shown in Figures 33 and 34 . The minimum midline radius for the $13 / 8$-in. diameter shaft would be $10.688 \mathrm{in}$.. and, for the 1-in. diameter shaft, the radius would be 10.5 in.

The change in tooth geometry shown in Figures 33 and 34 changes the center of force for the equivalent torsion force. These new critical stress values are:

\begin{tabular}{crr}
\hline & \multicolumn{2}{c}{ Stress Magnitude } \\
\cline { 2 - 3 } Critical Point & \multicolumn{1}{c}{1 -in. } & $13 / 8$ in. \\
\hline B & $-106,506$ & $-74,705$ \\
E & 73,599 & 43,804 \\
D & 110,609 & 65,033 \\
\hline
\end{tabular}

Although these stresses are larger, they are still within acceptable limits. The fatigue analysis for this new design predicts an infinite life for the $13 / 8$-in. flexible shaft segments. Based on an average time of 1.7 min to drill a hole and an average rotation speed of $250 \mathrm{rpm}$, a life of 2200 holes is predicted for the 1 -in. diameter flexible shaft segments.

The field tests discussed in Appendix $\mathrm{N}$ provided the most useful information acquired during Phase II. These tests showed that the $13 / 8$-in. flexible shaft drill could penetrate at a rate of $3 \mathrm{ft} / \mathrm{min}$ and drill within the $10^{\circ}$ tolerance specified in the contract. The limitation on the drilling rate for the 1-in. diameter drill was the inability of the system to remove the drill chips from the hole. There were two contributing factors: the performance of the drilling machine during the day that the 1-in. diameter drilling test was conducted, and the design of the staxter section for the 1-in. diameter drill. There is relatively less annular clearance between the drill hole and the 1-in. starter section for passage of air to flush the chips away from the bit and back through holes connected to the vacuum chip-return line. This is a correctable design defect, and Figure 35 shows a recommended starter section for use during future phases of this testing program. This starter section incorporates the necessary air passages for passage of air through the chip-extraction holes in the drilling bit. The design also incorporates the hexagonal 


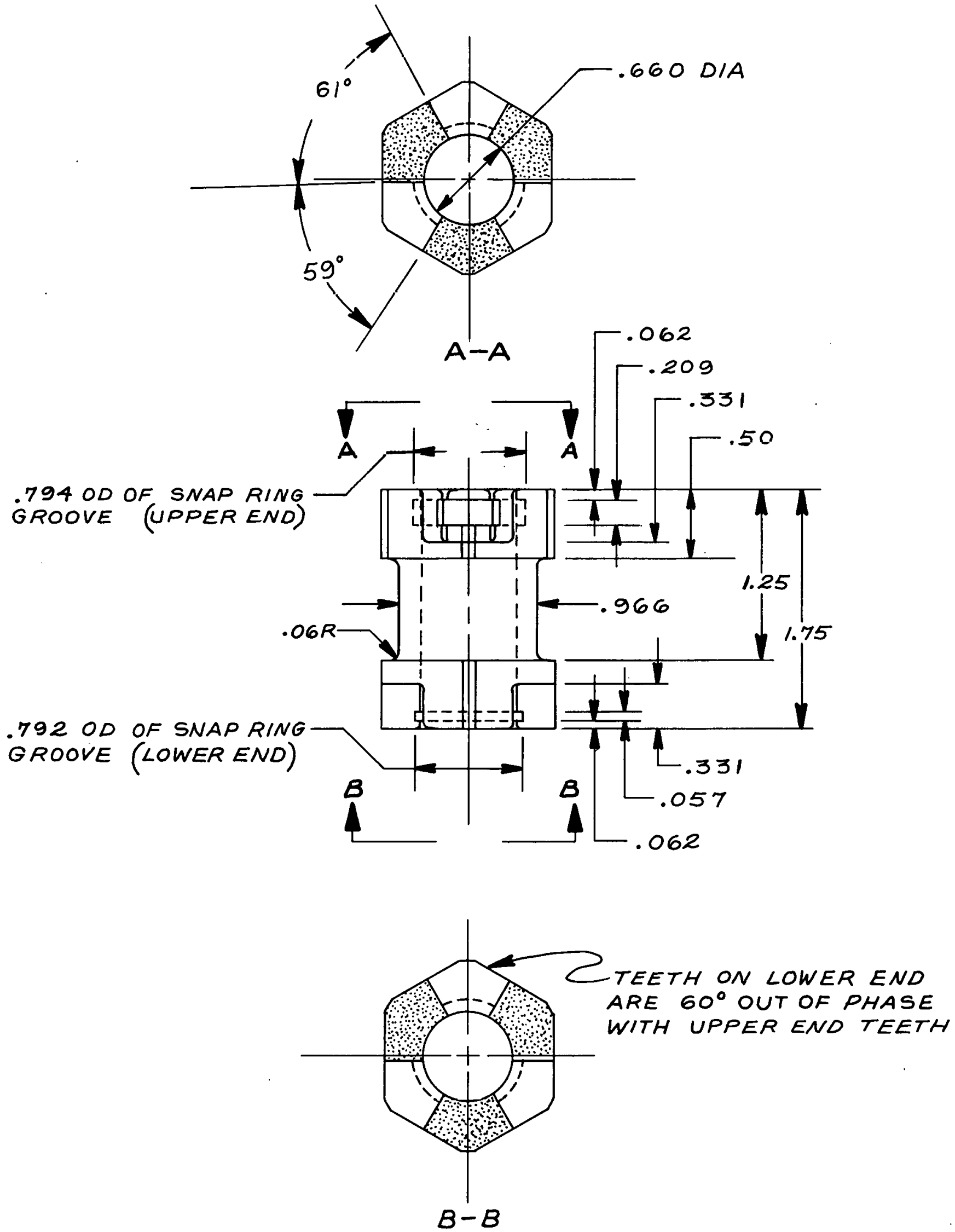

Figure 332 Proposed 3/8-in..Wiameterifexible, Shaft. 


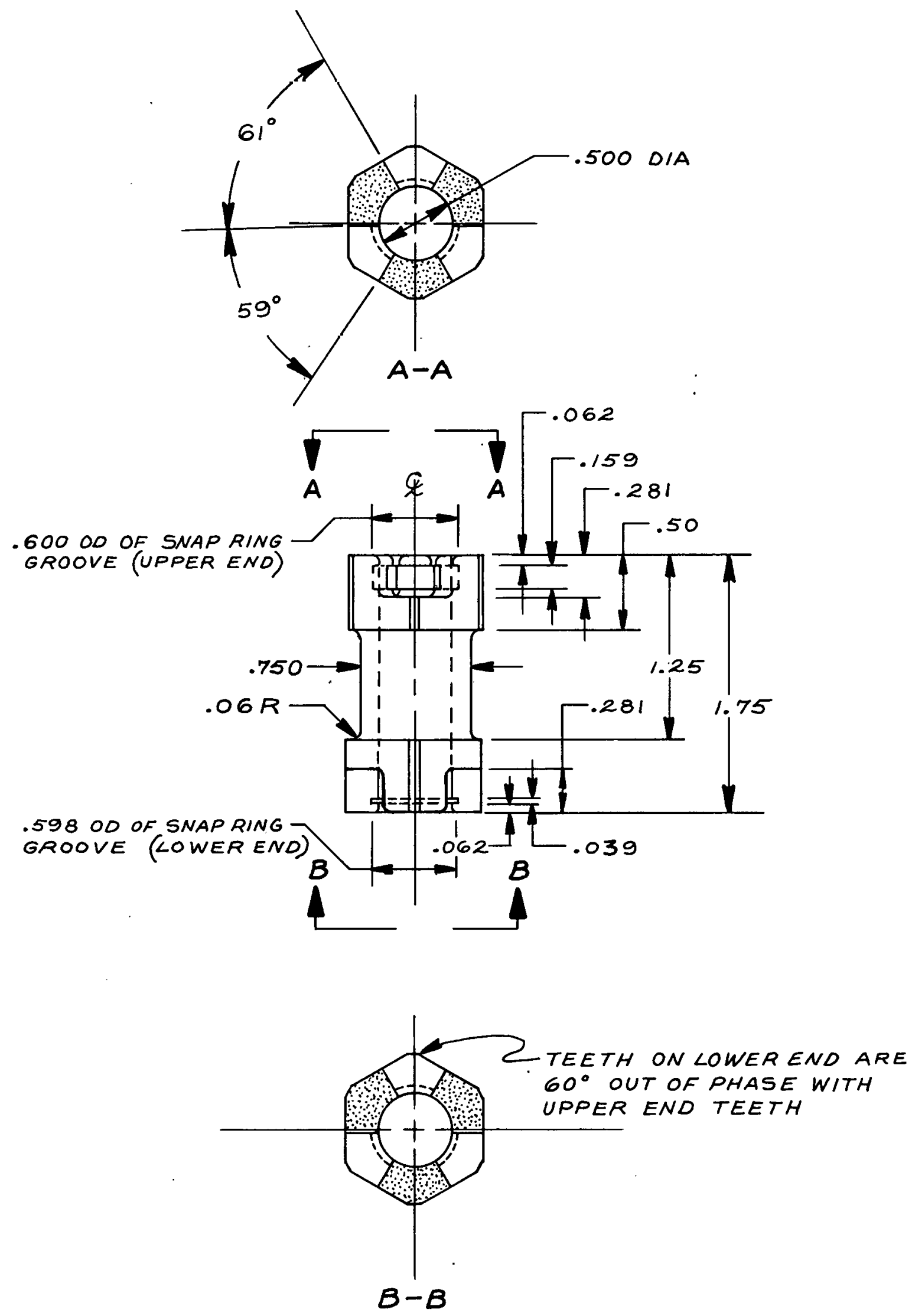




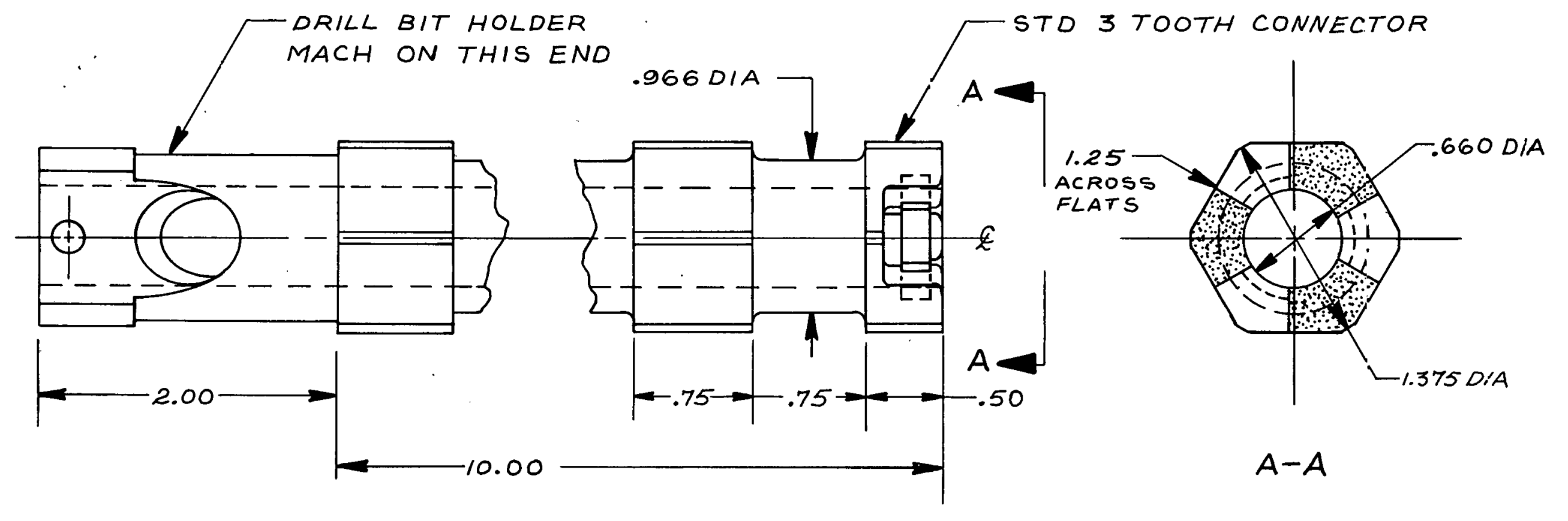

Figure 35. Proposed Starter Section for Flexible Shaft Dri]1. 
configuration with cylindrical waists so the starter section can be driven by the drivehead in the same manner as the flexible segments. This is necessary so that the drivehead may be positioned close to the roof of the mine in $30-$ in. coal, allowing a maximum distance beneath the drivehead and the mine floor for the shaft to curve back into the vehicle's stowage area.

The field tests also allowed for investigation of the potential dangers of drilling in shale and the consequences of these dangers. This relates to a failure experienced during the field tests toward the end of drilling a $7 \mathrm{ft}$ 6 in. hole with the $13 / 8$-in. diameter flexible shaft drill. This failure occurred when the drill bit penetrated an irregularity and stalled. When the operator tried to free the stuck bit by using the normal procedure, the shaft separated. The separation was due to the simultaneous application of both a tension and torsion load to the flexible shaft drill. The stuck bit on a flexible shaft would be freed by rotating the drill in the reverse direction and maintaining a slight thrust load. This would avoid the tensile loading under torque and permit the bit to work itself loose before any withdrawal load was applied.

The failure did suggest investigating a stronger retainer ring for connecting segments. A heavy-duty retainer ring is available. The load-carrying capabilities of the present retainer ring in a misaligned condition were investigated using the destructive tests discussed in Appendix 0 . The mean tension load for the retainer ring connection on the 1-in. diameter shaft was $272 \mathrm{lb}$ and for the $13 / 8$-in. diameter shaft the mean load was $516 \mathrm{lb}$. The suggested designs shown in Figures 33 and 34 have incorporated a wider retainer ring groove so the heavy-duty series of retainer rings could be used.

Field tests subjected the flexible shaft drill to the working environment it must operate in when fully developed. These tests exposed the flexible segments to abrasive cutting chips, which did not appear to affect them; however, the field tests were limited in time and certainly do not represent complete wear tests. Some of the segments that had been used in the field and tested in the laboratory were examined closely using the dynamic rotation apparatus discussed in Appendix M. Figures 36, 37, and 38 show the tooth surfaces of one segment that was examined. Only small areas of the teeth show any signs of wear. Such wear is indicated by the absence of machining marks. To further investigate the wear problem, another test was set up where the flexible shaft segments were rotated within a box filled with shale cutting 


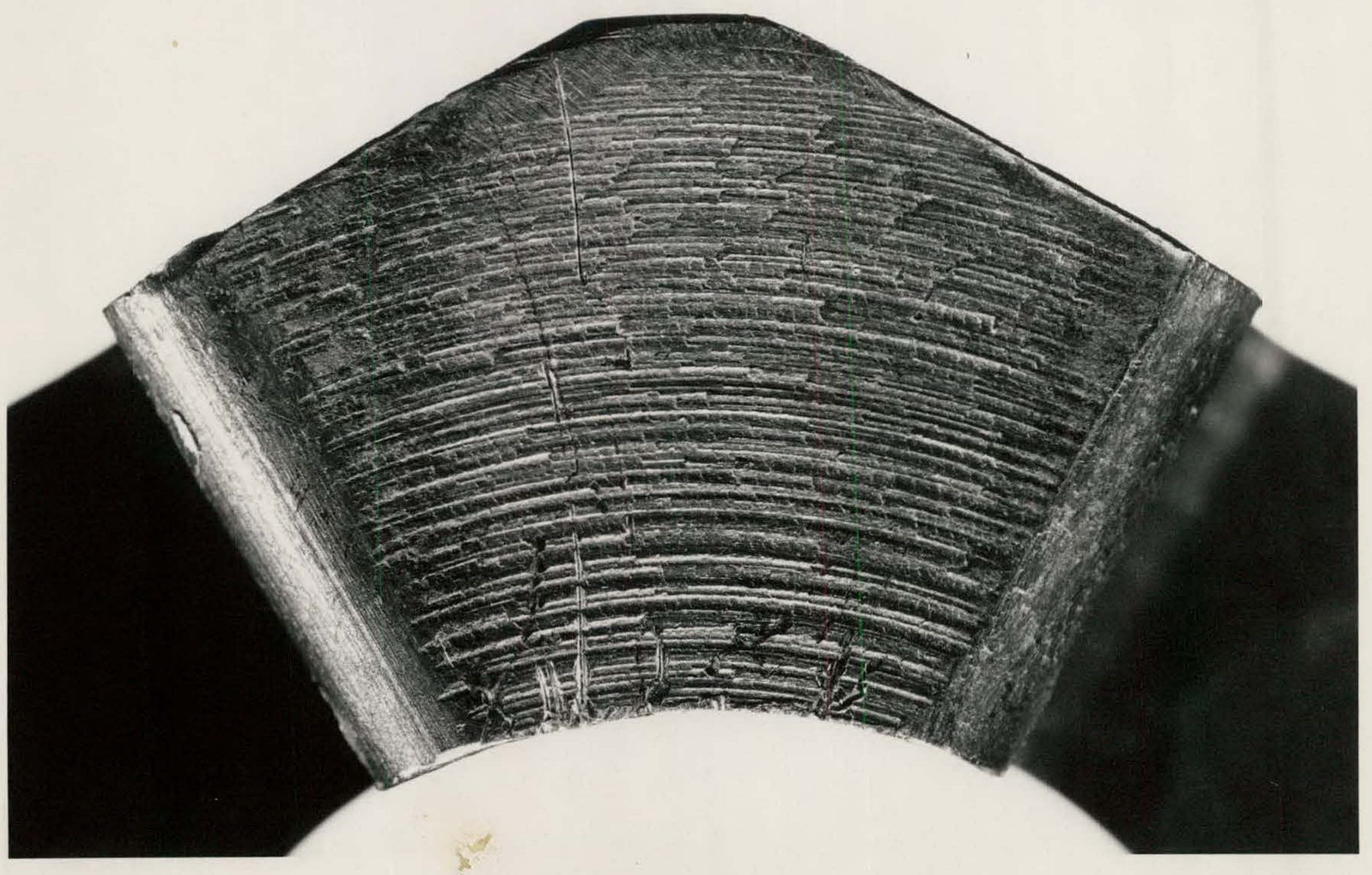

Figure 36. Tooth Surface Wear Pattern. 


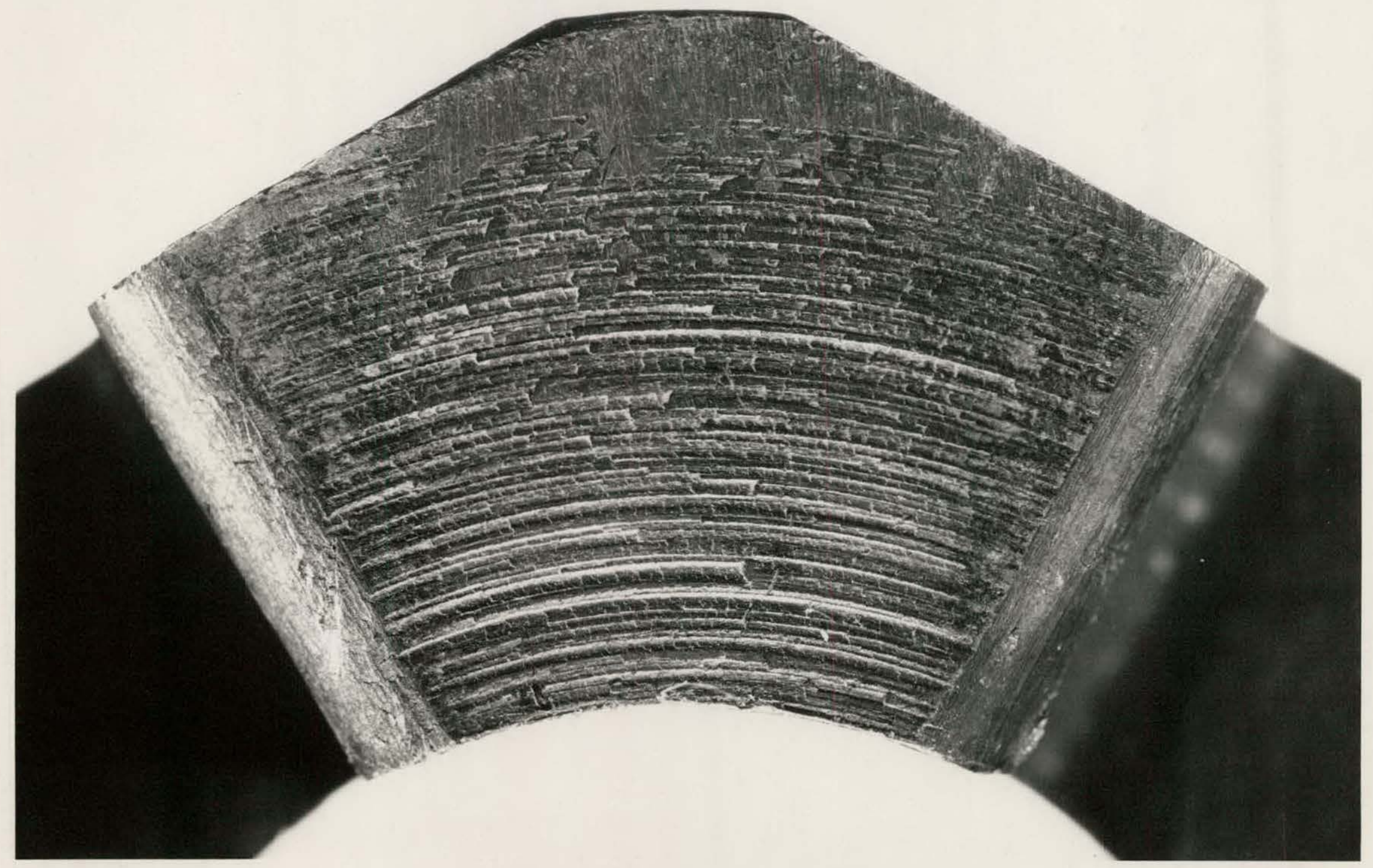

Figure 37. Tooth Surface Wear Pattern. 


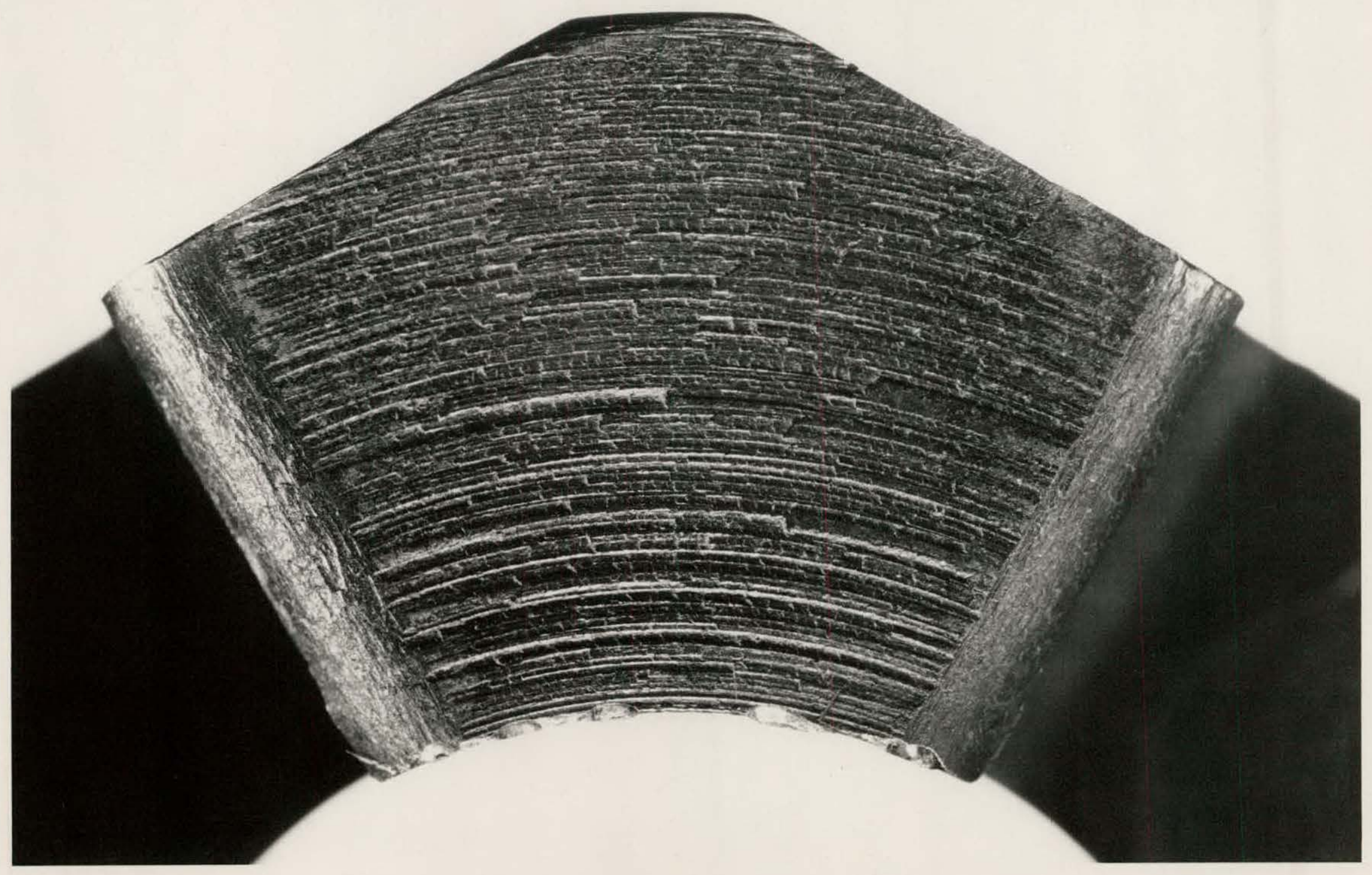

Figure 38. Tooth Surface Wear Pattern. 
chips. Figures 39 and 40 show the box and chips used for the study. The flexible shaft was rotated in this box at a speed of $357 \mathrm{rpm}$ for $1 \mathrm{hr}, 35 \mathrm{~min}$. The test was stopped at this time because there appeared to be no noticeable problem. Upon examination of the segments it was shown that there was no noticeable wear. How long an operating time would be necessary before failure or substantial wear would occur is unknown. Lack of time prevented extending this test to such a point. The equipment used for this study will be available during the later phases of investigation, and such tests could be used to check the wear characteristics of the final WSU design.

A real problem in the coal mine environment is the mishandling of equipment. Devising a test to simulate handling abuse is difficult. However, a $13 / 8$-in. diameter flexible shaft can be broken by applying a bending moment by hand. It does not take an unreasonable amount of effort to break the shaft in this manner. Figure 41 shows the shaft in its broken condition. This points out the need for a heavy-duty retention ring for connecting the flexible shafts together.

The destructive torsion tests provided failure information for comparison with stress calculations. The significance of the principal tensile stresses at the root of the tooth was apparent when the fracture was examined. An explanation of this mode of failure has to consider the possibility that the torsion force could be concentrated at the outer edge of the tooth face. The teeth faces were not machined on the radial paths indicated by angular dimensions shown in Figure 33. Tooth clearance was more readily obtained by milling faces of two teeth in a single pass and offsetting the cut faces a few thousandths from the true centerline. The surface thus generated could result in point contact; however, localized yielding would redistribute this force.

A consistent failure mode was not apparent for the 1-in. diameter specimens wherein direct and twisting shear stresses caused some of the teeth to shear off and in other instances a crack propagated from the base of the tooth down into the segment body. The failures on the $13 / 8$-in. shafts all started at the base of the tooth. A small number of failures indicated the critical twisting shear action and others had cracks propagating down into the segment body. The mean torsion loads for 1 -in. and $13 / 8$-in. diameter shafts were 9,733 in. $-1 \mathrm{~b}$ and 28,233 in. $-1 \mathrm{~b}$, respectively. The peak measured torques during our field tests were 1,785 in. $-1 \mathrm{~b}$ and 3,080 in. $-1 \mathrm{~b}$ for the 1-in. and $13 / 8$-in diameter shafts, respectively. The WSU design has adequate strength. 


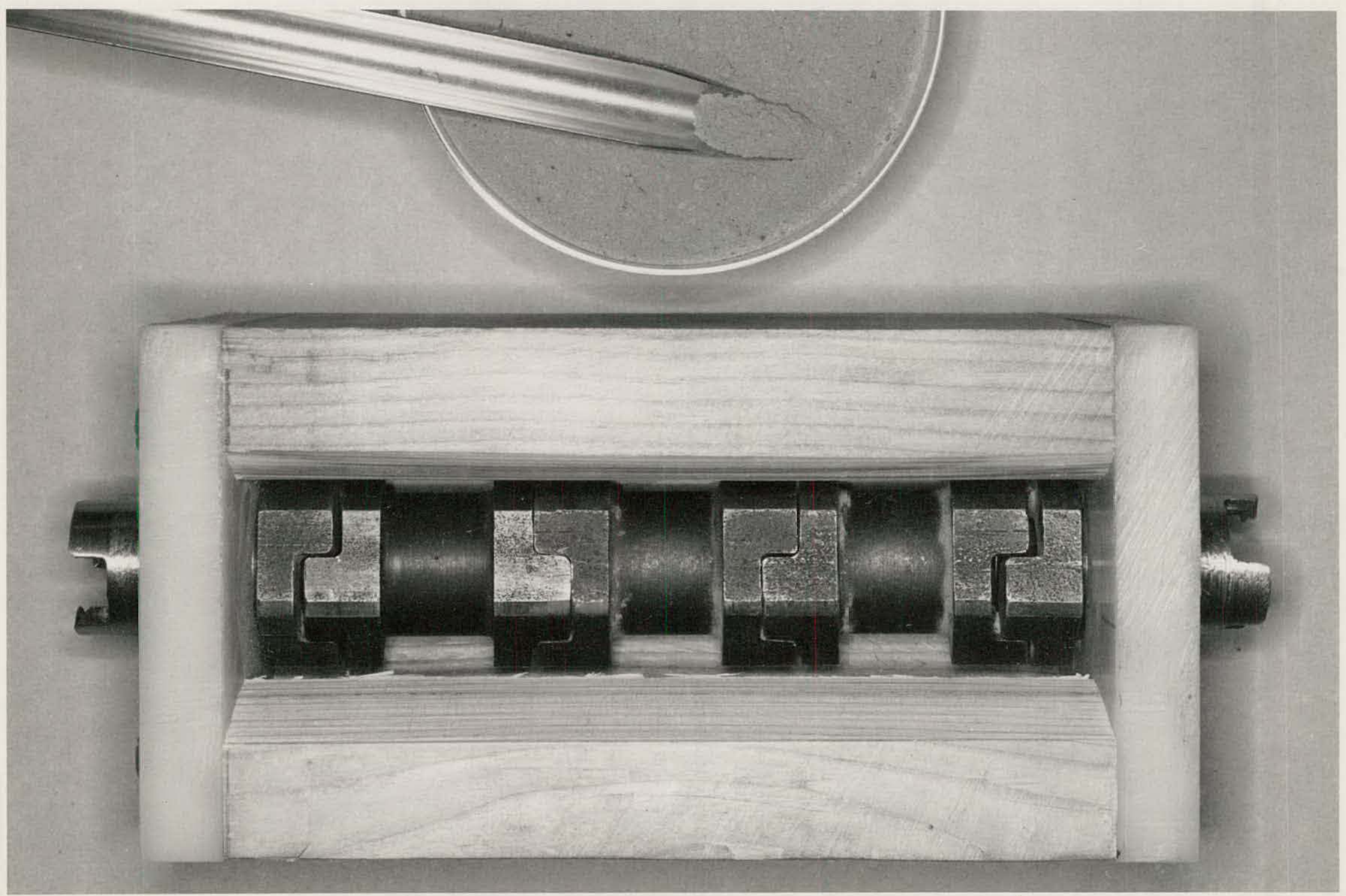

Figure 39. Wear Test Box with Drilling Chips. 


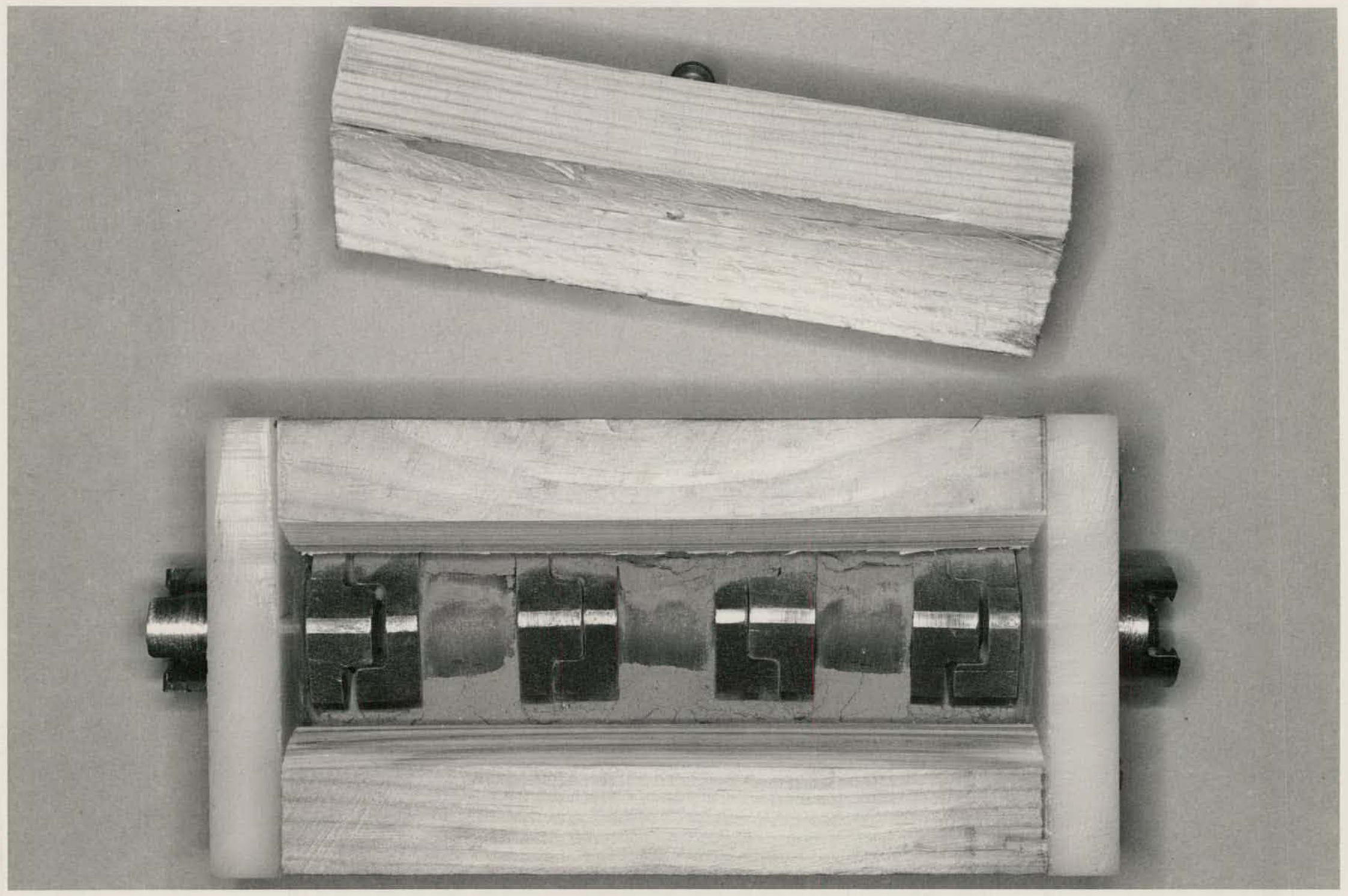

Figure 40. Wear Test Box as used During Test. 


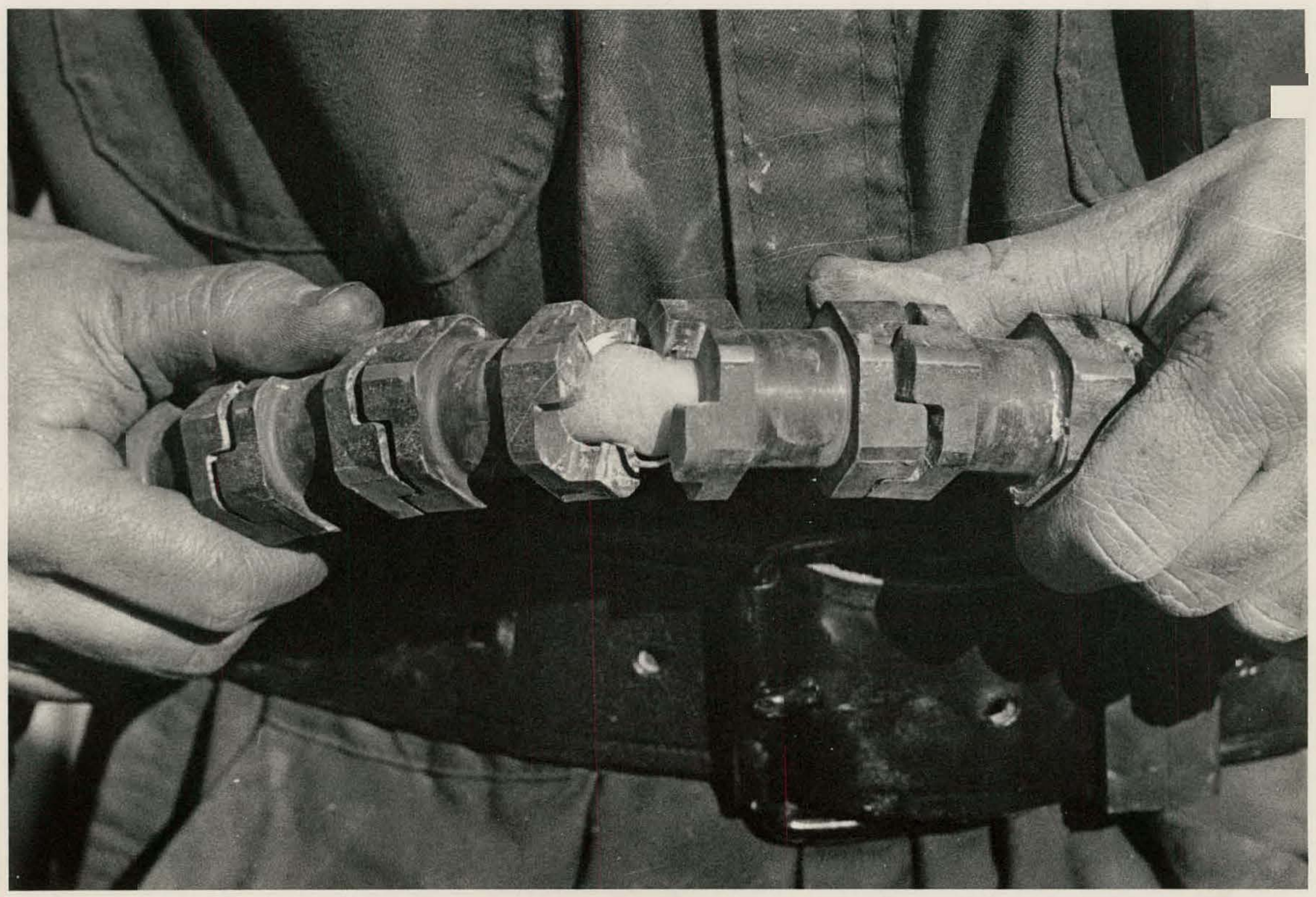

Figure 41. Shaft Broken by Mishandling. 
A rigid starter section serves two purposes. The first is that is provides a reasonable length of solid shafting for the drivehead to grasp as it starts the hole in the roof. Second, it prevents the drill hole from deviating more than $\sim 10^{\circ}$ from vertical. This tendency to deviate is caused by drill bits cut unevenly due to wear or lack of cutting edge symmetry, stratigraphy variations such as cracks or dipping strata, or excessive thrust force.

The proposed starter section is shown in Figure A-1. The hole curvature is a function of the distance between guide bushings, $b$, and the clearance distance, a, that occurs if the starter section always curves in the same direction by having the upper and lower guide bushing always bearing against the inner diameter of the hole as shown in Figure A-1. Mathematically, this situation can be evaluated by noting that the change in slope is given by

$$
\frac{d^{2} y}{d x^{2}}=\frac{b}{a}
$$

and the boundary conditions

and

$$
\frac{d x}{d y}=0 \quad \text { at } \quad y=0
$$

$$
x=0 \quad \text { at } \quad y=0
$$

The solution to Eq. (A-1) is

$$
x=\frac{a}{2 b} y^{2}
$$

The design required that

$$
\tan ^{-1} \frac{x}{y}=10^{\circ}
$$

For $y=8 \mathrm{ft}$ (96 in.), $x=16.9$ in.; Eq. (A-2) gives the relationship

$$
\mathrm{b}=273 \mathrm{a} \text {. }
$$



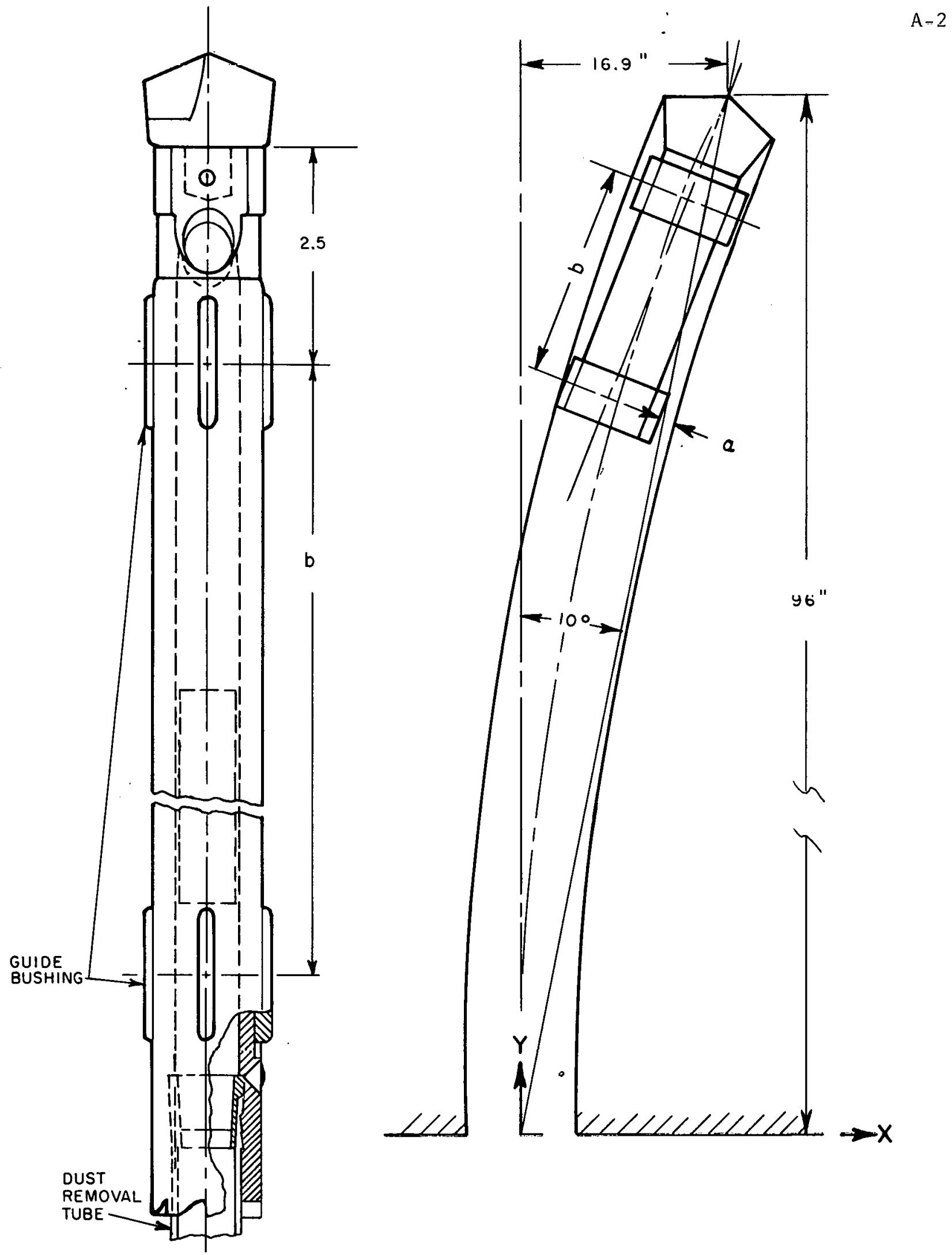
Appendix A showed how the length of the starter section and oversize of the hole affect the curvature of the hole. The segments of a segmental shaft will follow this curvature as shown in Figure B-1. For square teeth at the interlocking interface, the thrust force will be transmitted at a joint from segment to segment as shown in Figure B-1. At any. interface, the thrust force $F_{t}$ delivered by the drivehead will have a longitudinal force, $F_{1}$, and a side force, $F_{s}$, acting at the interface. For a given value of $F_{t}$, the value of $F_{1}$ will become smaller and the value of $F_{s}$. will become larger for segments deeper into the hole. The last segment before the starter section has the largest value of $F_{i s}$ and the smallest $F_{1}$.

To effectively drill, a minimum value of $\mathrm{F}_{1}$ must be maintained. The required drivehead thrust force for this minimum $F_{1}$ can be calculated by using the results of Appendix A. Let $y_{0}$ be the vertical depth to interface between last segment and starter segment. Using the curvature equation (A-2),

$$
\tan \phi=\frac{d x}{d y}=\frac{a y_{0}}{b}
$$

The required force relationships are

$$
F_{1}=F_{t} \sin \phi
$$

and

$$
F_{s}=F_{t} \cos \phi
$$

For a required $\mathrm{F}_{1}$

and

$$
F_{t}=\frac{F_{1}}{\sin \phi}
$$

$$
F_{s}=F_{1} \frac{\cos \phi}{\sin \phi}=\frac{F_{1} b}{a y_{0}}
$$




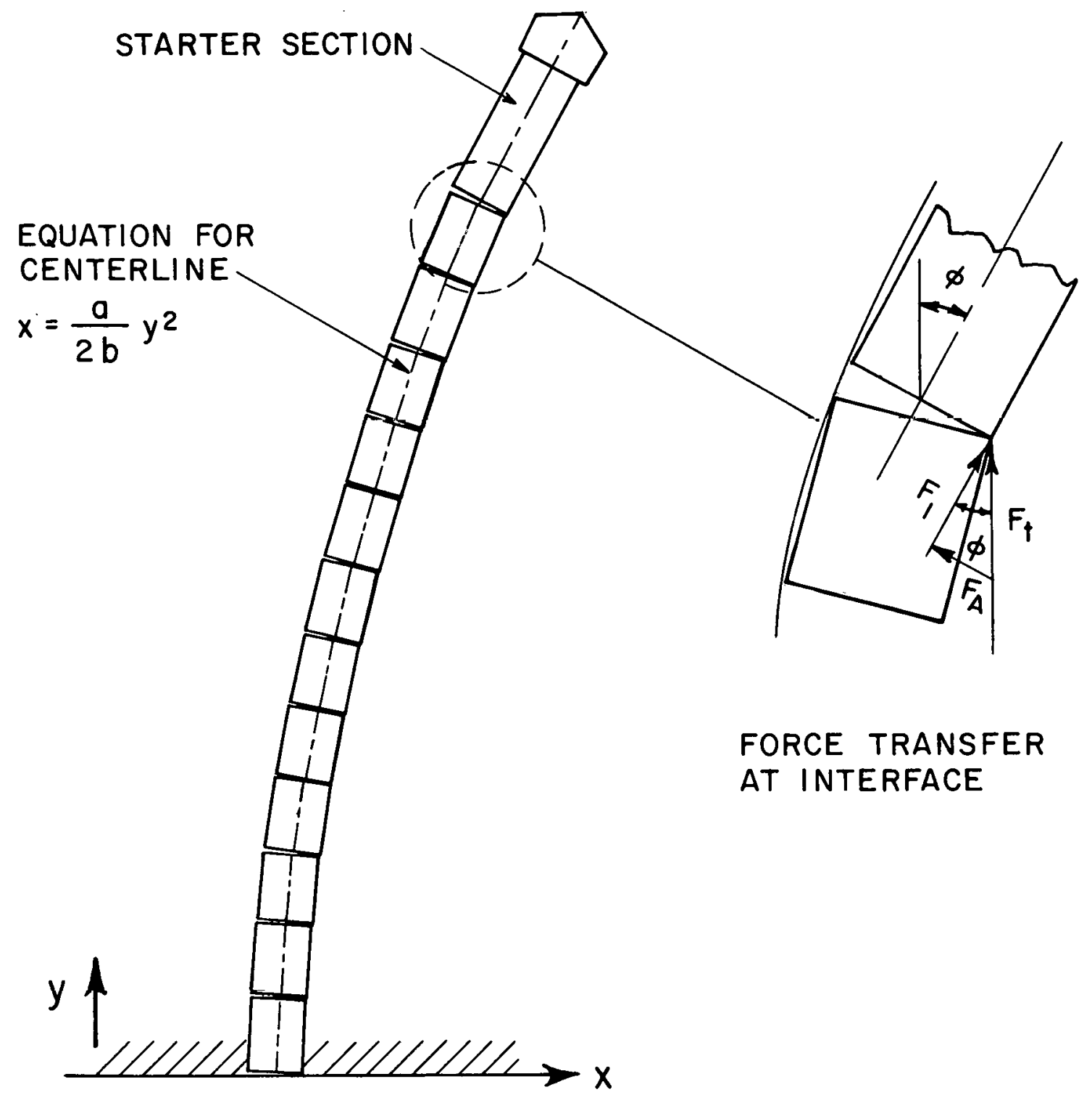

FIGURE B I. THRUST FORCE TRANSMISSION IN CURVED HOLE 
When the drivehead is located on the vehicle, the thrust load required to advance the drill must be transmitted through the shaft and around the curvature. The following analysis ignores dynamic forces of friction and shaft acceleration. This reduces the load analysis to the situation shown below:

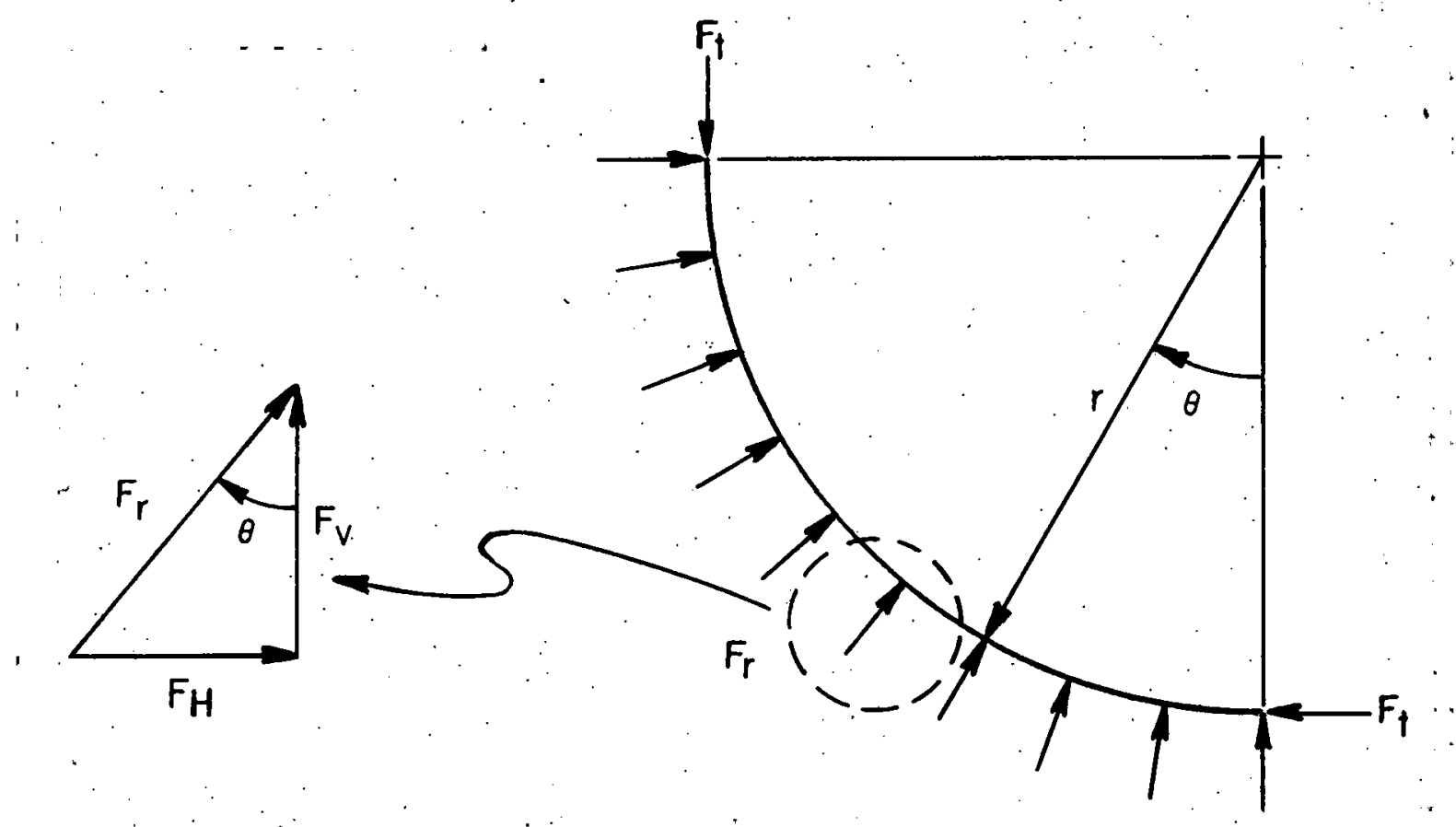

I

The horizontal and vertical force components, per unit length are $\mathrm{F}_{\mathrm{H}}$ and $\mathrm{F}_{\mathrm{V}}$, respectively, and are calculated from

and

$$
F_{v}=\frac{F_{t} \cos \theta}{r}
$$

$$
\mathrm{F}_{\mathrm{H}}=\frac{\mathrm{F}_{\mathrm{t}} \sin \theta}{\mathrm{r}}
$$

Proof of the above two relationships can be obtained by showing that

and

$$
\int_{0}^{\pi / 2} F_{v} \operatorname{rd} \theta=F_{t}
$$

$$
\int_{0}^{\pi / 2} F_{H} \operatorname{rd} \theta=F_{t} \text {. }
$$


The radial force per unit length, $F_{r}$, is

$$
\mathrm{F}_{\mathrm{r}}=\sqrt{\mathrm{F}_{\mathrm{H}}^{2}+\mathrm{F}_{\mathrm{v}}^{2}}
$$

Substituting Eqs. $(\mathrm{C}-1)$ and $(\mathrm{C}-2)$ into $(\mathrm{C}-3)$ results in

$$
F_{r}=\sqrt{\sin ^{2} \theta+\cos ^{2} \theta}=\frac{F_{t}}{r} \text {. }
$$

A thrust force of $6,0001 \mathrm{~b}$ transmitted through a flexible shaft having a 12 in. radius of curvature will require

$$
\mathrm{F}_{\mathrm{r}}=\frac{6000}{12}=500 \frac{1 \mathrm{~b}}{\mathrm{in} .} .
$$


Three interface categories were considered:

Type 1. Flexible interconnectors

Type 2. Toothed

Type 3. Male-female

These categories were chosen because they are representative of the common coupling methods which are compatible with hollow shafts. More exotic methods may have to be resorted to if no solution is found among these.

In the analysis to follow, strength estimates will be. made for singletooth contact, $50 \%$ tooth contact and $100 \%$ tooth contact. The results of the analysis presented below are summarized in Table D- 1 .

Type 1, Flexible Interconnectors

The flexible interconnector configuration is shown in Figure D-1. Note that the shear area of the shaft is approximately equal to the shear area of the flexible elements. The assumption here is that the shear strength of the connecting element and coupling will have to be equal. This would be the case if the coupling strength were critical. Shear is the assumed failure mode. Bending in either the steel jaws or flexible connectors is not considered. Shear stress, $\tau$, for single-element loading is calculated using Eq. (D-1)

$$
\tau=\frac{\frac{\text { torque }}{\text { mean tooth radius }}}{\text { cross-sectional tooth area }}
$$

It would be unrealistic to assume single-element loading for the Type 1 interface due to the assumed flexible nature of the interconnectors.

Type 2a, Square-Tooth

A square-toothed coupling is shown in Figure D-2. Stress estimates are based on the free-body diagram shown in the same figure, and the beam stress equation,

where

$$
\sigma_{\max }=\frac{M c}{I}
$$

\footnotetext{
*This apppendix has been extracted from the thesis, "The Design of a Flexible Shaft Roof Drill for Low Coal," by William A. McIlvanie, Masters Thesis, Washington State University, 1974.
} 
TABLE D-it;

Stress Comparison of Interface Types

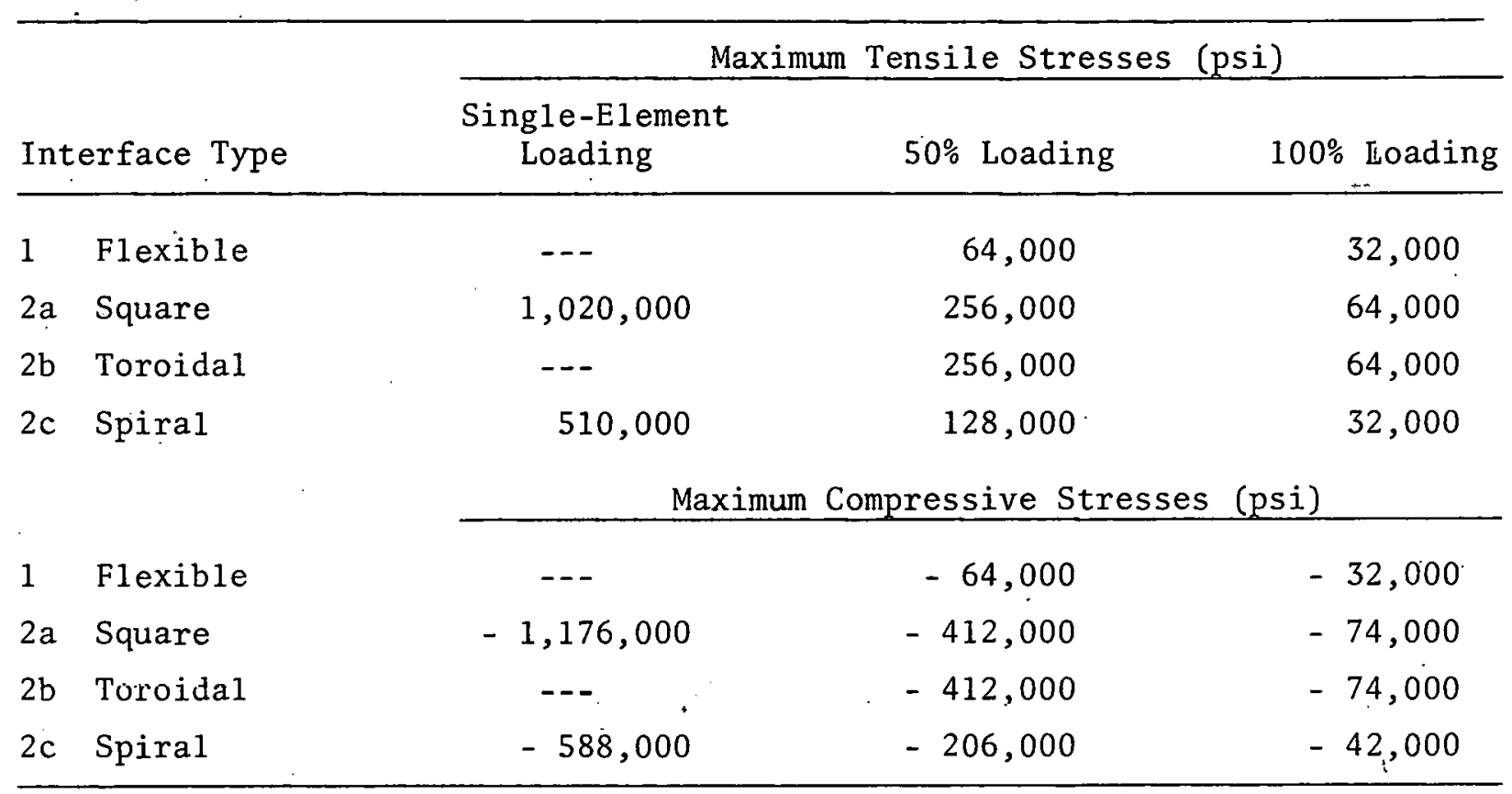



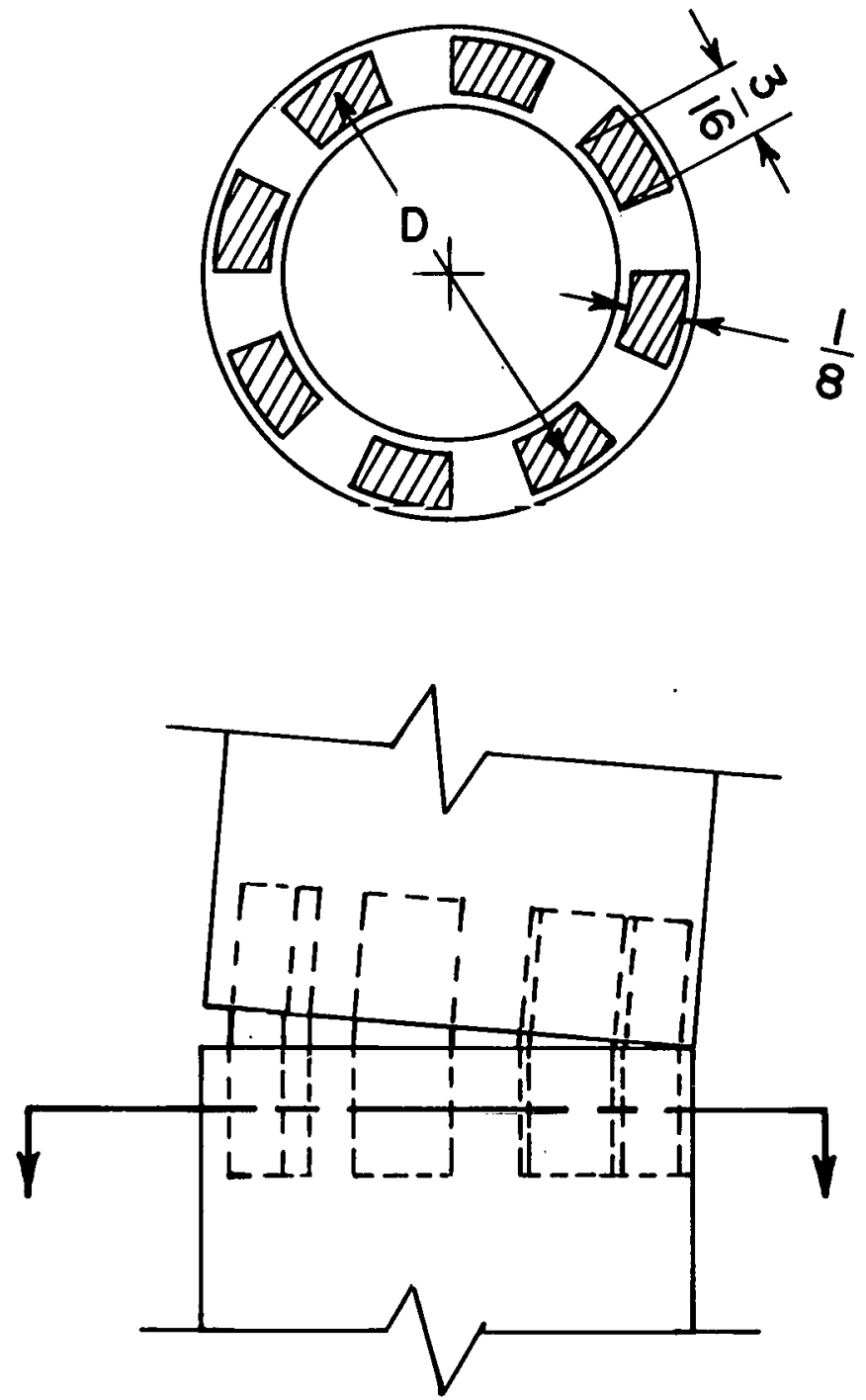

FIG. D-I. FLEXIBLE INTERCONNECTORS 

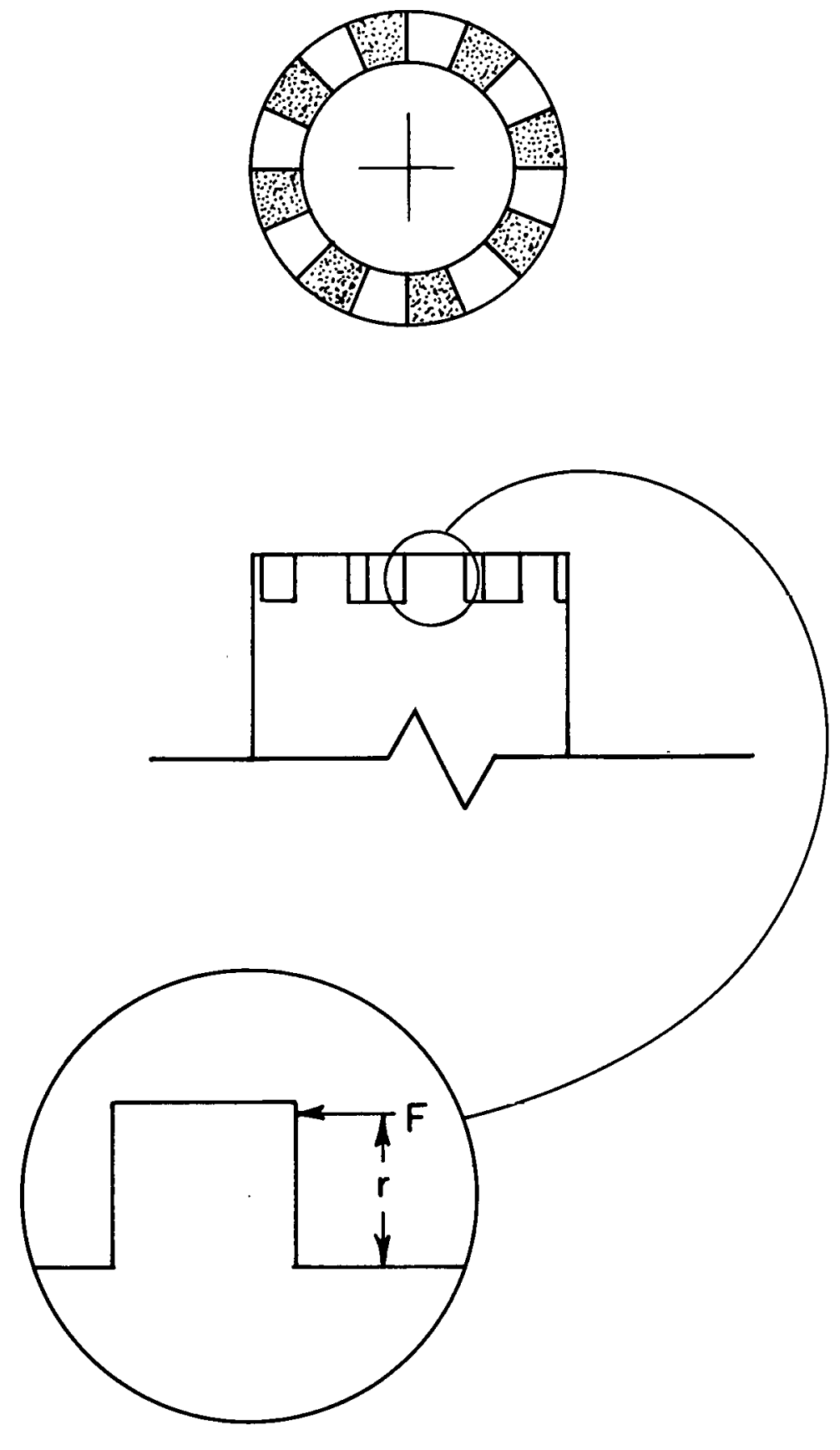

FIG. D-2. SQUARE TOOTH COUPLING 
$M=\frac{\text { Force } F \text { acting on the tooth at a distance } r \text { from the root }}{r}$

$F$ is chosen at the tip of the tooth in the case of single-tooth contact because of the anticipated gear action when the segments are misaligned and rotating. Since the teeth are square and not profiled, bearing will be either at the tip or at the root of the tooth. In the case of $100 \%$ contact, $F$ is assumed to act through the center of the tooth.

Type 2b, Ellipsoida1-Faced Tooth

Type $2 \mathrm{~b}$ is an ellipsoidal-faced toroidal toothed coupling and is shown in Figure D-3. A stress analysis of this tooth configuration is beyond the scope of this thesis. For preliminary comparisons, the analysis can be assumed the same as for the square-tooth with one exception. The geometry of this tooth is such that $50 \%$ contact will exist regardless of axis misalignment, and $100 \%$ contact will exist if the coupling axis is in alignment.

Type 2c, Spiral Tooth

A free-body diagram of the spiral tooth is shown in Figure D-4. Analysis of this tooth depends on its geometry. Theoretically it could have close to double the strength of the square tooth since its root thickness is double.

Thrust Loading on the Toothed Interfaces

Compressive stresses due to thrust loading would subtract from the tensile bending stresses, but small differences in tooth height could prevent a tooth from sharing any of the thrust load. Therefore, the thrust load is not considered when the maximum tensile stresses are calculated. The thrust load, however, will increase compressive stresses. Maximum compressive stresses are also tabulated in Table $\mathrm{D}-1$. These stresses are approximated by summing the bending stress and the stress due to thrust. For shaft misalignment cases, where only partial tooth contact exists, the thrust stresses are calculated by dividing the root area of a single tooth into the thrust force. When $100 \%$ contact exists, the thrust stress is calculated by dividing the cross-sectional area of the drill shaft into the thrust force. 

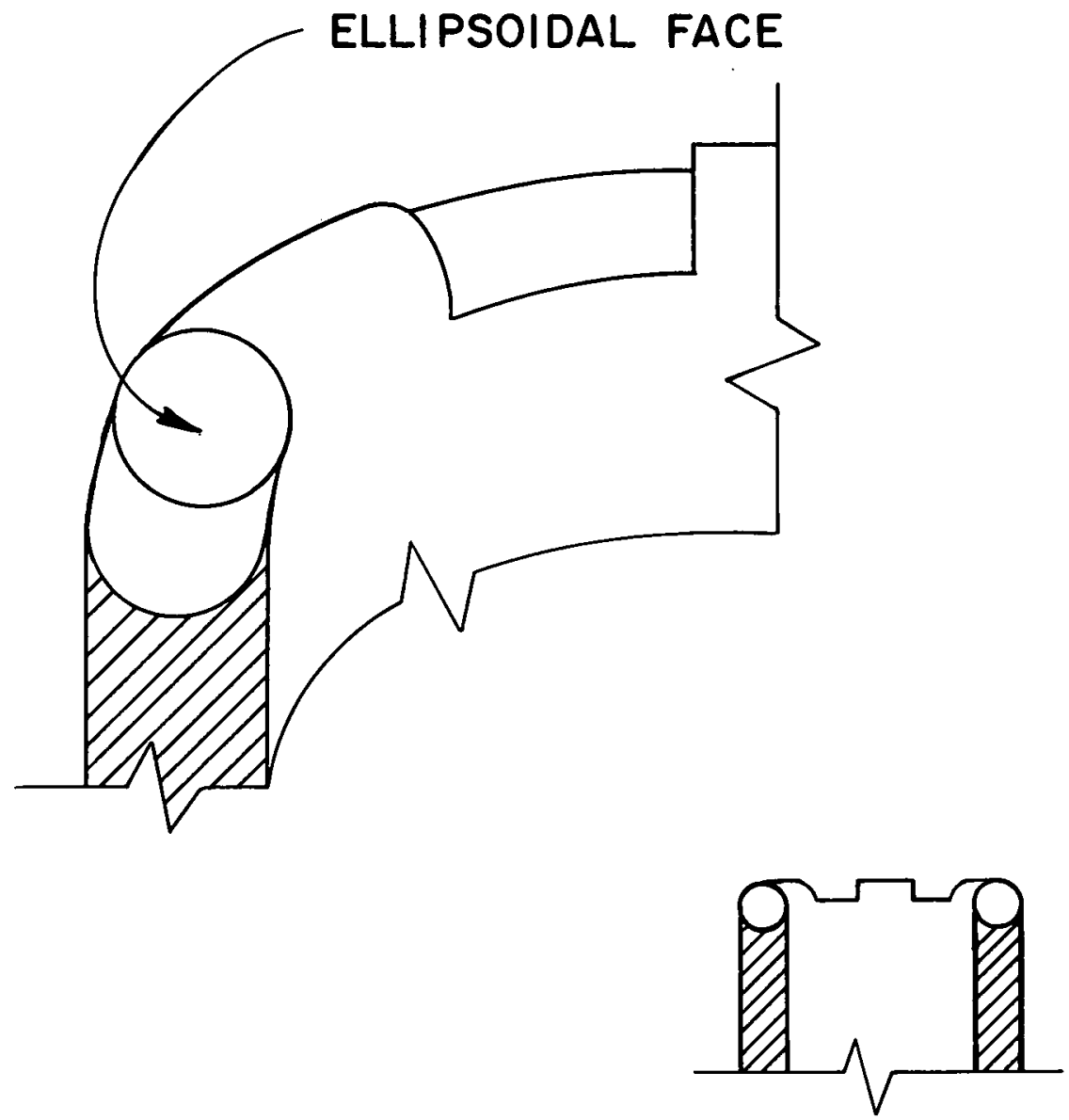

FIG. D-3. ELLIPSOIDAL FACE TOROIDAL TOOTH COUPLING 


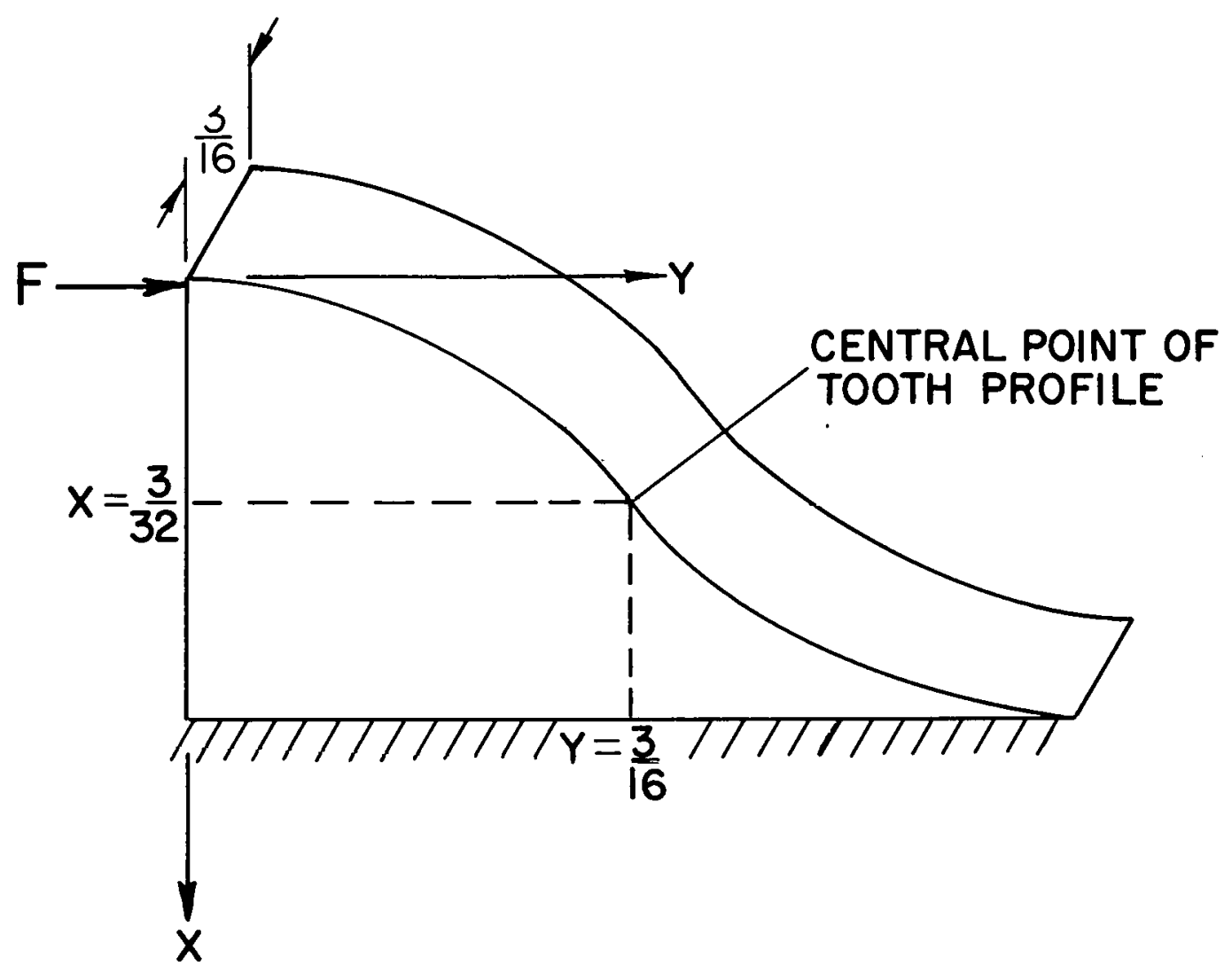

FREE BODY DIAGRAM OF SPIRAL TOOTH

(a)

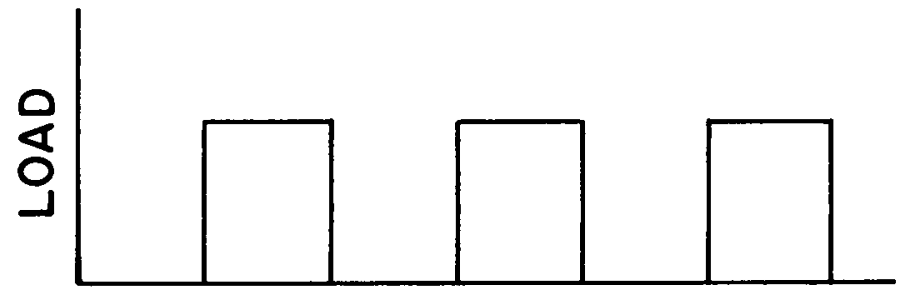

TIME

IDEALIZED LOADING CYCLE FOR $50 \%$ TOOTH CONTACT

(b)

FIG. D-4 SPIRAL TOOTH LOADING 
Type 3, Male-Female

Male-female fittings are currently used to connect drill rods. Although these fittings are already known to have enough strength, they would be difficult to make compatible with the overall system. They are long and not easily decoupled for bending around the corner.

\section{Selecting the Best Interface}

Table D-l shows that of the tooth type couplings, the spiral-toothed configuration, Type $2 \mathrm{c}$, is strongest for $100 \%$ contact or the aligned case. Type $2 b$ is strongest for the misaligned cases. The optimal tooth geometry would be a marriage of these two. A discussion of such a geometry is beyond the scope of this paper. Suffice it to say that a combination ellipsoidal would be very difficult to analyze or manufacture.

The flexible interconnector type has relatively low stresses for the assumed failure mode. Unfortunately, no highly elastic material with an ultimate shear stress near 50,000 psi is available for this application.

For the present, the spiral-toothed coupling is assumed to be best, hoping that single-tooth contact will never exist with this configuration.

Optimization of the Spiral-Tooth Profile

The optimum tooth profile will be such that the maximum principal stress will be minimum at all points on the face of the tooth. The tooth profile is assumed to lie on a plane rather than on a cylinder. The load is assumed to act at the tip of the tooth, corresponding to the worst case. Figure D-4a is a free-body diagram of the spiral tooth. The root. thickness of each tooth will be $3 / 8$ in. if the coupling is assumed to have a total of 8 teeth and a mean interface diameter of 1 in. Because a 1/8-in. gap may exist between segments in the curved section of the shaft, tooth height will be $3 / 16$ in. to ensure that there will be no partial disengagement of the teeth. It is feared that partial disengagement may cause the shaft to chatter or bind.

The assumed loading cycle is shown in Figure D-4b. A $10^{7}$ cycle life is desired; therefore, if the coupling material is AISI 4340 steel with an ultimate strength $\mathrm{S}_{\mathrm{u}}=180,000 \mathrm{psi}$,

$$
\begin{aligned}
\sigma_{\max } & =0.68 \mathrm{~s}_{\mathrm{u}}{ }^{1} \\
& =120,000 \mathrm{psi}
\end{aligned}
$$


From Figure D-4a, the moment, $M$, of any section is given by

$$
\mathrm{M}=\mathrm{Fx} \text {. }
$$

Therefore the bending stress, $\sigma_{b}$ from Eq. (D-2), at any point along the $x$-axis is given by

$$
\sigma_{b}=\frac{32 F x}{y^{2}}
$$

The shear stress, $\tau$, at any point along the $x$-axis is given by

$$
\tau=\frac{16 \mathrm{~F}}{3 y} \text {. }
$$

The maximum principal stress along any point of the tooth face becomes

$$
\sigma_{\max }=\left(\tau^{2}+\frac{\sigma_{b}^{2}}{2}\right)^{1 / 2}
$$

Substituting for $\tau, \sigma_{b}$, and $\sigma_{\max }$ into Eq. (D-5) results in

$$
120,000=\left[\left(\frac{16 F}{3 y}\right)^{2}+\left(\frac{16 F x}{y^{2}}\right)^{2}\right]^{1 / 2}
$$

Past the central point of the tooth, in this case $x=3 / 32, y=3 / 16$, the tooth assumes the shape of the mating tooth which is identical in profile. Therefore the central point of any profile is known. Substituting $x=3 / 32$ and $y=3 / 16$ into $\mathrm{Eq} .(\mathrm{D}-6)$ and solving for $\mathrm{F}$ yields

$$
\mathrm{F}=2350 \mathrm{1b} \text {. }
$$

With $F=23501 \mathrm{~b}$, at least three of the eight teeth must share the load equally to provide the necessary 3000 in.-1b torque.

The tooth profile governed by Eq. (D-6) is probably not optimum. Material selection and manufacturing methods will cause changes in the profile. Eventually coupling strength will have to be determined experimentally. What has been presented is a simple procedure for optimizing tooth profile given the number of teeth, their height, width, and material strength. 
APPENDIX E

SNAP-RING SEGMENTAL SHAFT DESIGN

A shaft made up of snap-ring segments is shown in Figure 19 and details of the shaft segments shown in Figure E-8. The design parameters that restrict the bending of the shaft are shown in Figure E-1, where

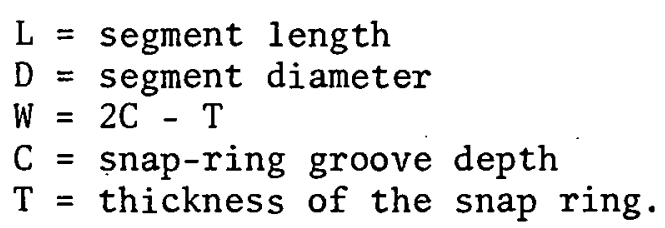

The radius of curvature, $R$, is given by

$$
\mathrm{R}=\frac{\mathrm{DL}}{\mathrm{W}} \text {. }
$$

Based on Eq. (E-1), the design shown in Figure E-8 will have a bend radius of 7.2 in.

\section{Static Stress Analysis}

The segment profile used for this stress analysis is shown in Figure E- 2 . The stress analysis is based upon the segments being in misalignment so the torque and thrust loads are concentrated at points rather than being distributed.

The 5,000-1b compressive force shown in Figure E-2 causes a bending moment at section a-a. As the shaft rotates, the combined stresses due to the compressive force and bending moment result in alternating longitudinal stresses at section a-a. Adding to these are shear stresses at section a-a caused by the torque load of 3,000 in. $-1 b$. The calculation of these stresses is as follows :

1. Shear stress, $\mathrm{S}_{\mathrm{S}}$

where

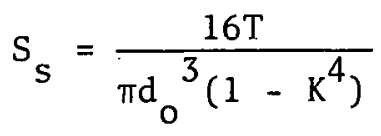

$$
\begin{aligned}
& \mathrm{T}=\text { torque, } 3000 \text { in. }-1 \mathrm{~b} \\
& \mathrm{~d}_{\mathrm{O}}=\text { outside diameter }=1 \mathrm{in} . \\
& \mathrm{K}=\text { ratio of } \mathrm{I} . \mathrm{D} . \text { to } 0 . \mathrm{D} .=0.75 \mathrm{in} .
\end{aligned}
$$

Substituting these values into Eq. (E-2) gives

$$
S_{S}=22,350 \text { psi. }
$$




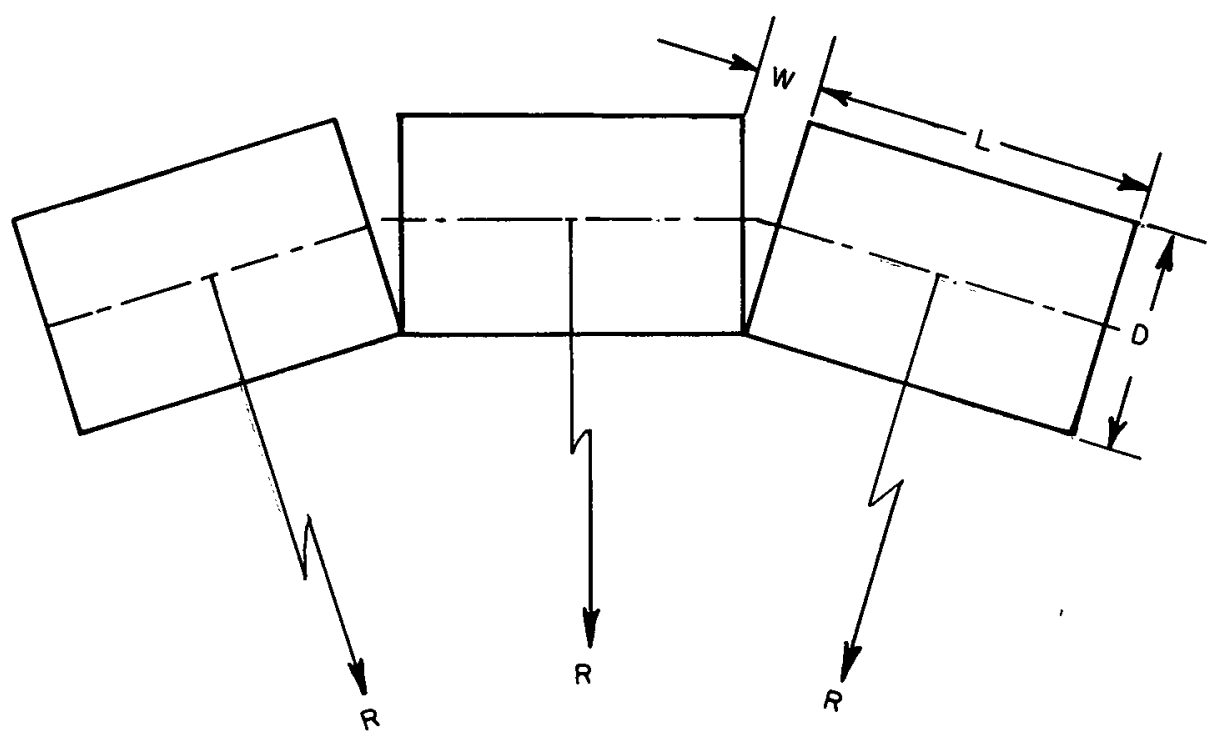

+ CEnter of curvature

FIGURE E-I. RELATIVE GEOMETRY OF SHAFT SEGMENTS
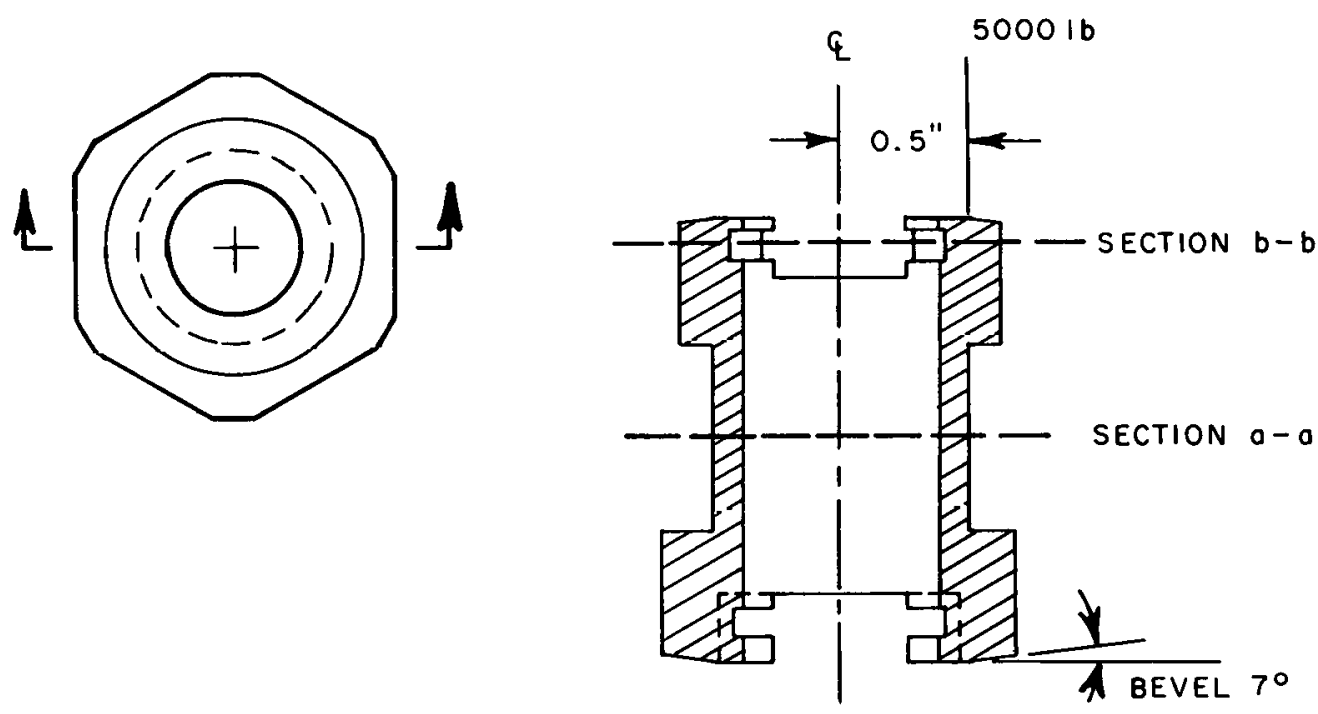

SECTION A-A

FIGURE E-2. STRESS ANALYSIS FOR SHAFT SECTION 
2. Compressive stress due to thrust load, $S_{c t}$

$$
S_{c t}=\frac{4 F}{\pi_{d_{0}^{2}}^{2}\left(1-k^{2}\right)}
$$

where $\mathrm{F}_{t}=-5000 \mathrm{1b}$. Therefore, $\mathrm{S}_{\mathrm{ct}}=-14,551 \mathrm{psi}$.

3. Bending moment stresses, $s_{b}$

The applied bending moment is $M=(5000)(0.5)=2500$ in. $-1 \mathrm{~b}$. and results in stresses at the surface of

$$
S_{M}=\frac{32 M}{\pi d_{0}^{3}\left(1-k^{4}\right)}= \pm 37,250 \text { psi }
$$

4. Combined stresses

a. combined longitudinal stresses, $\mathrm{S}_{1}$

$$
\mathrm{S}_{1}=-14,551 \pm 37,250 \mathrm{psi}
$$

or $-51,800$ psi to 22,700 psi.

b. The combined maximum longitudinal stresses are obtained from

$$
s_{1}, \max =\frac{s_{1}}{2} \pm\left(\frac{s_{1}^{2}}{2}+s_{s}^{2}\right)^{1 / 2}
$$

For $\mathrm{s}_{1}=22,700 \mathrm{psi}, \mathrm{s}_{1}, \max =36,418 \mathrm{psi}$. For $\mathrm{s}_{1}=-51,800 \mathrm{psi}, \mathrm{s}_{1}, \max =$ $-60,110$ psi.

c. The combined maximum shearing stresses are

$$
s_{j}, \max =\left(\frac{s_{1}^{2}}{2}+s_{s}^{2}\right)^{1 / 2}=34,210 \text { psi }
$$

At section $b-b$, the critical stresses are due to the tooth loads shown in. Figures E-3 and E-4. The combined effects of these stresses are obtained as follows:

1. Shearing stress, $\mathrm{S}_{\mathrm{s}}$

Estimated area of one tooth $=1 / 4$ (hex area - hole area $)=1 / 4(1.003-$ 0.4417 ) $=0.155$ in. ${ }^{2}$. Then

$$
s_{s}=\frac{3000}{0.155}=19,354 \text { psi. }
$$




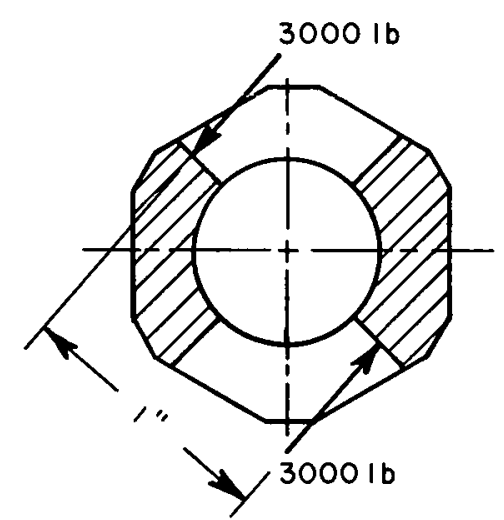

FIGURE E-3. FORCE COUPLE RESULTED FROM TORSION

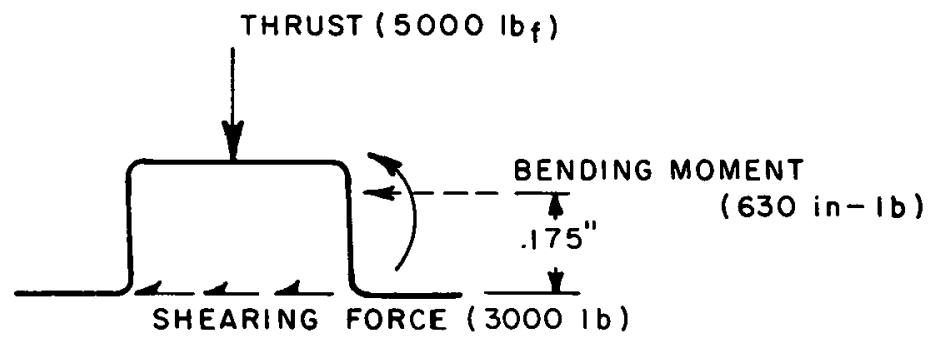

FIGURE E-4. LOAD PATTERN ON SHAFT TOOTH

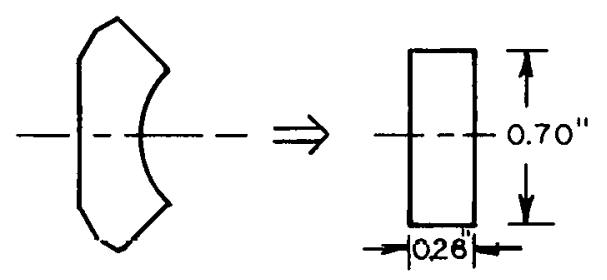

FIGURE E-5. APPROXIMATE SECTION MODULUS FOR SHAFT TOOTH 
2. Compressive stress due to thrust load, $\mathrm{S}_{c t}$

$$
S_{c t}=\frac{5000}{0.155}=33,258 \mathrm{psi} \text {. }
$$

3. Bending moment stresses, $\mathrm{S}_{b}$

$$
\text { bending moment, } M=(3000)(0.175)=525 \text { in. }-1 \mathrm{~b} \text {. }
$$

Figure 5 is used to approximate the moment of inertia using

Then

$$
I=\frac{\mathrm{bh}^{3}}{12}=\frac{(0.26)(0.70)^{3}}{12}=0.0074 \mathrm{in.}^{4}
$$

$$
\mathrm{S}_{\mathrm{b}}=\frac{\mathrm{M}_{\mathrm{c}}}{\mathrm{I}}=\frac{(525)(0.45)}{0.0074}=31,900 \mathrm{psi}
$$

where the value of $c=0.45$ represents the point of maximum bending stress.

4. Combined stresses

For the misaligned case, the 5000-1b thrust load and the 3000-1b bending moment load shown in Figures E-3 and E-4 will not occur at the same time.

This is due to the way that the teeth engage and the point loads move during rotation of the shaft. Based on this, the combined stress conditions are

a. combined stresses due to bending and shearing:

$$
\mathrm{S}_{1}, \max =\frac{31,900}{2}+\left(\frac{31,900^{2}}{2}+19,354^{2}\right)^{1 / 2}=41,000 \mathrm{psi}
$$

b. combined stresses due to thrust and shear:

$$
\mathrm{S}_{1} \max =\frac{-33,258}{2}-\left(\frac{33,258^{2}}{2}+19,354^{2}\right)^{1 / 2}=-42,145 \mathrm{psi}
$$

c. combined shear stress:

$$
S_{s}, \max =\left(\frac{31,900^{2}}{2}+19,354^{2}\right)^{1 / 2}=25,100 \mathrm{psi} \text {. }
$$

d. summary of combined stresses at the root of the tooth:

$$
\begin{aligned}
& \text { maximum stress }=41,000 \mathrm{psi} \\
& \text { minimum stress }=0 \mathrm{psi} \\
& \text { mean stress }=20,500 \mathrm{psi} \\
& \text { alternating stress }=20,500 \mathrm{psi}
\end{aligned}
$$


Dynamic Stress Analysis

The dynamic stress analysis is based upon a shaft that is always misaligned so that loading conditions shown in Figures E-2, E-3 and E-4 always exist. As such, every time the shaft makes a revolution, a stress cycle will occur. The total number of cycles per year can be calculated from the following data:

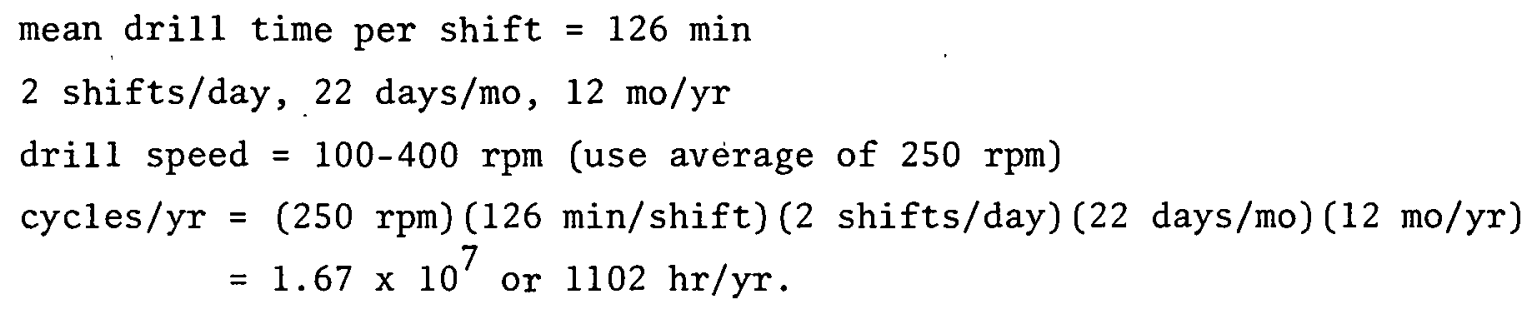

The properties for the two materials are

\begin{tabular}{lcc}
\hline \multirow{2}{*}{ Property } & \multicolumn{2}{c}{ Material } \\
\cline { 2 - 3 } $4340^{\star}$ & 1040 \\
\hline ultimate strength & $182 \mathrm{ksi}$ & $100 \mathrm{ksi}$ \\
yield strength & $162 \mathrm{ksi}$ & $88 \mathrm{ksi}$ \\
Brinnel hardness & 363 & 207 \\
\hline
\end{tabular}

* 0 il-quenched from $1550^{\circ} \mathrm{F}$ and tempered at $1000^{\circ} \mathrm{F}$.

The nominal mean stress method will be used to estimate the fatigue life. The reference for this method and the source of the stress concentration factors is the book, Stress, Strain, and Strength, by Juvinal1.

The critical section for fatigue is the root of the tooth. The stress concentration factor at $10^{6}$ cycles, $K_{f}$, for the location based on a radius of 0.1 in. and a height of $0.75 \mathrm{in}$. is 1.7 . At $10^{3}$ cycles, the stress riser is $49 \%$ effective, and this finite life factor, $K_{f}^{\prime}$, is $K_{f}^{\prime}=1+(0.49)(1.7-1)=$ 1.343 .

To determine the S-N curves for these two materials, the following formulas are used:

at $10^{6}$ cycles,

$$
S_{n}=\frac{(0.5) S_{u} C_{s} C_{L} C_{D}}{K_{f}}
$$

at $10^{3}$ cycles,

$$
S_{10^{3}}=\frac{(0.75) S_{u}}{. K_{f}^{\prime}}
$$

where 
$\mathrm{S}_{\mathrm{u}}=$ ultimate strength for the material

$\mathrm{C}_{\mathrm{s}}=$ surface factor $=0.65$ for the machined surface

$C_{L}=10 a d$ factor $=0.9$ due to eccentricity

$C_{D}=$ size factor $=0.9$ for diameter bigger than 0.4 in.

Applying Eqs.(E-7) and (E-8) to the two materials under consideration provides the $\mathrm{S}-\mathrm{N}$ curves shown in Figure E-7.

The Goodman diagram for these two materials based upon a mean stress of 20,500 psi and alternating stress of 20,500 psi is shown in Figure E-6. Combining the Goodman diagram results with the $S-N$ curve provides an estimate of fatigue life:

\begin{tabular}{cc}
\hline Material & Estimated Life \\
\hline 4340 & infinite \\
1040 & $1.2 \times 10^{5}$ cycles \\
\hline
\end{tabular}

For the 1040 material, this would represent 283 holes. 


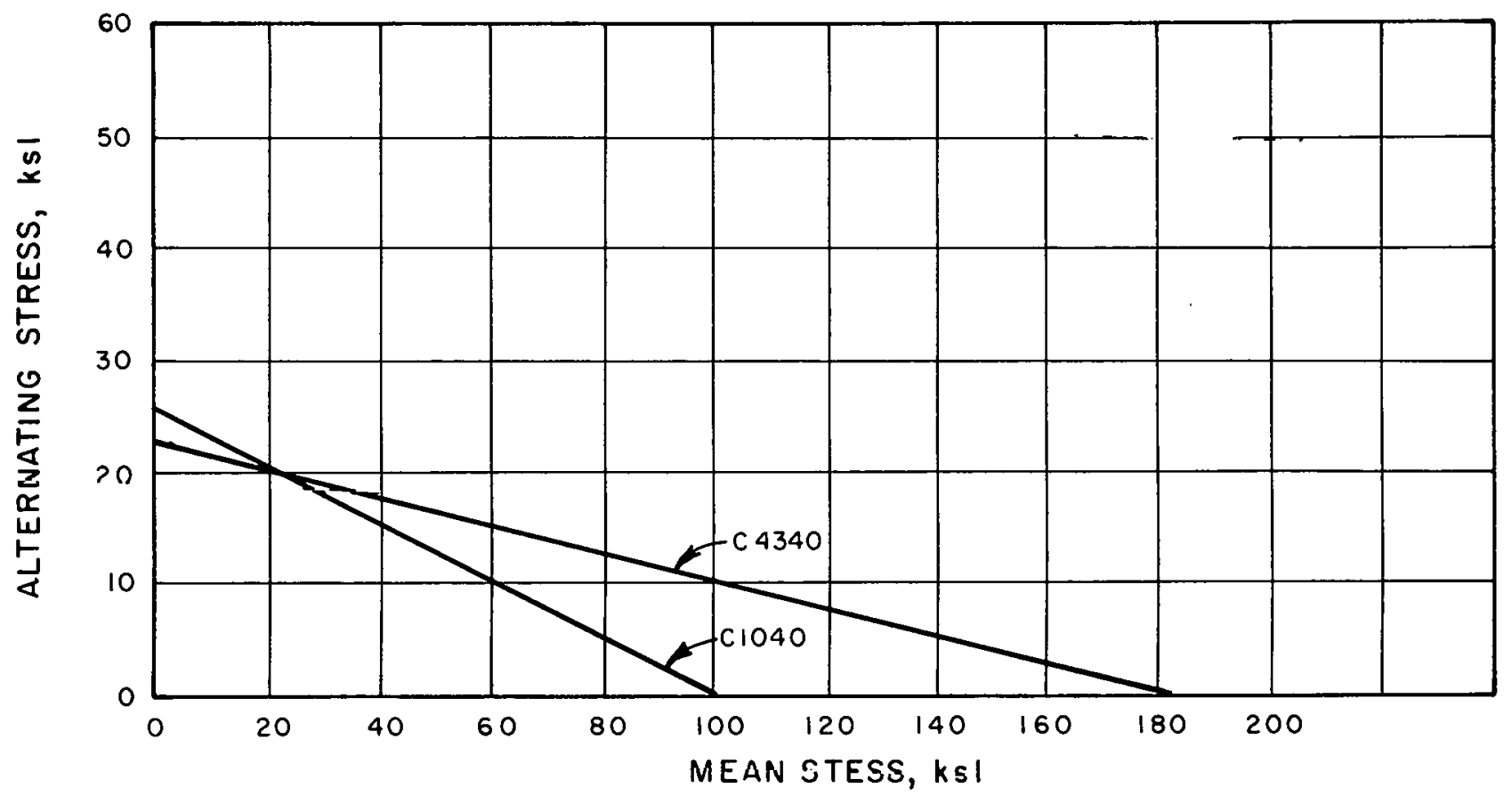

FIGURE E- 6. GOODMAN DIAGRAM FOR SNAP-RING SEGMENT LOADING

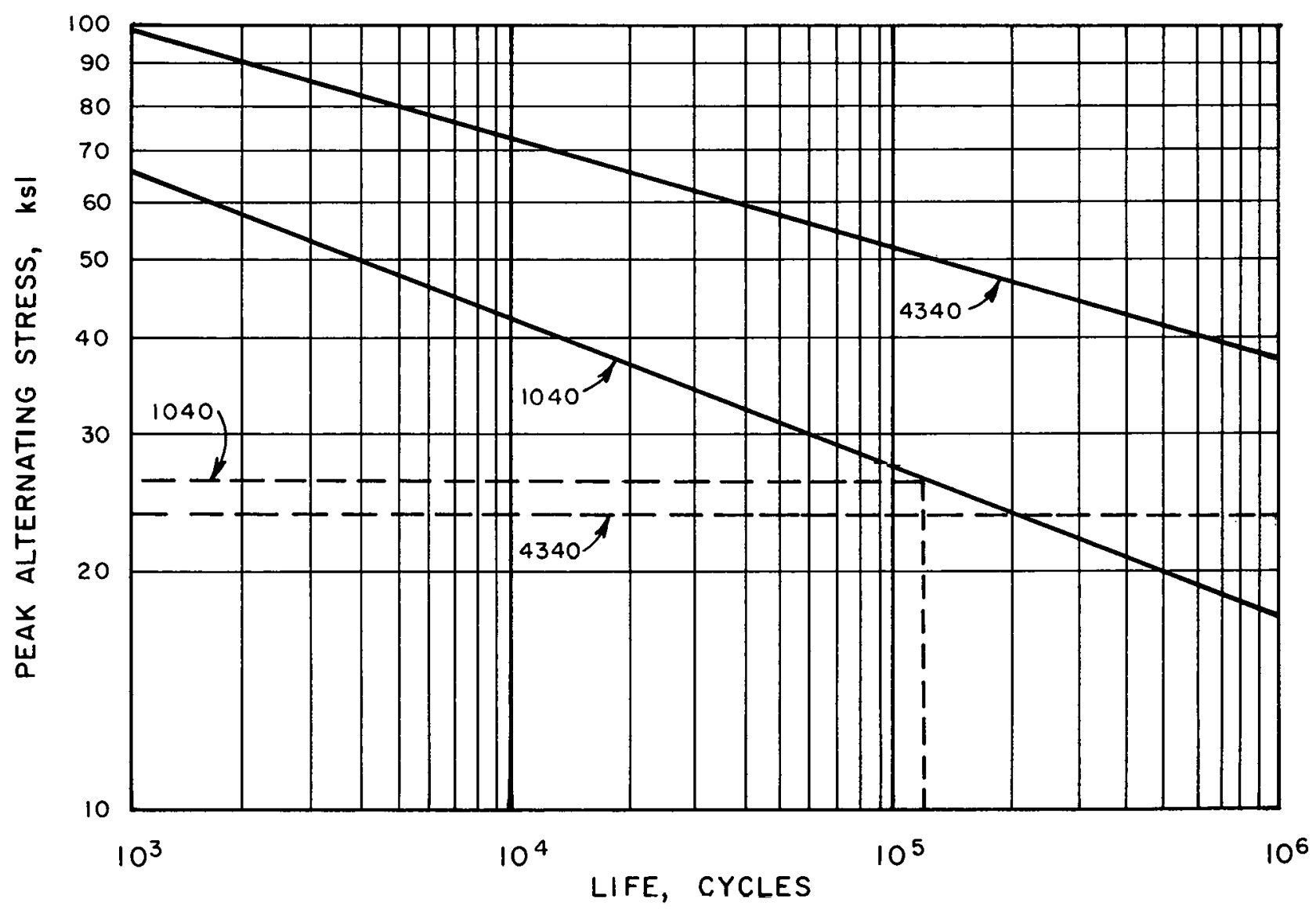

FIGURE E - 7. FATIGUE STRENGTH DIAGRAM FOR SNAP-RING SEGMENTS 


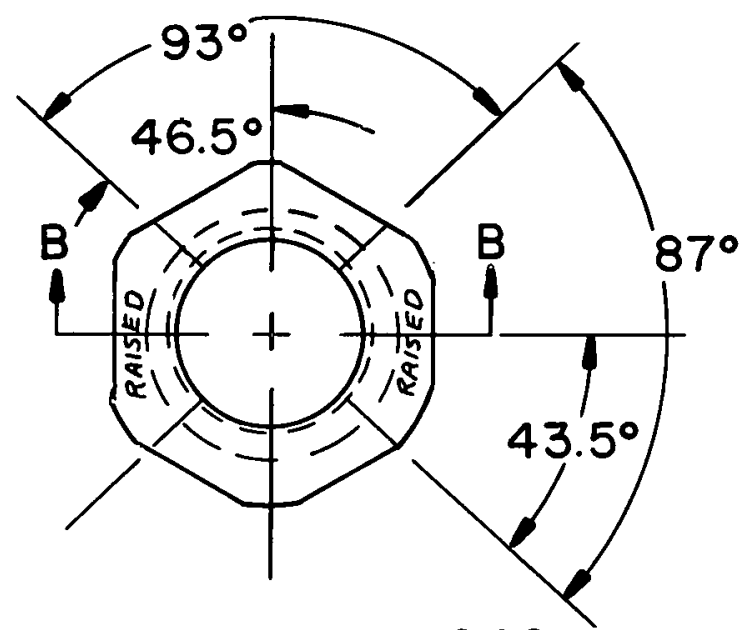

SNAP RING

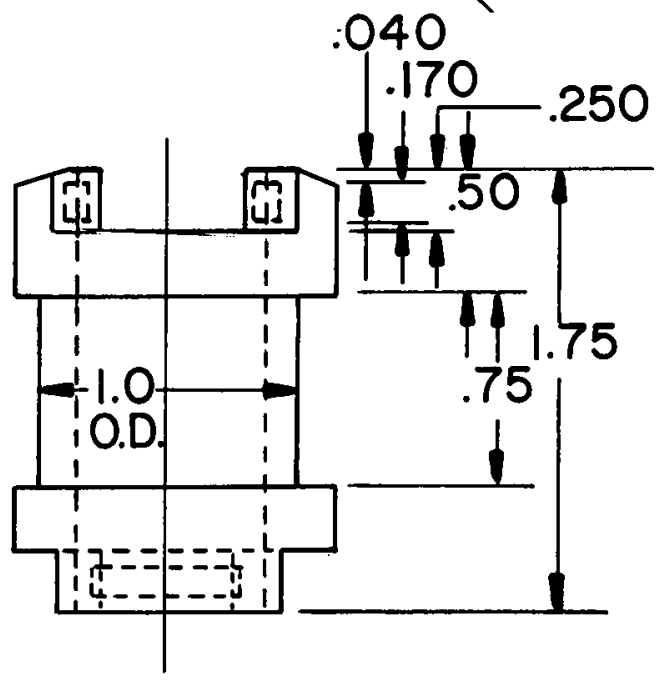
GROOVE
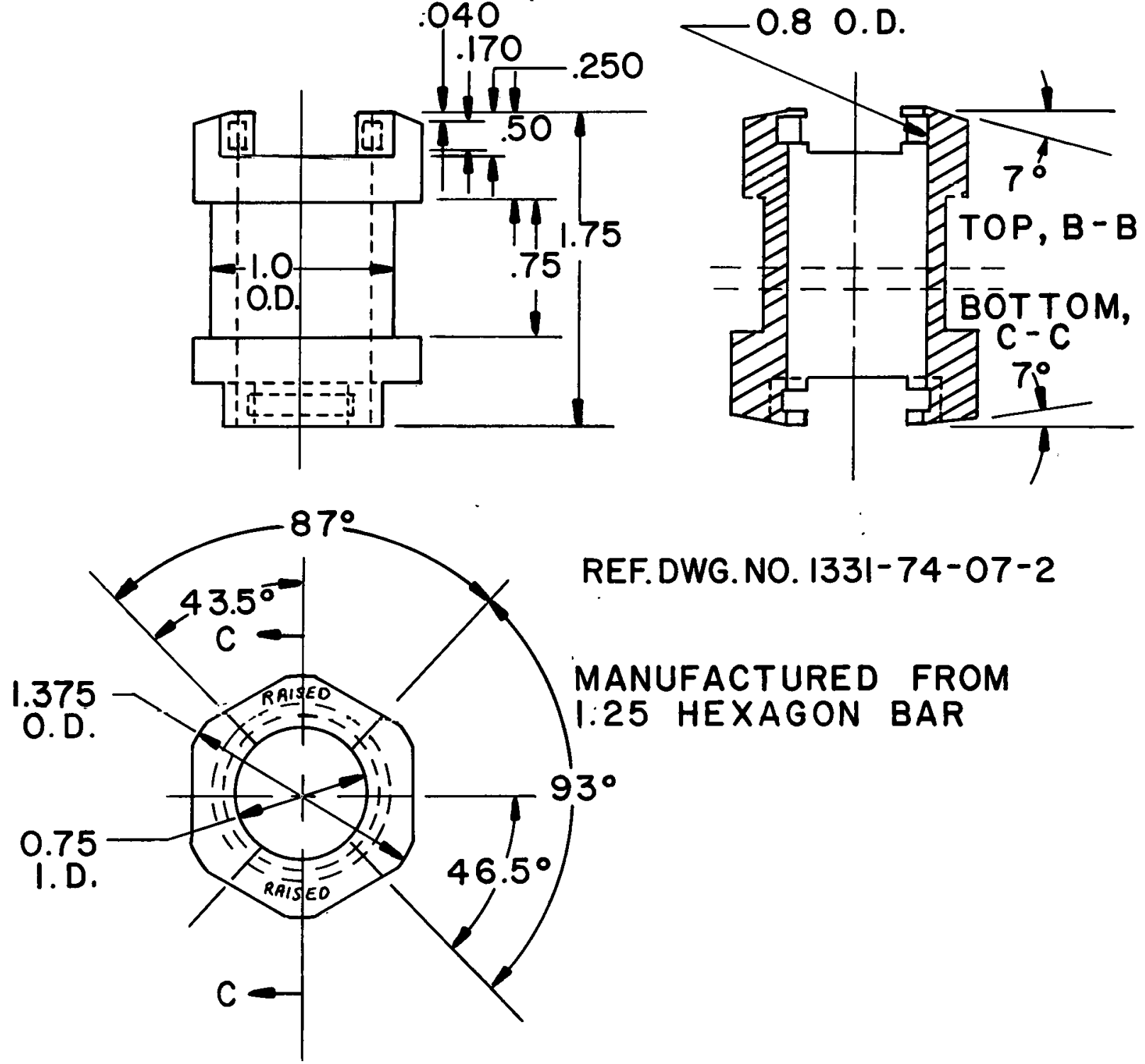

FIG. E-8 HEXAGON BAR SEGMENT 
A shaft made up of segments is shown in Figures 21 and F-1. The curvature of the shaft is determined by the top angle on the inner surface of the segment and the length of the cylindrical clip. This method of retention reduces the wall thickness of the center so that the critical design stresses occur here rather than in the interlocking teeth, as was shown in Appendix $E$ for the snap-ring concept. This conclusion was based on the same calculation procedure used in Appendix E.

At the narrow waist shown in Figure F-1, the state of stress can be calculated using Eqs. (E-1) through (E-6). The calculated stresses are:

1. shear stress, $S_{S}=41,640$ psi

2. compressive stress, $S_{c t}=31,160$ psi

3. bending moment stresses, $\mathrm{S}_{\mathrm{M}}=69,400 \mathrm{psi}$

4. combined stresses

a. combined longitudinal stresses, $\mathrm{S}_{1}=-31,200$ to 69,400 psi or $-106,000 \mathrm{psi}$ to $38,200 \mathrm{psi}$.

b. combined maximum longitudinal stresses, $s_{1}$, $\max =64,900$ psi for $\mathrm{S}_{1}=38,200 \mathrm{psi}$, and $\mathrm{s}_{1}, \max =-120,000 \mathrm{psi}$ for $\mathrm{s}_{1}=-106,000 \mathrm{psi}$.

c. combined maximum shear stress, $S_{S}, \max =67,400$ psi.

The mean and alternating stresses at this narrow waist are 32,400 psi. The mean and alternating stresses at the base of the tooth are $31,200 \mathrm{psi}$. A Goodman diagram similar to Figure E-6 was constructed to obtain a pcak alternating stress of 39,200 psi for 4340 steel and 47,500 psi for 1040 steel. Corresponding fatigue lives using Figure E-7 are $2 \times 10^{5}$ cycles or 460 holes for 4340 steel and $7.5 \times 10^{3}$ cycles or 17.2 holes for 1040 steel. 

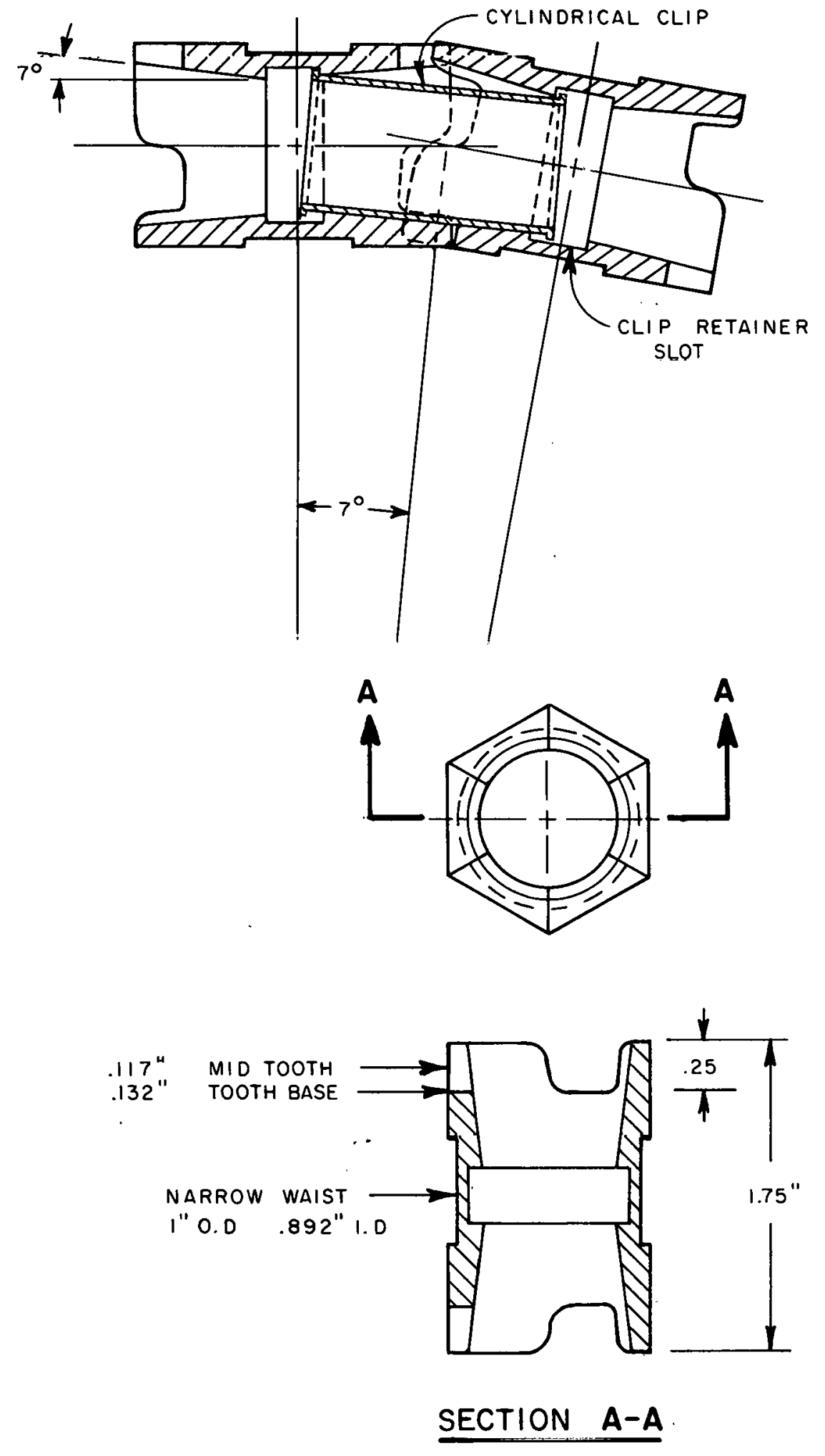

FIGURE F-I. CYLINDRICAL CLIP CONCEPT 
APPENDIX G

SEGMENTAL SHAFT WITH WIRE CONNECTION FOR TORQUE TRANSMISSION

Figure G-1 shows the type of segment being proposed in this appendix. The segments are strung together by a series of wires running through holes drilled longitudinally down the tubular wall of the segment. These wires could be solid piano wire or a braided wire. When the segmental shaft bends through the radius of curvature, the wire would permit the segments to separate sufficiently to accommodate this radius. When the segments entered the drivehead and were thrust up into the hole, this gap between the segments would close and the torsional load would be transferred from one segment to the other via shear loading across the wire interconnects.

For a torque load of 3000 in. $-1 b$ and a given wire size, the number of wires required can be calculated easily. Shear force loading would be most severe on the 1-in.-diameter shaft; therefore, only the results of this calculation are presented. For a 1-in.-diameter shaft, it is assumed that the centerline for these wire holes would be on a 3/4-in. diameter and the shear force on the wires at this diameter would be 4,000 1b. Calculations were based on a 1/8-in.-diameter wire, and the results are as follows:

\begin{tabular}{cc}
\hline Number of Wires & Shear Stress, psi \\
\hline 4 & 81,300 \\
8 & 40,650 \\
16 & 20,325 \\
\hline
\end{tabular}



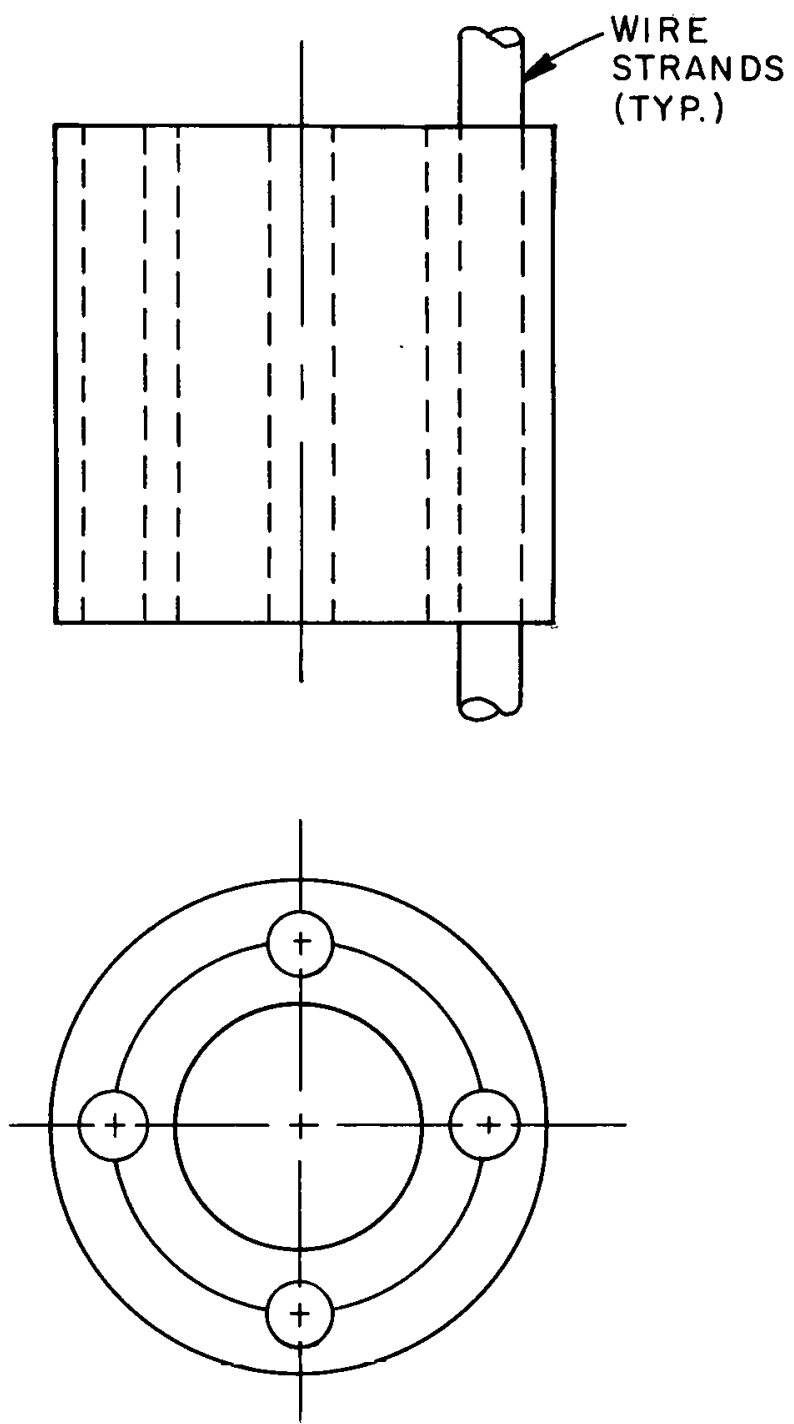

FIGUREG-I. SEGMENTAL SHAFT WITH WIRE CONNECTION FOR TORQUE TRANSMISSION 
APPENDIX H

BONDED INTERFACE

This method of linking segments together could be approached in two ways. The first method would use an elastomer to link the segments together and also transmit the torsion from segment to segment. This approach is not feasible since the torsion load is too high for existing elastomers.

The second approach would be to use.interlocking teeth. to transmit the torque and use the elastomeric bond at the interface to hold the segments together. The elastomeric connector would carry the tension load present when withdrawing the drill string. If the elastomeric connector joins the segments as shown in Figures $\mathrm{H}-1$ or $\mathrm{H}-2$, there will be no need for a separate chipreturn tube. The designs shown in these figures have teeth proportions similar to the teeth analyzed in Appendix E; therefore, they should be suitable for transmitting the required torque and thrust.

There are two new considerations for an elastomeric connector:

1. Will the elastomer elongate adequately to meet the curvature requirements?

2. Will the bond holding the connector to the segment be strong enough?

The elastomer used for the Type II connector shown in Figure H-2 would be elongated more than the Type I connector. The amount of elongation can be calculated using geometric relationships from Figure 23.

$$
\% \text { elongation }=\frac{(1.375-0.25) \sin \alpha}{0.5} \times 100
$$

For a 12-in. radius, segment length of 1.5 in. and a diameter of 1.375 in., $\alpha=7.6^{\circ}$ and the percent elongation is $30 \%$. This is well within the allowable elongation of most elastomers.

The bond strength of the elastomer-to-metal joint is more difficult to determine. The strength is dependent upon the joint geometry and the adhesive selected. There are a vast number of adhesives marketed today. The appropriate one to use will be based on more intensive examination of adhesive specifications and testing of appropriate candidates.

An adhesive may not be required if a hard elastomer is satisfactory. A Type I elastomeric connector made from such a material may have sufficient shear strength to carry the load on the shoulder recessed into the segment 

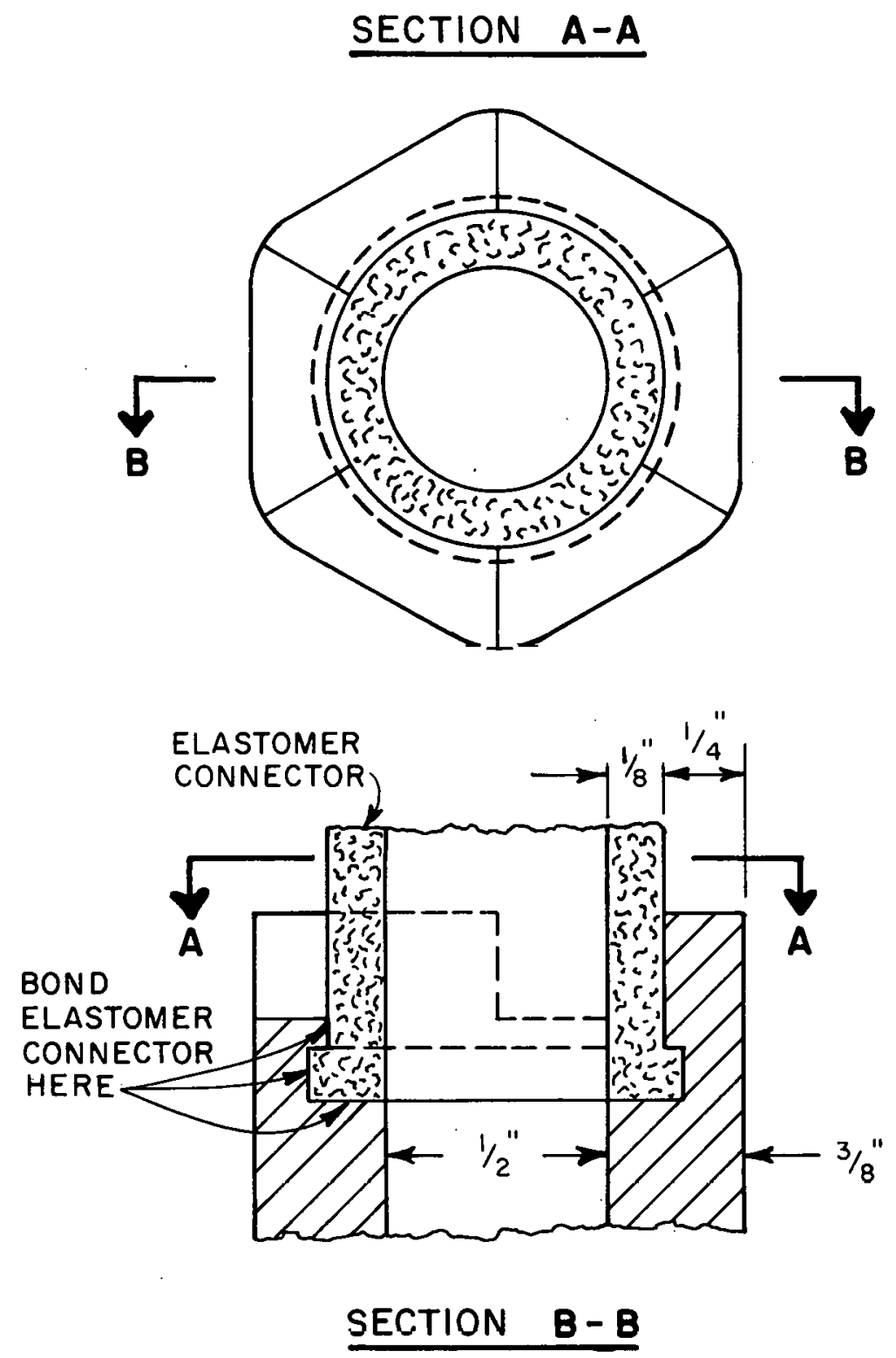

FIGURE H-I. ELASTOMER CONNECTOR FOR SEGMENTS - TYPE I 


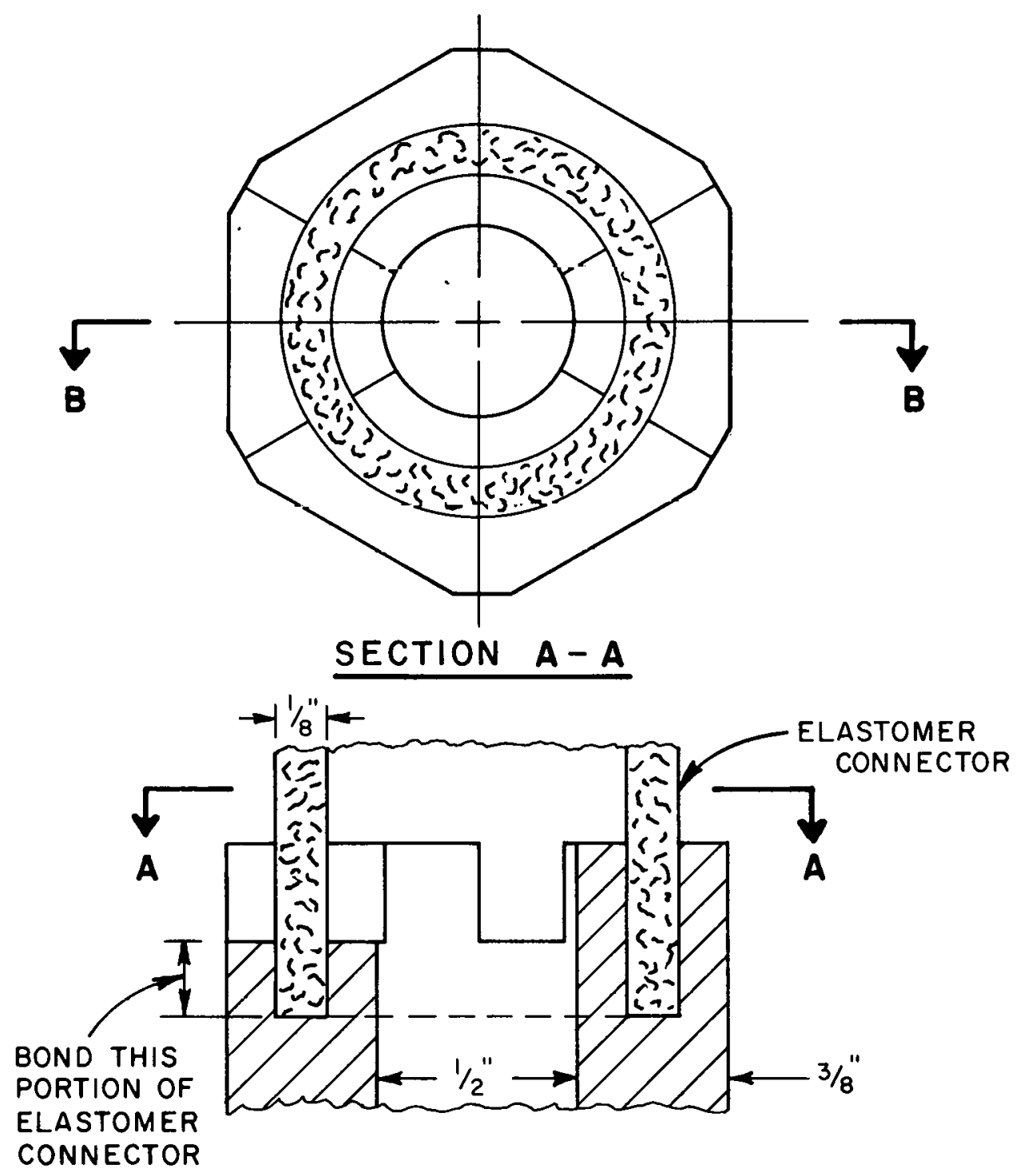

\section{SECTION B-B}

FIGURE H-2. ELASTOMER CONNECTOR FOR SEGMENTS - TYPE II 
groove. The elastomer would have to have a high durometer rating and sufficient flexibility.

Figure $\mathrm{H}-1$ shows a taper on the shoulder of the connector. This would aid in inserting the connector into the segment and make the replacement of a failed segment relatively easy. 
APPENDIX I

PAWL-AND-RATCHET DRIVEHEAD*

Figure $I \rightarrow 1$ is a detailed schematic of the drive unit. Shown in this figure is a pinion driving a ring gear. The ring gear is fixed around an annular-shaped cylinder. The cylinder drives the piston through a spline cut in the inner surface of the cylinder. Attached to the piston rod head are a pair of pawls which in turn drive the drill shaft. When the piston reaches the top of its stroke, it causes a holding pin to engage the drill shaft. The holding pin maintains the proper position of the shaft while the return spring is forcing the piston down. After the piston has been returned to the down position, the pawls re-engage the drill shaft to repeat the cycle.

In order to explain in detail the reciprocating action of the piston and the shaft removal procedure, it will be necessary to refer to several drawings. Figure I-2 shows how the holding pin is assembled into. the inner cylinder. Figure I-4 is a blowup of the paw1 control mechanism located at the top of the drive unit. Hydraulic and electrical schematics are given in Figure I5. Should the assembly drawing of the drive unit, Figure I-7, prove difficult to interpret, a blowup of its internal parts is presented in Figure $\mathrm{I}-6$.

\section{Reciprocating the Piston}

Figure I-7 shows two milled flats on the upper housing with holes drilled through them. These are switch mounting pads for SW-1 and SW-2. The switch actuator passes through the hole in the housing and is actuated by cam (16). Cam (16) is attached to sleeve (14) with pins (15). Sleeve (14) is connected to the piston and moves up and down with it. Thus the switches will be actuated at both ends of the piston's stroke. The switches in turn actuate hydraulic valve solenoids as shown in Figure I-5.

Retracting the Dril1 Shaft

To retract the shaft after the hole has been drilled to the desired depth, manual switch SW-3 activates the hydraulic valve, causing the return spring to force the cylinder back down. The same time that SW-3 is activated,

\footnotetext{
"This apppendix has been extracted from the thesis, "The Design of a Flexible Shaft Roof Drill for Low Coal," by William A. McIlvanie, Masters Thesis, Washington State University, 1974.
} 


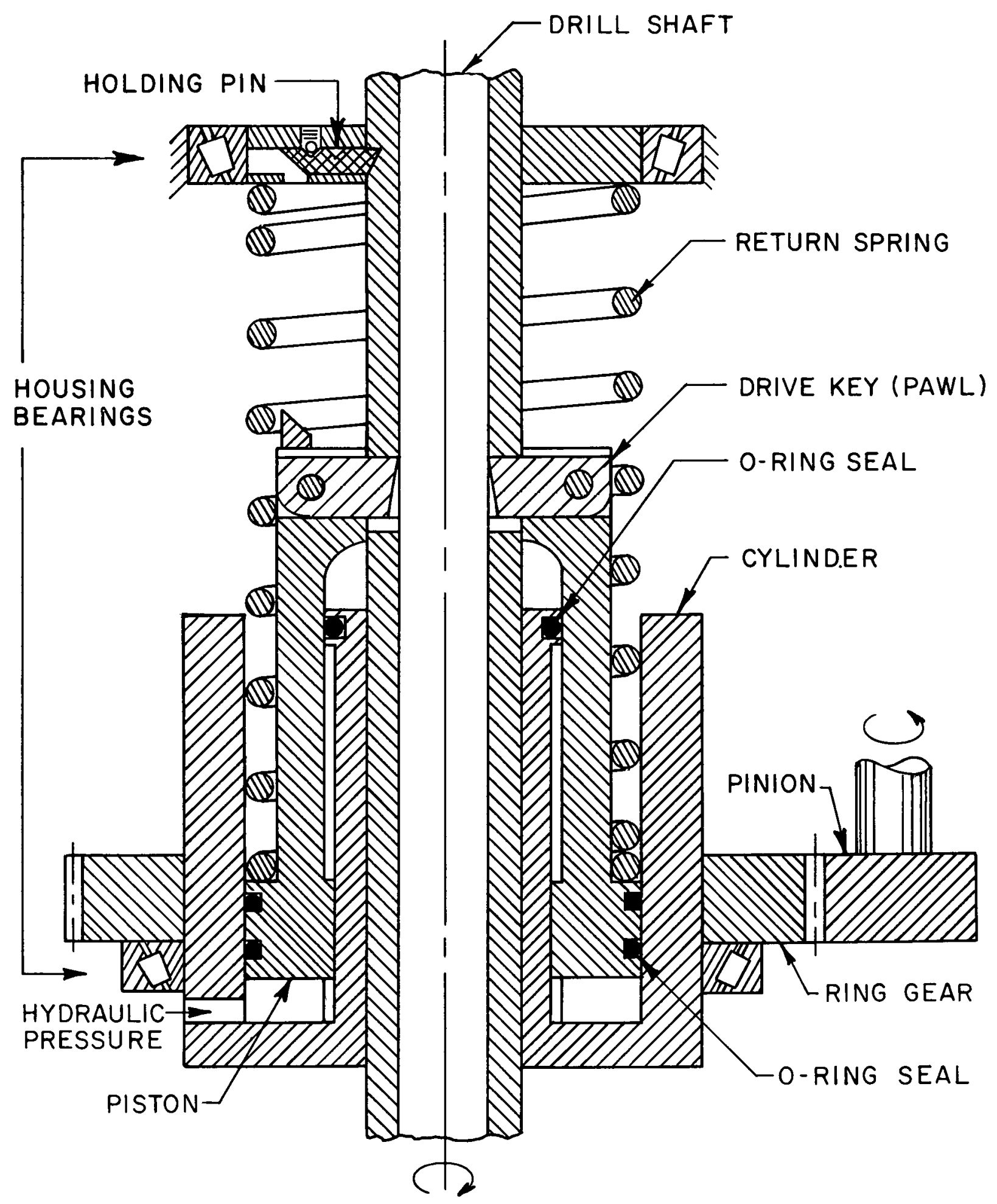

FIG. I - I. SCHEMATIC OF DRIVE UNIT 
定
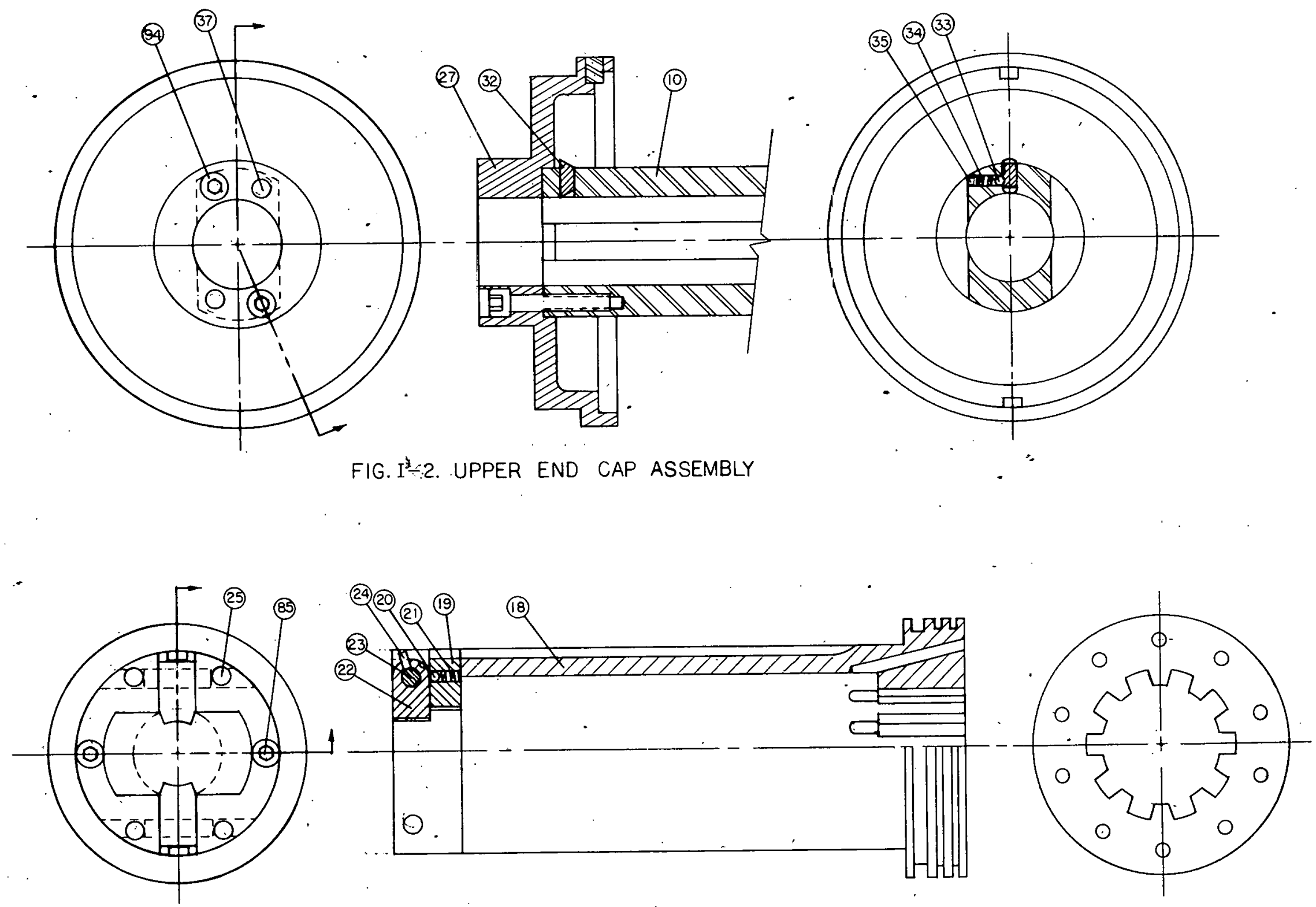

FIG. I $\div 3$ : ROD HEAD ASSEMBLY 


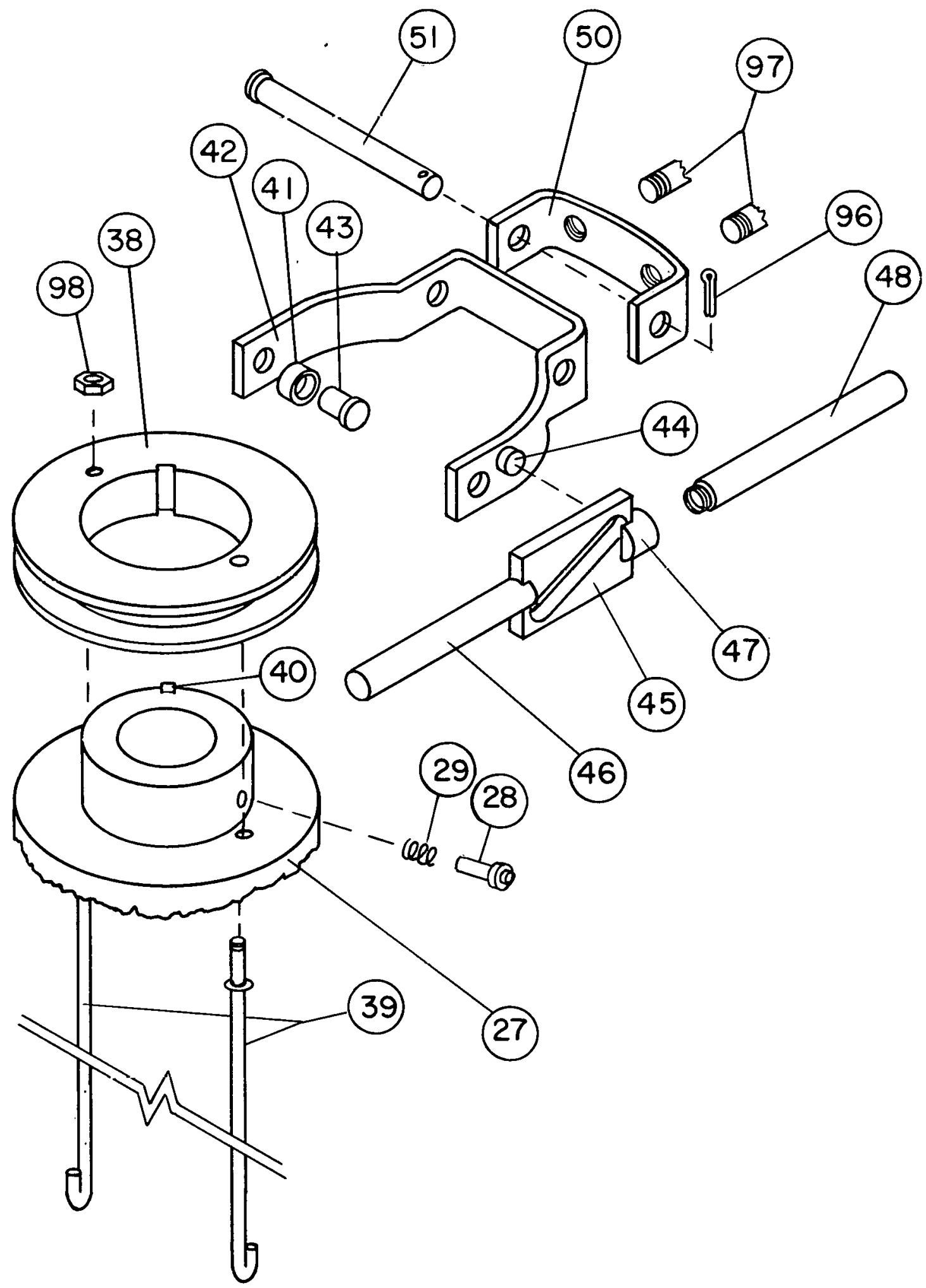

FIG. I - 4. EXPLODED VIEW OF PAWL CONTROL MECHANISM 

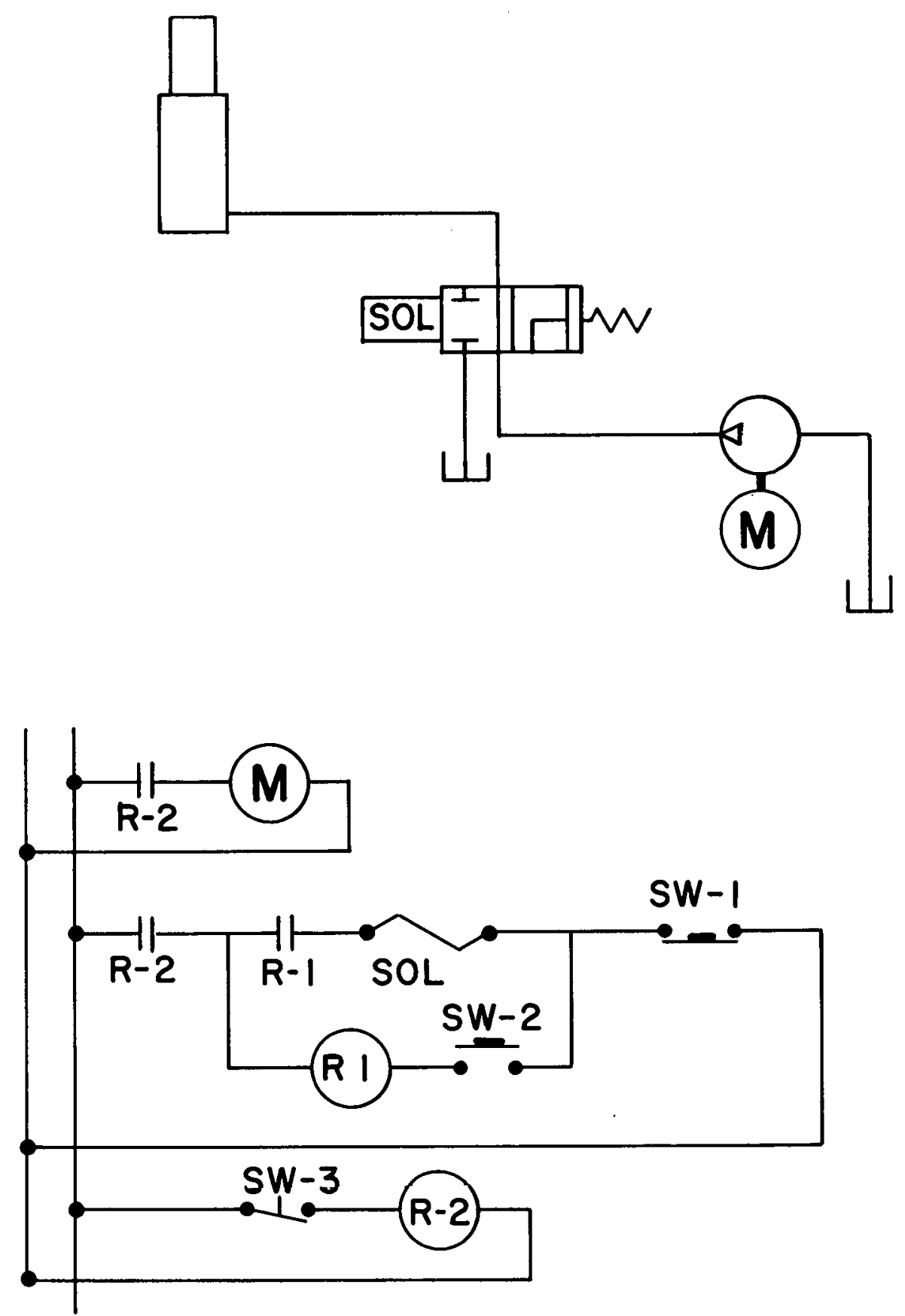

FIG. I- 5 HYDRAULIC AND ELECTRICAL SCHEMATICS 


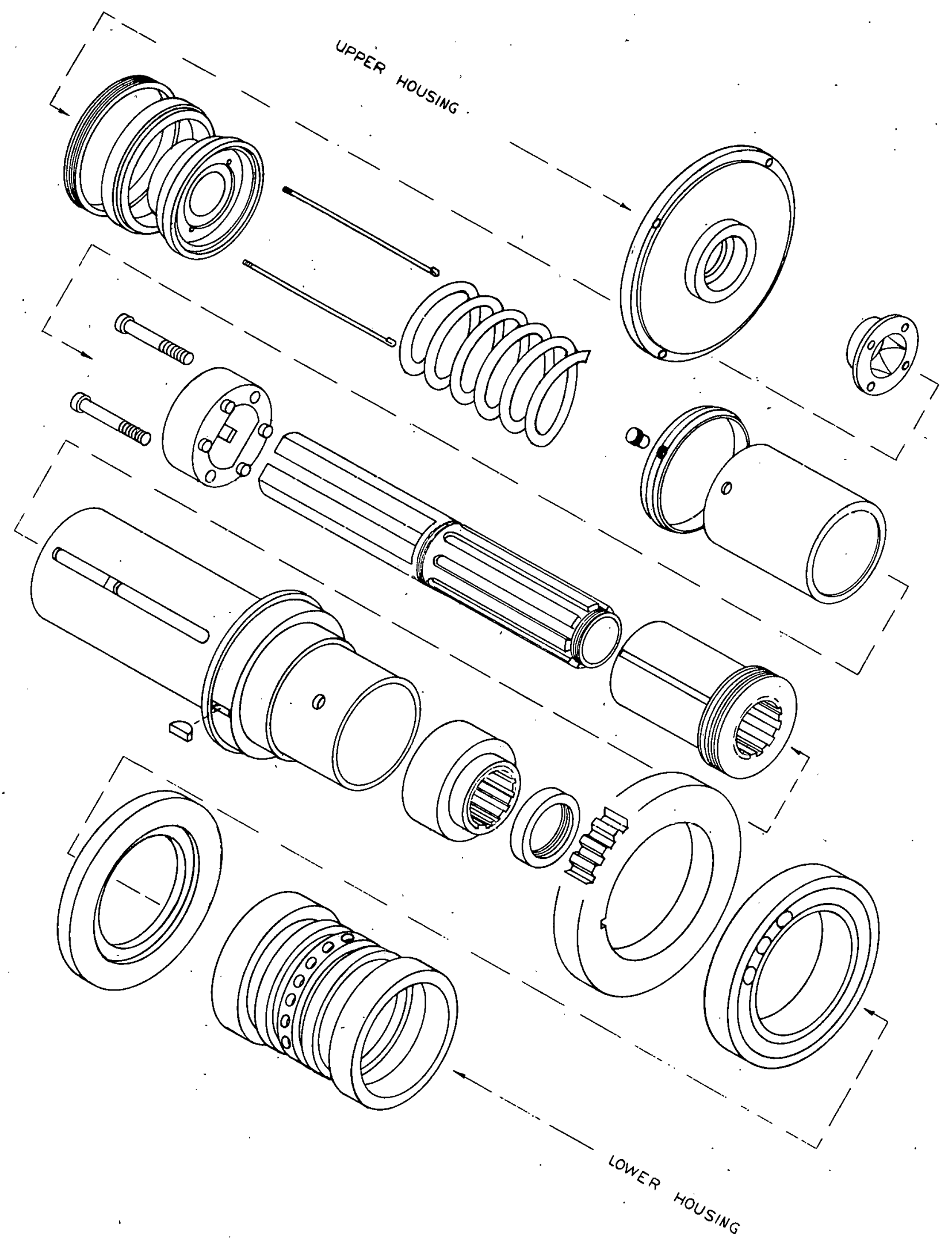

FIG. I - 6..- EXPLODED VIEW OF DRIVE UNIT 


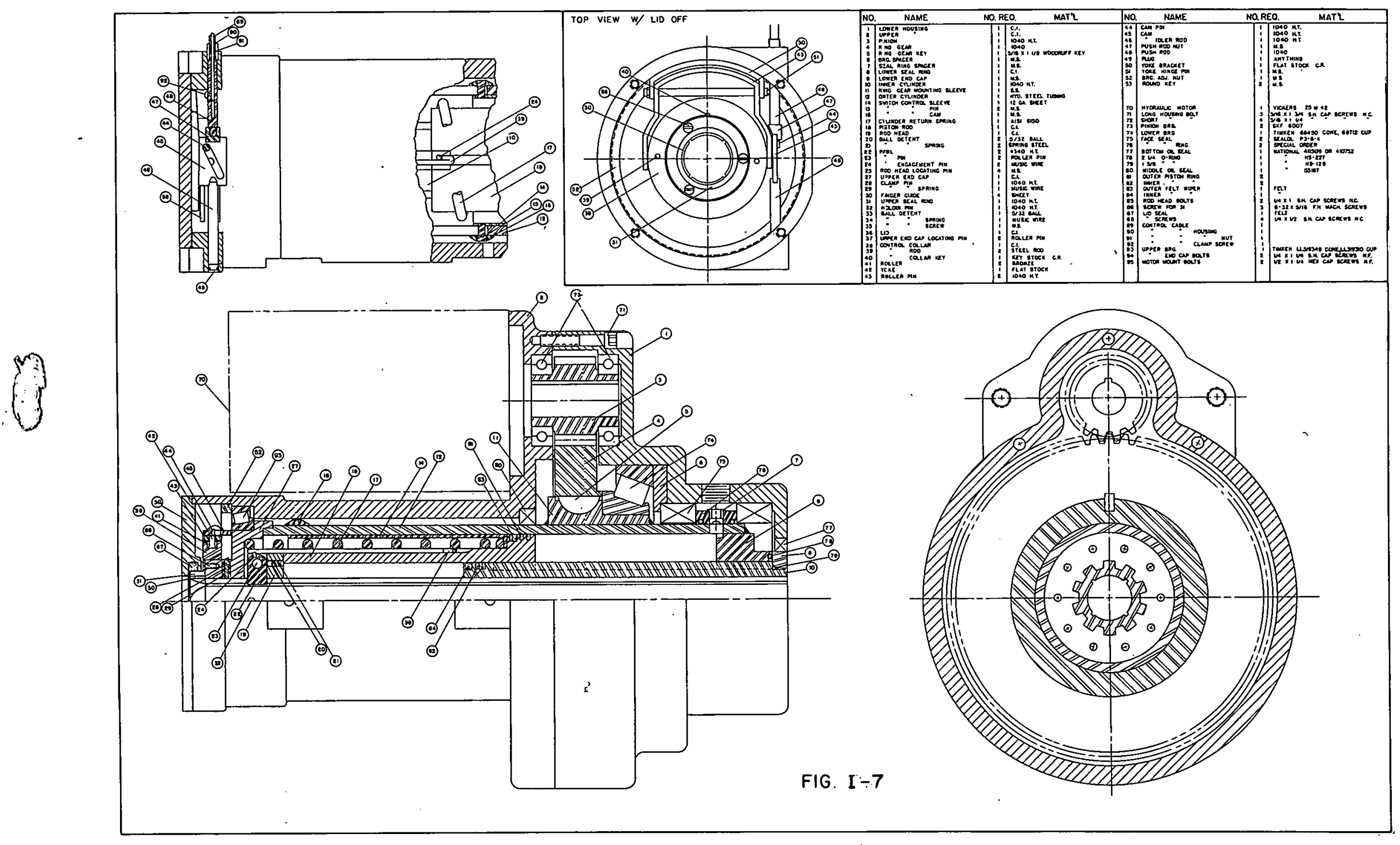


the control collar (38) is forced down via rollers (41) attached to yoke (42). The yoke is pivoted by cam (45) which is slid back and forth by the manually operated cable (89).

Downward force on the control roller causes clamp pin (28) to clamp the drill shaft, allowing. the pawls to disengage themselves. When the clamping pressure is released the drill shaft can be pulled from the hole. The pawls will remain disengaged from the shaft as long as the control rods (39) which are connected to the control collar remain in the down position. After the shaft has been completely retracted, the control rods are returned to the up position. This action causes the control rod tips to strike the control pins (24), forcing the pawls to re-engage the slots in the drill shaft for the start of a new drilling cycle. The up position of the control rods is the normal drilling position. 
Deflection Analysis

Referring to Figure $J-1$, the ring is wedged to deflect diametrically. The deflection is proportional to the applied force, $P$. In order to find the relationship between applied force and deflection, Castigliano's theorem (Juvinall, Stress, Strain, and Strength, p. 143) can be used. The load pattern is shown in. Figure $\mathrm{J}-2$ (a) and (b).

The moment is

$$
M=\frac{P a}{2}-\frac{P}{2}(a-a \cos \theta)=\frac{P a}{2} \cos \theta .
$$

The tensile force is

$$
\mathrm{C}=\frac{\mathrm{p}}{2} \cos \theta \text {. }
$$

The shearing force is

$$
V=\frac{P}{2} \sin \theta
$$

The deflection results from bending, axial load and transverse shear. Castigliano's theorem combines these to determine the deflection, $\delta$, as

$$
\begin{aligned}
\delta & =\frac{1}{\mathrm{EI}} \int_{0}^{\pi / 2} \mathrm{M} \frac{\partial \mathrm{M}}{\partial(\mathrm{P} / 2)} \operatorname{ad} \theta+\frac{1}{\mathrm{EA}} \int_{0}^{\pi / 2} \mathrm{C} \frac{\partial \mathrm{C}}{\partial(\mathrm{P} / 2)} \mathrm{ad} \theta+\frac{6}{5 \mathrm{GA}} \int_{0}^{\pi / 2} V \frac{\partial V}{\partial(\mathrm{P} / 2)} \operatorname{ad} \theta \\
& =\frac{1}{\mathrm{EI}} \int_{0}^{\pi / 2} \frac{\mathrm{Pa}^{-3}}{2} \cos ^{2} \theta \mathrm{d} \theta+\frac{1}{\mathrm{EA}} \int_{0}^{\pi / 2} \cdot \frac{\mathrm{Pa}}{2} \cos ^{2} \theta \mathrm{d} \theta+\frac{6}{5 \mathrm{GA}} \int_{0}^{\pi / 2} \frac{\mathrm{Pa}}{2} \sin ^{2} \theta \mathrm{d} \theta \\
& =\frac{\mathrm{Pa}^{3} \pi}{8 \mathrm{EI}}+\frac{\mathrm{Pa} \pi}{8 \mathrm{EA}}+\frac{3 \mathrm{~Pa} \pi}{20 \mathrm{GA}}
\end{aligned}
$$

where

$$
\begin{aligned}
& \mathrm{E}=\text { Young's modulus } \\
& \mathrm{A}=\text { cross-sectional area of ring } \\
& \mathrm{I}=\text { sectional modulus } \\
& \mathrm{G}=\text { modulus of rigidity }
\end{aligned}
$$

for a given condition that

$\delta=0.1$ in. diametrically or 0.05 in. radially

$E=30 \times 10^{6} \mathrm{psi}$ for steel

$G=12 \times 10^{6}$ psi for steel

$\mathrm{P}=12,000 \mathrm{lb}$

$\mathrm{a}=5 \mathrm{in}$. 

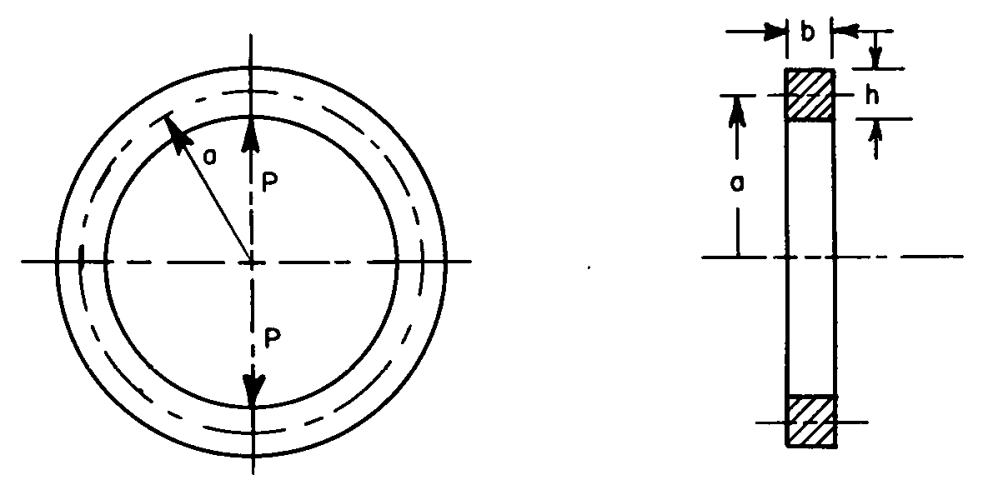

FIGURE J-I. DRIVING RING FOR FRICTIONAL DRIVE CONCEPT

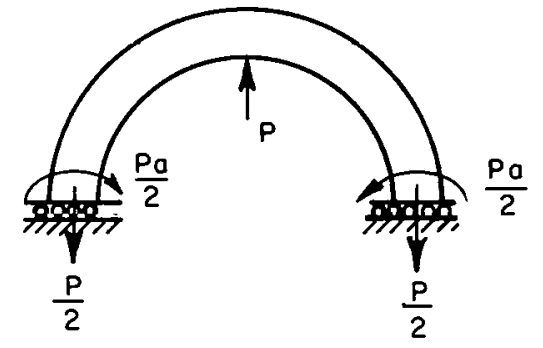

(a)

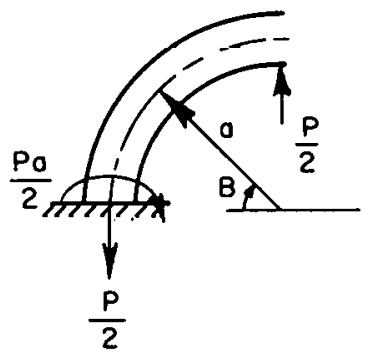

(b)

FIGURE J-2. LOAD PATTERN ON THE DRIVING RING 
Equation $(\mathrm{J}-4)$ is used to find the ring dimensions. The section modulus is $I=b h^{3} / 12$, where $b$ is the width and $h$ is the depth; therefore, Eq. (J-4)

reduces to

$$
\delta=\frac{\mathrm{Pa}^{3} \pi}{8 \mathrm{EI}}+\frac{\mathrm{Pa} \pi}{8 \mathrm{EA}}+\frac{3 \mathrm{~Pa} \pi}{20 \mathrm{GA}} .
$$

The first term on the right-hand side contributes $99 \%$ of the deflection;

therefore,

$$
0.05=\frac{12,000 \times 5^{3} \times 12}{8 \times 30 \times 10^{6} \times b \times h^{3}}
$$

and, if $b$ is fixed at $2.5 \mathrm{in.}$, then $h$ is found to be 1.235 in., or $11 / 4$ in.

In another case, the radius $a=3.75 \mathrm{in}$. and $\mathrm{h}=1 \mathrm{in}$, then for a deflection of $0.05, b$ can be found to be approximately equal to 2.0 in.

\section{Stress Analysis}

The ring is under a radial load of $\mathrm{P}=12,000 \mathrm{lb}$ for the following two cases:

(A) mean radius $a=5$ in.; section $b=2.5$ in.; $h=1.25$ in.

(B) mean radius $a=3.75$ in.; section $b=2.0$ in.; $h=1.0$ in.

Case A: (Referring to Fig. J-3) The equation for the tensile stress on the bar according to Seeley and Smith, Advanced Mechanics of Material, p.. 148 is
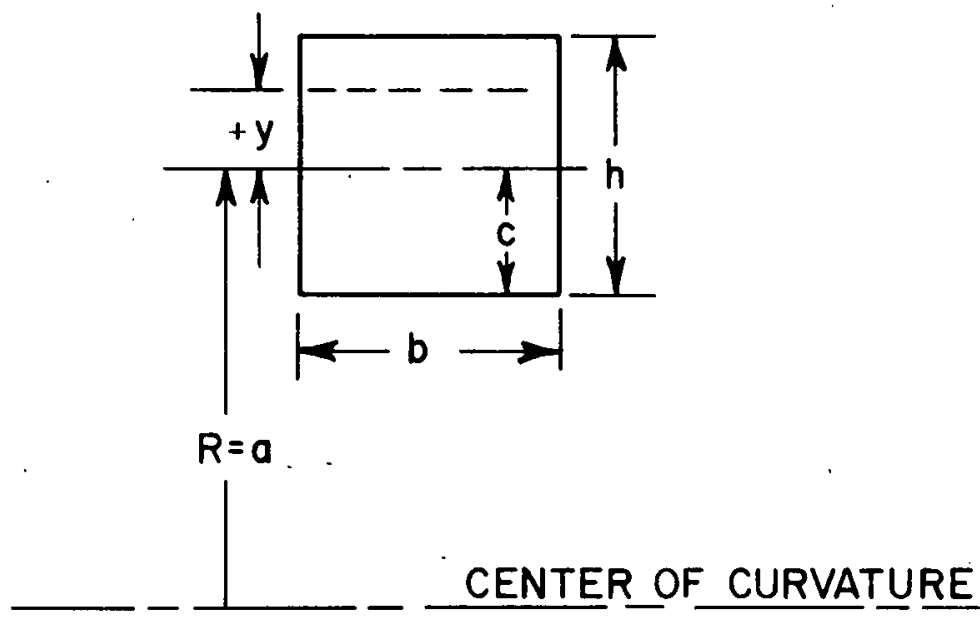

Figure J-3 Bending of a Curved Bar with a Symmetric Cross Section 
where

$$
s=\frac{F}{A}-\frac{M}{A R}\left(1+\frac{1}{Z} \frac{y}{R+y}\right)
$$

$$
Z=-1+\frac{R}{h}\left[\log _{e}\left(\frac{R+c}{R-c}\right)\right]
$$

since

$$
\begin{gathered}
F=\frac{P}{2}=6,0001 b, M=\frac{P a}{2}=6,000 \times 5=30,000 \text { in. }-1 b, c=\frac{h}{2}=0.625 \text { in. } \\
Z=-1+\frac{5}{1.25}\left[\log \left(\frac{5+0.625}{5-0.625}\right)\right]=0.00525
\end{gathered}
$$

The maximum tensile stress at the inner surface due to bending and tension (where $y=-0.625$ ) is

$$
\begin{aligned}
s_{\max } & =\frac{6,000}{2.5 \times 1.25}-\frac{30,000}{2.5 \times 1.25 \times 5}\left(1+\frac{1}{0.00525} \times \frac{-0.625}{5-0.625}\right) \\
& =1,920+50,324=52,244 \mathrm{psi}
\end{aligned}
$$

The maximum compressive stress at the inner surface is due to pure bending only and is $-50,324$ psi.

The maximum compressive stress at the outer surface due to bending and tension (where $y=0.625$ ) is

$$
\begin{aligned}
s_{\max } & =\frac{6,000}{2.5 \times 1.25}-\frac{30,000}{2.5 \times 1.25 \times 5}\left(1+\frac{1}{0.00525}-\frac{+0.625}{5+0.625}\right) \\
& =1,920-42,555=40,635 \mathrm{psi} .
\end{aligned}
$$

Similarly, the maximum tensile stress at the outer surface due to pure bending is 42,555 psi.

Similarly, the stresses for Case B can be calculated. The load patterns for the rings are:

\begin{tabular}{lrrrr}
\hline Case & $s_{\max }$ & $s_{\min }$ & $\mathrm{s}_{\text {mean }}$ & $\mathrm{s}_{\text {a1ternating }}$ \\
\hline A & $+52,244 \mathrm{psi}$ & $50,324 \mathrm{psi}$ & $960 \mathrm{psi}$ & $51,284 \mathrm{psi}$ \\
$\mathrm{B}$ & $77,180 \mathrm{psi}$ & $-74,180 \mathrm{psi}$ & $1,500 \mathrm{psi}$ & $75,680 \mathrm{psi}$ \\
\hline
\end{tabular}

Fatigue lives are determined for a ring made from 4340 and 6145 stee1. The method used in Appendix $E$ is applied to this problem. No stress concentration factor is used. Other correction factors are $C_{L}=1.0, C_{S}=0.66$, and $C_{D}=$ 0.9 for 4340 steel, and $C_{L}=1.0, C_{S}=0.58$, and $C_{D}=0.9$ for 6145 steel. Figures J-4 and J-5 were used to estimate the fatigue life. The results are as follows: 


\begin{tabular}{cccr}
\hline Material & Case & Life, Cycles & Hours \\
\hline \multirow{2}{*}{4340} & A & $10^{6}$ & 463 \\
& B & $6 \times 10^{4}$ & 28 \\
6145 & A & $10^{6}$ & 463 \\
& B & $1.5 \times 10^{5}$ & 69 \\
\hline
\end{tabular}




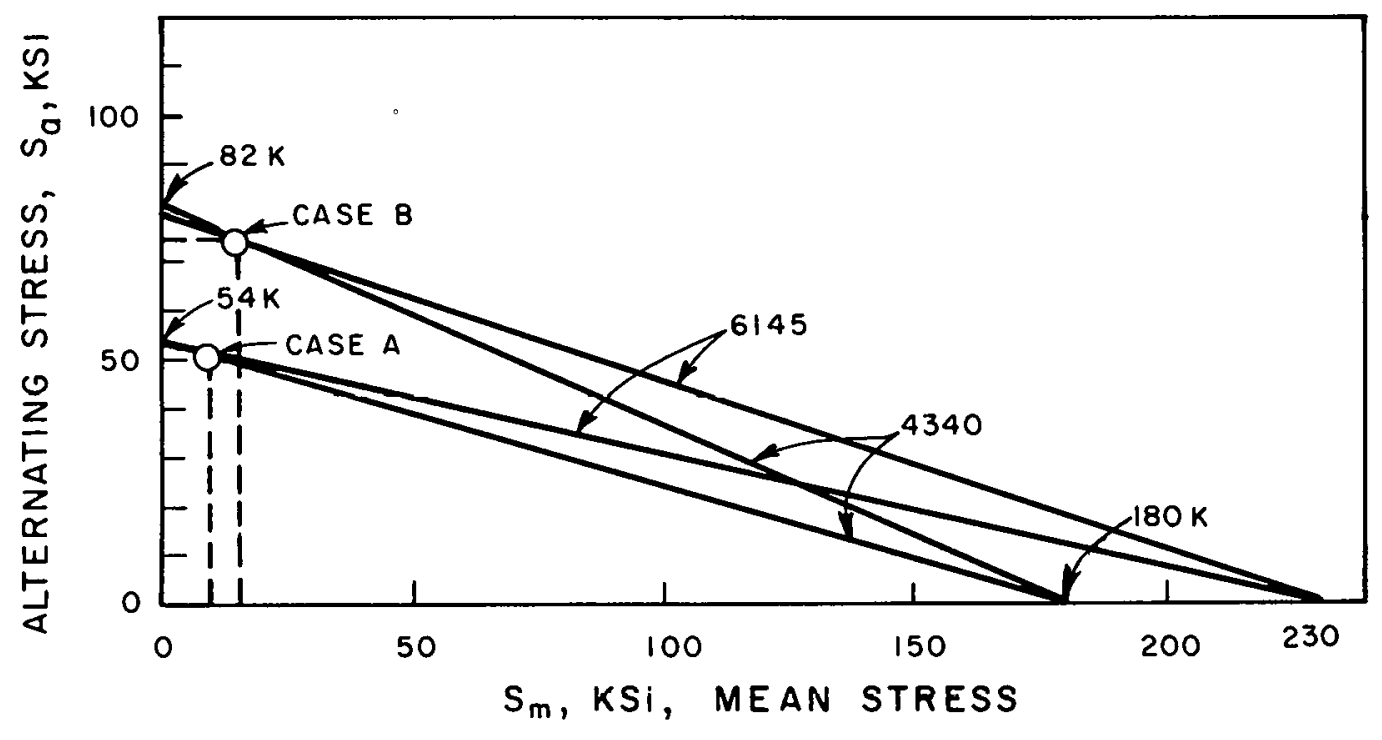

FIGURE J-4. LOAD CONDITION OF RING

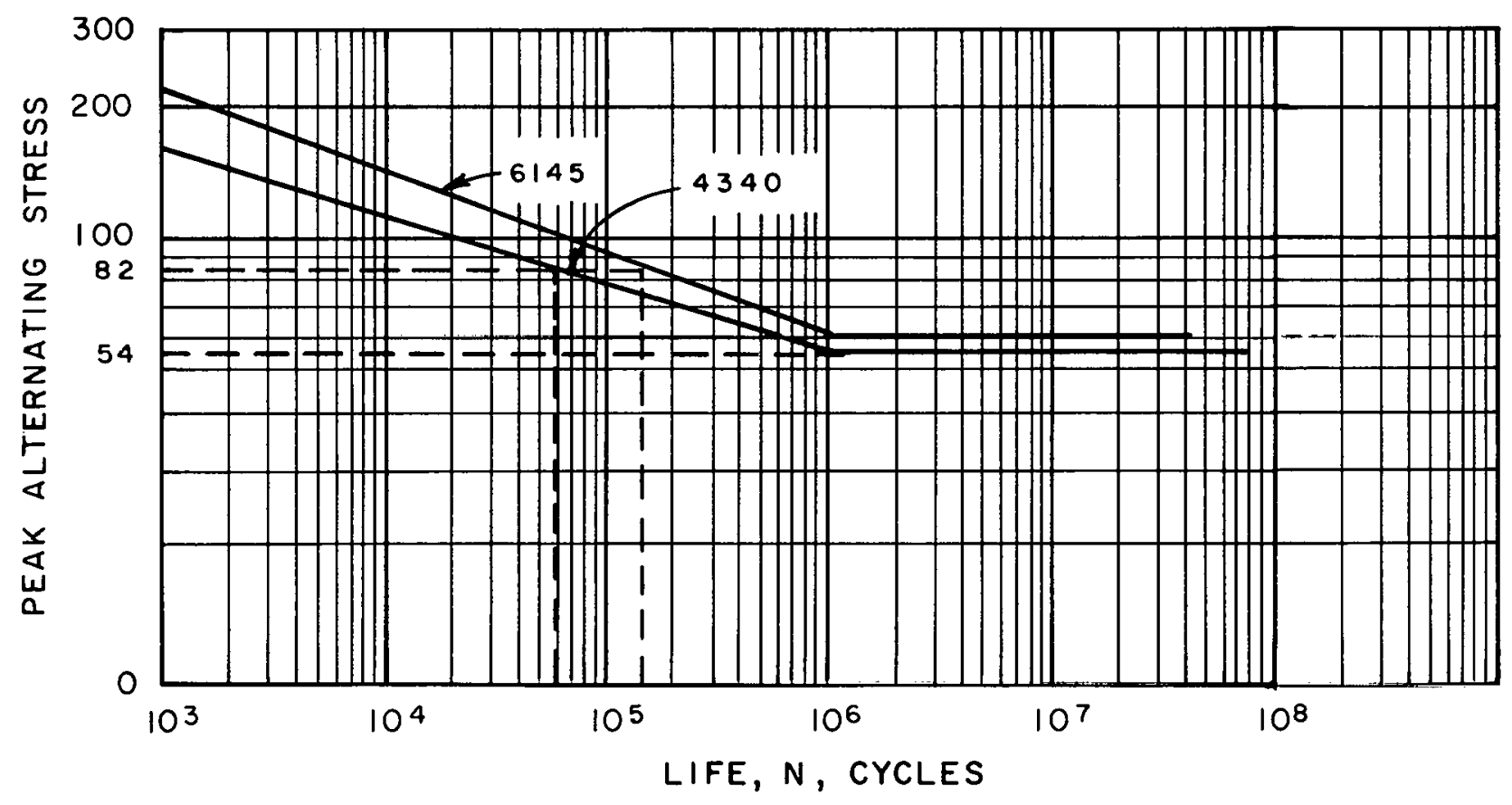

FIGURE J-5. ESTIMATION OF FATIGUE LIFE 
APPENDIX $K$

REFERENCE DRAWINGS 


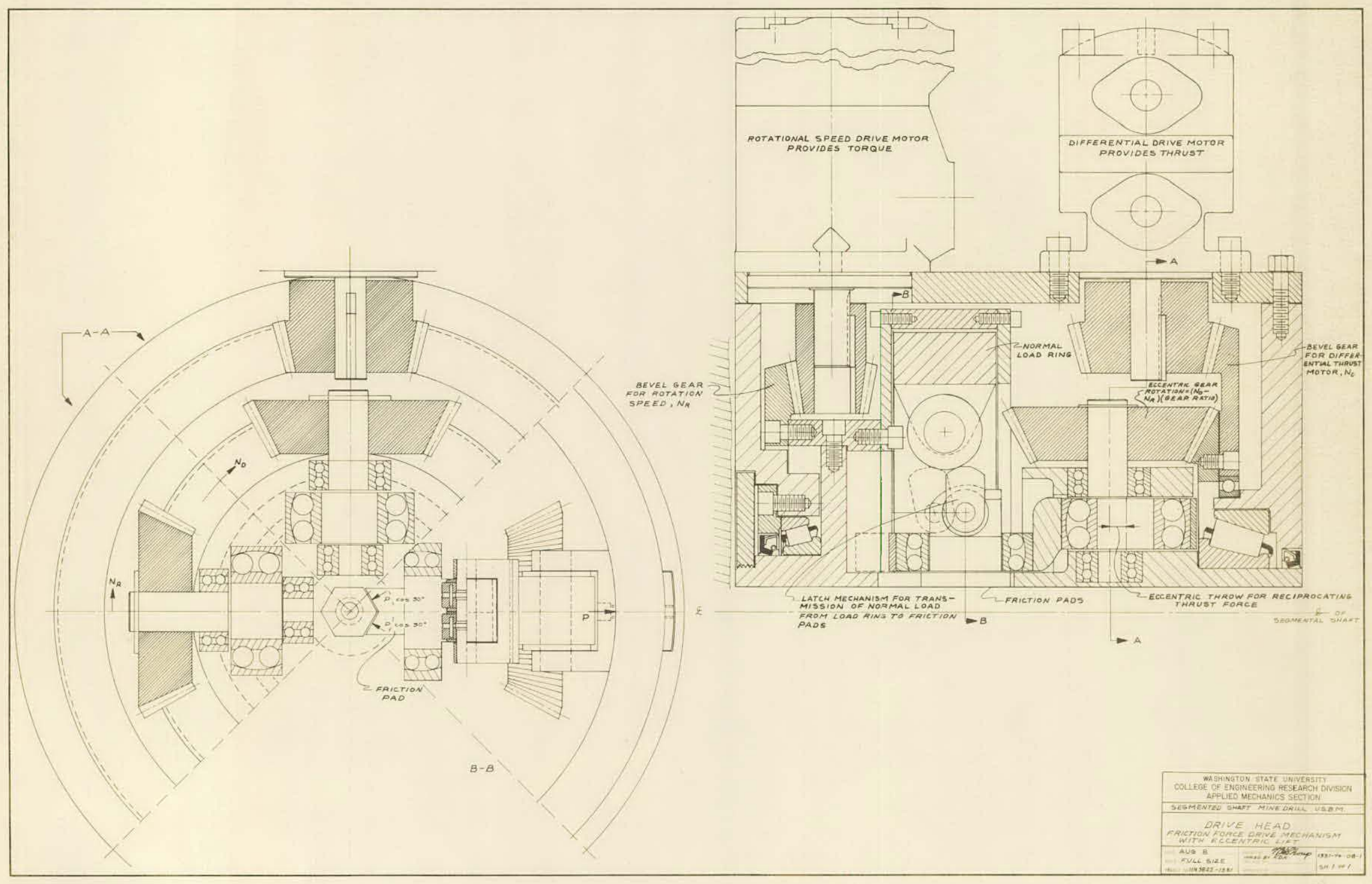

Figure K-1. Drivehead Friction Force Drive Mechanism with Eccentric Lift. 


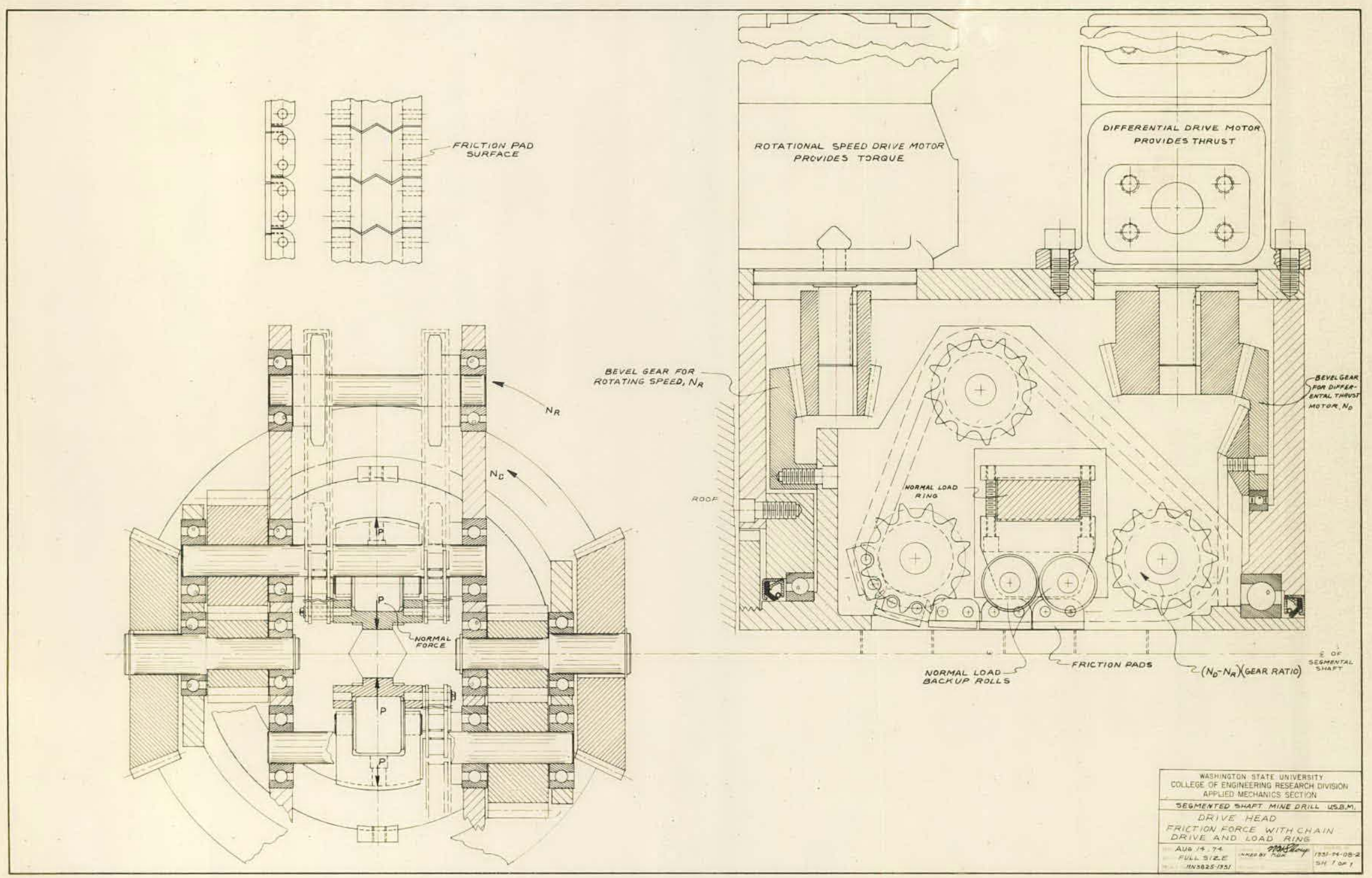

Figure K-2. Drivehead Friction Force with Chain Drive and Load Ring. 


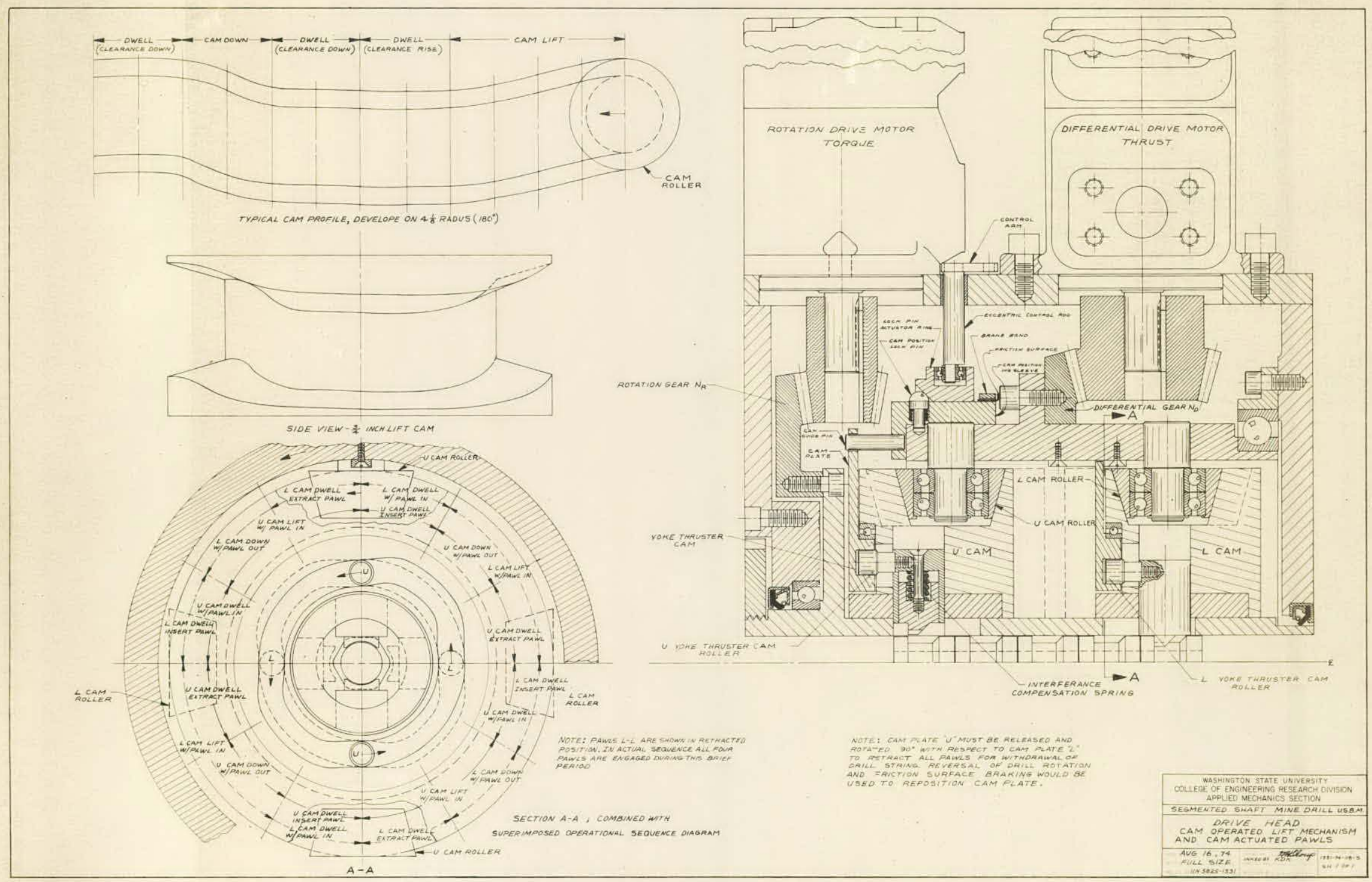

Figure K-3. Drivehead Cam-Operated Lift Mechanism and Cam-Actuated Paw1s. 


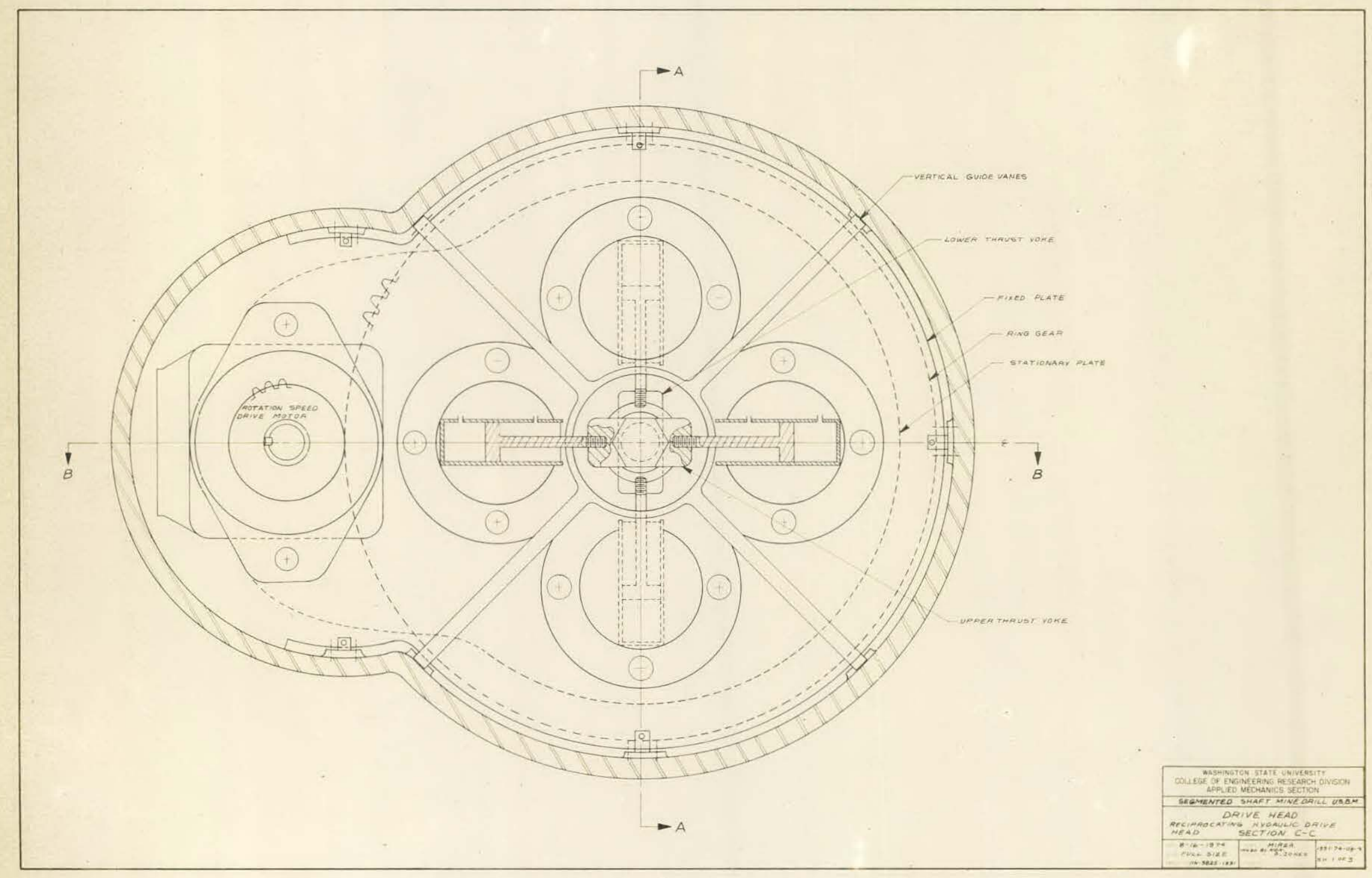

Figure K-4. Section C-C Reciprocating Hydraulic Drivehead. 


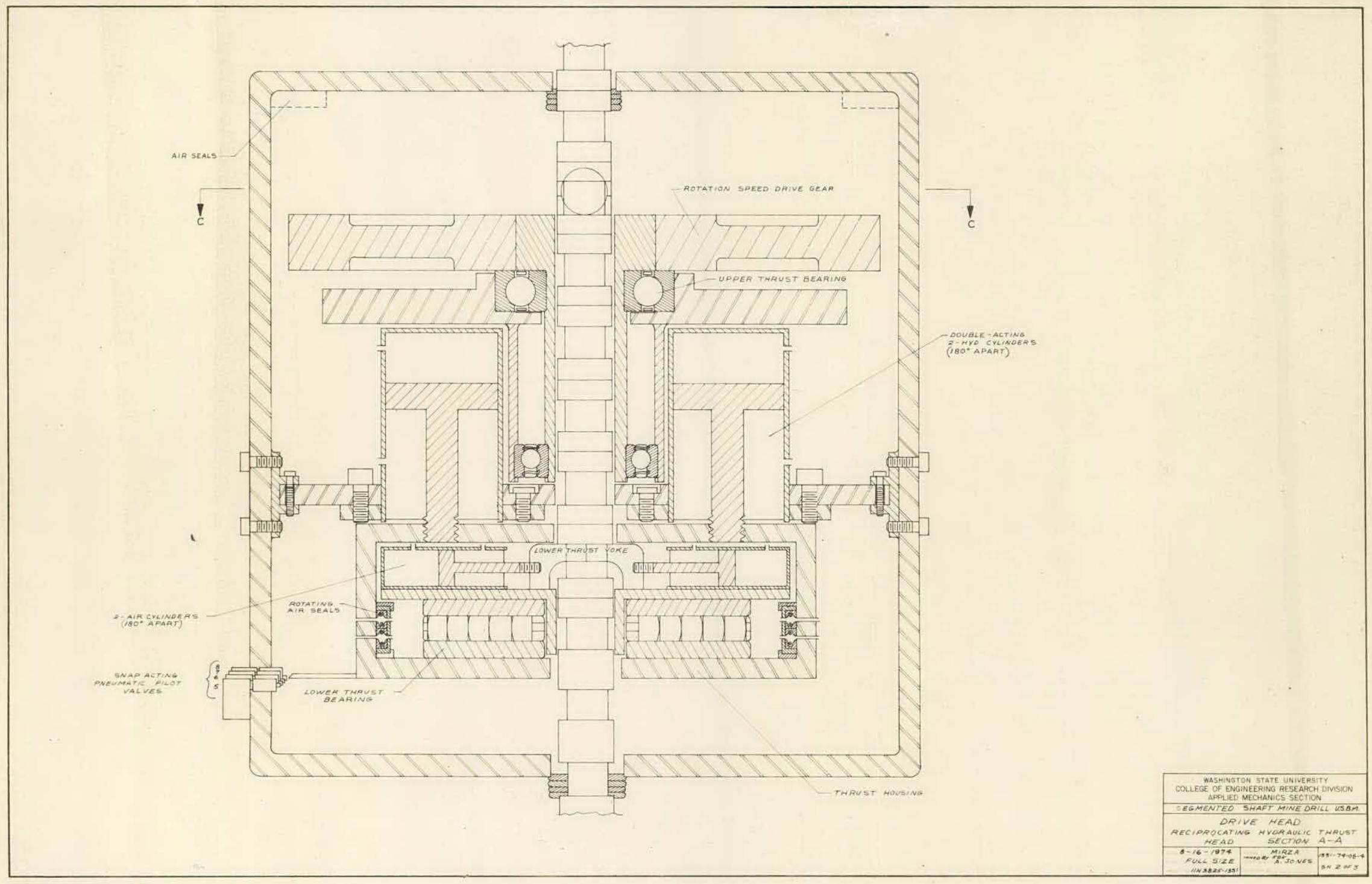

Figure K-5. Section A-A Reciprocating Hydraulic Drivehead. 


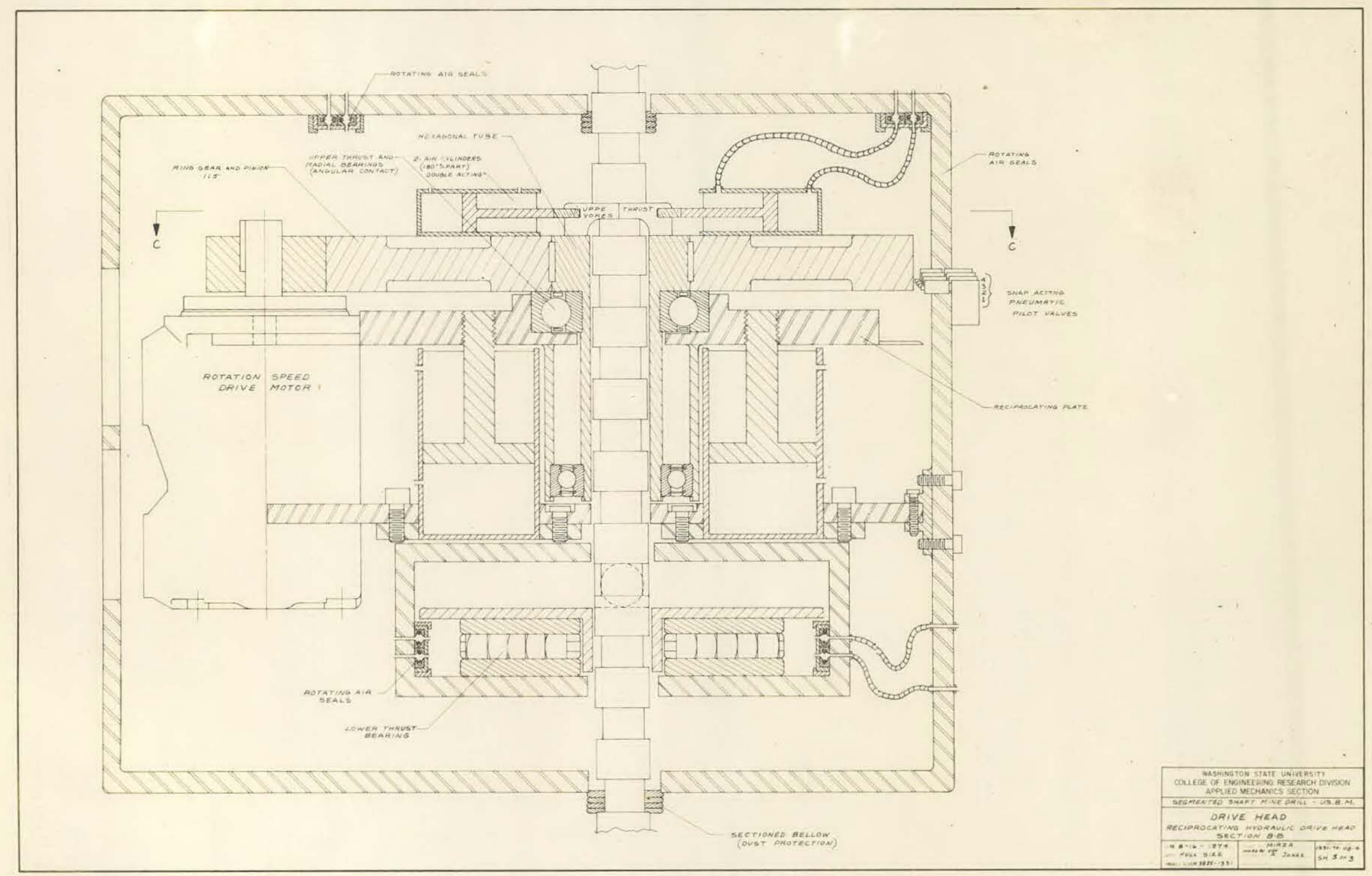

Figure K-6. Section B-B Reciprocating Hydraulic Drivehead. 


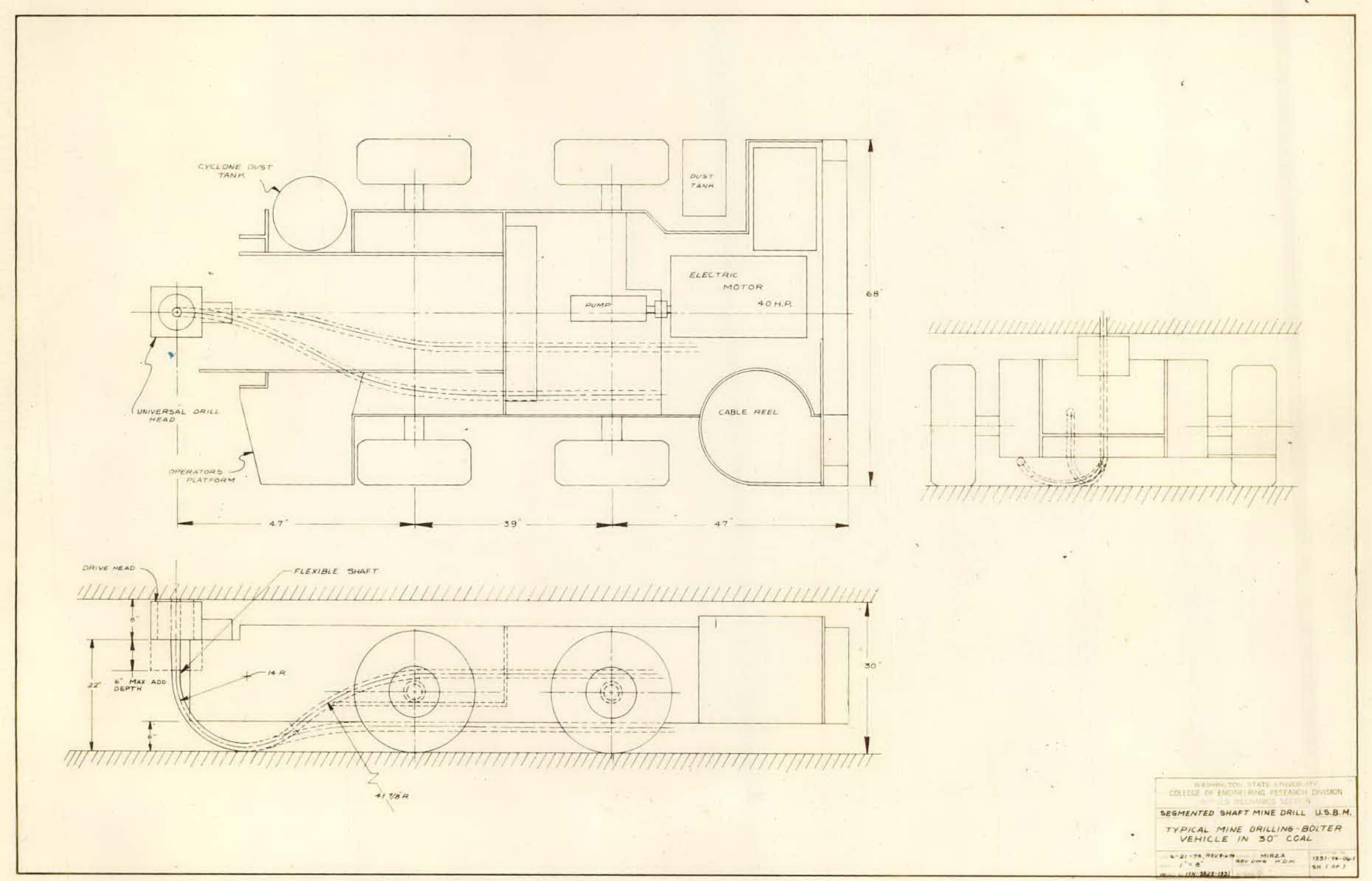

Figure K-7. Mine Vehicle in 30-in. Coal. 

APPENDIX L

DRILL STRESS ANALYSIS

In the interaction of sequential segments in the drill string, the torque transmitted by the string is seen as a distributed force over the surface of each of the load-carrying teeth. In addition, the thrust load must be supported by one or more teeth. Consequently, the state of stress at the base of a tooth is composed of four contributing factors:

1. A bending stress caused by the distributed force acting above the base of the tooth.

2. A compressive stress of the axial thrust load.

3. A shear stress across the tooth base.

4. A shear stress from the twisting of the tooth caused by the resultant of the distributed force not acting through the centroid of the tooth base.

\section{Load Division Between Teeth}

First, establish the premise that all three teeth will equally carry the applied torque. Assume no axial loading and let the distributed force of the torque be represented by an equivalent concentrated point force. Since there are no net forces on a segment other than the torque, the load of the two segments in Figure L-1 is severed and replaced with a moment. Assume the position of the :upper segment is fixed in space while the lower segment is free to translate and rotate in the $x-y$ plane. If only two teeth are contacting, the resulting unbalanced forces on the lower portion tend to move it to the left until contact is made on the unloaded tooth. The force equilibrium (Figure L-2) of the segment then requires that

$$
\begin{gathered}
F_{1}=F_{2} \sin 30+F_{3} \sin 30 \\
F_{2} \cos 30=F_{3} \cos 30
\end{gathered}
$$

or

$$
\mathrm{F}_{1}=\mathrm{F}_{2}=\mathrm{F}_{3}
$$

It should be noted that this is valid independent of the radial point of contact of each tooth; i.e., the distance from the drill segment center to the point of contact of each tooth does not have to be the same. Consequently, the load is distributed equally over all three teeth regardless of where the actual resultant forces contact the individual teeth. 


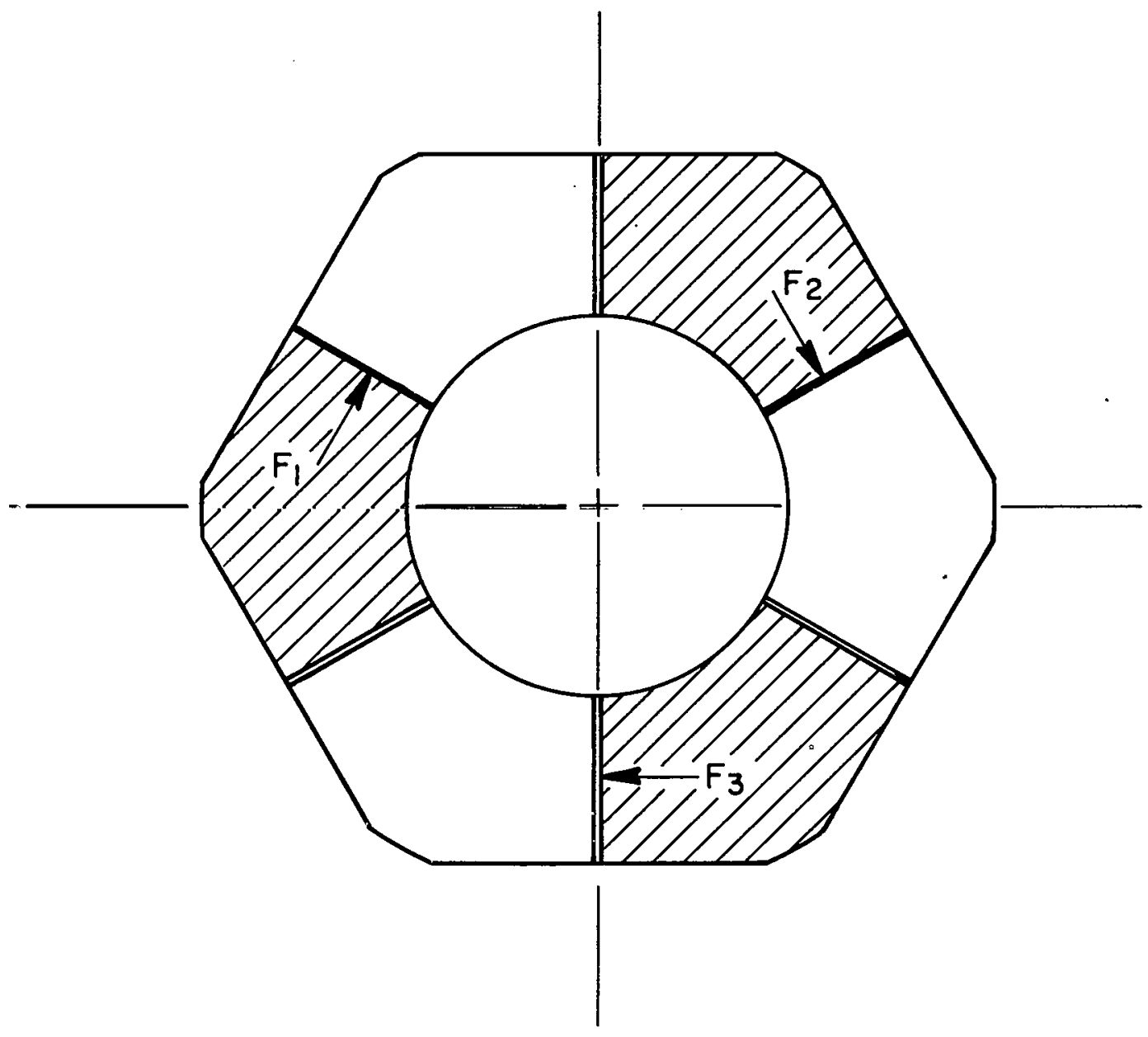

FIGURE L-I DRILL SEGMENTS FORCE ACTING ON TWO TEETH 


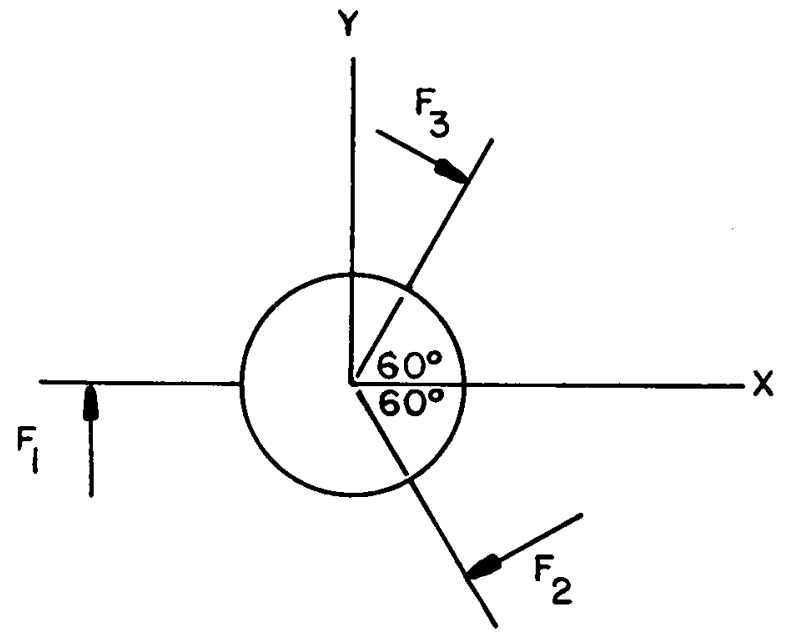

FIGURE L-2 FORCE BALANCE

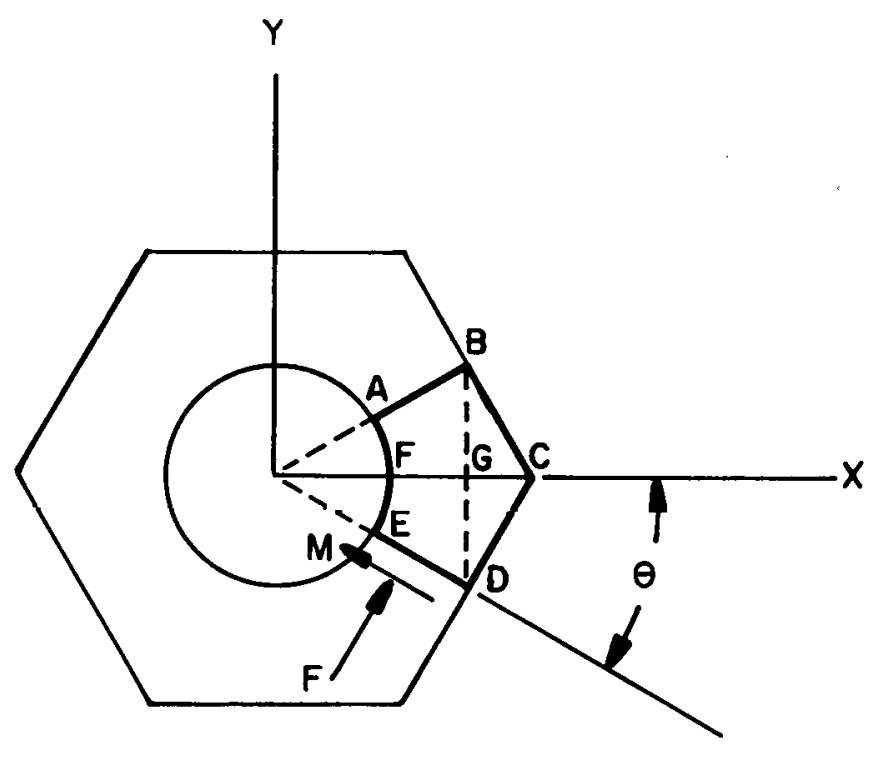

FIGURE L-3 DRILL SEGMENT-TOP VIEW 
Geometrical Considerations

The top view of a drill segment is shown in Figure L-3 along with point labeling and axes. The loading force is on face DE. Considering tooth 1, the geometrical quantities of area and moment of inertia are determined by starting with the base triangle, $O B D$, adding the triangle $B C D$, and subtracting the circular sector OAE.

\begin{tabular}{|c|c|c|c|}
\hline & Triangle OBD (1) & Triangle BCD (2) & Sector OAE (3) \\
\hline Area & $\frac{1}{2} \overline{\mathrm{OG}} \overline{\mathrm{BD}}$ & $\frac{1}{2} \overline{C G} \overline{B D}$ & $\overline{\mathrm{OA}}^{2} \theta$ \\
\hline$x_{c}$ & $\frac{2}{3} \overline{O G}$ & $\overline{\mathrm{OG}}+\frac{1}{3} \overline{\mathrm{CG}}$ & $\frac{2}{3} \overline{\mathrm{OA}} \frac{\sin \theta}{\theta}$ \\
\hline$y_{c}$ & 0 & 0 & 0 \\
\hline$I_{x}$ & $\frac{1}{6} \overline{\mathrm{OG}} \overline{\mathrm{BC}}^{3}$ & $\frac{1}{6} \overline{\mathrm{CG}} \overline{\mathrm{BG}}^{3}$ & $\frac{\overline{\mathrm{OA}}^{4}}{4}\left(\theta-\frac{1}{2} \sin 2 \theta\right)$ \\
\hline $\mathrm{I}_{\mathrm{o}}$ & $\frac{1}{2} \overline{\mathrm{BG}} \overline{\mathrm{OG}}^{3}$ & $\begin{array}{l}\frac{1}{36} \overline{\mathrm{BD}} \overline{\mathrm{CG}}^{3}+\frac{1}{2} \overline{\mathrm{BD}} \overline{\mathrm{CG}}(\overline{\mathrm{OG}}+ \\
\left.\frac{1}{3} \overline{\mathrm{CG}}\right)^{2}\end{array}$ & $\frac{\overrightarrow{O A}^{4}}{4}\left(\theta+\frac{1}{2} \sin 2 \theta\right)$ \\
\hline
\end{tabular}

When combining, the quantities from a circular sector must be subtracted and the parallel axis theorem must be used to transfer the moment of inertia to the centroid.

$$
\text { Area: } \quad \begin{aligned}
A & =A_{1}+A_{2}-A_{3} \\
\text { Centroid: } \quad & \bar{x}_{c}=\frac{1}{A}\left(A_{1} x_{c 1}+A_{2} x_{c 2}-A_{3} x_{c 3}\right) \\
\bar{y}_{c} & =0
\end{aligned}
$$

Moments of Inertia

$$
\begin{array}{ll}
\text { about Centroid } & I_{x c}=I_{x 1}+I_{x 2}-I_{x 3} \\
I_{y c} & =I_{y o 1}+I_{y o 2}-I_{y o 3}-\bar{x}_{c}{ }^{2} A
\end{array}
$$

The polar moment of inertia of the centroid is approximately given by

$$
\mathrm{J}=\frac{1}{6} \overline{\mathrm{OD}} \overline{\mathrm{BC}}\left(3 \overline{O D}^{2}+\overline{\mathrm{BC}}^{2}\right)-\frac{1}{2} \overline{O A}^{4} \theta-\bar{x}_{\mathrm{c}}^{2} \mathrm{~A}
$$


Force and Moment Analysis

The contact area occurs across the entire face of the mating teeth; then it is reasonable to suppose that the force producing the torque is linear and can be represented by the expression $f=k r$, where $f$ is the force per unit length in the radial direction, $k$ is a constant, $r$ is the radial distance from the centerline. The force distribution is shown in Figure L-4. For analysis, it is convenient to replace this distributed force by an equivalent concentrated force, $F$, that produces the same tooth torque (1/3 total torque). Consequent1y,

$$
\mathrm{Fx}_{\mathrm{cf}}=\frac{1}{3} \text { torque }
$$

or

$$
F=\frac{\text { torque }}{3 x_{c f}}
$$

where $x_{c f}$ is the area centroid of the force distribution, given by

$$
x_{c f}=\frac{\frac{2}{3} c \frac{1}{2} c d-\frac{2}{3} b \frac{1}{2} b e}{\frac{1}{2} c d-\frac{1}{2} b e}=\frac{2}{3} \frac{c^{2} d-b^{2} e}{c d-b e} .
$$

But by similar triangles, $D=\frac{e c}{v}$. Therefore,

or

$$
x_{c f}=\frac{2}{3} \frac{c^{3}-b^{3}}{c^{2}-b^{2}}=\frac{2}{3} \frac{c^{2}+b c+b^{2}}{c+b}
$$

$$
x_{c f}=\frac{2}{3} \frac{\overline{O D}^{2}+\overline{O D} \times \overline{O E}+\overline{O E}^{2}}{\overline{O D}+\overline{O E}} \text {. }
$$

The equivalent force acts at a distance $v$ above the base of the tooth, producing a bending moment, $M$. If the teeth are seated together (situation when there is an axial load), the distance $v$ is assumed to be one-half the too height, and

$$
\mathrm{M}=\frac{1}{2} \mathrm{Fh}
$$

which is normal to the tooth surface. Resolving into components along the $x$ and $y$ axes, we have

$$
\begin{aligned}
& M_{x}=-M \cos \theta \\
& M_{y}=M \sin \theta .
\end{aligned}
$$

A larger bending moment is developed if the teeth are not seated since the point of application of the force is higher. The worst case arises when the tooth is as high as possible, i.e., up against the snap ring. Referring to 


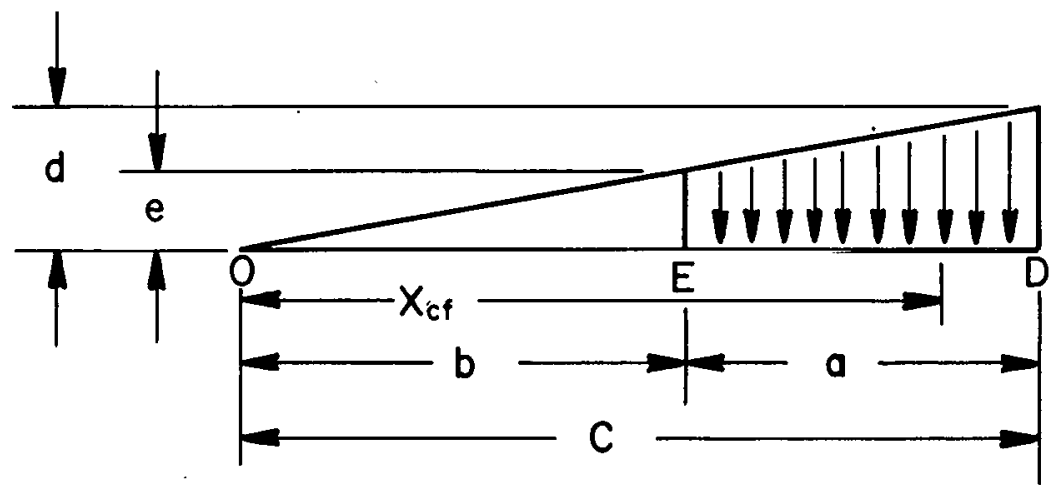

FIGURE L-4 FORCE DISTRIBUTION

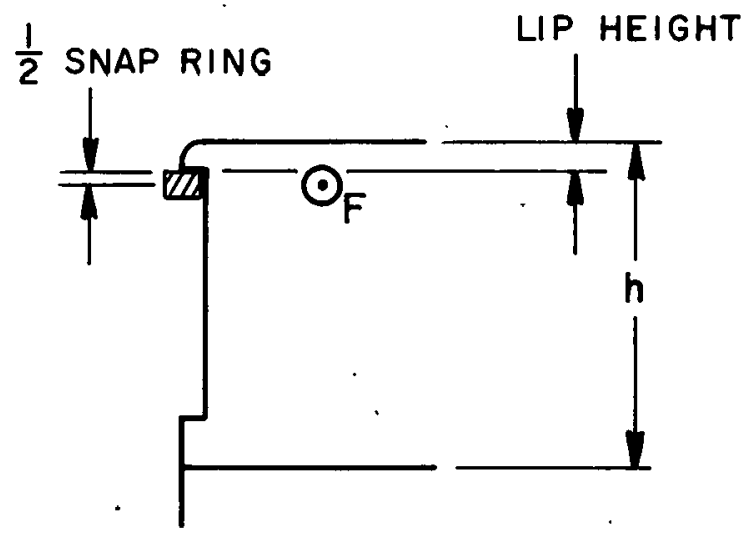

FIGURE L-5 MISALIGNED CASE 
Figure L-5, at this point

$$
\mathrm{v}=\mathrm{h}-\text { (lip height) }-\frac{1}{2} \text { (snap ring thickness) }
$$

Since the bending moment is linearly proportional to the contact height, the moment for a misaligned tooth can be expressed as.

$$
M^{*}=\frac{v^{*}}{V} M
$$

where $v^{*} / v$ is the ratio of the conact heights. Typically $v^{*} / v$ is about 1.5 .

Referring to Figure L-6, the twisting moment about the centroid is given by

$$
M_{F}=F\left(x_{c f}-\bar{x}_{c} \cos \theta\right)
$$

\section{Stress Analysis}

Since the product of inertia of the tooth base area is zero, the stress caused by the bending moment [1] $M$ at point "i" is.

$$
\sigma M_{i}=\frac{M_{x} y}{I_{y}}-\frac{M_{y} x}{I_{x}}
$$

where $x$ and $y$ are the distances from the centroid to point " $i$ " aong the respective axes. For the misaligned case,

$$
\sigma_{1}^{*}=\left(\frac{v^{*}}{v}\right)^{*} \sigma_{1}
$$

The compressive stress is from the axial load and is considered as being carried entirely by the one tooth. Assuming it is distributed uniformly over the tooth,

$$
\sigma_{F_{c}}=-\frac{F}{A}
$$

where $F_{c}$ is the axial thrust load and $A$ is the cross-sectional area of the tooth. The negative sign indicates compressive stress.

If we assume the shear stress to be uniformly distributed across the base of the tooth, then

$$
: \tau_{F}=\frac{F}{A}
$$

which can be decomposed into components along the $x-y$ axes as

$$
\tau_{F_{X}}=\frac{F}{A} \sin \theta
$$




$$
\tau_{F_{Y}}=\frac{F}{A} \cos \theta \text {. }
$$

The shear due to twisting about the centroid can be expressed as

$$
\tau_{M_{F}}=\frac{{ }_{F} r}{J}
$$

where $r$ is the distance from the centroid to a point of interest. Letting $x_{i}$ and $y_{i}$ be the coordinates of points $A, B, C, D, E$ and $F$, then define

$$
\phi=\tan ^{-1}\left(\frac{x_{i}}{y_{i}}\right) \text {. }
$$

Then the $\mathrm{x}$ and $\mathrm{y}$ components of the twisting shear stress are given by

$$
\begin{aligned}
& \tau_{M F_{i x}}=\tau_{M F_{i}} \cos (\phi+90) \\
& \tau_{\mathrm{MF}_{i y}}=\tau_{\mathrm{MF}_{i}} \cos (\phi+90)
\end{aligned}
$$

The combined shear stress at a point " $i$ " is then given by

$$
\tau_{i}=\sqrt{\left(\tau_{F x}+\tau_{M F_{i x}}\right)^{2}+\left(\tau_{F y}+\tau_{M F_{i y}}\right)^{2}},
$$

and the combined bending and.compressive stress is

$$
\sigma_{b_{i}}=\sigma_{m_{i}}+\sigma_{F_{c}} \text {. }
$$

From Mohr's circle, the principal stresses at point "i" are

$$
\sigma_{1,2}=\frac{1}{2} \sigma_{b_{i}} \pm \sqrt{\left(\frac{\sigma_{b_{i}}}{2}\right)^{2}+\tau_{i}^{2}} \ldots
$$

Results of the Static Stress Analysis

The numerical results for the values of stress at critical locations for different tooth configurations and signs are shown in Table L-1. The stress states at all points are included for the latest design. The pattern of different tooth configurations at locations of points on the teeth is shown in Figure $L-7$. 
TABLE L-1

Drill Tooth Stress Summary

\begin{tabular}{|c|c|c|c|c|c|c|c|c|c|c|}
\hline \multicolumn{5}{|c|}{ Tooth Description } & \multirow{2}{*}{\multicolumn{6}{|c|}{ Stress (psi) }} \\
\hline \multirow[b]{2}{*}{$\begin{array}{l}\text { Size } \\
\text { (in.) }\end{array}$} & \multirow[b]{2}{*}{$\begin{array}{l}\text { No. } \\
\text { Teeth }\end{array}$} & \multirow{2}{*}{$\begin{array}{l}\text { Tooth } \\
\text { Height } \\
\text { (in.) }\end{array}$} & \multirow[b]{2}{*}{ Pattern } & \multirow[b]{2}{*}{ Location } & & & & & & \\
\hline & & & & & Bending & Compressive & Shear & $\begin{array}{l}\text { Bending } \\
+ \text { Shear }\end{array}$ & Combined & Misaligned \\
\hline \multirow[t]{6}{*}{1.0} & 3 & 0.281 & I & A & 15,400 & $-41,300$ & 8,100 & 18,900 & $-28,200$ & 24,700 \\
\hline & & & & B & $-61,600$ & & 19,500 & $-67,300$ & $-106,500$ & $-92,300$ \\
\hline & & & & $\mathrm{C}$ & $-51,200$ & & 11,700 & $-53,800$ & $-94,000$ & $-75,100$ \\
\hline & & & & D & 42,500 & & 30,600 & 58,600 & 31,300 & 73,600 \\
\hline & & & & $E$ & 74,900 & & 19,600 & 79,700 & 42,600 & 110,600 \\
\hline & & & & $\mathrm{F}$ & 34,300 & & 14,000 & 39,300 & 10,900 & 52,800 \\
\hline \multirow[t]{3}{*}{1.0} & 3 & 0.25 & I & B & $-54,800$ & $-41,300$ & 19,500 & $-61,100$ & $-99,900$ & $-81,800$ \\
\hline & & & & $\mathrm{D}$ & 37,800 & & 30,600 & 54,900 & 28,900 & 67,200 \\
\hline & & & & $E$ & 66,600 & & 19,600 & 72,000 & 36,000 & 97,700 \\
\hline \multirow[t]{2}{*}{1.0} & 3 & 0.25 & II & B & $-55,200$ & $-41,400$ & 19,600 & $-61,400$ & $-100,425$ & $-87,200$ \\
\hline & & & & $\mathrm{E}$ & 67,700 & & 19,600 & 73,000 & 36,800 & 105,200 \\
\hline \multirow[t]{2}{*}{1.0} & 2 & 0.25 & III & $\mathrm{C}$ & $-59,800$ & $-26,600$ & 18,100 & $-64,900$ & $-90,100$ & $-93,300$ \\
\hline & & & & G & 74,800 & & 18,100 & 79,000 & 54,300 & 115,100 \\
\hline \multirow[t]{2}{*}{1.0} & 2 & 0.25 & IV & A & $-70,600$ & $-29,300$ & 20,500 & $-76,100$ & $-104,000$ & $-109,700$ \\
\hline & & & & $\mathrm{E}$ & 76,600 & & 20,500 & 81,700 & 54,900 & 118,400 \\
\hline \multirow[t]{6}{*}{1.375} & 3 & 0.331 & I & A & 8,900 & $-39,500$ & 5,300 & 11,400 & $-31,400$ & 15,100 \\
\hline & & & & B & $-33,000$ & & 12,900 & $-37,400$ & $-74,700$ & $-52,100$ \\
\hline & & & & $\mathrm{C}$ & $-29,200$ & & 7,800 & $-31,100$ & $-69,500$ & $-44,600$ \\
\hline & & & & $\mathrm{D}$ & 23,200 & & 20,400 & 35,000 & 13,800 & 43,800 \\
\hline & & & & $\mathrm{E}$ & 42,100 & & 13,300 & 45,900 & 14,700 & 65,000 \\
\hline & & & & $\mathrm{F}$ & 19,000 & & 9,400 & 22,800 & 3,600 & 30,900 \\
\hline
\end{tabular}


TABLE L-I (Continued).

\begin{tabular}{|c|c|c|c|c|c|c|c|c|c|c|}
\hline \multicolumn{5}{|c|}{ Tooth Description } & \multirow{2}{*}{\multicolumn{6}{|c|}{ Stress (psi) }} \\
\hline \multirow[b]{2}{*}{$\begin{array}{l}\text { Size } \\
\text { (in.) }\end{array}$} & \multirow[b]{2}{*}{$\begin{array}{l}\text { No. } \\
\text { Teeth }\end{array}$} & \multirow{2}{*}{$\begin{array}{l}\text { Tooth } \\
\text { Height } \\
\text { (in.) }\end{array}$} & \multirow[b]{2}{*}{ Pattern } & \multirow[b]{2}{*}{ Location } & & & & & & \\
\hline & & & & & Bending & Compressive & Shear & $\begin{array}{l}\text { Bending } \\
+ \text { Shear }\end{array}$ & Combined & Misaligned \\
\hline \multirow[t]{3}{*}{1.375} & 3 & 0.25 & I & B & $-24,900$ & $-39,500$ & 12,900 & $-30,400$ & $-66,900$ & $-38,600$ \\
\hline & & & & D & 17,500 & & 20,400 & 31,000 & 12,200 & 35,700 \\
\hline & & & & $\mathrm{E}$ & 31,800 & & 13,300 & 36,600 & 10,000 & 47,500 \\
\hline \multirow[t]{3}{*}{1.375} & 3 & 0.25 & I & $\mathrm{B}$ & $-24,900$ & $-39,500$ & 12,900 & $-30,400$ & $-66,900$ & $-38,600$ \\
\hline & & & & D & 1,00 & & 20,400 & 31,000 & 12,200 & 35,700 \\
\hline & & & & $\mathrm{E}$ & 31,800 & & 13,300 & 36,600 & 10,000 & 47,500 \\
\hline \multirow[t]{2}{*}{1.375} & 3 & 0.25 & II & B & $-31,000$ & $-39,800$ & 11,800 & $-34,900$ & $-72,600$ & $-49,300$ \\
\hline & & & & $\mathrm{E}$ & 29,600 & & 11,800 & 33,800 & 7,800 & 47,400 \\
\hline \multirow[t]{2}{*}{1.375} & 2 & 0.25 & III & C & $-28,600$ & $-25,300$ & 12,100 & $-33,000$ & $-56,500$ & $-46,000$ \\
\hline & & & & $\mathrm{G}$ & 26,500 & & 12,100 & 31,200 & 12,700 & 43,200 \\
\hline \multirow[t]{2}{*}{1.375} & 2 & 0.25 & IV & A & $-45,400$ & $-31,500$ & 15,700 & $-50,300$ & $-80,000$ & $-71,500$ \\
\hline & & & & $E$ & 46,400 & & 15,700 & 51,700 & 25,200 & 73,800 \\
\hline
\end{tabular}




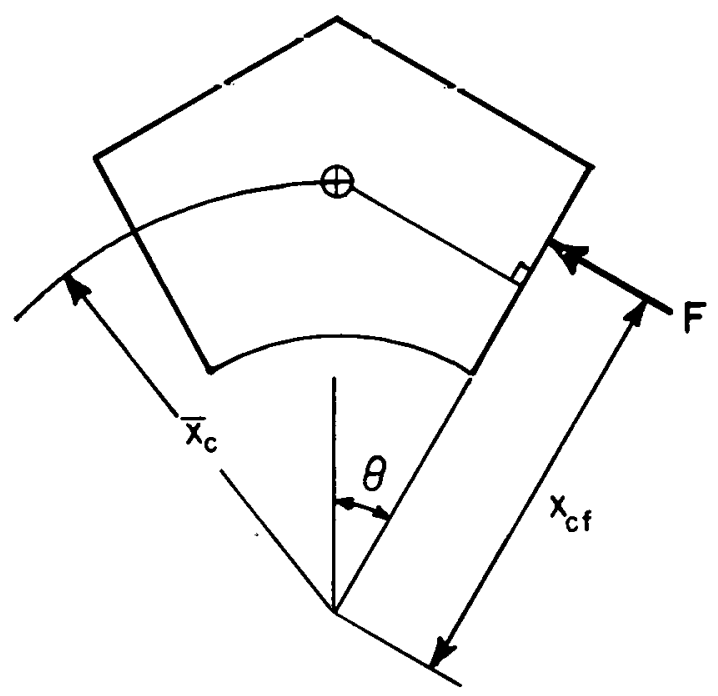

FIGURE L- 6 TWISTING MOMENT

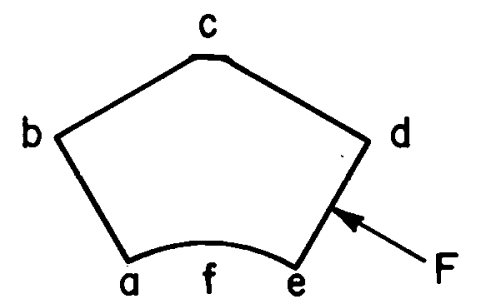

PATTERN I

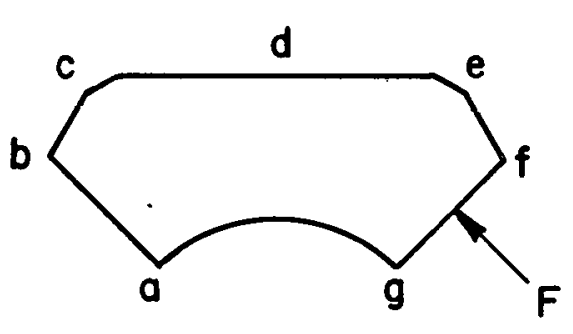

PATTERN III
C

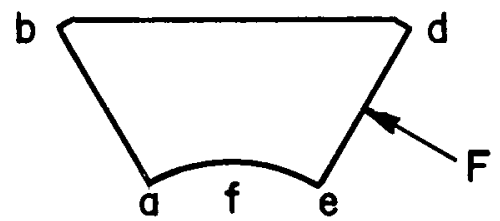

PATTERN II

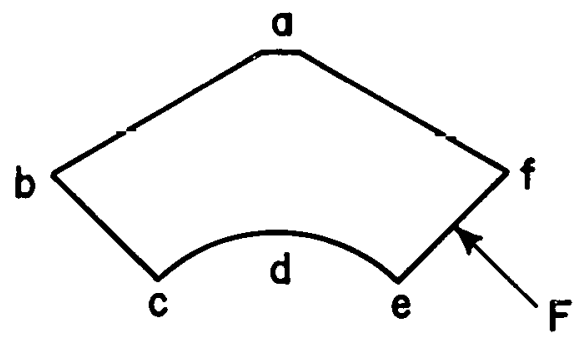

PATTERN IY

FIGURE L-7 TOOTH CONFIGURATIONS 
The "misaligned" case is when the teeth are as far apart as possible. Consequently, the bending stress is multiplied by the factor $\left(v^{*} / v\right)$ and the total stress is found using Eq. (L-23). Since the contact point has moved up the tooth face from the center, no compressive force is acting.

If the material being used is 4140 steel, heat-treated to a Rockwell hardness Rc 35, the ultimate and yield strengths can be expected to be $165 \mathrm{kpsi}$ and $150 \mathrm{kpsi}$, respectively [2]. As a result, this stress analysis predicts that all teeth forms will perform adequately in the static case. The comparison between the two- and three-tooth configurations shows the three-tooth to be the stronger for equal tooth heights. By increasing the tooth depth to achieve a small radius of curvature of the drill string, the stress level at the critical point was increased approximately $25 \%$. Even so, it will remain we11 within the yield strength of the material.

\section{Fatigue Analysis}

This analysis follows the methods presented in Reference [1]. Modifying the endurance limit $\left(S_{e}^{\prime}\right)$ to account for surface finish $\left(k_{a}\right)$, size factor $\left(k_{b}\right)$ and stress concentration $\left(\mathrm{k}_{\mathrm{e}}\right)$, we have the corrected endurance limit,

$$
\mathrm{S}_{\mathrm{e}}=\mathrm{k}_{\dot{\mathrm{a}} \mathrm{b}} \mathrm{k}_{\mathrm{e}} \mathrm{S}_{\dot{\mathrm{e}}}^{\prime} \text {. }
$$

From the Metals Handbook [2], $\mathrm{S}_{\mathrm{e}}^{\prime}=90 \mathrm{kpsi}, \mathrm{S}_{\mathrm{u}}=165 \mathrm{kpsi}$, and $\mathrm{S}_{\mathrm{y}}=150 \mathrm{kpsi}$. For a machined surface, $\mathrm{k}_{\mathrm{a}}=0.66$ while $\mathrm{k}_{\mathrm{b}}=0.85$. This $\mathrm{k}_{\mathrm{b}}$ corresponds to $\mathrm{a}$ part diameter between 0.3 and $2.0 \mathrm{in.}$ The modifying factor for stress concentration is found from

$$
\frac{1}{k_{e}}=k_{f}=1+q\left(k_{t}-1\right)
$$

where $q$ is the notch sensitivity $(0.89)$ and $K_{t}$ is the stress concentration factor. Considering the tooth as a simple number under a bending moment, $k_{t}$ is a function of the notch radius ( $1 / 16 \mathrm{in.}$ ), the depth across the tooth at the point (d) and the drill diameter across the flats (D): Using the values for our drill segment and Shigley's Figure A-20-6 [1], we have 


\begin{tabular}{|c|c|c|c|c|}
\hline & \multicolumn{2}{|c|}{ Smal1 Segment } & \multicolumn{2}{|c|}{ Large Segment } \\
\hline & $\mathrm{D}$ & $\mathrm{E}$ & $\mathrm{D}$ & $E$ \\
\hline $\mathrm{D}$ & 0.875 & 0.875 & 1.25 & 1.25 \\
\hline $\mathrm{d}$ & 0.431 & 0.246 & 0.616 & 0.363 \\
\hline $\mathrm{r} / \mathrm{d}$ & 0.145 & 0.254 & 0.101 & 0.172 \\
\hline $\mathrm{D} / \mathrm{d}$ & 2.03 & 3.56 & 2.03 & 3.44 \\
\hline$k_{t}$ & 1.63 & 1.46 & 1.6 & 1.8 \\
\hline$k_{e}$ & 0.641 & 0.710 & 0.584 & 0.652 \\
\hline $\mathrm{S}_{\mathrm{e}}$ & 32,364 & 35,848 & 29,486 & 32,920 \\
\hline
\end{tabular}

Points B and D have the same geometry; therefore, they have the same stress concentration values. If we assume the drill remains within the ten-inchesin-ten-feet drill hole tolerance, then the maximum deviation between succeeding teeth centerlines is approximately 0.25 degrees. This corresponds to an increase in load application height of 0.005 in. (1.33 in. across segment times $\sin 0.25^{\circ}$ ), which does not significantly alter the bending stress in the tooth. It does, however, remove the compressive load for this tooth. As a result, the cyclic loading corresponds to application and removal of the thrust loading on a tooth. Define the mean $\left(\sigma_{m}\right)$ and alternating $\left(\sigma_{a}\right)$ stresses as

$$
\begin{aligned}
& \sigma_{m}=\frac{1}{2}\left(\sigma_{\max }+\sigma_{\min }\right) \\
& \sigma_{a}=\frac{1}{2}\left(\sigma_{\max }-\sigma_{\min }\right) .
\end{aligned}
$$

Using the modified Goodman Diagram (Figure L-8), the y-intercept for tension is

and for compression

$$
S_{f}=\frac{\sigma_{a} S_{u}}{S_{u}-\sigma_{m}}
$$

$$
S_{f}=\frac{\sigma_{a} S_{y}}{S_{y}-\sigma_{m}} \text {. }
$$

Infinite life is predicted if $\mathrm{S}_{f}$ is less than $\mathrm{S}_{e}$ for tension. For compression, $\sigma_{a}$ must be less than $S_{e}$.. and $s_{f}$ must be less than $s_{y}$ for infinite life. The fatigue life analysis of the drill segments for the latest tooth design is summarized in Table L-2.

Based on our calculated stress levels, the life of the gear teeth should exceed one million cycles. 
$\mathrm{L}-14$

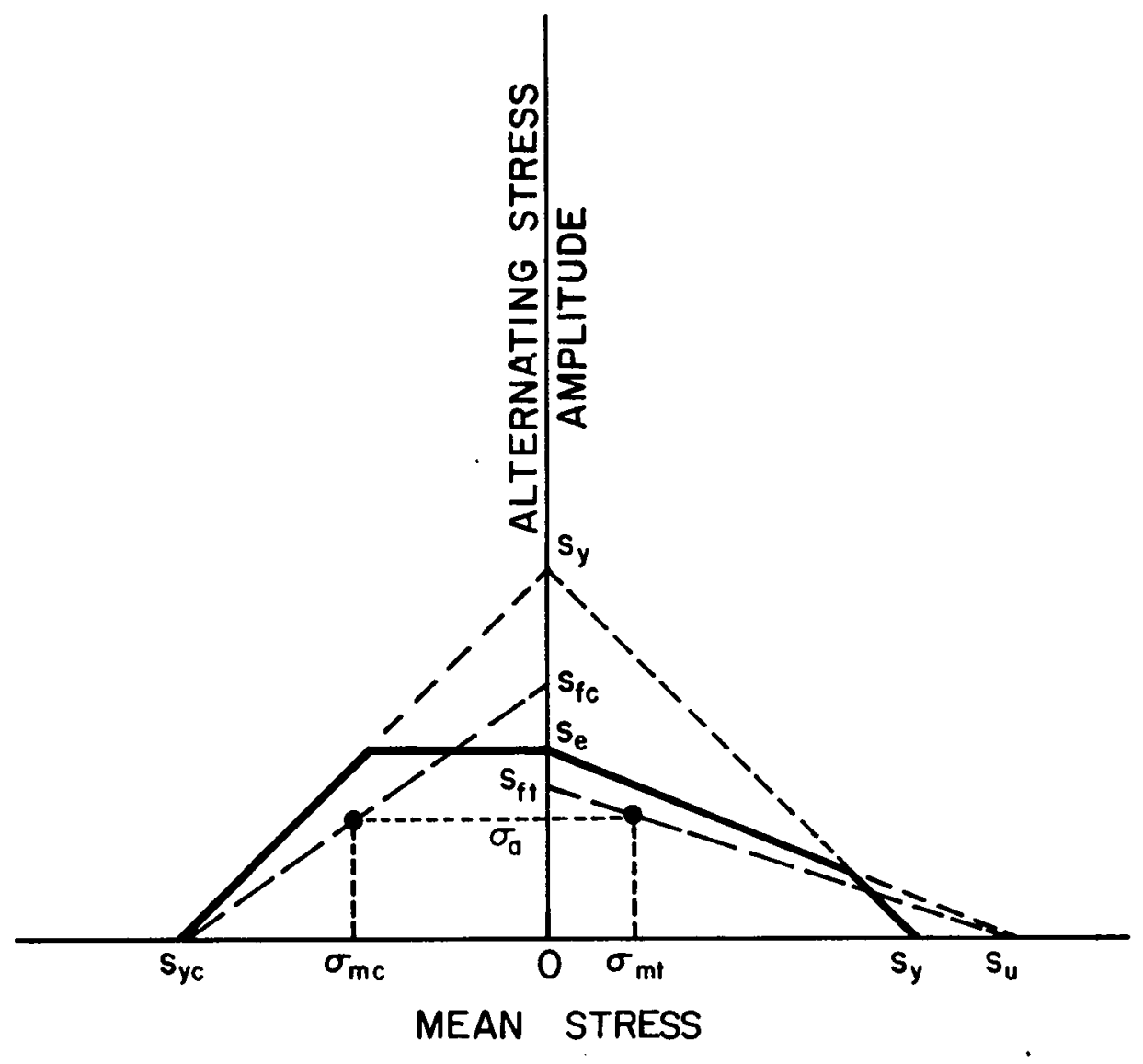

FIGURE LI GOODMAN DIAGRAM 
TABLE L-2

Summary of Fatigue Analysis

\begin{tabular}{lcrrrrr}
\hline $\begin{array}{c}\text { Segment } \\
\text { Size, in. }\end{array}$ & Location & $\sigma_{\mathrm{m}}$ & $\sigma_{\mathrm{a}}$ & $\mathrm{S}_{\mathrm{f}}$ & $\mathrm{s}_{\mathrm{e}}$ & \\
\hline 1.375 & $\mathrm{~B}$ & $-56,100$ & 18,600 & 29,800 & 29,500 & infinite \\
1.375 & $\mathrm{D}$ & 24,400 & 10,600 & 12,500 & 29,500 & infinite \\
1.375 & E & 32,300 & 15,600 & 19,200 & 32,900 & infinite \\
1.00 & B & $-86,900$ & 19,600 & 46,600 & 32,400 & infinite \\
1.00 & D & 44,900 & 13,700 & 18,800 & 35,800 & infinite \\
1.00 & E & 61,100 & 18,600 & 29,500 & 32,400 & infinite \\
\hline
\end{tabular}




\section{References}

1. J. E. Shigley, Mechanical Engineering Design, 2nd Ed., McGraw-Hill.

2. Metals Handbook, Vol. 1, 8th Ed., ASM. 
APPENDIX M

CURVATURE TESTS

These tests were conducted to determine the ability of the segmental flexible shaft to curve through the required arcs needed in the design that was proposed in Phase $I$ of this project. A midline radius of curvature of 14 in. was specified in Phase $I$ and is shown in Figure 1 . In addition to the simple radius, it was felt that our flexible shaft should be able to work through a compound curvature. Such a configuration would be required if the flexible shaft stowage tube were located off the centerline of the drilling vehićle.

In order to perform such tests, an engine lathe was modified so that the lathe chuck could provide the rotation speeds for the shaft and a support bearing could be mounted on the tail stock to. secure the rotating shaft during the test. Figure M-1 shows how these fixtures were used with the engine lathe to provide the test configurations desired. This figure uses coordinate dimensions $A, B$ and $C$ to specify the radius of curvature, $R$, used for each test. A summary of these coordinate dimenstions with the related minimum radius is tabulated for each test in Table $M-1$. Fígures $M-2$ and $M-3$ show the engine lathe so modified with a test specimen mounted.

Only the $13 / 8$-in. diameter segmental flexible shaft was tested in this way. The smaller 1 -in. diameter flexible shaft will be able to easily handle any radius the $13 / 8$ shaft can operate in. The flexible shaft was contained within a flexible metal tube during the test. This flexible metal tube had an inner diameter of 1 1/2 in. and an outer diameter of $15 / 8 \mathrm{in.}$ This flexible tube was very similar to electrical conduit. Flexible shafts containing twoand three-toothed segments were tested. The two-toothed variation was first tested using segments machined from AISI 1018 carbon steel. The three-toothed variety was tested later and was fabricated from heat-treated AISI 4140 steel (Rockwe11 hardness Rc 35). Each test configuration was tested at the speeds and for test duration times shown in Table M-2.

Tests 1-19 using the two-toothed geometry had a retainer ring groove that differed from the later tests using the three-toothed arrangements. Observations made during the testing of the two-toothed geometry suggested the design change that was made for the three-toothed geometry. This design change modified the retaining ring groove so that three of the six inner meshed teeth had a narrow groove slightly wider than the thickness of the retaining ring, 

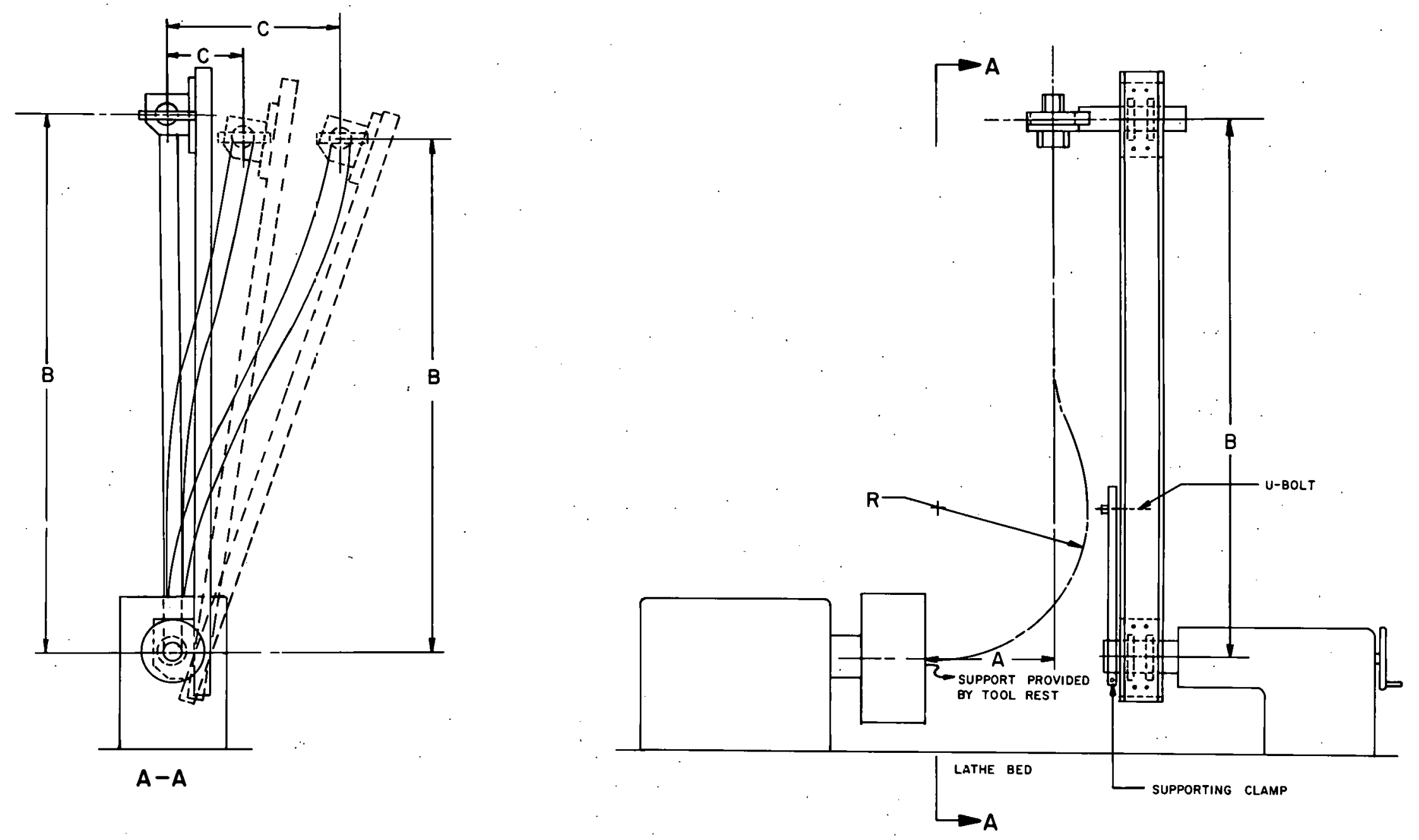

Figure $M-1$. Curvature Test Configurations. 
TABLE $M-1$

Curvature Specifications for Dynamic Testing

\begin{tabular}{|c|c|c|c|c|c|}
\hline \multirow[b]{2}{*}{ Test } & \multirow[b]{2}{*}{ Teeth } & \multicolumn{3}{|c|}{ Dimensions (in.) } & \multirow{2}{*}{$\begin{array}{c}\text { Minimum Radius } \\
\text { R (in.) }\end{array}$} \\
\hline & & A & B & C & \\
\hline 1 & 2 & 16.5 & 19 & 0 & 12 \\
\hline 2 & 2 & 16.5 & 41 & 0 & 12 \\
\hline 3 & 2 & 16.5 & 45.5 & 18 & 14 \\
\hline 4 & 2 & 17 & 19 & 0 & 14 \\
\hline 5 & 2 & 21 & 51 & 0 & 14 \\
\hline 6 & 2 & 21 & 51 & 0 & 14 \\
\hline 7 & 2 & 21 & 40 & 32.5 & 14 \\
\hline 8 & 2 & 25 & 33 & 0 & 16 \\
\hline 9 & 2 & 25 & 50 & 0 & 16 \\
\hline 10 & 2 & 25 & 50 & 0 & 16 \\
\hline 11 & 2 & 25 & 48 & 18 & 16 \\
\hline 12 & 2 & 25 & 40 & 31. & 16 \\
\hline 13 & 2 & 16 & 53 & 0 & 16 \\
\hline 14 & 2 & 18.5 & 47 & 0 & 14 \\
\hline 15 & 2 & 3.5 & 49 & 0 & 16 \\
\hline $16^{(1)}$ & 2 & 22 & 51 & 0 & 14 \\
\hline 17 & 2 & 22 & 51 & 0 & 14 \\
\hline 18 & 2 & 18 & 51 & 0 & 14 \\
\hline 19 & 2 & 19.5 & 41 & 30 & 14 \\
\hline 20 & 3 & 23 & 51 & 0 & 16 \\
\hline 21 & 3 & 23 & 51 & 0 & 16 \\
\hline 22 & 3 & 19.5 & 51 & 0 & 16 \\
\hline $23^{(2)}$ & 3 & 18.5 & 51 & 0 & 14 \\
\hline $24^{(3)}$ & 3 & 19 & 51 & 0 & 16 \\
\hline $25^{(4)}$ & 3 & 19 & 40 & 0 & 16 \\
\hline
\end{tabular}

(1) Tests 16-25 had chip-return tube inside flexible shaft.

${ }^{(2)}$ Shaft separated at $232 \mathrm{rpm}$.

(3) Test speed $357 \mathrm{rpm}$ for $60 \mathrm{~min}$.

(4) Test speed $357 \mathrm{rpm}$ for $30 \mathrm{~min}$.

(5) Radius at centerline. 


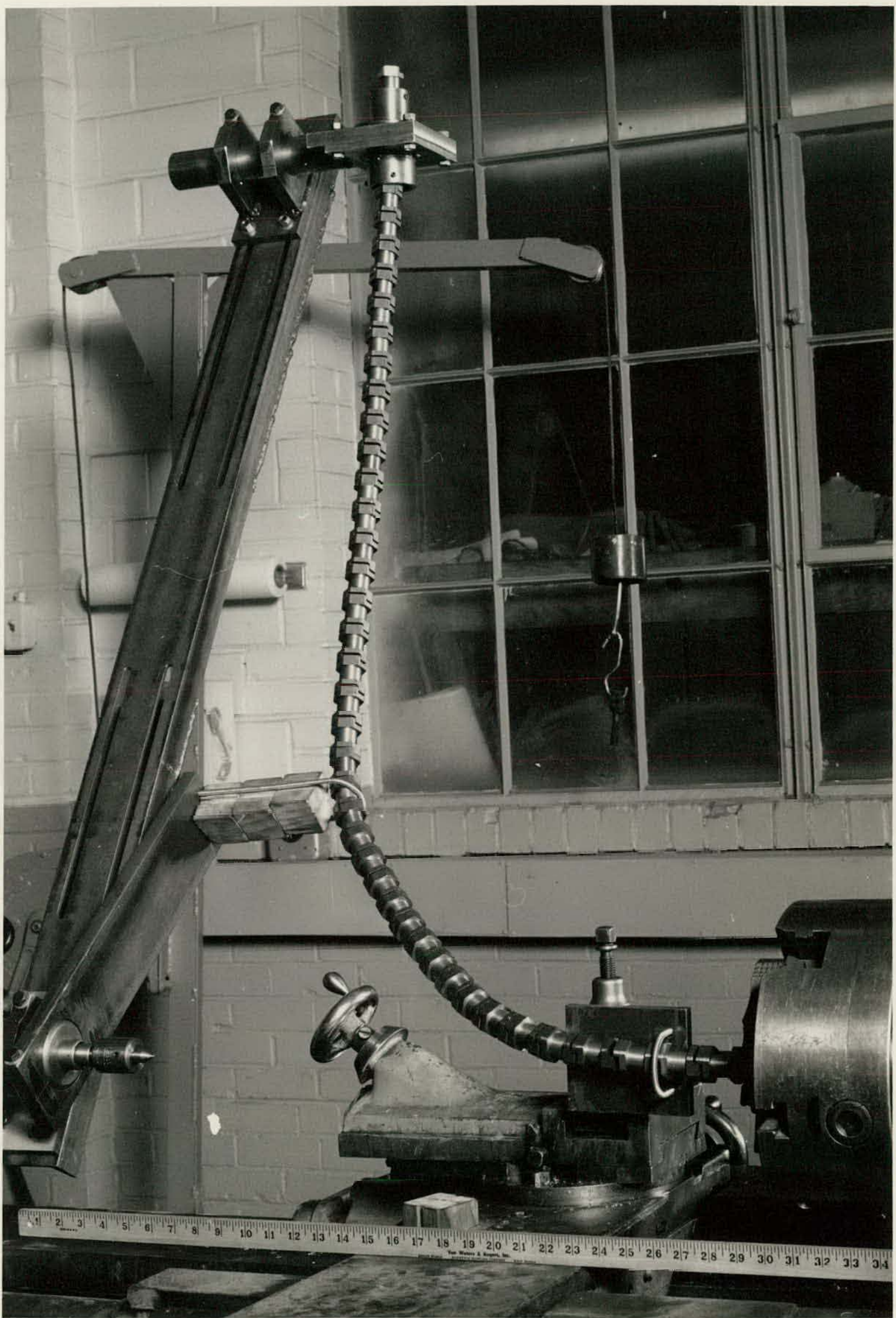

Figure M-2. Unshielded Flexible Shaft Drill During Curvature Tests. 


$$
74272 B-11
$$




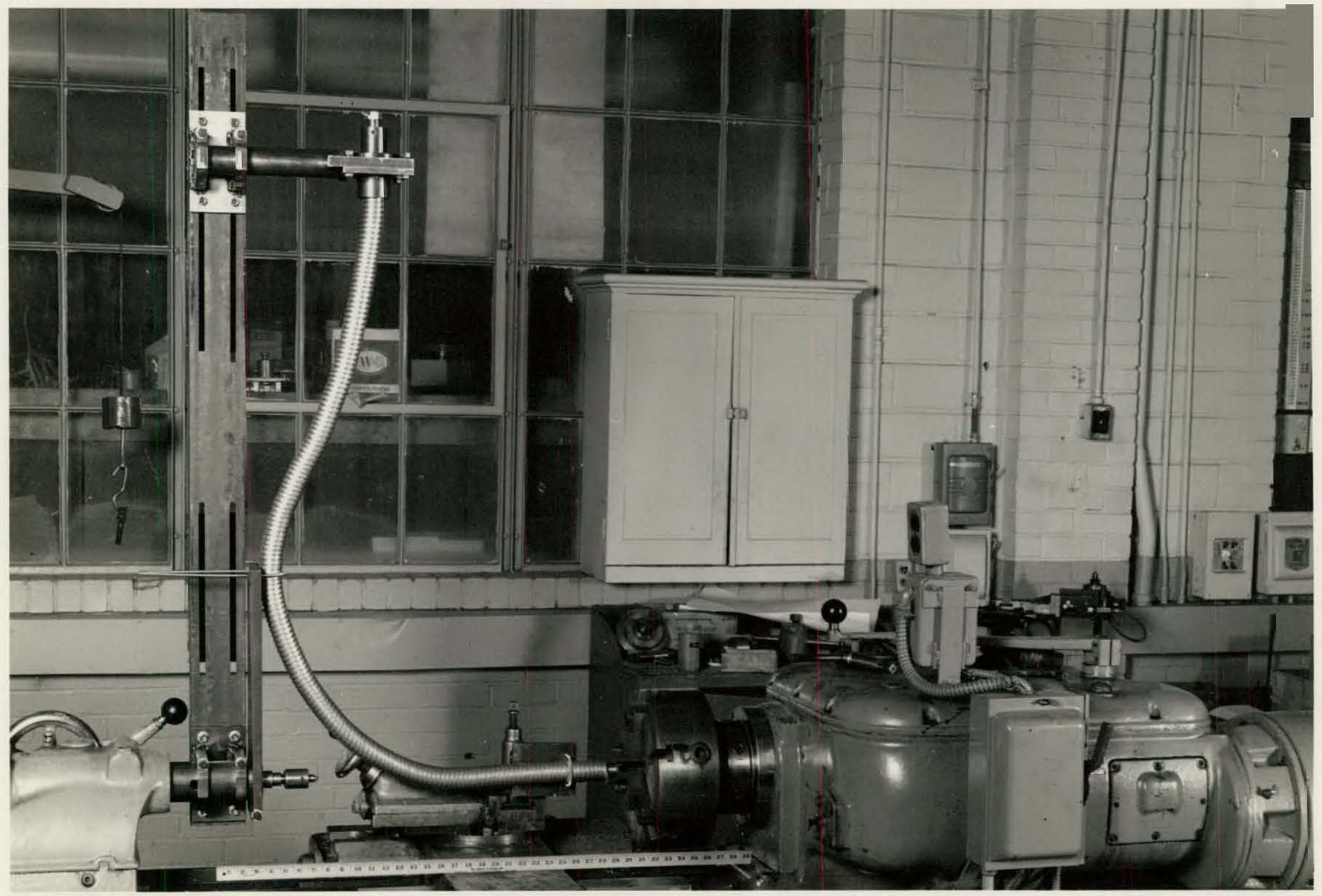

Figure M-3. Shielded Flexible Shaft Drill During Curvature Tests. 
$74272 A-2$

10. $742724-2^{\cdots}$ 
TABLE $M-2$

Dynamic Testing Speeds and Times

\begin{tabular}{cc} 
Speed, rpm & Test Duration, min. \\
36 & 1 \\
114 & 3 \\
152 & 3 \\
199 & 3 \\
265 & 3 \\
357 & 3 \\
474 & 3 \\
\hline
\end{tabular}


whereas the remaining three teeth had grooves sufficiently wide to permit the segments to separate apart the required distance needed by this flexible coupling. This groove size difference is clearly shown in Figure M-8, referenced to Section D-D. of Drawing 1331-74-09-1, sheet 1 of 1 . By narrowing the retaining ring groove, the retaining ring was more securely held and reduced the likelihood of separation of the segments via careless handling or abnormal operating conditions. Figure M-4 shows how the narrow groove and wide groove function during misalignment of the segments.

The governing relationships that determine the bending radius of the shaft can be derived by referring to Figures $M-5$ and $M-6$. The symbols used in these figures are defined as:

$r=$ inner radius of curvature for the drill string

$\ell=$ effective segment length

$\beta=$ included angle of separation at tooth interface

$\mathrm{d}=$ pivot distance between contact point and engagement point of adjacent teeth at retainer ring

$S=$ separation at pivot distance $d$

$A=$ tangent point for inner radius of curvature

$B=$ contact point at tooth interface

$t=$ width of retainer ring groove

$a=$ edge shoulder on teeth

D $=$ tooth depth

The trigonometric relationships

and

$$
\tan \frac{B}{2}=\frac{\ell}{2 r}
$$

$$
\tan \frac{\beta}{2}=\frac{S}{2 d}
$$

result in

$$
\frac{\ell}{2 r}=\frac{S}{2 d}
$$

From Figure M-5

$$
D=s+t+2 a .
$$

By solving for $S$ in Eq. (M-3) and substituting into Eq. (M-4), the resulting equation is

$$
r=\frac{l d}{D-t-2 a} .
$$

The radius at the centerline is 


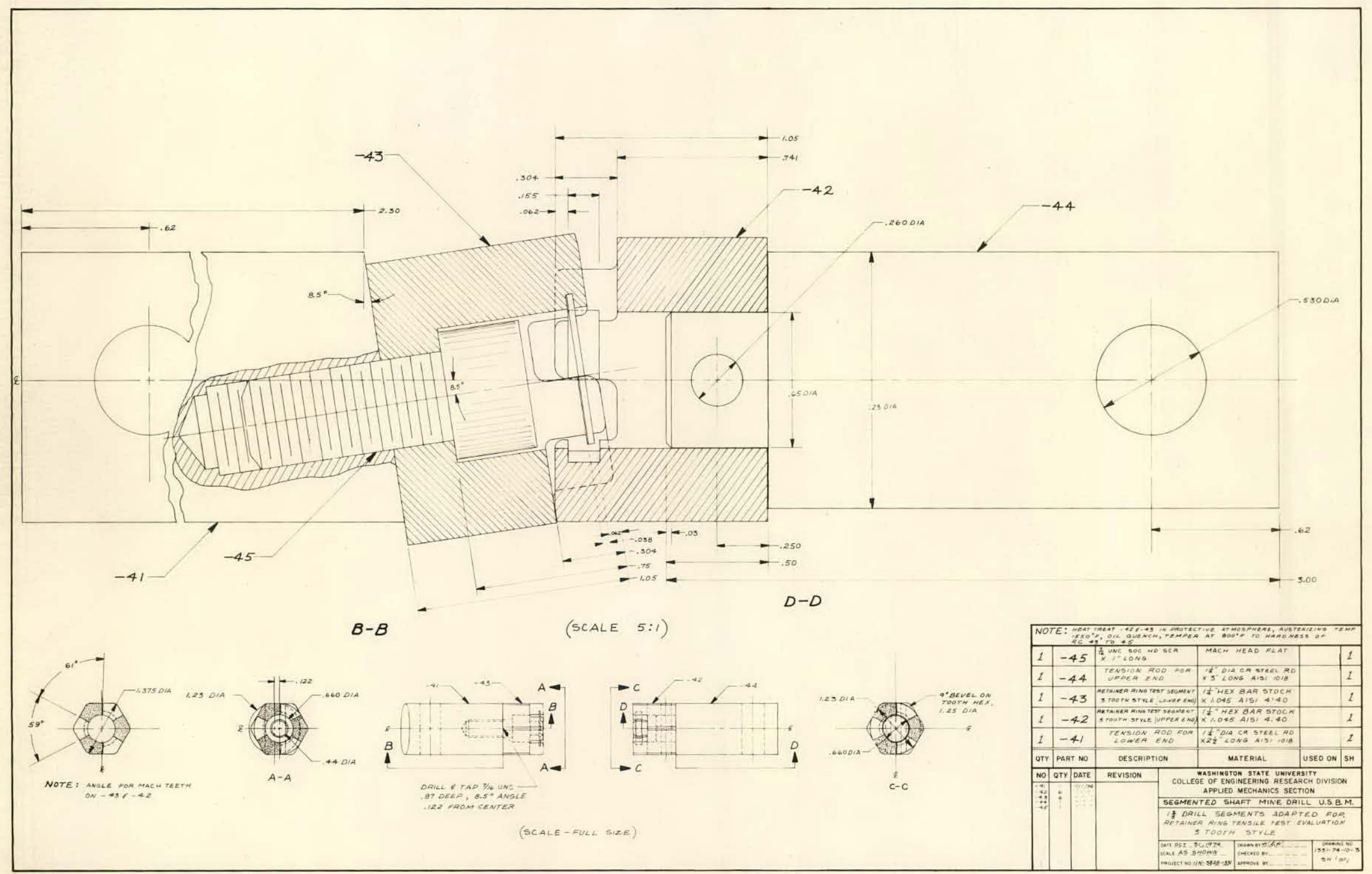

Figure M-4. Orientation of Flexible Segments and Retainer Ring During Misalignment. 
M-9

1

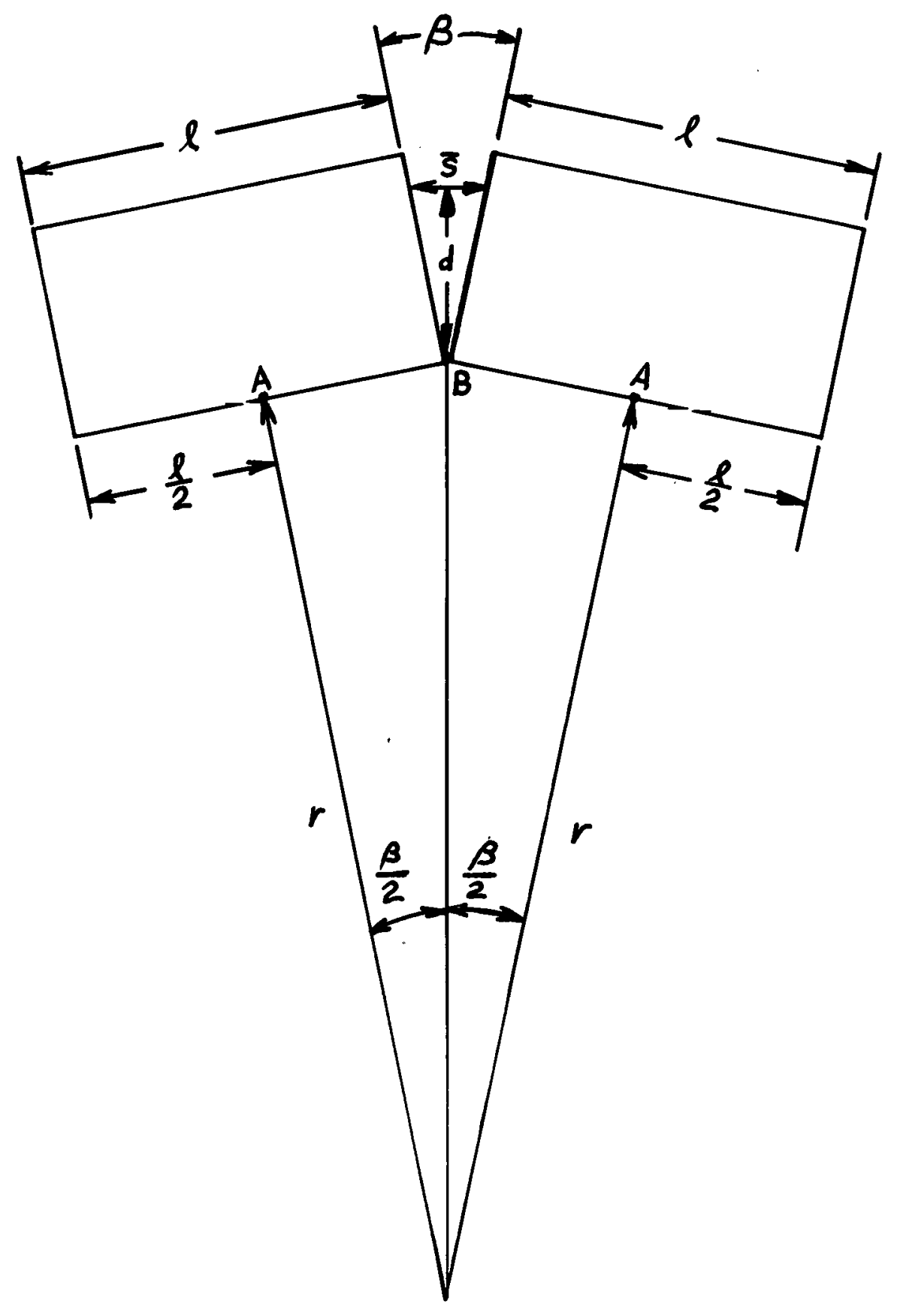

Figure 1 -5. Radius Geometry for Flexible Shaft Drill. 


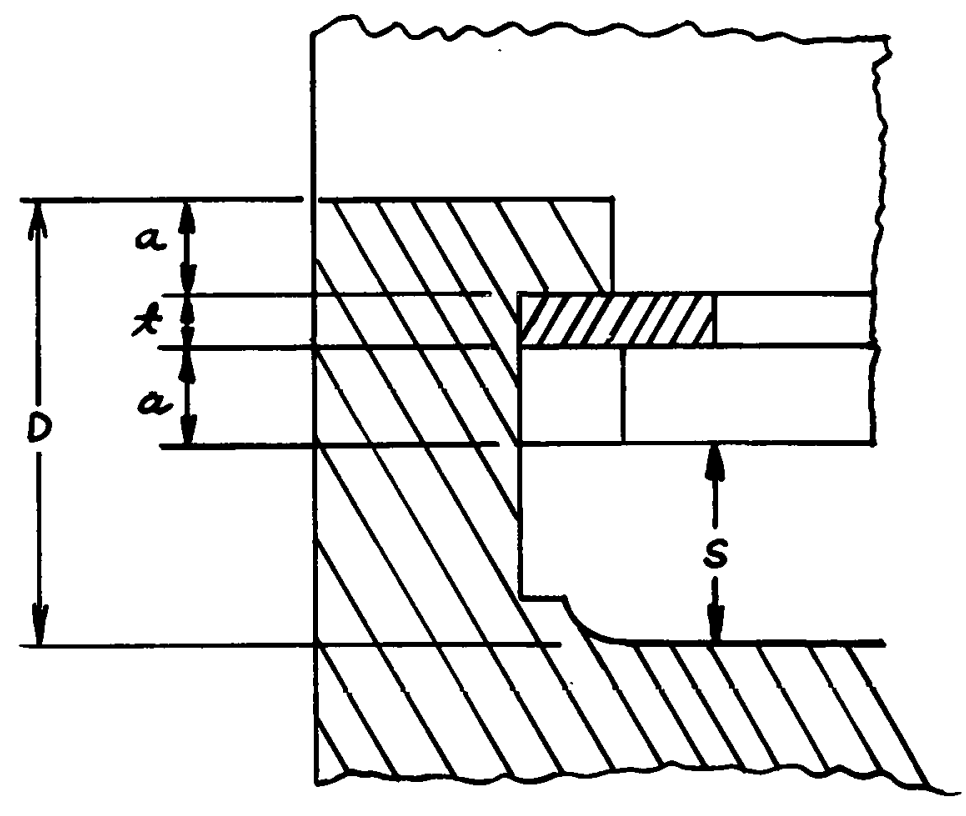

Figure M-6: Retainer Ring Groove Geometry. 


$$
R=r+\frac{\text { shaft diameter }}{2}
$$

Results of Dynamic Tests on the Two-Toothed Geometry

This segment geometry was tested for radii from 12 in. to 16 in. No great difficulty was experienced in rotating a shaft of this type through the configurations that were tested. There were some noticeable problems which we felt could be eliminated by the smaller retainer ring groove mentioned earlier and by going to a three-toothed segment. The problem noticed that suggested a retainer groove modification was that normal handling of the shaft sometimes caused it to separate. Additionally, at certain speeds, vibration was present that was not of a damaging nature but certainly irritating in terms of noise and heat generated. The conclusions from this series of tests were that the two-tooth configuration would be dynamically acceptable if the retainer ring groove were modified to make the holding of the ring more secure. This conclusion gave us the assurance that, if the three-tooth geometry did not have sufficient strength during actual drilling tests, the two-toothed geometry would have satisfactory dynamic characteristics as well as the possibility of being stronger.

Dynamic Tests of Three-Toothed Geometry

The tests conducted were confined to the $14-i n$. and $16-i n$. radius using simple curvatures and compound curvatures. Test No. 23 at a bend radius of 14 in. resulted in the shaft separating at a speed of $232^{\circ} \mathrm{rpm}$. In fact, the tests using a simple curvature at a 16-in. radius resulted in partial separations of the segments. This partial separation caused the retainer ring to be bent, as shown in Figure $M-7$.

In order to explain this behavior, we investigated what effect machining tolerances would have on the radius of curvature. Normal tolerances for this work would be \pm 0.002 in. for dimensions $D, d, a$ and $t$, and $\pm 0.020^{\circ}$ for $\ell$. Inserting these into $\mathrm{Eq}$. $(\mathrm{M}-5)$ results in

and

$$
r^{+}=\frac{(l+0.020)(d+0.002)}{D-t-2 a-0.008}
$$

$$
r^{-}=\frac{(l-0.020)(d-0.002)}{D-t-2 a+0.008} \text {. }
$$

For $D=0.25, t=0.38$ and $a=0.05$, the limits on $r$ for the $13 / 8$-in. diameter 


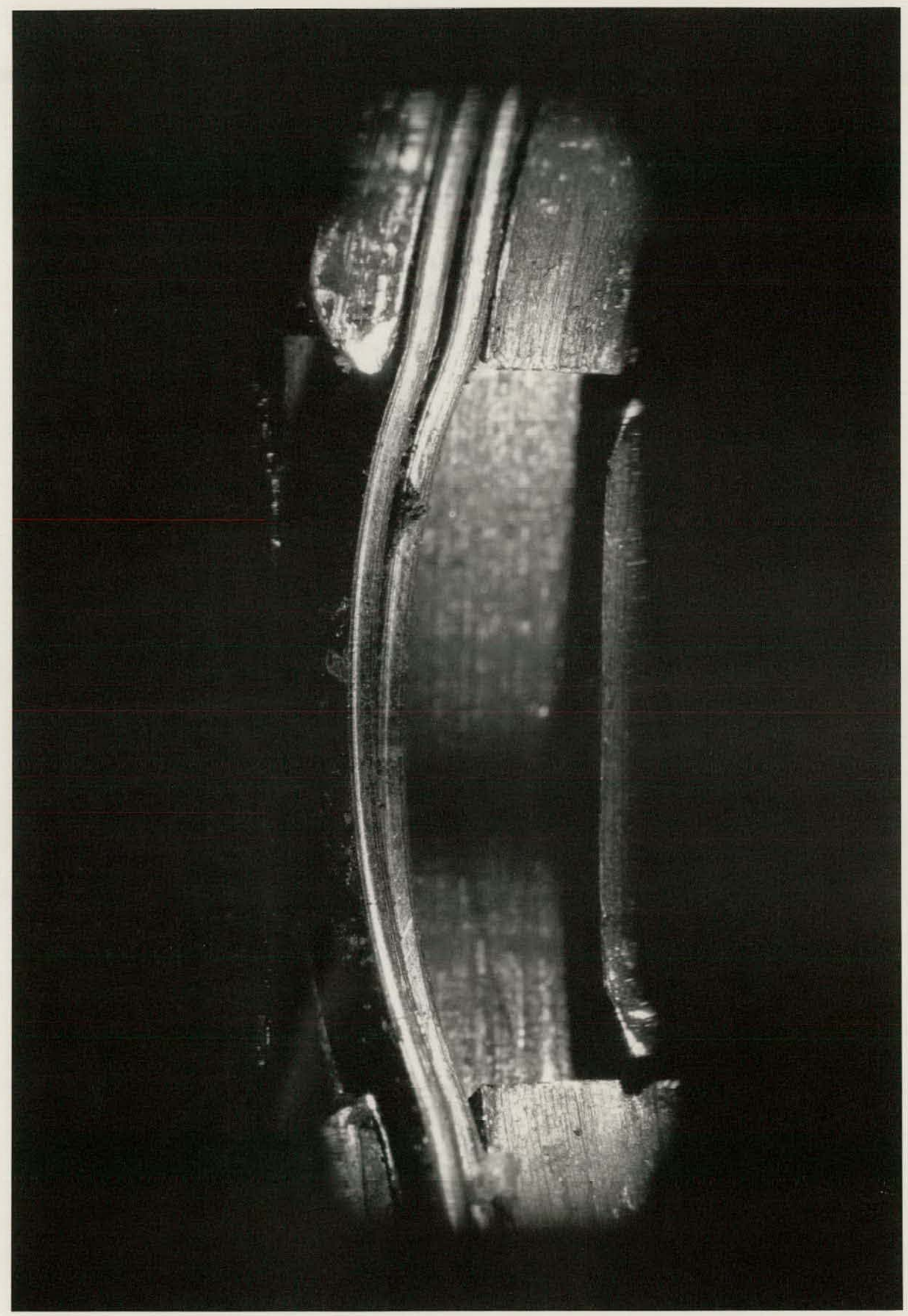

Figure M-7. Bent Retainer Ring Caused by Too Sma11 a Radius of Curvature. 
preys ay

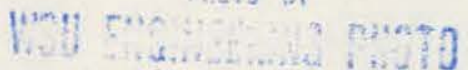

19. $74323 y-14 \ldots$ 
flexible shaft are 12.309 in. to 14.645 in., making the nominal variation in midline radius 13 in. to $155 / 16$ in.

The variation explains the difficulty that we encountered with the 14-in. radius of curvature. For simple radii of 16 in. no separation problem was experienced. The three-toothed design ran smoother and with less vibration than the two-toothed geometry. Our conclusions were that the three-toothed design was superior to the two-toothed design; however, the flexible shaft must be designed for a smaller radius of curvature so that a greater margin is available for variation in the radius of curvature due to manufacturing tolerances. 

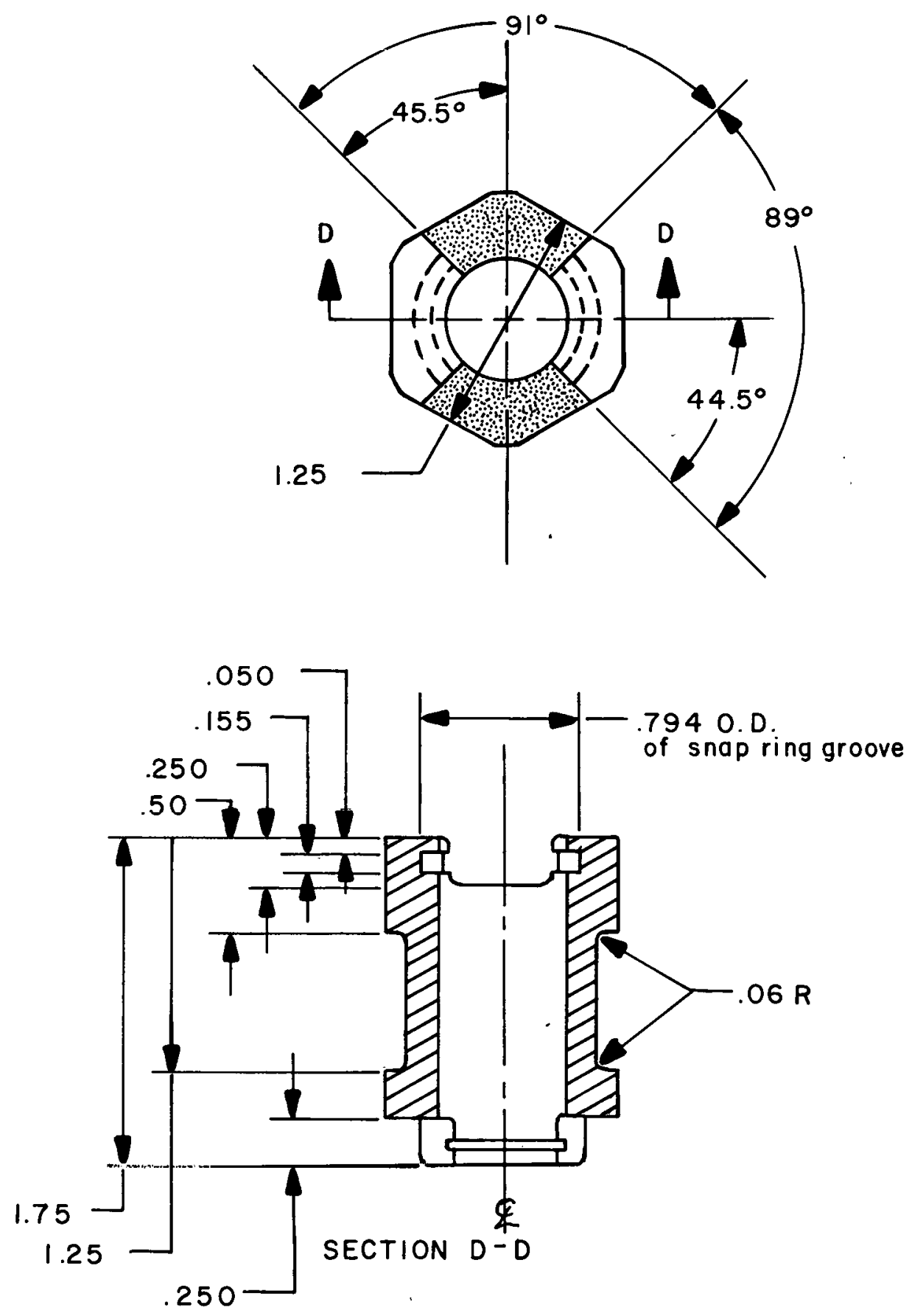

REF DRWG $1331-74-09-1$

FIGURE M-8 I 3/8" DRILL SEGMENT DETAIL 


\section{APPENDIX . N}

\section{FIELD TEST}

On November 4 and 5 , the flexible shaft drill was tested at U.S. Steel Corporation's Mine No. 10 in the Gary mining district of West Virginia. The U.S. Steel Corporation cooperated in this test by supplying a standard doubleheaded bolter machine, operating assistance and a test area in the developmental portal called Adkins main. The coal height in this area was about $6 \mathrm{ft}$ and the roof was predominantly fine gray-black shale. The drilling characteristics of this material were described by the mine personnel as medium to hard. Bolt holes drilled in this area.were nominally about $7 \mathrm{ft}$ deep.

This field test was conducted to verify the following:

1. Will the flexible shaft drill maintain alignment while drilling shale?

2. Will the flexible shaft drill be able to transfer the necessary torque and thrust without catastrophic results?

3. What is the drilling torque and thrust transmitted under such conditions?

4. What will be the drilling rate?

5. Are there geometric deficiencies in the design that will create problems during drilling or during withdrawal of the flexible shaft drill from the hole?

6. Does the drill, as designed, have the capability to evacuate the cutting chips from the hole?

In order to use a standard drill for our tests, the flexible shaft drill had to be fabricated in sections that could be coupled together. Figure N-1 shows two 18-in. sections of this field test flexible shaft drill. These sectional flexible shaft drills were designed so that a drilling sequence could be employed whereby the standard drilling head could power the flexible shaft drill without having the flexible portion outside of the hole in an unsupported condition. Such a drive procedure would simulate the actual drive mode via the roof-located drivehead that was recommended in the Phase I report. Before inserting the flexible shaft drive, Figure N-2 shows that a 28 -in. starter hole had to be drilled using standard drill steel. For a flexible shaft test run, starter sections with bit holders and bits as shown in Figure N-3 were inserted. A section of flexible drill was then coupled to the starter section using the male coupler as shown in Figure $\mathrm{N}-4$. 

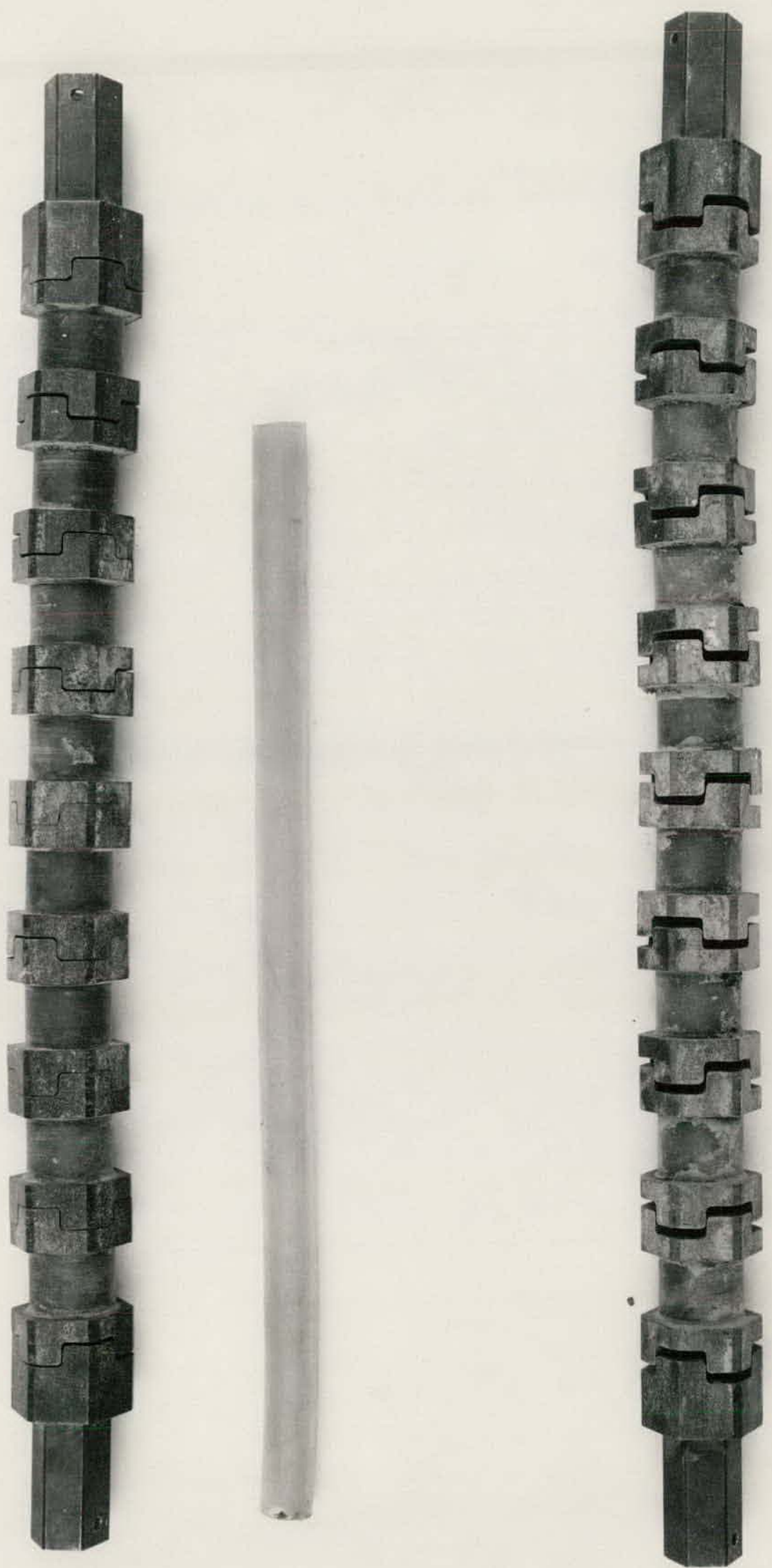

Figure N-1. Flexible Shaft Sections for Field Test. 


$$
743078-6
$$

$$
74307 B .6
$$




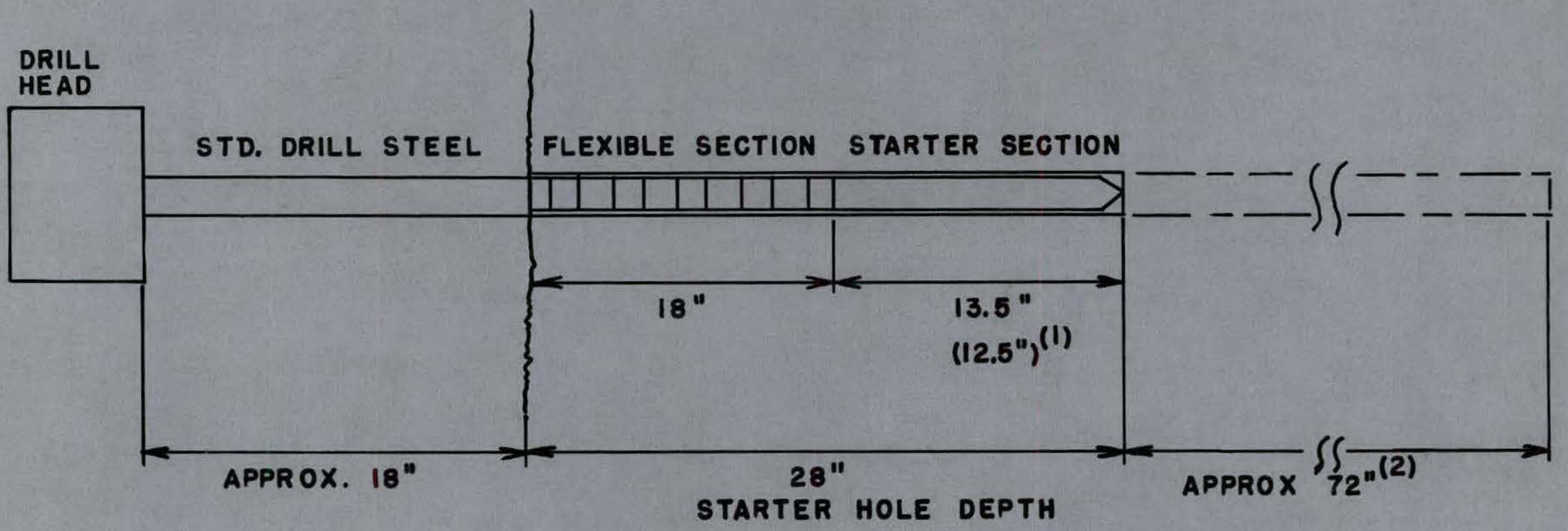

(1) STARTER SECTION LENGTH FOR I" DRILL

(2) POSSIQLE HOLE DEPTH EXTENSION 

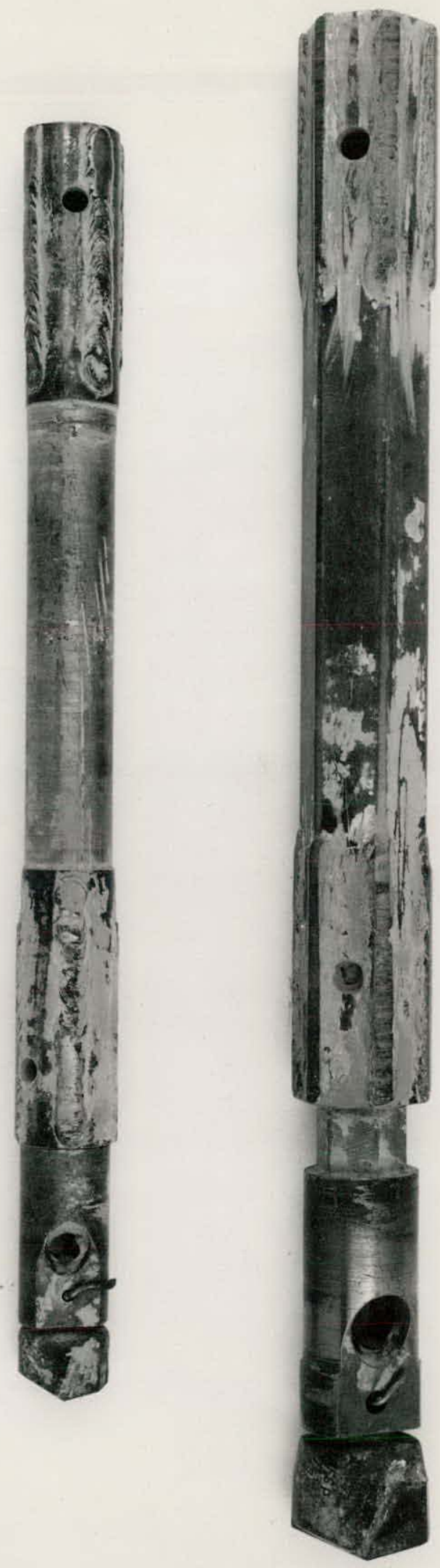

Figure N-3. Starter Section, Bit Holder and Drilling Bit. 


$$
74307 B-5
$$

1. $4436713-5$ 
Figures N-4 and N-5 show these male couplers mounted on the flexible shaft sections. The standard section of drill steel that is shown in Figure $\mathrm{N}-5$ connects the male coupler to the drivehead. A completely coupled system is shown in Figure N-6. With this arrangement, a test run extending the hole depth by 18 in. could be conducted. Additional 18-in. and 36-in. sections could be added so that the total extension of the hole depth could have been 72 in. The flexible drill sections differed from our proposed design in that the male-male couplers provided some rigid restraint for about 4 in. at the connecting point between flexible sections.

The support equipment used for the field test was:

1. A type 3500 Galis double-headed drill with internal dust collection. Flow to torque motor was set at $27.5 \mathrm{gpm}$ until the pressure-relief valve (set at 1300 or 1600 psi) operated. This resulted in a speed of 300-350 rpm (see Fig. N-7).

2. A strobe tachometer for rpm measurement.

3. A compressive load cell for calibration of the hydraulic system for drilling thrust.

4. A flowmeter for measurement of drilling torque.

5. A pressure gauge for measurement of thrust.

6. Measuring scales and stopwatch for determination of mean drilling rate.

\section{Field Test Results}

Tables N-1 and N-2 report the data obtained from these tests. The most successful series of tests was with the $13 / 8$-in. diameter flexible shaft dri11. Our first series of tests using this drill resulted in a hole depth of $7 \mathrm{ft} 7 \mathrm{in.}$ Of this total depth drilled, about $7 \mathrm{ft}$ consisted of flexible shaft sections plus starter, with the remaining portion of the hole containing the standard drill steel for driving purposes. The average drilling rate was $3.17 \mathrm{ft} / \mathrm{min}$, which was identical to the drilling rate obtained using a standard drill in the same material. The hole was very straight and the flexible shaft drill could be withdrawn easily by hand from the drill hole. No unusual characteristics were observed during the drilling process. These results were very satisfying; however, the test was stopped when the flexible drill penetrated an "irregularity." This irregularity caused the drill to freeze and separate. Separation took place 7 segments up from the bottom end of the 


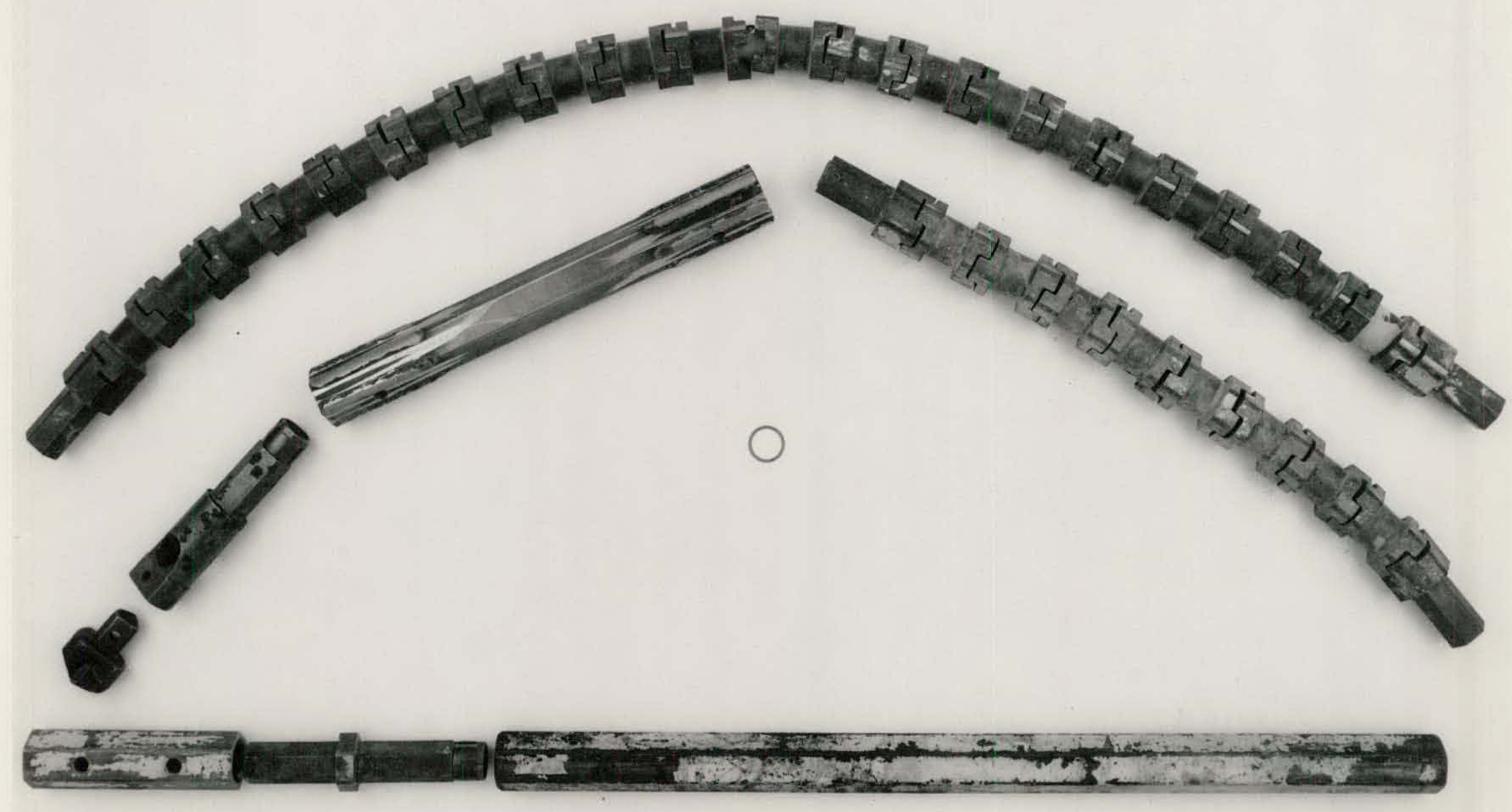

Figure N-4. Drilling System for $13 / 8$-in. Flexible Shaft. 

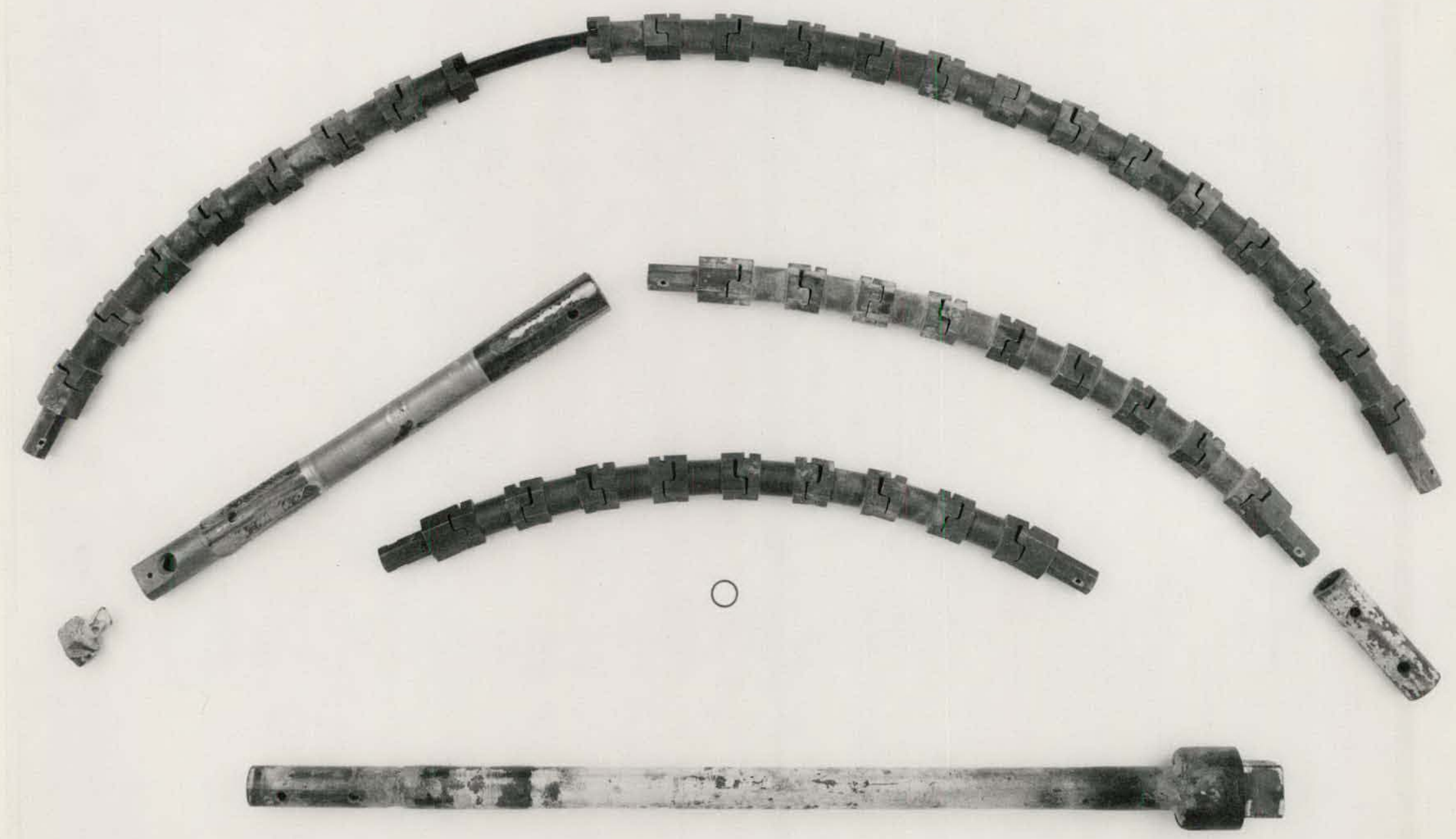

Figure N-5. Drilling System for 1-in. Flexible Shaft Drill. 


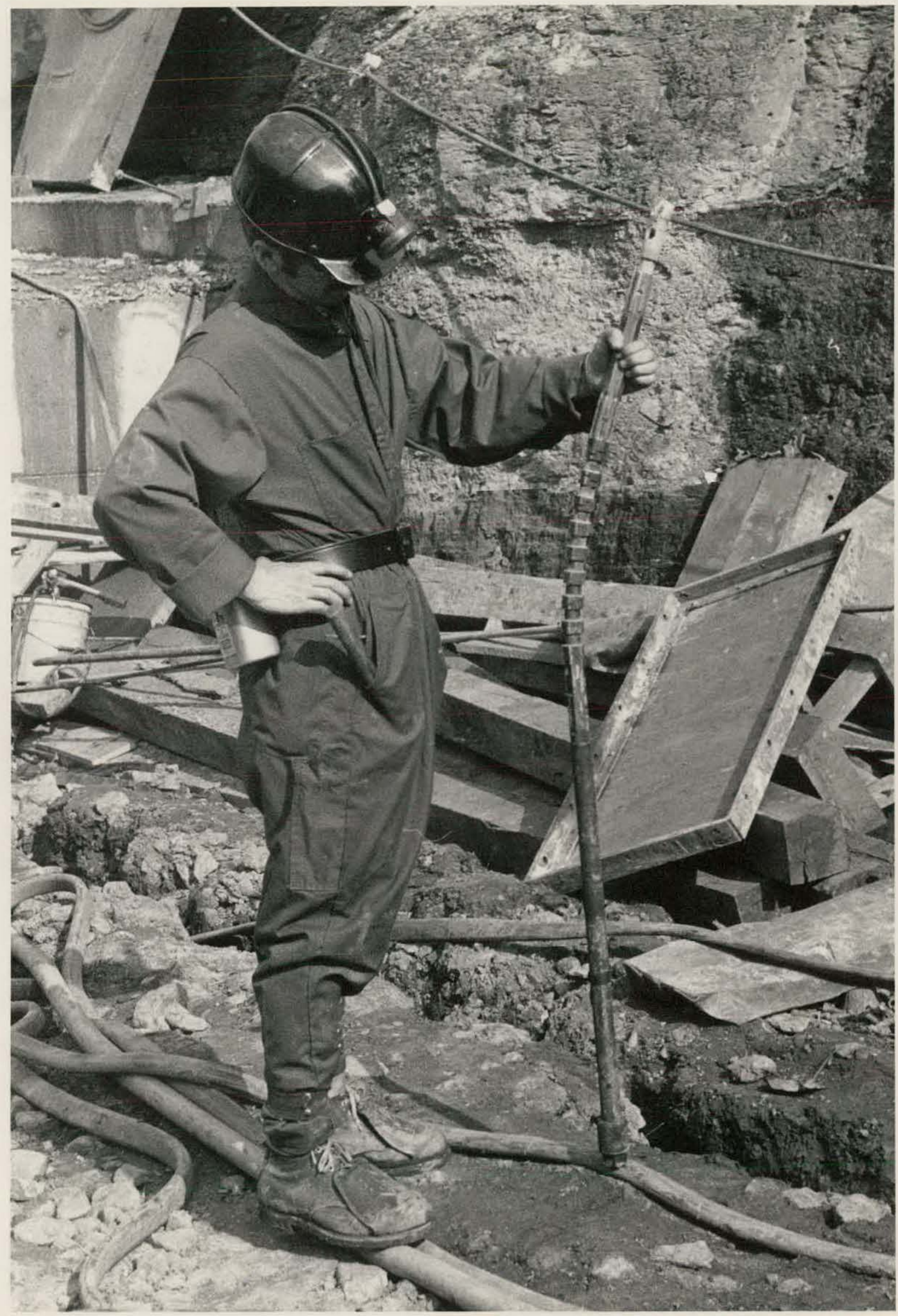

Figure N-6. Coupled Field Test System Ready for Testing. 


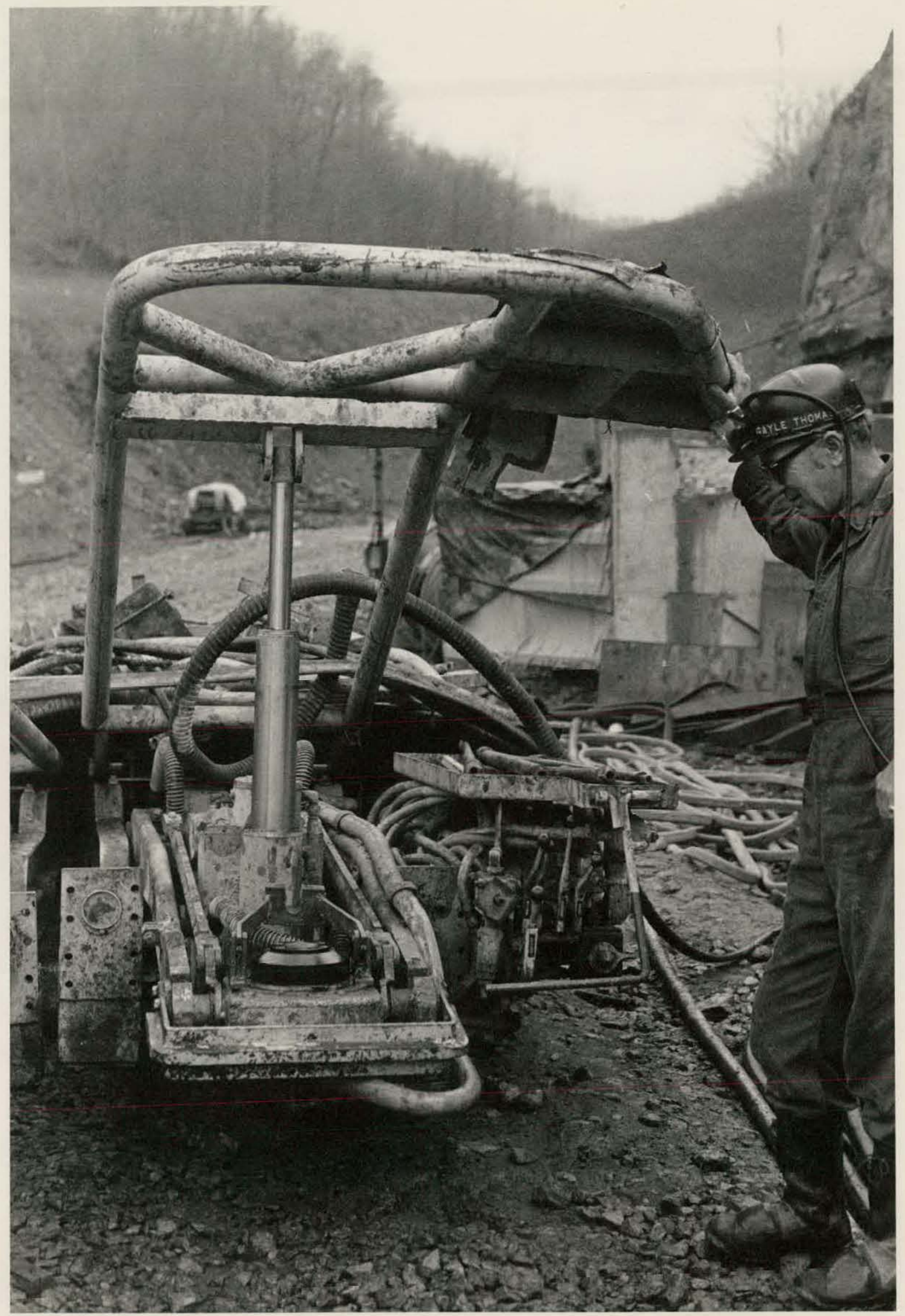

Figure N-7. Drill Used for Field Tests. 
TABLE N-1

Field Test Data - November 4, 1974

\begin{tabular}{|c|c|c|c|c|c|c|c|c|}
\hline \multirow[b]{2}{*}{ Test } & \multirow[b]{2}{*}{ Dri11 } & \multirow{2}{*}{$\begin{array}{l}\text { Thrust } \\
\text { (lb) }\end{array}$} & \multirow{2}{*}{$\begin{array}{l}\text { Torque } \\
(1 b-i n .)\end{array}$} & \multirow{2}{*}{$\begin{array}{l}\text { Drill Rate } \\
\text { (ft/min) }\end{array}$} & \multicolumn{3}{|c|}{ Horsepower } & \multirow[b]{2}{*}{ Remarks } \\
\hline & & & & & Torque & Thrust & Total & \\
\hline $1 a$ & $\mathrm{~F}-1 \quad 3 / 8^{11^{\S}}$ & 1643 & 1029 & 2.73 & 5.31 & 0.14 & 5.45 & $18^{\prime \prime}$ depth \\
\hline $1 b$ & F-1 $3 / 8^{\prime \prime}$ & 2671 & 1741 & 2.90 & 8.98 & 0.24 & 9.22 & $18^{\prime \prime}$ depth \\
\hline $1 c$ & $\mathrm{~F}-1 \quad 3 / 8^{\prime \prime}$ & $\begin{array}{c}3082 \\
(2465)\end{array}$ * & $\begin{array}{c}1730 \\
(1500)\end{array}$ & $\begin{array}{c}3.88 \\
(3.17)\end{array}$ & $\begin{array}{c}8.92 \\
(7.74)\end{array}$ & $\begin{array}{c}0.28 \\
(0.22)\end{array}$ & $\begin{array}{c}9.20 \\
(7.96)\end{array}$ & $18-36 "$ depth \\
\hline $1 d$ & $S-1 \quad 3 / 8^{\prime \prime}$ & 3082 & 1619 & 3.70 & 8.35 & 0.34 & 8.69 & $33^{\prime \prime}$ depth \\
\hline $1 \hat{\mathrm{e}}$ & $S-13 / 8^{\prime \prime}$ & 2979 & 1903 & 3.11 & 9.81 & 0.28 & 10.09 & $28^{\prime \prime}$ depth \\
\hline If & $S-1 \quad 3 / 8$ & $\begin{array}{c}2928 \\
(2996)\end{array}$ & $\begin{array}{c}1329 \\
(1617)\end{array}$ & $\begin{array}{l}2.69 \\
(3.17)\end{array}$ & $\begin{array}{c}6.85 \\
(8.34)\end{array}$ & $\begin{array}{c}-- \\
(0.31)\end{array}$ & $\begin{array}{c}-- \\
(9.39)\end{array}$ & . \\
\hline
\end{tabular}

*Mean value for column

$\S_{S}$ - standard drill steel

F - flexible drill 
TABLE N-2

Field Test Data - November 5, 1974

\begin{tabular}{|c|c|c|c|c|c|c|c|c|}
\hline \multirow[b]{2}{*}{ Test } & \multirow[b]{2}{*}{ Dril1 } & \multirow{2}{*}{$\begin{array}{l}\text { Thrust } \\
\text { (1b) }\end{array}$} & \multirow{2}{*}{$\begin{array}{c}\text { Torque } \\
(1 b-i n .)\end{array}$} & \multirow{2}{*}{$\begin{array}{l}\text { Drill Rate } \\
(\mathrm{ft} / \mathrm{min})\end{array}$} & \multicolumn{3}{|c|}{ Horsepower } & \multirow[b]{2}{*}{ Remarks } \\
\hline & & & & & Torque & Thrust & Total & \\
\hline $2 a$ & $\mathrm{~S}-1 \quad 3 / 8^{\prime \prime} \S$ & 3493 & 1593 & 5.0 & 8.21 & 1.32 & 9.53 & $60^{\prime \prime}$ depth \\
\hline $2 \mathrm{~b}$ & $\mathrm{~S}-13 / 8^{\prime \prime}$ & 3287 & 1261 & 4.02 & 6.50 & 0.40 & 6.90 & $29^{\prime \prime}$ depth \\
\hline $2 c$ & $\mathrm{~S}-13 / 8^{\prime \prime}$ & 3082 & 1183 & 4.39 & 6.10 & 0.41 & 6.51 & $29 " '$ depth \\
\hline $2 \mathrm{~d}$ & $\mathrm{~S}-1 \quad 3 / 8^{\prime \prime}$ & $\frac{3082}{(3236)}$ * & $\begin{array}{c}1123 \\
(1290)\end{array}$ & $\begin{array}{c}3.72 \\
(4.28)\end{array}$ & $\begin{array}{c}5.79 \\
(6.65)\end{array}$ & $\begin{array}{c}0.35 \\
(0.62)\end{array}$ & $\begin{array}{c}6.14 \\
(7.27)\end{array}$ & $29 "$ depth \\
\hline $2 \mathrm{e}$ & $\mathrm{F}-1 \quad 3 / 8^{\prime \prime}$ & 3493 & 3080 & 2.22 & 15.88 & 0.24 & 16.12 & $\begin{array}{l}\text { 8!' depth, vacuum } \\
\text { leak }\end{array}$ \\
\hline $2 f$ & $\mathrm{~F}-1 \quad 3 / 8^{\prime \prime}$ & 2397 & 1899 & 1.66 & 9.79 & 0.12 & 9.91 & $\begin{array}{l}4 " \text { depth, plugged } \\
\text { by chips }\end{array}$ \\
\hline $2 g$ & $\mathrm{~F}-1 \quad 3 / 8^{\prime \prime}$ & 3082 & 1593 & 2.43 & 8.21 & 0.23 & 8.44 & $\begin{array}{l}19 " \text { depth, new } \\
\text { tube }\end{array}$ \\
\hline $2 \mathrm{~h}$ & $\mathrm{~F}-1 \quad 3 / 8^{\prime \prime}$ & 2260 & 2432 & 2.77 & 12.54 & 0.19 & 12.73 & $\begin{array}{l}15^{\prime \prime} \text { depth, air } \\
\text { leak }\end{array}$ \\
\hline \multirow[t]{2}{*}{$2 i$} & $\mathrm{~F}-1 \quad 3 / 8^{\prime \prime}$ & 3082 & 1838 & 3.33 & 9.48 & 0.31 & 9.79 & $18^{\prime \prime}$ depth \\
\hline & & $(2863)$ & $(2168)$ & $(2.48)$ & $(11.18)$ & $(0.22)$ & $(11.40)$ & \\
\hline $2 j$ & $S-I^{\prime \prime}$ & 1497 & 916 & 1.96 & 4.72 & 0.09 & 4.81 & $27^{\prime \prime}$ depth \\
\hline \multirow[t]{2}{*}{$2 \mathrm{k}$} & $S-1^{\prime \prime}$ & 3082 & 1228 & 3.75 & 6.33 & 0.35 & 6.68 & $27^{\prime \prime}$ depth \\
\hline & . & $(2290)$ & $(1072)$ & $(2.86)$ & $(5.52)$ & $(0.22)$ & $(5.75)$ & \\
\hline 21 & $F-1 "$ & 1022 & 1785 & 0.83 & 9.20 & 0.03 & 9.23 & $\begin{array}{l}2^{\prime \prime} \text { depth, plugged } \\
\text { by chips }\end{array}$ \\
\hline \multirow[t]{2}{*}{$2 \mathrm{~m}$} & $F-1^{\prime \prime}$ & 2260 & 963 & 1.66 & 4.97 & 0.11 & 5.08 & $3^{\prime \prime}$ depth, plugged \\
\hline & & $(1644)$ & $(1374)$ & $(1.25)$ & $(7.08)$ & $(0.07)$ & $(7.16)$ & \\
\hline
\end{tabular}

* Mean value for column

$\S_{S}$ - standard drill steel

F - flexible dri11 
drill, as shown in Figure N-8. Miners and supervisory observers felt that the irregularity was a crack, which commonly causes problems when using standard drilling equipment. It is important to note that the separation of the flexible shaft drill did not occur while drilling torque and thrust were being applied. The separation occurred when the operator tried to dislodge the bit using his normal operating procedure. This consisted of withdrawing the drill while rotating. This put a combined tension and torsional load on the retainer ring coupling between the flexible segments. Such a loading condition caused the retainer ring to fail. In reviewing this failure, it became apparent to us that the dislodging of a stuck flexible shaft drill had to be done using a different procedure than the operators normally use. We felt that the failure could have been avoided by maintaining a slight compressive thrust and rotating the drilling bit in the reverse direction. This would avoid the tension load on the retainer ring but would provide a rotation motion which could clear the hole and free the bit so that the drill could be withdrawn by a tension force alone. We did not stick another bit during any of our remaining tests; therefore we were not able to verify that such a procedure would indeed solve the problem. The above caused a moment of trauma during our testing program; however, upon reflection, the information gained concerning this aspect of our design will be very helpful in the future.

Our November 5 tests were conducted about $20 \mathrm{ft}$ deeper into the porta1 than the November 4 tests. The operator applied full thrust during these tests, which resulted in hïgher drilling rates using the standard drilling equipment. Also, it was noticed that the drilling chips collected during some of these tests were much larger and coarser than the fine dust type of particle we had obtained the previous day. This new drilling condition revealed a design deficiency in our drilling system.

The drilling tests that we conducted using our 1-in. flexible shaft drill showed that this drill was not adequately removing the drilling chips from the hole. Soon after penetrating the shale, the drilling dust began to puff back out of the hole through the annular space around the drill string. Immediately the drilling torque increased and the drill test was stopped. When we removed the flexible shaft drill from the hole the drilling chips were caked around the outside of the starter section and were plugging the chip extraction hole in the drilling bit. This condition; shown in Figures $\mathrm{N}-9$ and N-10, resulted in the low drilling rates for the l-in. flexible shaft drill that are reported 


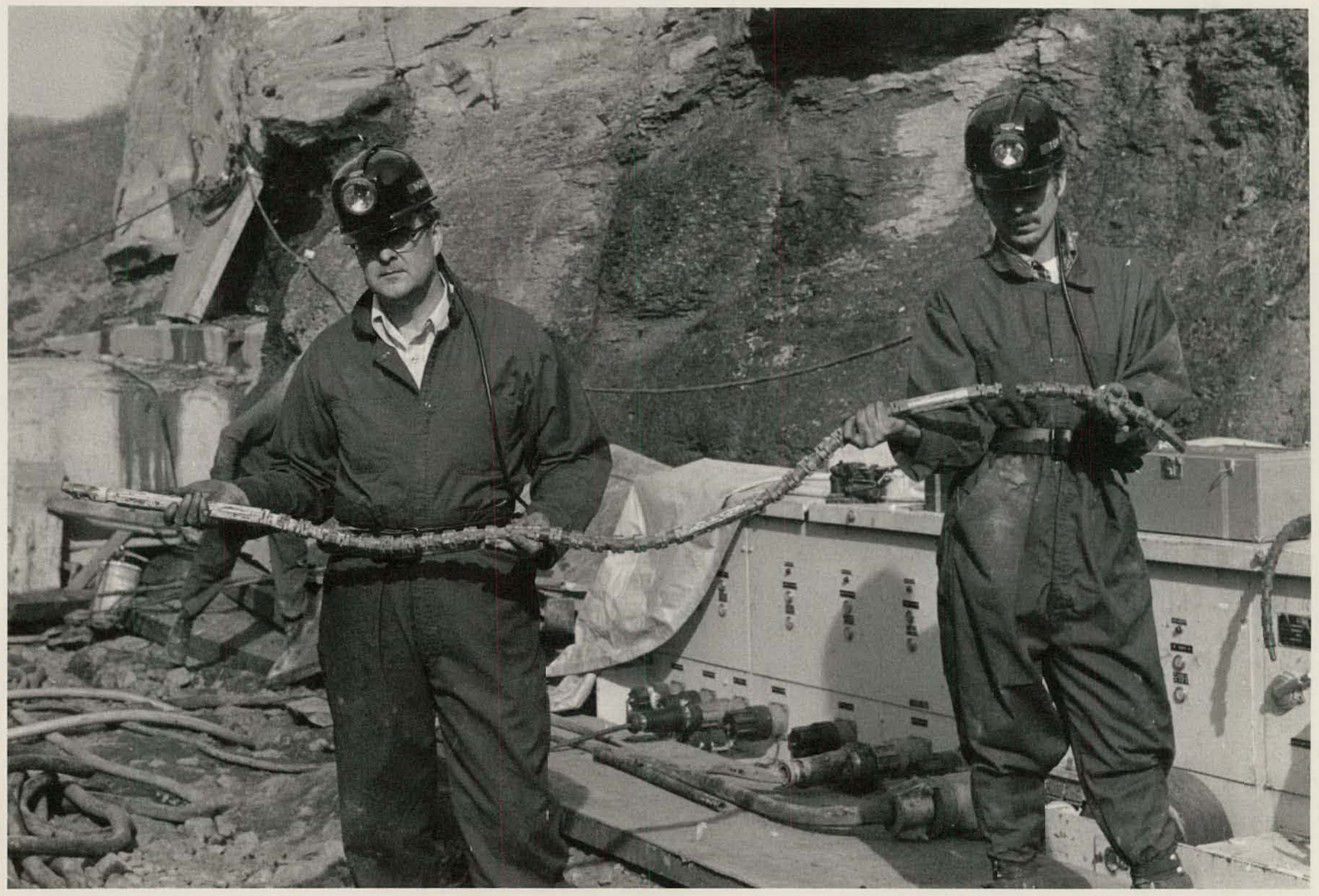

Figure N-8. Location of Separation on the 1 3/8-in. Diameter Drill That Failed During Field Testing. 


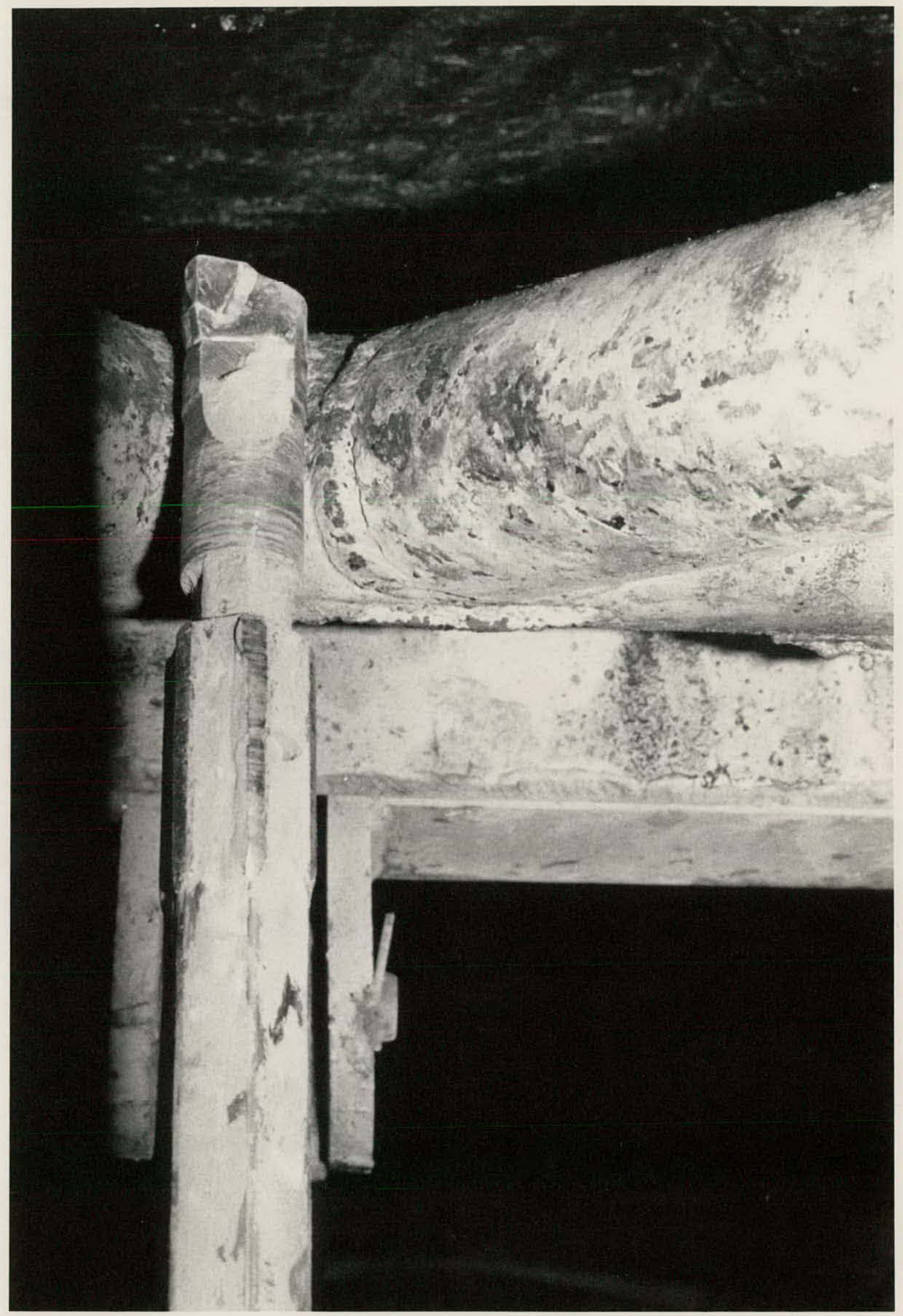

Figure N-9. Plugging of Chip-Return Passages-1 3/8-in. Diameter Drill. 


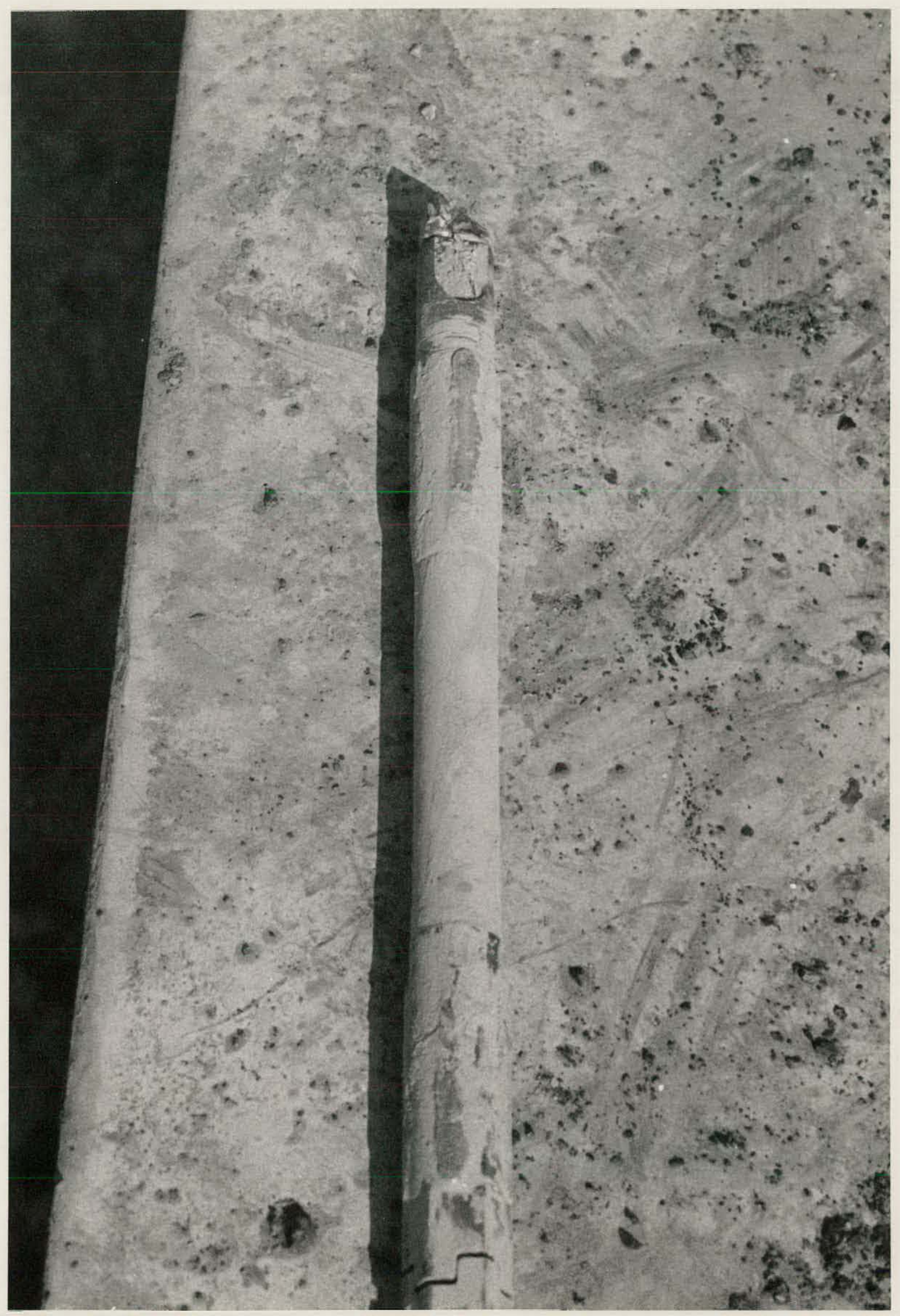

Figure N-10. Plugging of Chip-Return Passages-1-in. Diameter Drill. 
in Table N-2. The miners and supervisory personnel who were observing our tests did not feel that our difficulty was entirely due to our flexible shaft drill. Test $2 \mathrm{j}$ reported in Table $\mathrm{N}-2$ used the standard drill steel and also experienced some difficulty with cutting chip extraction. This difficulty is reflected by its low drilling rate of $1.96 \mathrm{in} / \mathrm{min}$. All agreed that the vacuum system was not operating at its best. If so, this would certainly contribute to our difficulty; however, the flexible shaft drill had greater difficulty removing the cutting chips, and this indicated to us that redesign effort should be directed toward the starter section and its associated clearance with the drill hole. Future starter sections must have a greater clearance. This can be obtained in a number of ways without sacrificing starter section efficiency or strength. Another reason why chip extraction was not as good with the flexible shaft drill was that the tubing used to channel the cutting chips through the center of the drill back to the dust collection system was smaller than necessary in order to clear the male coupler holes used on the flexible sections. Our final design will be able to use a larger-diameter tubing. Another problem.with this tubing was that it was not continuous from the drill bit back to the dust collection connection at the drill head. This was necessary because of the sectional nature of our flexible test drills. Each of these section joints provided many leakage passages that reduce the vacuum pressure available at the drilling bit for evauation of drilling chips. In summary, we feel our field tests were successful. Our $13 / 8$-in. diameter flexible shaft drill showed that it was able to drill at acceptable rates over a sizable distance and maintain good hole alignment. The difficulty we experienced with the 1 -in. diameter flexible shaft drill was not connected to the alignment or torque-and-thrust-transmission capabilities. It was associated with a problem that is correctable by redeisgn of our starter section without sacrificing any of the basic benefits of the flexible shaft drilling system we have developed. 
APPENDIX 0

DESTRUCTIVE IESTS

The destructive tests were designed to probe the maximum capabilities of our flexible shaft drilling system. Two critical areas were investigated. First, the strength of the interface under torsional stress was evaluated by fabricating special test pieces. Second, the strength of the retainer ring coupling concept under a tension load was investigated. These destructive tests were conducted with both the $13 / 8$-in. and 1-in. diameter flexible shaft segments.

\section{Torsional Tests}

Figures 0-7 and 0-8 show the test specimens fabricated for the torsional tests. Our stress analysis indicated that we should be primarily concerned about the torsional loading on the segments. The test was set up so that the primary load would be torsional; however, a compressive load that simulated the load during drilling would be applied in the following manner. Figure $\mathrm{N}-1$ shows the test fixture designed and built to apply this compressive load. The test specimen was inserted over the rod identified as part $1 \mathrm{~A}$ and $1 \mathrm{~B}$ in Figure $0-1$. The test specimen was then compressed by tightening down on the nut shown at the left end of the bar and identified as $1 \mathrm{~A}$ and $1 \mathrm{~B}$. . The amount of compressive load applied was controlled by observing the deflection of the dial indicator which resulted when the compression bar elongated, causing the dial indicator stem to move. This was an effective way of applying an initial compressive load to the tcst specimen during the torsion test; however, the method did not sustain this compressive load throughout the entire test.

Table 0-1 reports the results of the torsion test. The $13 / 8$-in. diameter flexible shaft segment had a compressive p̀reload of 6,000 $1 \mathrm{~b}$ and the 1 -in. diameter flexible shaft segment had a preload of $3,270 \mathrm{lb}$. These compressive preloads were consistent with the loads used in our stress analysis. Two basic types of failure were observed during these tests. Figure 0-2 shows a failure by shear across the teeth. This type of failure occurred only on the three-tooth segment used on the 1-in. diameter shaft. Figure 0-3 shows the common type of failure observed in all other tests. Sometimes the longitudinal fracture shown on Figure 0-3 was preceded by severe crushing of the tooth face and twisting of the tooth. This crushing is observable in Figure 0-3. 


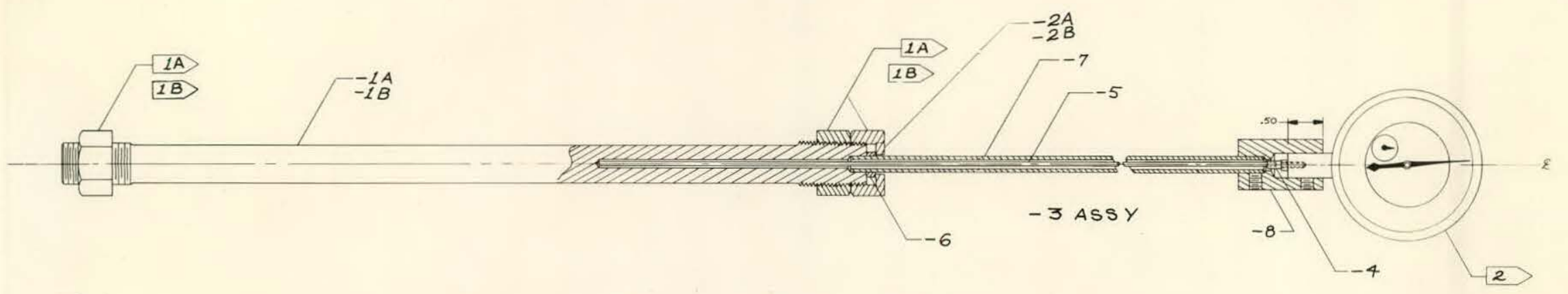

Figure 0-1. Torsion Test Compression Fixture. 
Table 0-1

Segment Torsion Tests

\begin{tabular}{lccc}
\hline $\begin{array}{c}\text { Dril1 } \\
\text { Size, in. }\end{array}$ & $\begin{array}{c}\text { No. of } \\
\text { Teeth }\end{array}$ & $\begin{array}{c}\text { Failure } \\
\text { Load }\end{array}$ & $\begin{array}{c}\text { Mean Failure } \\
\text { Load, in.-1b }\end{array}$ \\
\hline $13 / 8$ & 2 & 19,050 & \\
$13 / 8$ & 2 & 18,800 & 21,450 \\
$13 / 8$ & 2 & 26,500 & \\
$13 / 8$ & 3 & 28,500 & \\
$13 / 8$ & 3 & 27,500 & 28,233 \\
$13 / 8$ & 3 & 28,700 & \\
1 & 2 & 8,100 & \\
1 & 2 & 8,940 & 8,030 \\
1 & 2 & 7,050 & \\
1 & 3 & 9,900 & \\
1 & 3 & 9,600 & 9,733 \\
1 & 3 & 9,700 & \\
\hline
\end{tabular}



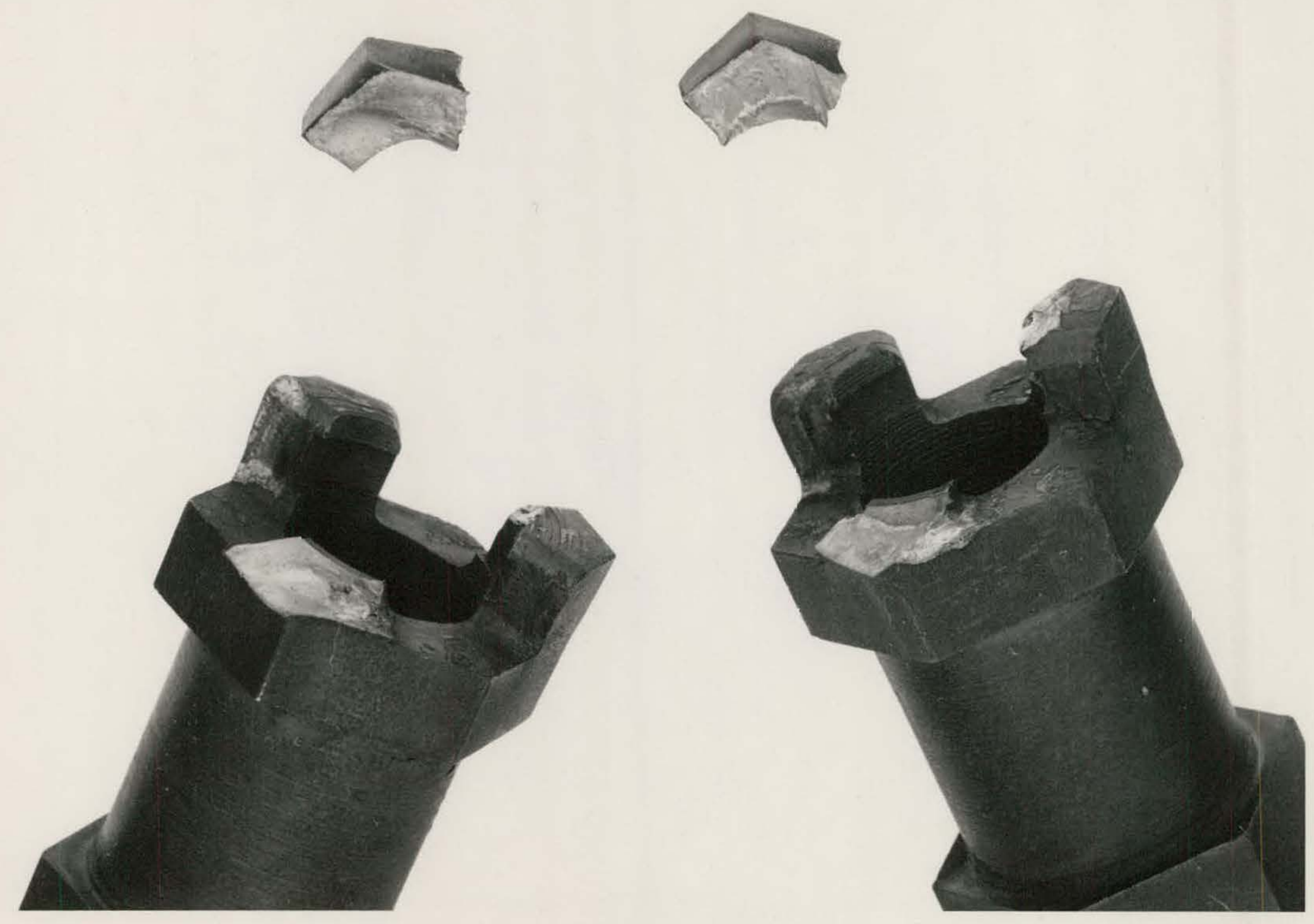

Figure 0-2. Tooth Failure by Shear Across Teeth--1-in. Diameter Shaft. 

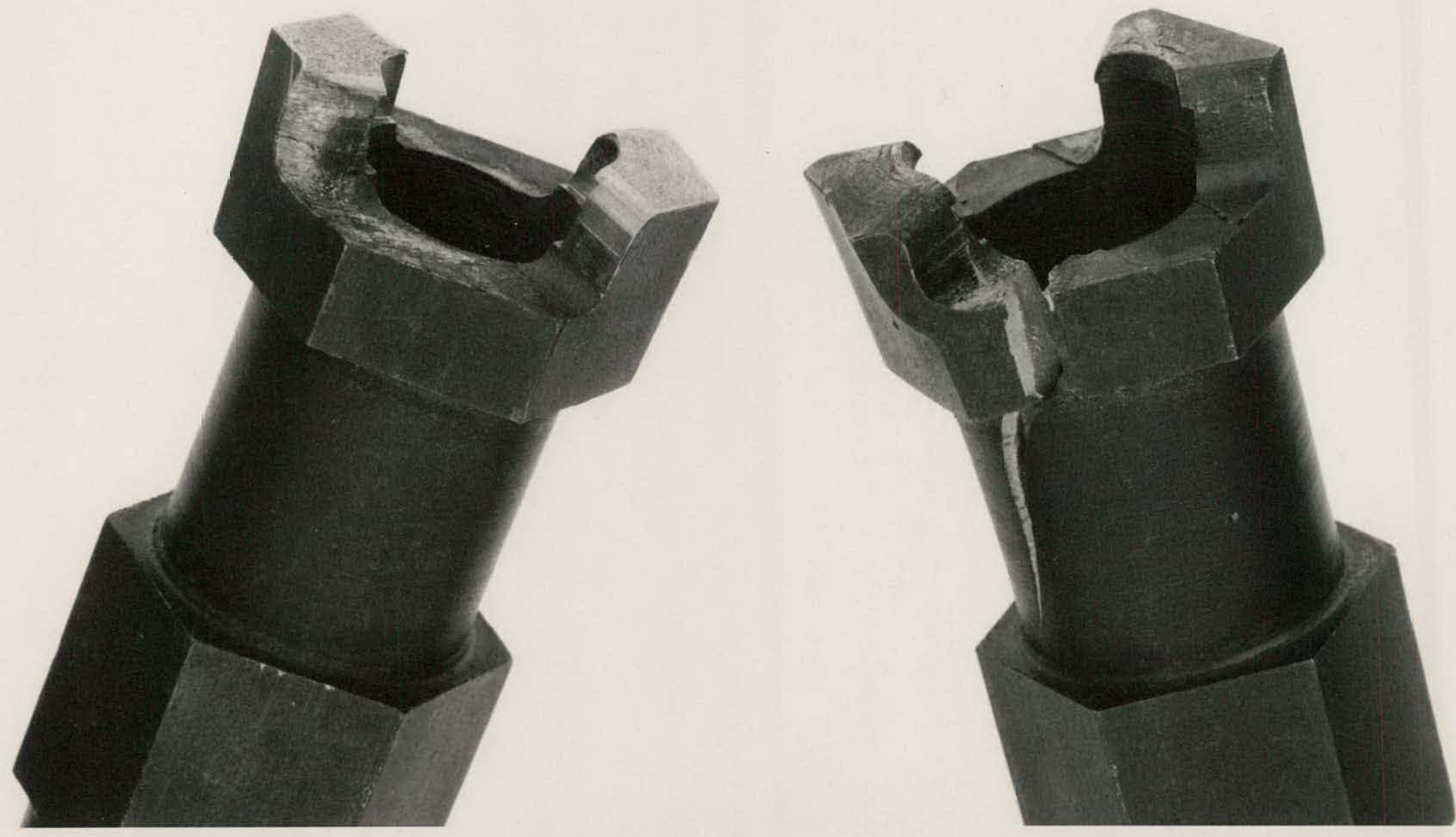

Figure 0-3. Segment Failure Through Hexagonal Web. 
We were pleased to learn that the three-tooth configuration in both cases was able to sustain a higher torsional load than the two-tooth configuration. We had concluded from our stress analysis that there was marginal difference between the two- and three-tooth configurations and had decided to proceed with the three-tooth configuration for the field test because of its superior dynamic characteristics during our curvature test: One of the reasons for this better strength performance by the three-tooth configuration was that our calculations showed that the torsional load would distribute itself on all three teeth. This load distribution would occur if the manufacturing tolerances were kept within those specified.

These results showed that the breaking strength of the $13 / 8$-in. diameter shaft exceeded the maximum recorded torque from our field tests by about nine times. For the 1-in. diameter shaft, the breaking torque was about $51 / 2$ times greater than the observed torsional load from our field test data. These results indicate that the flexible shaft segments have sufficient strength to sustain the type of drilling duty they will experience when used in shale.

\section{Retảiner Ring Tension Tests}

Our Phase I report recommended that the drill string be withdrawn from the hole by applying a tension load to the flexible shaft drill. Such a load would require that the retainer ring connecting segment to segment would have to transfer this tension load. This design concept indicated that we should make some destructive tests on segments so that the load capacity of this type of connection could be established. These destructive tension tests were made using a special fixture that provided for a 5 1/2-degree misalignment between segments. This misäligned condition simulates the condition that would exist for a flexible shaft being withdrawn through a typical radius of curvature.

Table 0-2 reports the results of these tests. Two basic types of loading conditions were used. In one case, the retainer ring was oriented in the groove so that the section of the retainer ring where a single thickness of metal existed was at the shear plane. This was called a single-shear test and the orientation increased the likelihood that the failure would be by. single shear. The other test condition used was that the orientation of the retainer ring was such that a double thickness of metal was at the shear: plane. This orientation increased the likelihood of the double-shear type of failure. The test results did not show that this orientation made a substantial difference 
TABLE $0-2$

Retainer Ring Connector Pull Test Results

\begin{tabular}{|c|c|c|c|}
\hline $\begin{array}{l}\text { Desired } \\
\text { Failure Mode }\end{array}$ & $\begin{array}{c}\text { Drill } \\
\text { Size, in. }\end{array}$ & Load, $1 \mathrm{~b}$ & Mean Load, 1b \\
\hline $\mathrm{SS}^{*}$ & 1 & 420 & \multirow{3}{*}{350} \\
\hline SS & 1 & 350 & \\
\hline SS & 1 & 280 & \\
\hline SS & $13 / 8$ & 770 & \multirow{4}{*}{560} \\
\hline SS & $13 / 8$ & 470 & \\
\hline SS & $13 / 8$ & 480 & \\
\hline SS & $13 / 8$ & 520 & \\
\hline $\mathrm{DS}^{\S}$ & 1 & 220 & \multirow{3}{*}{193} \\
\hline DS & 1 & 160 & \\
\hline DS & 1 & 200 & \\
\hline DS & $\ldots 13 / 8$ & 530 & \multirow{5}{*}{472} \\
\hline DS & $13 / 8$ & 410 & \\
\hline DS & $13 / 8$ & 640 & \\
\hline DS & $13 / 8$ & 380 & \\
\hline DS & $13 / 8$ & 400 & \\
\hline \multicolumn{4}{|c|}{$\begin{array}{l}\text { * SS - single shear. The retainer ring was oriented so } \\
\text { that a single thickness of metal was at the shear plane. } \\
\text { This orientation increased the likelihood of single } \\
\text { shear. }\end{array}$} \\
\hline \multicolumn{4}{|c|}{$\begin{array}{l}{ }^{\S} \text { DS - double shear. The retainer ring was oriented so } \\
\text { that a double thickness of metal was at the shear plane. } \\
\text { This orientation increased the likelihood of double } \\
\text { shear. }\end{array}$} \\
\hline
\end{tabular}


in the mean failure load for the retainer rings. The load reduction recorded in Table 0-1 for double shear as compared to a single shear could be explained by the fact that most of these failures were failures by deformation. Figure 0-4 shows the two types of retainer ring failure we observed. The deformation failure occurs when the load pulls the retainer ring from the retainer groove without shearing. The separation mode of failure occurred when the retainer ring sheared. It appears that a failure by deformation does not require as much load as a failure by shear.

Another reason for the predominance of a deformation type of failure during the double-shear test is due to the fact that the double-shear tests were conducted after the single-shear test. The test specimens used during the single-shear test were also used during the double-shear test. The only change made was the replacement of the failed retainer ring with a new ring. The single-shear test caused the corners of the retainer ring groove to deform and bend upward. By the time the double-shear tests were conducted, this deformed edge made it easier for the retainer ring to fail by deformation.

In general, the test results showed that a heavy-duty retainer ring should be used instead of the medium-duty ring. Another alternative to be considered in the future design is the use of a specially fabricated retainer ring. A number of ideas are under consideration. 


\section{NEW RING}

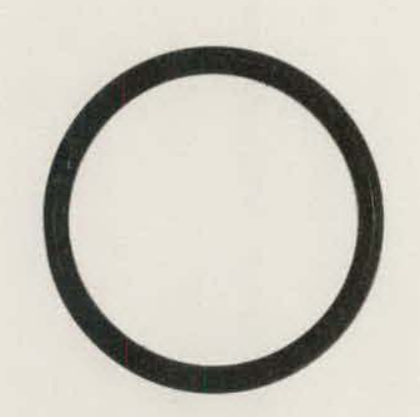

\section{FAILURES}
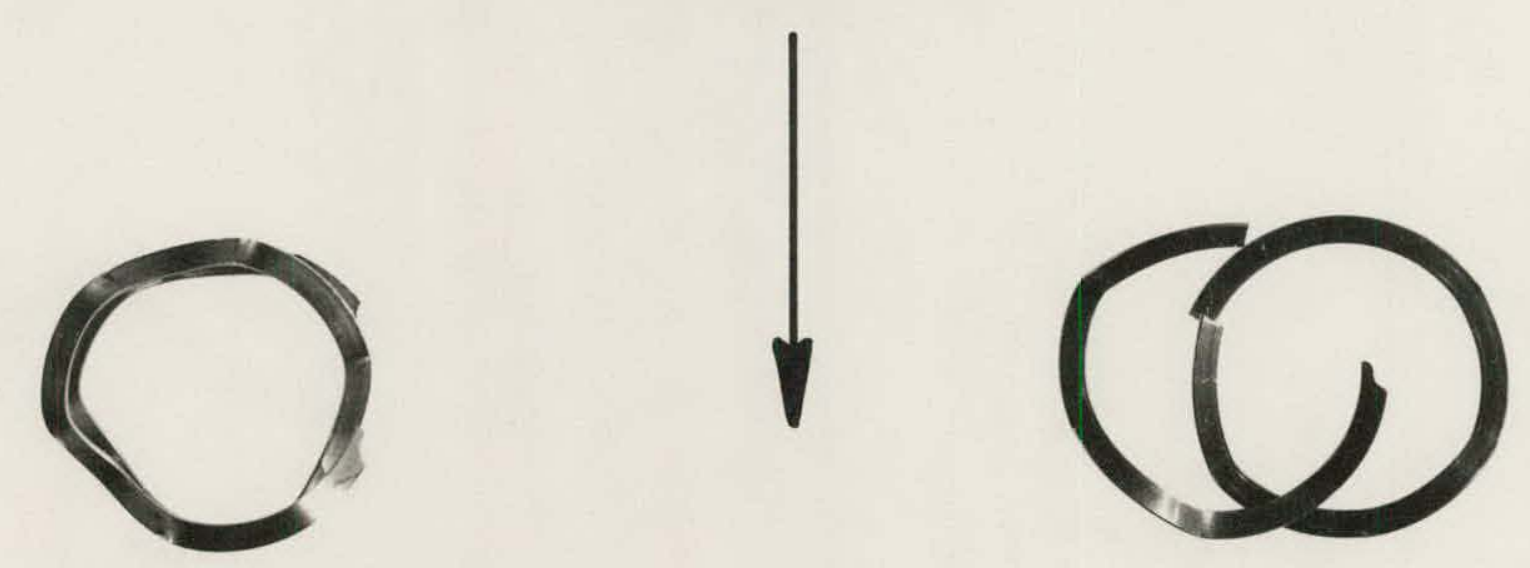

\section{BY DEFORMATION}

BY SEPERATION

Figure 0-4. Retainer Ring Failures. 


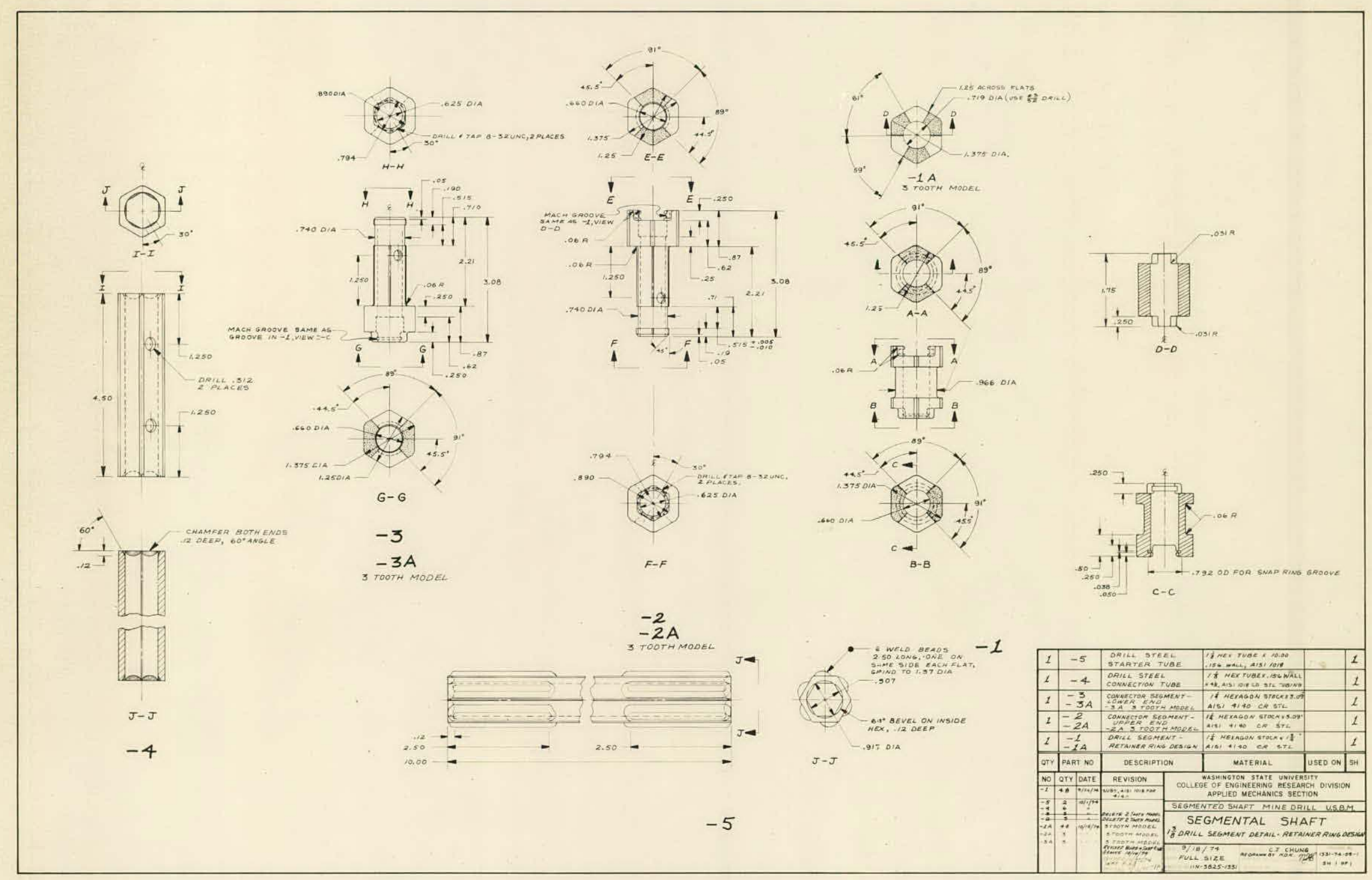

Figure 0-5. Segmental Shaft 1 3/8-in. Drill Segment Retainer Ring Design. 


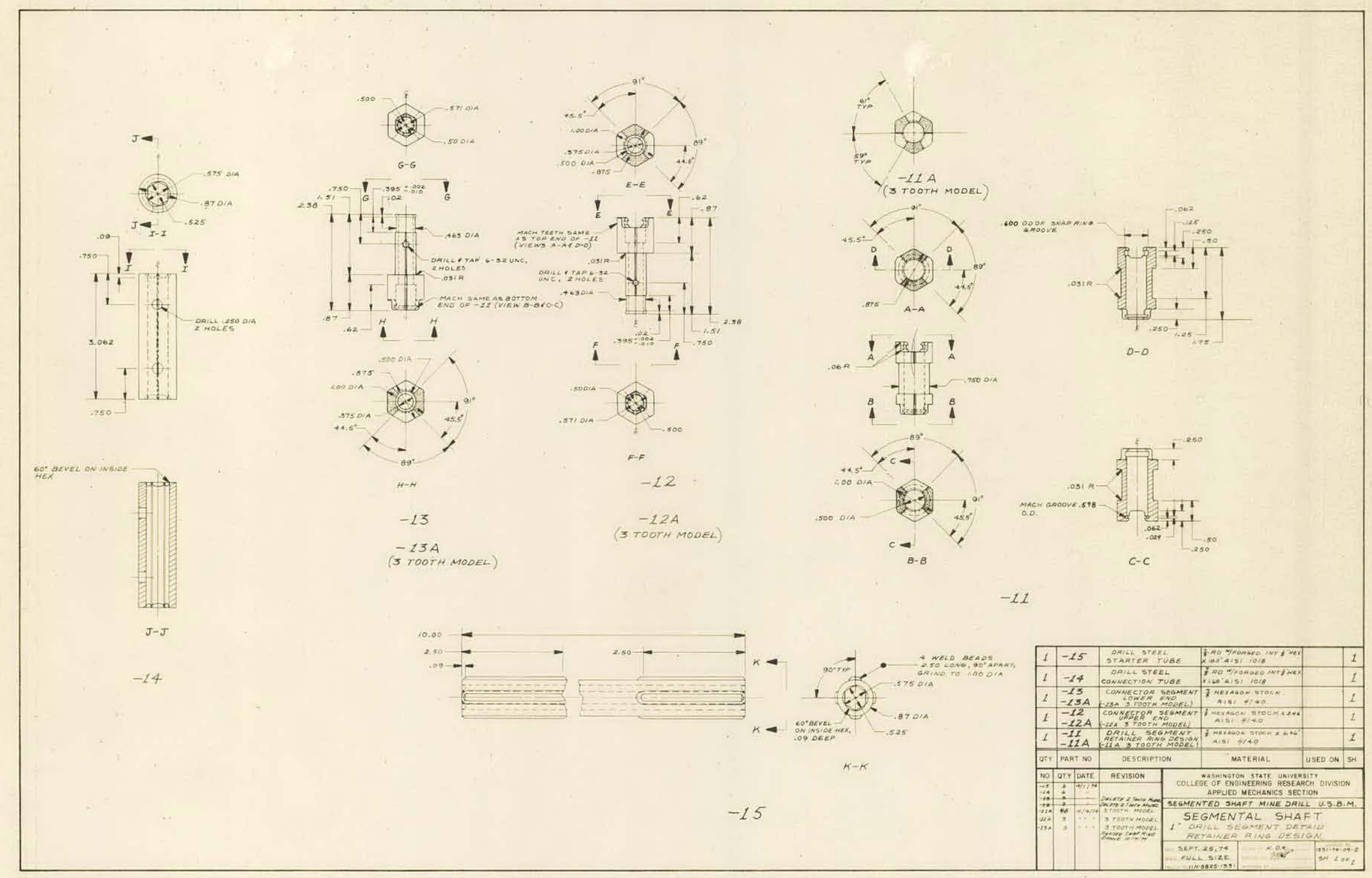

Figure 0-6. Segmental Shaft 1-in. Drill Segment Detail Retainer Ring Design. 


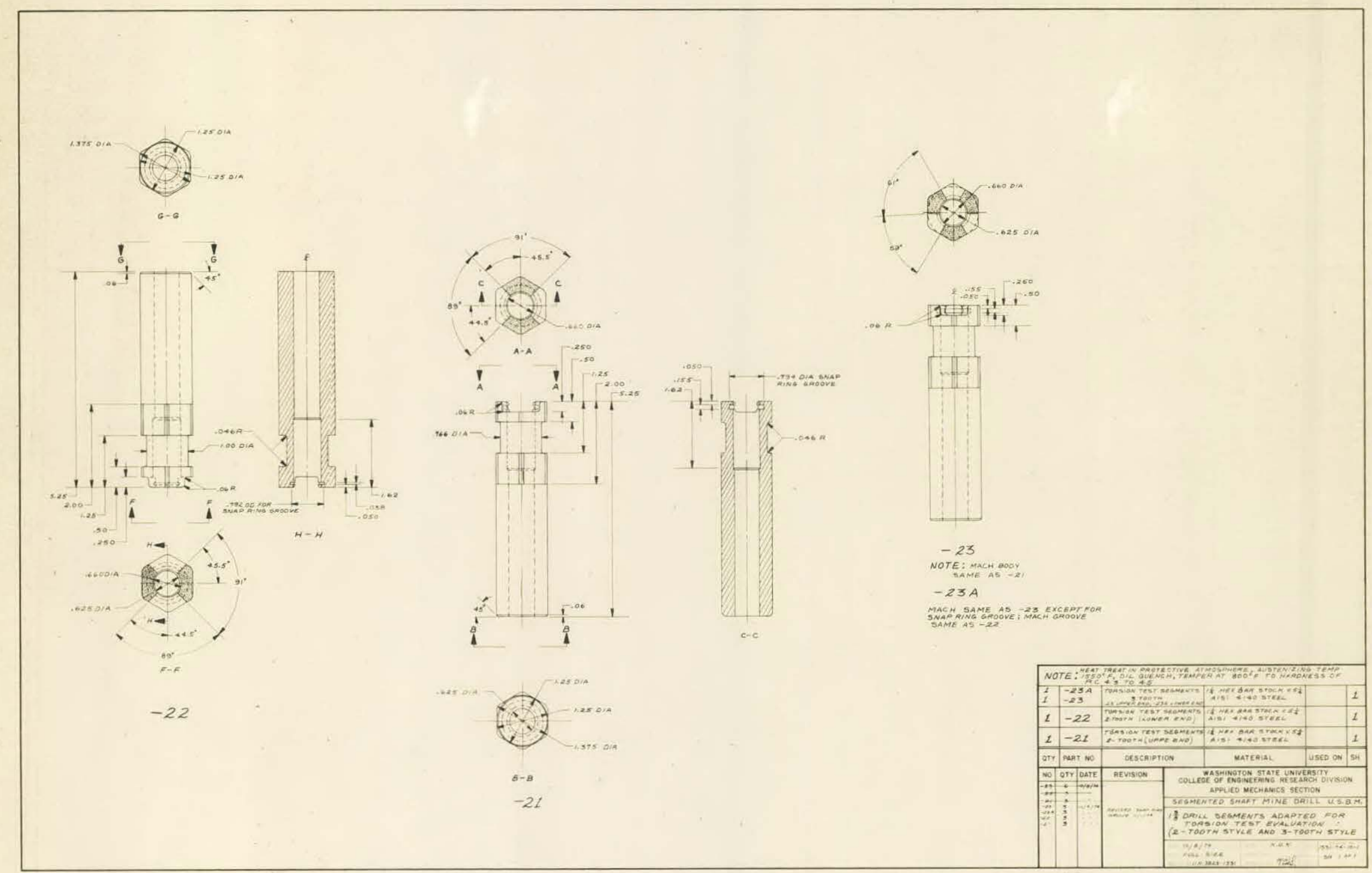

Figure 0-7. 1 3/8-in. Drill Segments Adapted for Torsion Test Evaluation (2- and 3-tooth style). 


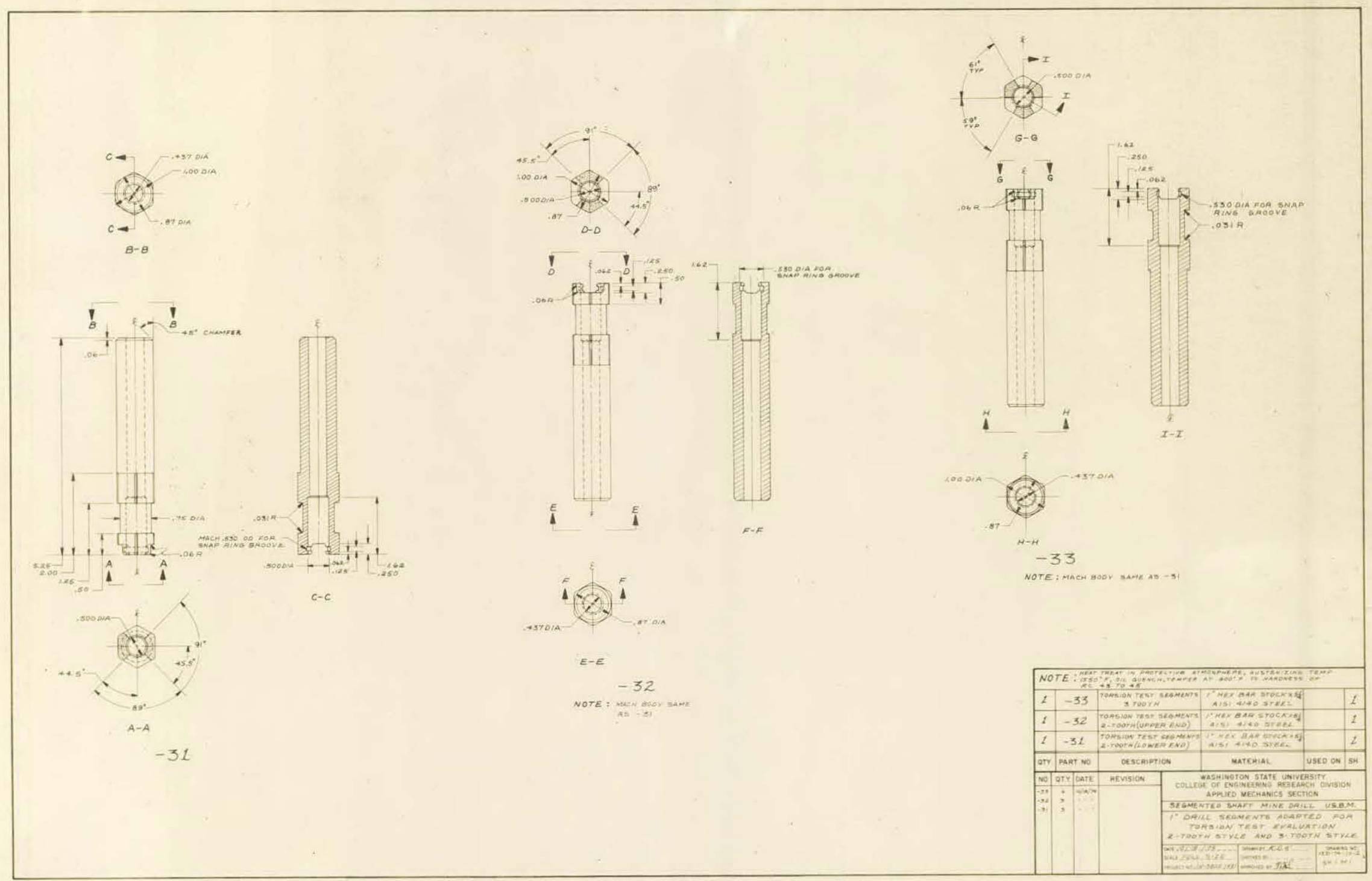

Figure 0-8. 1-in. Drill Segments Adapted for Torsion Test Evaluation (2- and 3-tooth style). 


\section{APPENDIX P}

\section{CHIP RETURN TESTS}

Our expectations were that the chip return line would be a limiting factor in the flexible shaft design. Our field tests revealed that a chip return problem existed but that it was related to the starter section. As discussed in Appendix C, cutting chips caked up around the starter section and blocked the chip removal holes in the drilling bit. Our problem changed from a concern over the chip return line to an effort to redesign the starter section.

A proposed new design is shown in Figure 35. With this new concern, we felt that our chip return test should concentrate on the evaluation of the chip return capabilities of starter sections coupled to the chip return line. The test facility that was needed to carry out such an evaluation was only partially completed. Having recognized the problem and proposed the solution shown in Figure 35, the purpose of these tests would be to validate that design. This does not make these tests unimportant but reduces their significance. This test can be activated during later phases for such a validation effort. 